\title{
Biochemical tests of placental function versus ultrasound assessment of fetal size for stillbirth and small-for-gestational-age infants (Review)
}

Heazell AEP, Hayes DJL, Whitworth M, Takwoingi Y, Bayliss SE, Davenport C

Heazell AEP, Hayes DJL, Whitworth M, Takwoingi Y, Bayliss SE, Davenport C.

Biochemical tests of placental function versus ultrasound assessment of fetal size for stillbirth and small-for-gestational-age infants.

Cochrane Database of Systematic Reviews 2019, Issue 5. Art. No.: CD012245.

DOI: 10.1002/14651858.CD012245.pub2.

\section{www.cochranelibrary.com}




\section{TABLE OF CONTENTS}

HEADER

ABSTRACT

PLAIN LANGUAGE SUMMARY ....

SUMMARY OF FINDINGS

BACKGROUND

Figure 1.

OBJECTIVES

METHODS

RESULTS

Figure 2.

Figure 3.

Figure 4.

Figure 5.

Figure 6.

Figure 7.

Figure 8.

Figure 9.

Figure 10.

Figure 11.

Figure 12.

Figure 13.

DISCUSSION

AUTHORS' CONCLUSIONS

ACKNOWLEDGEMENTS

REFERENCES

CHARACTERISTICS OF STUDIES

DATA

Test 1. EFW and SGA.

Test 2. Placental grading and SGA.

Test 3. hPL and SGA.

Test 4. E3 and SGA.

Test 5. Urinary E3 and SGA.

Test 6. PIGF and SGA.

Test 7. UA and SGA.

Test 8. E3 AND/OR hPL and SGA.

Test 9. EFW for SGA - 10th centile threshold only.

Test 10. hPL for SGA - 10th centile threshold only.

Test 11. EFW and SGA3.

Test 13. PIGF and SGA3.

Test 14. hPL and stillbirth.

Test 15. Urinary E3 and stillbirth.

Test 16. PIGF and stillbirth.

Test 17. UA and stillbirth.

Test 18. Placental grading and stillbirth.

Test 19. SGA data from studies with both SGA infants and stillbirths.

Test 20. Stillbirth data from studies with both SGA infants and stillbirths.

Test 22. PIGF or EFW and SGA.

Test 23. PIGF or EFW and SGA3.

ADDITIONAL TABLES

APPENDICES

Figure 14.

Biochemical tests of placental function versus ultrasound assessment of fetal size for stillbirth and small-for-gestational-age infants

Copyright @ 2019 The Cochrane Collaboration. Published by John Wiley \& Sons, Ltd. 


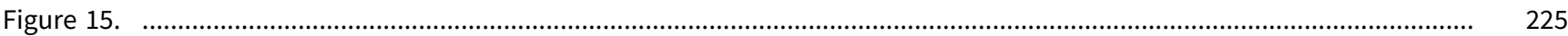

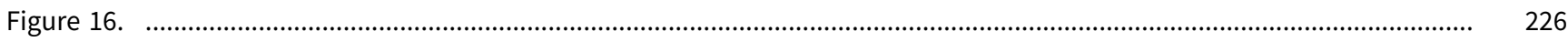

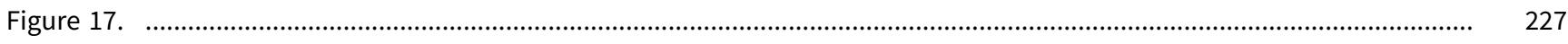

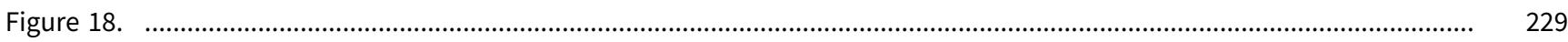

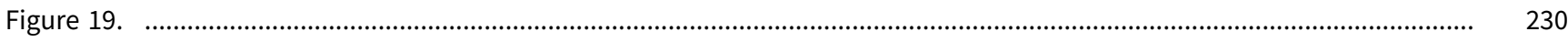

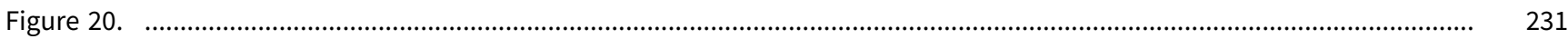

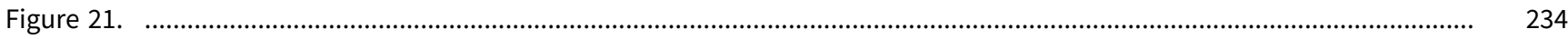

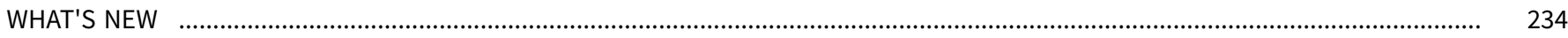

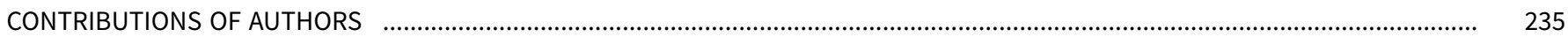

DECLARATIONS OF INTEREST

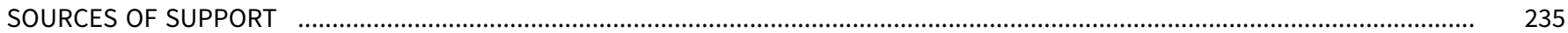

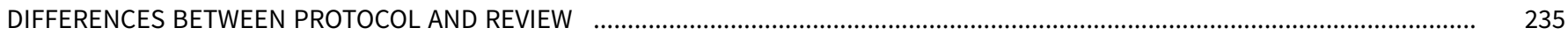

INDEX TERMS 


\section{Biochemical tests of placental function versus ultrasound assessment of fetal size for stillbirth and small-for-gestational-age infants}

Alexander EP Heazell ${ }^{1}$, Dexter JL Hayes ${ }^{1}$, Melissa Whitworth ${ }^{1}$, Yemisi Takwoingi², Susan E Bayliss ${ }^{2}$, Clare Davenport ${ }^{2}$

1Maternal and Fetal Health Research Centre, University of Manchester, Manchester, UK. 2Institute of Applied Health Research, University of Birmingham, Birmingham, UK

Contact address: Alexander EP Heazell, Maternal and Fetal Health Research Centre, University of Manchester, 5th floor (Research), St Mary's Hospital, Oxford Road, Manchester, M13 9WL, UK. alexander.heazell@manchester.ac.uk, alex_heazell@talk21.com.

Editorial group: Cochrane Pregnancy and Childbirth Group.

Publication status and date: Edited (no change to conclusions), published in Issue 6, 2019.

Citation: Heazell AEP, Hayes DJL, Whitworth M, Takwoingi Y, Bayliss SE, Davenport C. Biochemical tests of placental function versus ultrasound assessment of fetal size for stillbirth and small-for-gestational-age infants. Cochrane Database of Systematic Reviews 2019 , Issue 5. Art. No.: CD012245. DOI: 10.1002/14651858.CD012245.pub2.

Copyright @ 2019 The Cochrane Collaboration. Published by John Wiley \& Sons, Ltd.

\section{A B S T R A C T}

\section{Background}

Stillbirth affects 2.6 million pregnancies worldwide each year. Whilst the majority of cases occur in low- and middle-income countries, stillbirth remains an important clinical issue for high-income countries (HICs) - with both the UK and the USA reporting rates above the mean for HICs. In HICs, the most frequently reported association with stillbirth is placental dysfunction. Placental dysfunction may be evident clinically as fetal growth restriction (FGR) and small-for-dates infants. It can be caused by placental abruption or hypertensive disorders of pregnancy and many other disorders and factors

Placental abnormalities are noted in $11 \%$ to $65 \%$ of stillbirths. Identification of FGR is difficult in utero. Small-for-gestational age (SGA), as assessed after birth, is the most commonly used surrogate measure for this outcome. The degree of SGA is associated with the likelihood of FGR; $30 \%$ of infants with a birthweight $<10$ th centile are thought to be FGR, while $70 \%$ of infants with a birthweight $<3$ rd centile are thought to be FGR. Critically, SGA is the most significant antenatal risk factor for a stillborn infant. Correct identification of SGA infants is associated with a reduction in the perinatal mortality rate. However, currently used tests, such as measurement of symphysis-fundal height, have a low reported sensitivity and specificity for the identification of SGA infants.

\section{Objectives}

The primary objective was to assess and compare the diagnostic accuracy of ultrasound assessment of fetal growth by estimated fetal weight (EFW) and placental biomarkers alone and in any combination used after 24 weeks of pregnancy in the identification of placental dysfunction as evidenced by either stillbirth, or birth of a SGA infant. Secondary objectives were to investigate the effect of clinical and methodological factors on test performance.

\section{Search methods}

We developed full search strategies with no language or date restrictions. The following sources were searched: MEDLINE, MEDLINE In Process and Embase via Ovid, Cochrane (Wiley) CENTRAL, Science Citation Index (Web of Science), CINAHL (EBSCO) with search strategies adapted for each database as required; ISRCTN Registry, UK Clinical Trials Gateway, WHO International Clinical Trials Portal and ClinicalTrials.gov for ongoing studies; specialist abstract and conference proceeding resources (British Library's ZETOC and Web of Science Conference Proceedings Citation Index). Search last conducted in Ocober 2016.

\section{Selection criteria}

We included studies of pregnant women of any age with a gestation of at least 24 weeks if relevant outcomes of pregnancy (live birth/ stillbirth; SGA infant) were assessed. Studies were included irrespective of whether pregnant women were deemed to be low or high

Biochemical tests of placental function versus ultrasound assessment of fetal size for stillbirth and small-for-gestational-age infants 
risk for complications or were of mixed populations (low and high risk). Pregnancies complicated by fetal abnormalities and multi-fetal pregnancies were excluded as they have a higher risk of stillbirth from non-placental causes. With regard to biochemical tests, we included assays performed using any technique and at any threshold used to determine test positivity.

\section{Data collection and analysis}

We extracted the numbers of true positive, false positive, false negative, and true negative test results from each study. We assessed risk of bias and applicability using the QUADAS-2 tool. Meta-analyses were performed using the hierarchical summary ROC model to estimate and compare test accuracy.

\section{Main results}

We included 91 studies that evaluated seven tests - blood tests for human placental lactogen (hPL), oestriol, placental growth factor (PIGF) and uric acid, ultrasound EFW and placental grading and urinary oestriol - in a total of 175,426 pregnant women, in which 15,471 pregnancies ended in the birth of a small baby and 740 pregnancies which ended in stillbirth. The quality of included studies was variable with most domains at low risk of bias although 59\% of studies were deemed to be of unclear risk of bias for the reference standard domain. Fifty-three per cent of studies were of high concern for applicability due to inclusion of only high- or low-risk women.

Using all available data for SGA (86 studies; 159,490 pregnancies involving 15,471 SGA infants), there was evidence of a difference in accuracy $(P<0.0001)$ between the seven tests for detecting pregnancies that are SGA at birth. Ultrasound EFW was the most accurate test for detecting SGA at birth with a diagnostic odds ratio (DOR) of 21.3 (95\% Cl 13.1 to 34.6); hPL was the most accurate biochemical test with a DOR of 4.78 (95\% Cl 3.21 to 7.13$)$. In a hypothetical cohort of 1000 pregnant women, at the median specificity of 0.88 and median prevalence of $19 \%, \mathrm{EFW}, \mathrm{hPL}$, oestriol, urinary oestriol, uric acid, PIGF and placental grading will miss 50 (95\% Cl 32 to 68 ), 116 (97 to 133 ), 124 (108 to 137), 127 (95 to 152), 139 (118 to 154), 144 (118 to 161), and 144 (122 to 161) SGA infants, respectively. For the detection of pregnancies ending in stillbirth (21 studies; 100,687 pregnancies involving 740 stillbirths), in an indirect comparison of the four biochemical tests, PIGF was the most accurate test with a DOR of $49.2(95 \% \mathrm{Cl} 12.7$ to 191). In a hypothetical cohort of 1000 pregnant women, at the median specificity of 0.78 and median prevalence of $1.7 \%$, PIGF, hPL, urinary oestriol and uric acid will miss 2 ( $95 \%$ Cl 0 to 4 ), 4 (2 to 8 ), 6 (6 to 7 ) and 8 ( 3 to 13 ) stillbirths, respectively. No studies assessed the accuracy of ultrasound EFW for detection of pregnancy ending in stillbirth.

\section{Authors' conclusions}

Biochemical markers of placental dysfunction used alone have insufficient accuracy to identify pregnancies ending in SGA or stillbirth. Studies combining $\mathrm{U}$ and placental biomarkers are needed to determine whether this approach improves diagnostic accuracy over the use of ultrasound estimation of fetal size or biochemical markers of placental dysfunction used alone. Many of the studies included in this review were carried out between 1974 and 2016. Studies of placental substances were mostly carried out before 1991 and after 2013; earlier studies may not reflect developments in test technology.

\section{PLAIN LANGUAGE SUMMARY}

\section{Blood tests in late pregnancy to identify small babies and those at risk of stillbirth}

\section{Background}

Placental dysfunction describes when the placenta does not meet the demands of the growing baby; it may result in a baby that is smaller than expected or is stillborn. Currently, it is not easy to detect placental dysfunction before birth; ultrasound scans are most often used to identify small babies. However, tests can measure substances made by the placenta in mothers' blood and urine which may detect a placenta that is not functioning well. We aimed to find the best test to identify placental dysfunction.

\section{What we did}

We searched for studies in October 2016 and identified and total of 24,059 studies - with 91 of those studies providing us with information that we could include in this review. We looked at ultrasound scanning and six different tests of placental substances, including proteins and hormones. These studies involved 175,426 women in total of which 15,471 pregnancies ended in the birth of a small baby and 740 pregnancies which ended in stillbirth.

\section{What we found}

Of the 91 included studies, 86 had information on small babies, of which 18 also looked at stillbirth; another five studies only looked at stillbirth. The most accurate test for detecting a small baby was ultrasound scan to estimate a baby's weight. Of the substances measured in mother's blood, human placental lactogen (hPL), a hormone produced by the placenta during pregnancy, was the most accurate. There was only one study which looked at both ultrasound scanning and measurement of a placental substance. Placental growth factor (PIGF) was the most accurate test of a placental substance to identify a baby that would be stillborn; there were no studies of ultrasound scanning to detect a baby that would be stillborn. Tests of placental substances were better at identifying a baby at risk of stillbirth than detecting a small baby.

\section{Other important information to consider}

Biochemical tests of placental function versus ultrasound assessment of fetal size for stillbirth and small-for-gestational-age infants (Review)

Copyright (C) 2019 The Cochrane Collaboration. Published by John Wiley \& Sons, Ltd. 
Many of the studies included in this review were carried out between 1974 and 2016. Studies of placental substances were mostly carried out before 1991 and after 2013; earlier studies may not reflect developments in test technology. More studies are needed to find out whether a combination of ultrasound scans and mother's blood tests could improve identification of pregnancies which end in the birth of a small baby or in a stillborn baby. No studies were identified for this review that looked at the accuracy of ultrasound and blood tests used together. 


\begin{tabular}{|c|c|c|c|c|c|c|c|c|c|c|c|c|c|}
\hline \multirow{14}{*}{ 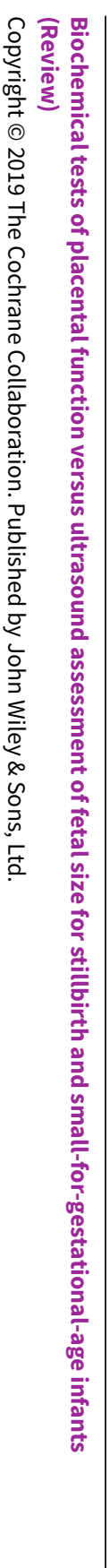 } & \multirow{13}{*}{ 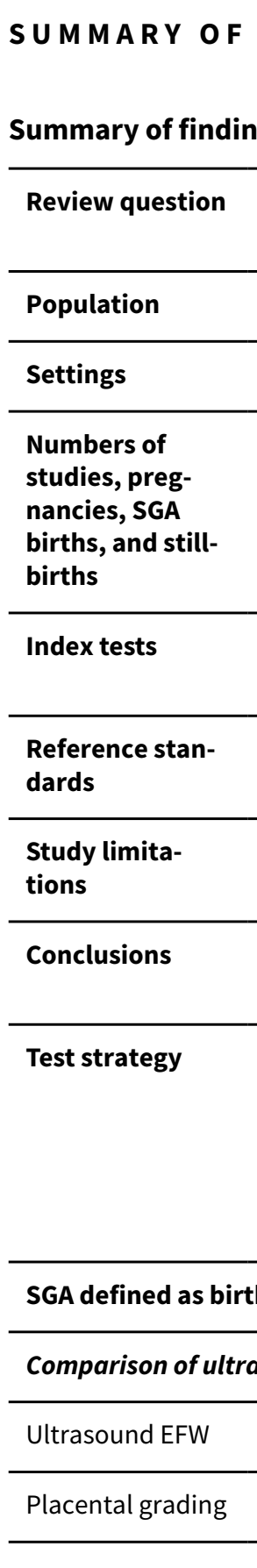 } & \multirow{14}{*}{\multicolumn{6}{|c|}{ 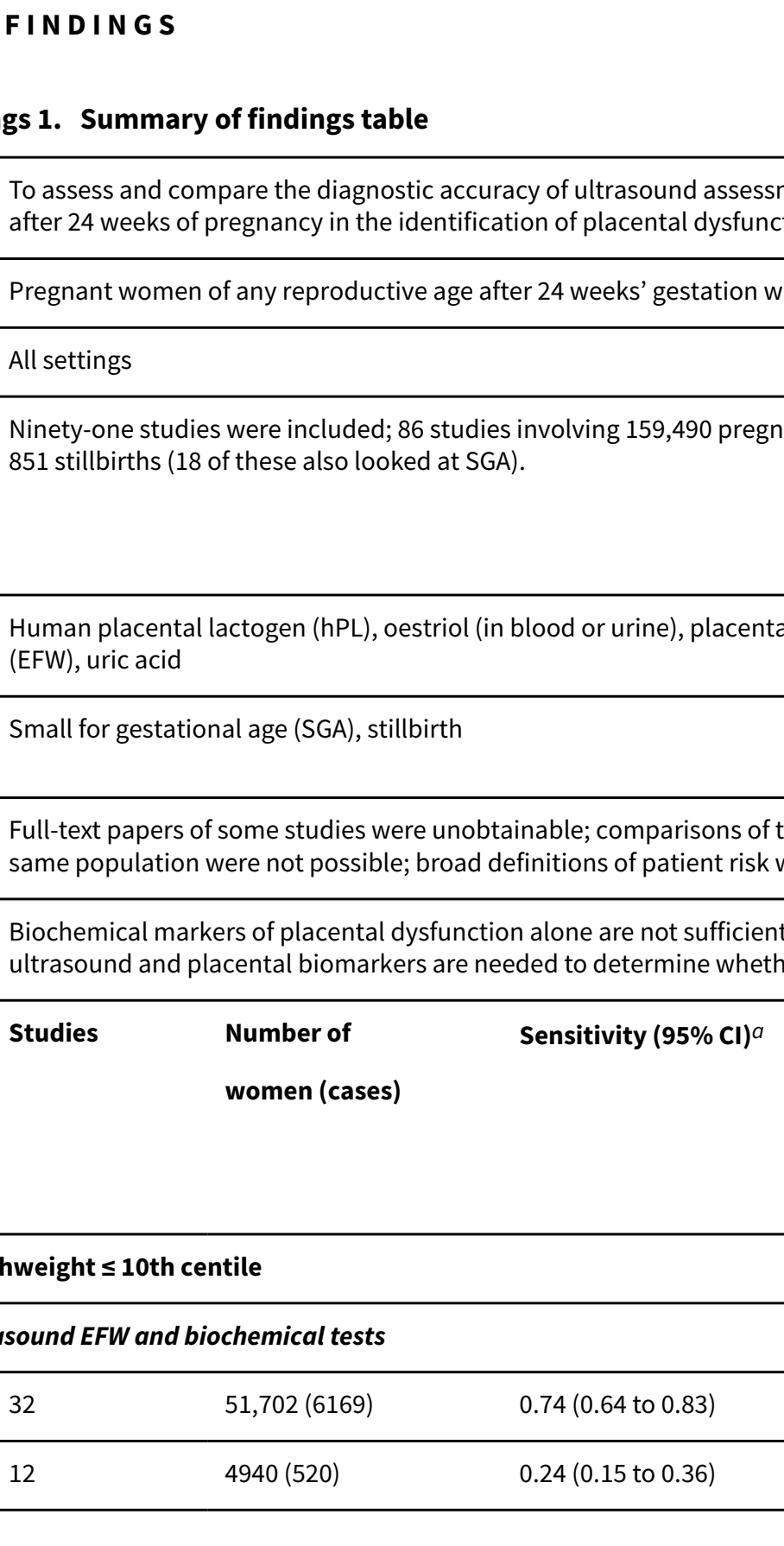 }} & & & & & & \\
\hline & & & & & & & & & & & $\begin{array}{l}\text { wth and place } \\
\text { d by either st }\end{array}$ & $\begin{array}{l}\text { biomarkers alone and in any } \\
\text { h or born small-for-gestation }\end{array}$ & $\begin{array}{l}\text { ombination used } \\
\text { l age (SGA). }\end{array}$ \\
\hline & & & & & & & & & & & comes of preg & y recorded. & \\
\hline & & & & & & & & & & & & & \\
\hline & & & & & & & & & & & 71 SGA infant & 23 studies involving 115,911 & regnancies with \\
\hline & & & & & & & & & & & ntal growth fa & P(GF), ultrasound estimated & etal weight \\
\hline & & & & & & & & & & & & & \\
\hline & & & & & & & & & & & nt gestationa & were not possible; comparis & ns of tests in the \\
\hline & & & & & & & & & & & $\begin{array}{l}\text { dentify pregna } \\
\text { h improves di }\end{array}$ & $\begin{array}{l}\text { ending in SGA or stillbirth. } \\
\text { tic accuracy. }\end{array}$ & dies combining \\
\hline & Test strategy & & & & & & & & & & $\begin{array}{l}\text { Specificity } \\
(95 \% \mathrm{CI})^{a}\end{array}$ & $\begin{array}{l}\text { Number of missed cases } \\
\text { in a hypothetical cohort } \\
\text { of } 1000 \text { pregnant wom- } \\
\text { en } b\end{array}$ & $\begin{array}{l}\text { Number of } \\
\text { false positives } \\
\text { in a hypothet- } \\
\text { ical cohort of } \\
1000 \text { pregnant } \\
\text { women } b\end{array}$ \\
\hline & & & & & & & & & & & & & \\
\hline & & & & & & & & & & & & & \\
\hline & & & & & & & & & & & 0.88 & 50 (32 to 68 ) & 97 \\
\hline & & & & & & & & & & & & 144 (122 to 161$)$ & \\
\hline
\end{tabular}

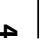




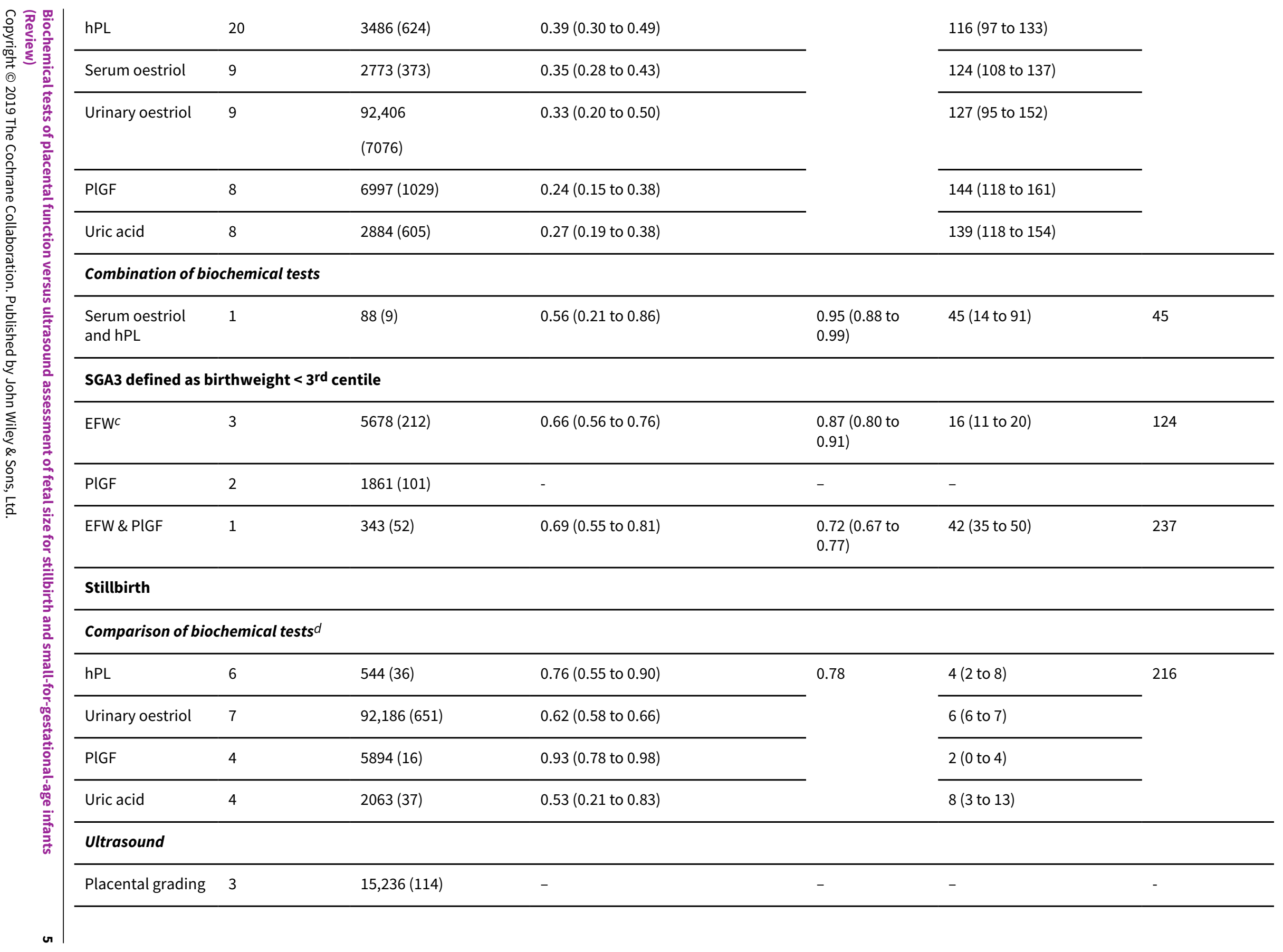


For SGA and stillbirth, the sensitivities were estimated from the SROC curves at fixed values of specificity that correspond to the median of the specificities reported in the studies included in each comparative meta-analysis. For SGA3, the estimates are the pooled sensitivity and specificity from the only meta-analysis that was possible. All other estimates are the sensitivity and specificity from a single study.

bTo calculate the number of missed cases and false positives for SGA and stillbirth in a hypothetical cohort of 1000 pregnant women, we used the median prevalence of $19 \%$ and $1.7 \%$ from the studies included in the comparative meta-analysis of SGA and stillbirth, respectively. For SGA3, we used the median prevalence of $4.6 \%$ to calculate the number of missed cases from the pooled estimates of sensitivity and specificity from the only meta-analysis that was possible. For all single studies, we used the prevalence derived from the study.

cMeta-analysis was not possible for EFW. For the three studies, the sensitivities were between 0.58 and 0.77 , and the specificities were between 0.79 and 0.91 .

$d$ This comparison was limited to only biochemical tests because there were several tests and only three placental grading studies. Including placental grading increased model complexity and made the comparative meta-analysis model impossible to fit. Therefore, placental grading was excluded. The sensitivities of the three placental grading studies ranged between 0.35 and 0.69 , and the specificities between 0.14 and 0.94 . 


\section{B A C K G R O U N D}

Stillbirth affects 2.6 million pregnancies worldwide each year (Lawn 2016). Whilst the majority of cases occur in low- and middle-income countries, stillbirth remains an important clinical issue for highincome countries (HICS) - with both the UK and the USA reporting rates above the mean for HICs (Flenady 2016).

In HICs, the most frequently reported association with stillbirth is placental dysfunction, which may be clinically evident as fetal growth restriction (FGR), small-for-gestational-age (SGA) infants, placental abruption or hypertensive disorders of pregnancy. Placental abnormalities are noted in $11 \%$ to $65 \%$ of stillbirths (Ptacek 2014). Identification of FGR is difficult in utero and even after birth, with SGA being most commonly used as a surrogate measure (Worton 2014). The degree of SGA is associated with the likelihood of FGR; $30 \%$ of infants with a birthweight $<10$ th centile are thought to be FGR, while $70 \%$ of infants with a birthweight $<3 \mathrm{rd}$ centile are thought to be FGR. Critically, SGA is the most significant antenatal risk factor for a stillborn infant (Flenady 2011; Gardosi 2013; McCowan 2007). Correct identification of SGA infants is associated with a reduction in the perinatal mortality rate (Gardosi 2013). However, currently used tests, such as measurement of symphysis-fundal height, have a low reported sensitivity and specificity for the identification of SGA infants (RCOG 2014).

Due to the importance of the placenta in FGR and stillbirth there is growing interest in antenatal placental evaluation in an attempt to identify pregnancies at increased risk of stillbirth or fetal compromise (Heazell 2015a). A systematic review of biochemical tests of placental function found insufficient evidence to conclude whether these interventions had any effect on perinatal mortality or fetal compromise (Heazell 2015b). In contrast, a single trial of placental grading assessed by ultrasound demonstrated reduced perinatal mortality (Proud 1987). Systematic reviews of other methods employed to identify fetal compromise such as ultrasound assessment of fetal growth or umbilical artery Doppler (measurement of blood flow through the umbilical artery) in late pregnancy have also found insufficient evidence to conclude whether these interventions reduce perinatal mortality in a lowrisk maternity population (Alfirevic 2015; Bricker 2015), although both are effective in women deemed to be at high risk of pregnancy complications (Alfirevic 2017). The efficacy of umbilical artery Doppler in high-risk populations may be due to its prognostic accuracy; a systematic review found this test predicted SGA infants with a positive likelihood ratio of 3.76 and stillbirth with a positive likelihood ratio of 4.37 (Morris 2011).

Two components are necessary to reduce perinatal mortality and minimise unwarranted intervention. Firstly, the test must accurately identify fetal compromise and secondly, the intervention must be effective in preventing the adverse outcome. There is now strong evidence that planned delivery (by induction of labour) after 37 weeks of pregnancy is associated with a reduction in perinatal mortality (Stock 2012). Therefore, the most accurate test to identify fetal compromise needs to be determined so that it may be combined with planned delivery where appropriate.

\section{Target condition being diagnosed}

The target condition of interest is placental dysfunction - which describes the condition in which the placenta does not meet the demands of the fetus (Heazell 2015a). As with other organ dysfunction, there are multiple pathways that can result in placental dysfunction including vascular, inflammatory, infective and genetic disorders. These various processes may lead to changes in placental structure and/or function that may lead to two clinical outcomes i) stillbirth or ii) the birth of an SGA infant. As placental dysfunction cannot easily be quantified, this review will use these two clinical outcomes as the target conditions of interest.

\section{Index test(s)}

This review evaluated tests used in late pregnancy (after 24 weeks) to identify pregnancies with placental dysfunction to inform decisions to continue with the pregnancy or institute intervention. Tests that were included in this review assessed placental structure or biochemical function by one or more of ultrasound scan or measurement of placental products in maternal blood (plasma or serum) or urine.

Biochemical tests of placental function measure placental products (proteins, peptides, metabolites, hormones) in maternal biofluids (serum, plasma, urine); it is hypothesised that levels of such products in maternal fluids reflect endocrine and metabolic functions of the placenta. Many placental products can be detected in maternal biofluids including protein hormones: human chorionic gonadotrophin (hCG), human placental lactogen (hPL), human placental growth hormone (hPGH), placental growth factor (PIGF), placental protein-13 (PP-13), pregnancy specific glycoproteins and steroid hormones including oestrogens and progesterone with their related metabolites. Ultrasonography has been used to measure the size, shape, and echotexture of the placenta; the majority of such studies have used 2D ultrasound to evaluate placental morphology, although newer studies have utilised 3D techniques.

\section{Clinical pathway}

Antenatal care differs between countries; the clinical pathway described here applies to the UK and follows guidance from the Royal College of Obstetricians and Gynaecologists (RCOG 2014) and the National Institute for Health and Social Care Excellence (NICE 2008).

\section{Prior test(s)}

Currently, in the UK women are grouped into high risk and low risk for SGA in early pregnancy at the booking-visit by assessing a woman's past medical history, obstetric history and risk factors for an SGA infant (RCOG 2014). All women are offered screening for Down's syndrome (which is currently based on measurement of nuchal translucency by ultrasound scan and measurement of serum analytes between 11 and $13+6$ weeks of pregnancy) and for fetal anomaly (by ultrasound scan from 18 to $20+6$ weeks).

In clinical practice, placental dysfunction is suspected by identification of an SGA infant. However, testing for SGA currently depends upon the risk status of the woman (RCOG 2014). The National Institute for Health and Care Excellence do not recommend routine measurement of fetal growth by ultrasound scan in late pregnancy (NICE 2008). Fetal growth is assessed in women deemed to be at low risk of an SGA infant by measurement of symphysis-fundal height with a tape measure (RCOG 2014). Women at increased risk of SGA are recommended to have a uterine artery Doppler (to assess blood flow through both uterine arteries) at 20 weeks' gestation and regular scans to measure fetal

Biochemical tests of placental function versus ultrasound assessment of fetal size for stillbirth and small-for-gestational-age infants 
biometry with assessment of liquor volume and umbilical artery Doppler. Umbilical artery Doppler is the most frequently employed test to predict fetal outcome; the relationship between umbilical artery Doppler indices and placental function is not clear. In addition to recommendations for the diagnosis and management of an SGA fetus, ultrasound assessment of fetal growth, liquor volume and umbilical artery Doppler are recommended following maternal presentation with reduced fetal movements, as this may be a symptom of placental insufficiency (RCOG 2011). The current clinical pathway is shown in Figure 1.

Figure 1. Current clinical pathway and three proposed uses of a placental function test. Currently, women are screened for a small-for-gestational age fetus (as a proxy for placental dysfunction) using symphysis-fundal height and maternal awareness of fetal movements. Women deemed to be at increased risk are screened using ultrasound measurement of fetal biometry. We propose three different clinical pathways for placental function tests. Firstly, they could be used as an additional test when Doppler measurements are normal. They could be used in combination with currently used tests, and finally they could be used as a triage test to differentiate infants who are constitutionally small from those with placental dysfunction. Although treatment decisions would be tailored to individual cases, a positive test would be expected to lead to increased surveillance or intervention (planned delivery) and a negative test would lead to continuing with the pregnancy.

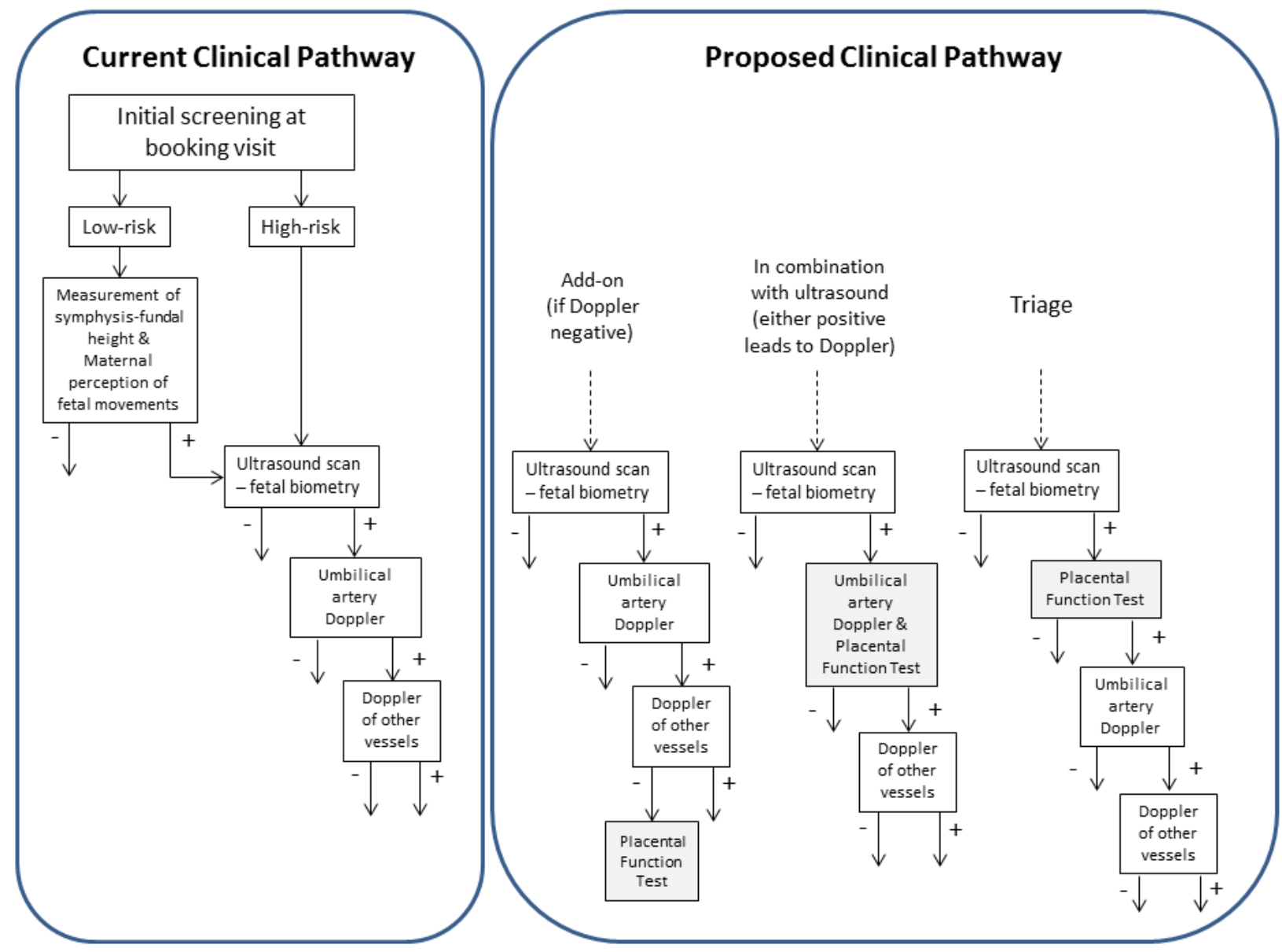

When an SGA infant is identified by tests, clinical management is dependent upon gestation. Prior to 37 weeks' gestation, identification of SGA prompts further assessment of fetal wellbeing, primarily by measurement of Doppler waveforms in the umbilical artery, but may also include the middle cerebral artery and ductus venosus. Delivery is recommended when evidence of fetal compromise is identified (RCOG 2014). After 39 weeks' gestation, delivery of the baby may be offered as this is associated with a reduction in stillbirth, avoids potential hazards of early term birth (Mackay 2010), and is not associated with an increase in obstetric intervention (Stock 2012).

There are currently no routinely used measures of placental function after 16 weeks of pregnancy. There is evidence that measurement of placental analytes as part of screening for aneuploidy may identify fetuses at high risk of early-onset FGR (Smith 2002; Smith 2006). Assessment of these analytes is incorporated into the current clinical pathway (RCOG 2014); women with low pregnancy-associated plasma protein A (PAPP-A) levels are managed as high risk for SGA. Therefore, we wish to focus

Biochemical tests of placental function versus ultrasound assessment of fetal size for stillbirth and small-for-gestational-age infants 8 (Review)

Copyright (c) 2019 The Cochrane Collaboration. Published by John Wiley \& Sons, Ltd. 
on placental tests performed in late pregnancy (after 24 weeks' gestation).

\section{Role of index test(s)}

Due to the established use of ultrasound in obstetric practice, we envisage that additional tests of placental function would most likely be added to an ultrasound measurement of fetal size rather than replacing it (Figure 1); this is certainly true of the intervention trials of placental assessment (by biochemical tests) that have been conducted (Duenholter 1976; Heazell 2013; Sharf 1984). It is hypothesised that the addition of a placental function test to an ultrasound scan would improve identification of an SGA infant and consequently focus intervention on those pregnancies at the greatest risk of stillbirth or fetal compromise, thereby reducing the burden of perinatal mortality and morbidity. It is also possible that a placental function test could be used to triage infants who were SGA to identify which were constitutionally small and which had placental dysfunction. This would allow the pregnancy to continue in otherwise healthy constitutionally small infants, reducing unnecessary intervention.

The importance of specific aspects of test performance will depend upon the context in which it is used in late pregnancy. From the perspective of reducing perinatal mortality and morbidity in a high-risk population (e.g. triage of women with a small baby on ultrasound scan or women presenting with reduced fetal movements, Figure 1), a false negative test would be more harmful than a false positive test as pregnant women may be deprived of further monitoring or intervention which may mitigate some of the increased risk. In women at low risk of SGA or stillbirth then a false negative test would mean that the mother continued upon the pathway of care she would have otherwise received, whereas a false positive result would mean she may be exposed to monitoring or intervention which was unnecessary, which may have negative medical and economic consequences. Thus, it is important to consider the clinical group being studied and how this impacts upon test performance.

\section{Alternative test(s)}

Presently, there are no tests in widespread clinical use that directly assess placental biochemical function. Umbilical artery Doppler is often used in clinical practice to identify placental dysfunction but has not been included in this analysis as a systematic review and meta-analysis has already been conducted (Morris 2011).

\section{Rationale}

There are several tests of placental structure and function. Systematic reviews of the measurement of biochemical placental factors and the effectiveness of ultrasound in late pregnancy found that few tests of placental structure or function have been evaluated in robust intervention studies (Bricker 2015; Heazell 2015a). This review aims to identify and evaluate tests of placental structure and function, not restricted to those evaluated in intervention studies, to determine which measurement(s) have the greatest diagnostic accuracy for detection of placental dysfunction leading to stillbirth and SGA. The most accurate test(s) can then be taken forward into intervention studies to determine whether performing investigations can reduce perinatal morbidity or mortality.

\section{O B JECTIVES}

The primary objective of this review was to assess and compare the diagnostic accuracy of ultrasound assessment of fetal growth and placental biomarkers alone and in any combination used after 24 weeks of pregnancy in the identification of placental dysfunction as evidenced by either stillbirth or born small-forgestational age (SGA). Accuracy is described by the proportion of fetuses who are subsequently stillborn or who have an SGA baby detected by a positive test result (the presence of placental dysfunction) (sensitivity) and by the proportion of fetuses that have an uncomplicated pregnancy following a negative index test result (absence of placental dysfunction) (specificity).

\section{Secondary objectives}

We investigated the effect of clinical (patient and test characteristics) and methodological factors (study design, threshold used to define SGA) on test performance. The clinical factors include patient group (low-risk or high-risk pregnancies), gestation at measurement, ethnicity, maternal age and method of testing. With regard to methodological variation, studies may include an intervention (delivery or additional fetal surveillance for index test positive cases) which impacts on the outcome; therefore we assessed whether this is a source of heterogeneity.

\section{METHO D S}

\section{Criteria for considering studies for this review}

\section{Types of studies}

Presently, there are no effective interventions to reverse placental dysfunction in utero. This means that an intervention cannot be employed to reverse the small-for-gestational age (SGA) phenotype following a positive test result. Delivery may be indicated, although at earlier gestations this does not affect perinatal mortality (GRIT 2003).

We included prospective and retrospective cross-sectional or cohort studies in which all women received one or more index tests and the outcome of their pregnancy was known. Case-control studies were excluded.

We included studies which measured index tests on one occasion (cross-sectional design).

We excluded studies where it was not possible to derive a $2 \times 2$ table of the number of true positives, false positives, false negatives and true negatives, or studies that reported preliminary experimental findings, i.e. laboratory-based studies.

\section{Participants}

We included studies of pregnant women after 24 weeks' gestation that recorded relevant outcomes of pregnancy (live birth/stillbirth; SGA infant).

We included studies of pregnant women of any reproductive age, who were deemed to be low or high risk for complications (e.g. who had pre-existing medical disorders or previous stillbirth) or studies of mixed populations (of low and high risk for complications). 
We excluded pregnancies complicated by fetal abnormalities, as they often have a higher risk of stillbirth from non-placental causes. We excluded studies of women with multi-fetal pregnancies.

\section{Index tests}

We included, but were not restricted to, the following index tests of placental biochemical function, placental structure or assessment of fetal biometry to identify an SGA infant:

- human placental lactogen (hPL) in maternal urine/blood;

- oestriol in maternal urine/blood;

- placental growth factor (PIGF) in maternal blood;

- ultrasound assessment of placental echogenicity;

- ultrasound assessment of fetal size.

With regard to biochemical tests, we included assays that were performed using different techniques, including: immunoassay, enzyme-linked immunosorbent assay (ELISA), chromatography or point of care test in any combination and at any threshold used to determine test positivity. Examples of current commercially available tests are listed in Appendix 1.

\section{Target conditions}

The target conditions were stillbirth and delivery of a SGA infant at the centile or threshold used by each study, as clinical manifestations of placental dysfunction.

\section{Reference standards}

The outcome of pregnancy was considered as the reference standard. A "positive" result was either i) a stillbirth - an infant born with no signs of life after 24 weeks' gestation, or ii) a birthweight classified as SGA. A "negative" result was a live birth after 24 weeks' gestation or a birthweight classified as appropriate for gestational age.

The classification of SGA was determined according to the definition used in the study. Where possible, the definition of an infant with a birthweight $\leq 10$ th centile using a customised birthweight calculator was used (Clausson 2001). Where this was not possible, the definition of SGA from the manuscript was used and recorded. The effects of different definitions of SGA were addressed as a potential source of heterogeneity.

\section{Search methods for identification of studies}

We conducted a comprehensive search for existing systematic reviews and primary studies relevant to the prevention of adverse pregnancy outcome in women at increased risk of stillbirth by detecting placental dysfunction. A scoping search was undertaken in the bibliographic databases MEDLINE, MEDLINE In Process, Embase, the Cochrane Library (CDSR, DARE, HTA, NHS EED and Central Register of Controlled Trials (CENTRAL) databases), HTA and relevant web sites in order to identify existing reviews and to gauge the nature and number of relevant studies to inform the protocol.

\section{Electronic searches}

We developed full search strategies based on the scoping searches, expert advice, and consultation with the Cochrane Pregnancy and Childbirth Group's Information Specialist. Search strategies included a combination of text words and index terms.
Methodological search filters for diagnostic test accuracy were avoided as they have been shown to miss relevant studies (Whiting 2011a). We did not apply any language or date restrictions. We searched the following sources:

- bibliographic databases - MEDLINE, MEDLINE In Process and Embase via Ovid, Cochrane (Wiley) CENTRAL, Science Citation Index (Web of Science), CINAHL (EBSCO) with search strategies adapted for each database as required;

- ISRCTN Registry, UK Clinical Trials Gateway, WHO International Clinical Trials Portal (ICTRP) and ClinicalTrials.gov for ongoing studies;

- specialist abstract and conference proceeding resources (British Library's ZETOC and Web of Science Conference Proceedings Citation Index).

Searches were last conducted on 27 Ocober 2016. The full search strategy is provided in Appendix 2.

\section{Searching other resources}

We checked citation lists of included studies and relevant reviews. We examined grey literature by searching websites of companies producing biochemical tests of placental function (Alere 2015; Perkin Elmer 2015; Roche 2015). We also undertook consultation with experts in the field to access relevant unpublished data.

\section{Data collection and analysis}

We used the methods advocated by the Cochrane Screening and Diagnostic Test Methods Group.

\section{Selection of studies}

Two review authors ( $\mathrm{DH}$ and $\mathrm{AH}$ ) independently screened the titles and abstracts of all studies identified by the search strategy. We obtained full-text versions of all potentially relevant studies. Two review authors ( $\mathrm{DH}$ and $\mathrm{AH}$ ) independently assessed studies for inclusion using pre-specified inclusion criteria stated earlier. We included studies of pregnant women after 24 weeks' gestation that recorded relevant outcomes of pregnancy (live birth/stillbirth; SGA infant), and presented data to construct a $2 \times 2$ table. We resolved any disagreement between the two review authors or by discussion with a third party $(C D)$ if needed. Reasons for study exclusion were documented.

\section{Data extraction and management}

We developed a customised form to ensure reproducible collection of data items. Data collection was piloted on five manuscripts then reviewed by the review authors. Data were extracted independently by two review authors ( $\mathrm{DH}$ and $\mathrm{AH}$ ). We resolved discrepancies, where they occurred, through discussion or if required we consulted a third author (CD or MW), drawing on clinical and methodological expertise in the team as appropriate to the content of the query. We extracted characteristics of participants, index tests or test combinations (including thresholds used), and details of the reference standard in terms of pregnancy outcome (live birth or stillbirth) and whether the infant was SGA. For studies that reported data at multiple thresholds for a test, we extracted a 2 $\times 2$ table at each reported threshold. Where possible we recorded the frequency of obstetric intervention and infant admission to neonatal intensive care. If reported, we also recorded data on outcomes including harms of testing, need for further testing, and

Biochemical tests of placental function versus ultrasound assessment of fetal size for stillbirth and small-for-gestational-age infants 
the effects of the test. We did not address women's experiences of testing, caregivers' satisfaction with testing or economic evaluation of testing as this is beyond the scope of this review.

We attempted to contact the authors of included studies where information considered key to assessment of methodological quality, investigation of heterogeneity, or completion of a $2 \times 2$ table was unclear or missing. Studies published only as conference abstracts were followed up to identify whether a subsequent full paper had been published.

\section{Assessment of methodological quality}

We used the QUADAS-2 tool (Whiting 2011b) to assess the risk of bias and applicability of included studies. We tailored the tool to our review question using the operational criteria detailed in Appendix 3 to answer signalling questions and make the overall judgement of risk of bias and applicability concerns for each domain of the tool. Two review authors ( $\mathrm{DH}$ and $\mathrm{AH}$ ) assessed each included study separately. We resolved differences in assessment through discussion and if required, by discussion with a third person (CD). We assessed each criteria in QUADAS-2 as "yes", "no" or "unclear" and summarised the results graphically or in tables.

We included all signalling questions of QUADAS-2 assessment including the time interval between testing and the outcome and any intervention as these may alter the outcome. We have operationalised the domains of the QUADAS-2 tool for the clinical context of this review. For example, the domain concerning patient selection was amended to reflect review exclusion criteria including women with multiple pregnancies or with fetal abnormalities. However, other criteria that might be expected to alter the accuracy of tests in universal populations (e.g. ethnicity, maternal age and income) would be inappropriate exclusions. Studies restricted to specific high-risk groups, e.g. maternal hypertension, will reduce the applicability of review findings. We also tailored the target condition domain to assess the quality of measures of SGA used in studies, some of which may not be related to gestation, e.g. low birthweight $(<2.5 \mathrm{~kg})$. Studies using a threshold which alters with sex and gestation, e.g. individualised birthweight centile, were rated more highly than those which did not.

\section{Statistical analysis and data synthesis}

From here on we use the term SGA for SGA defined as birthweight $\leq 10$ th centile, and SGA3 for SGA defined as birthweight < 3rd centile. We performed separate analyses for each target condition (SGA, SGA3 and stillbirth). For each test and target condition, estimates of sensitivity and specificity from each study were plotted in receiver operating characteristic (ROC) space and forest plots for preliminary investigations of the data. Since studies used different thresholds to determine test positivity, we performed metaanalyses using the hierarchical summary ROC (HSROC) model (Rutter 2001) to estimate and compare the SROC curves of the tests. Methods that allow joint synthesis of sensitivities and specificities at multiple thresholds have been proposed, but are not yet used routinely in practice and require further evaluation before they can be used in diagnostic test accuracy reviews (Ensor 2018; Riley 2015; Steinhauser 2016). As such, where a study reported multiple thresholds for a test, we selected the threshold most frequently reported across studies so that only one $2 \times 2$ table was included in a meta-analysis. In separate analyses of each test, where studies reported common thresholds for the test, we estimated summary sensitivities and specificities using functions of HSROC model parameters.

Before performing meta-analyses to compare test accuracy, we performed meta-analysis of each test separately for preliminary investigation of the shape of the SROC curve of each test and to explore if assuming common variances across tests for the random effects would be reasonable. The main test comparison was an indirect comparison pooling all relevant studies that assessed at least one of the index tests. In secondary analyses, we performed direct comparisons by restricting the analyses to only studies that compared tests head-to-head in the same study population. This analytical strategy was adopted because of the paucity of comparative studies of diagnostic accuracy (Takwoingi 2013). We limited the indirect comparison to only tests with at least four studies because of potential model complexity given the number of tests included and number of model parameters to be estimated. For direct comparisons, we performed pairwise comparisons of tests. Test comparisons were performed by adding a covariate for test type to the HSROC model to estimate differences in accuracy, threshold, and/or shape of SROC curves. When there were adequate data, we also allowed the variance parameters for accuracy and threshold to depend on test type, i.e. differences in accuracy and threshold modelled as random effects. We assessed the statistical significance of differences between tests using likelihood ratio tests comparing models with and without the covariate terms. The NLMIXED procedure in the SAS software package (version 9.4; SAS Institute, Cary, NC, USA) was used for meta-analyses.

To quantify differences in accuracy between tests, we computed ratios of diagnostic odds ratios when SROC curves were symmetric or a common shape was assumed. Using the estimate statement within NLMIXED, we also estimated sensitivities along the SROC curves at fixed values of specificity that correspond to the median and interquartile range of specificities from the studies included in the comparative meta-analysis. We used these values along with the median and interquartile range of the prevalence estimated from the studies to compute numbers of missed cases and false positives in a hypothetical cohort of 1000 pregnant women. We used these frequencies to illustrate the accuracy of the tests in absolute terms.

\section{Investigations of heterogeneity}

We initially examined heterogeneity between studies by visually inspecting forest plots of sensitivity and specificity and SROC plots. Where a sufficient number of studies assessed the same index test and there were at least four studies per subgroup of a categorical covariate, we performed meta-regression by adding the potential source of heterogeneity as a covariate to the HSROC model. We assessed the effect of the covariate on test accuracy by using likelihood ratio tests to compare models with and without the covariate terms.

\section{Sensitivity analyses}

We planned to perform sensitivity analyses by restricting analyses to studies that:

- were without an intervention that may have altered outcome;

- were at low risk of bias in each of the four domains of the QUADAS-2 tool; 
- specifically described histological evidence of placental insufficiency.

These analyses were not possible due to limited data.

\section{Assessment of reporting bias}

We did not undertake any formal assessment of reporting bias in our review due to current uncertainty about how to assess reporting bias in diagnostic accuracy reviews, especially in the presence of heterogeneity (Macaskill 2010).

\section{RES U LTS}

\section{Results of the search}

Our literature searches identified a total of 24,059 papers before duplicates were removed (Figure 2) After initial screening based on title and abstract, we obtained full-text copies of 471 papers, of which 91 were included. The included studies evaluated seven tests - blood tests for human placental lactogen (hPL), oestriol, placental growth factor (PIGF) and uric acid, ultrasound EFW and placental grading and urinary oestriol - in a total of 175,426 pregnant women, in which 15,471 pregnancies ended in the birth of a small baby and 740 pregnancies which ended in stillbirth. 
Figure 2. PRISMA flow diagram for selection of studies.

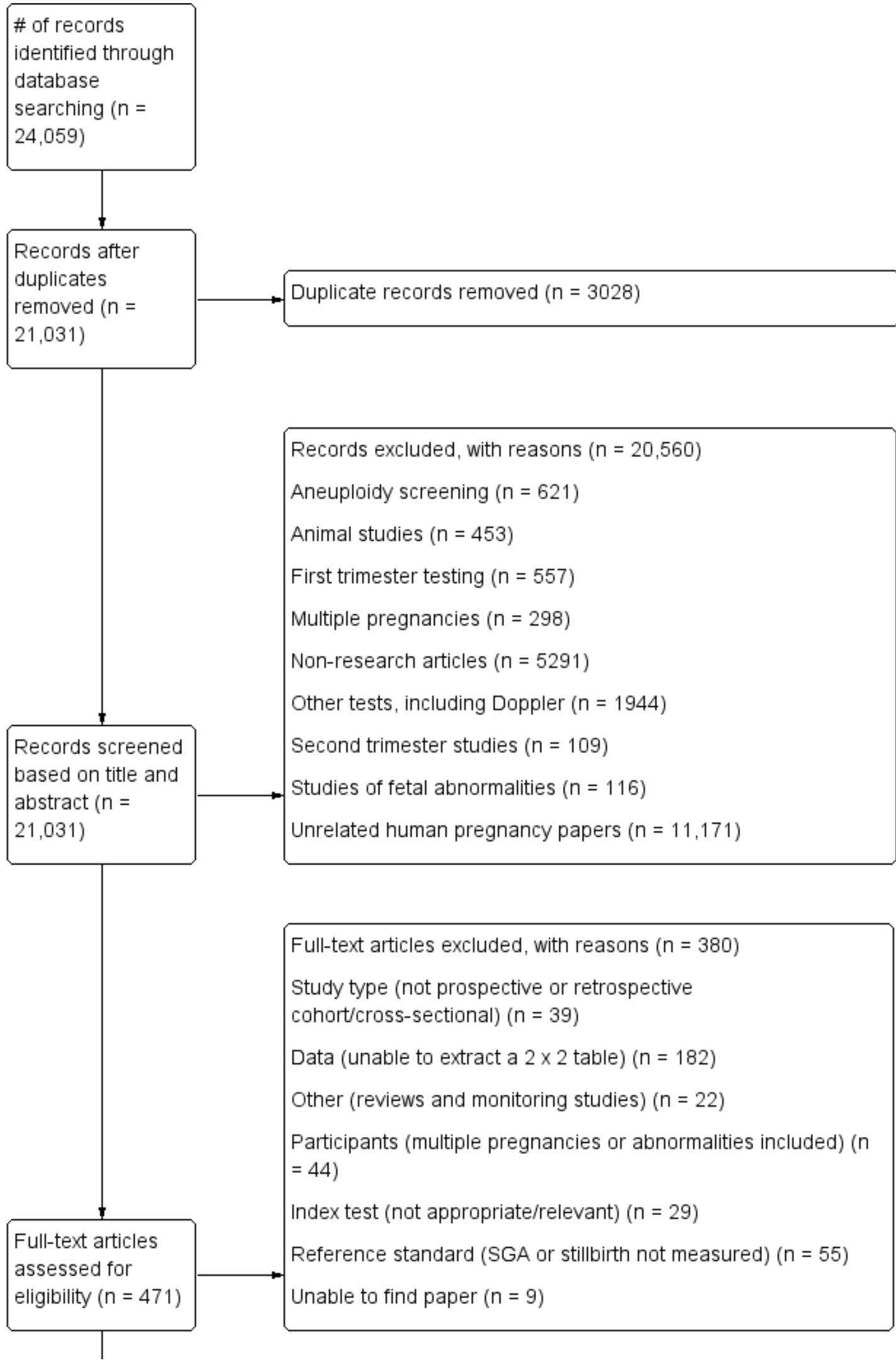


Figure 2. (Continued)

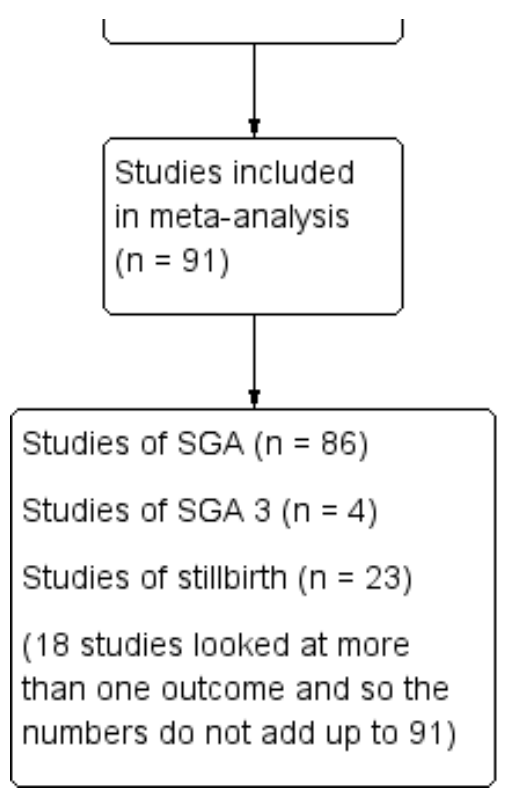

In total, seven different tests were evaluated, as well as two combinations of these tests. Included studies are described in Table 1. We described the studies that were excluded after full-text assessment in Characteristics of excluded studies. Some papers could not be obtained, index tests used in these papers are stated in Characteristics of studies awaiting classification where possible.

\section{Methodological quality of included studies}

Figure 3 shows the summary risk of bias and applicability concerns for included studies. Risk of bias and applicability concerns for individual index tests are in Appendix 5. The quality of included studies was judged to be mostly high, with most domains at low risk of bias, although risk of bias for the reference standard domain was mostly unclear (59\% of studies) due to definitions of smallfor-gestational age (SGA) not being reported or uncertainty as to whether index test results were blinded. In terms of applicability concerns; $53 \%$ of studies were at high concern for patient selection, mostly due to inclusion of only high- or low-risk women rather than an unselected population of pregnant women where both are likely to be included. Fourteen studies (15\%) were of high concern regarding the reference standard due to differing definitions of SGA, for example if gestation was not taken into account or centiles were based on the study population only. Eighty-four per cent of studies were judged to be at low risk of bias for flow and timing as testing was mostly performed with an appropriate interval between testing and delivery. 
Figure 3. Risk of bias and applicability concerns graph: review authors' judgements about each domain presented as percentages across included studies. E3 = oestriol; EFW = estimated fetal weight; $\mathrm{hPL}=$ human placental lactogen; PIGF = placental growth factor. Each bar shows the number of studies in each category for a domain. The index test domain was evaluated separately for each test. Of the 91 included studies, 9 studies evaluated more than one test and so the numbers of studies shown for the 7 index test domains do not add up to 91 across tests.

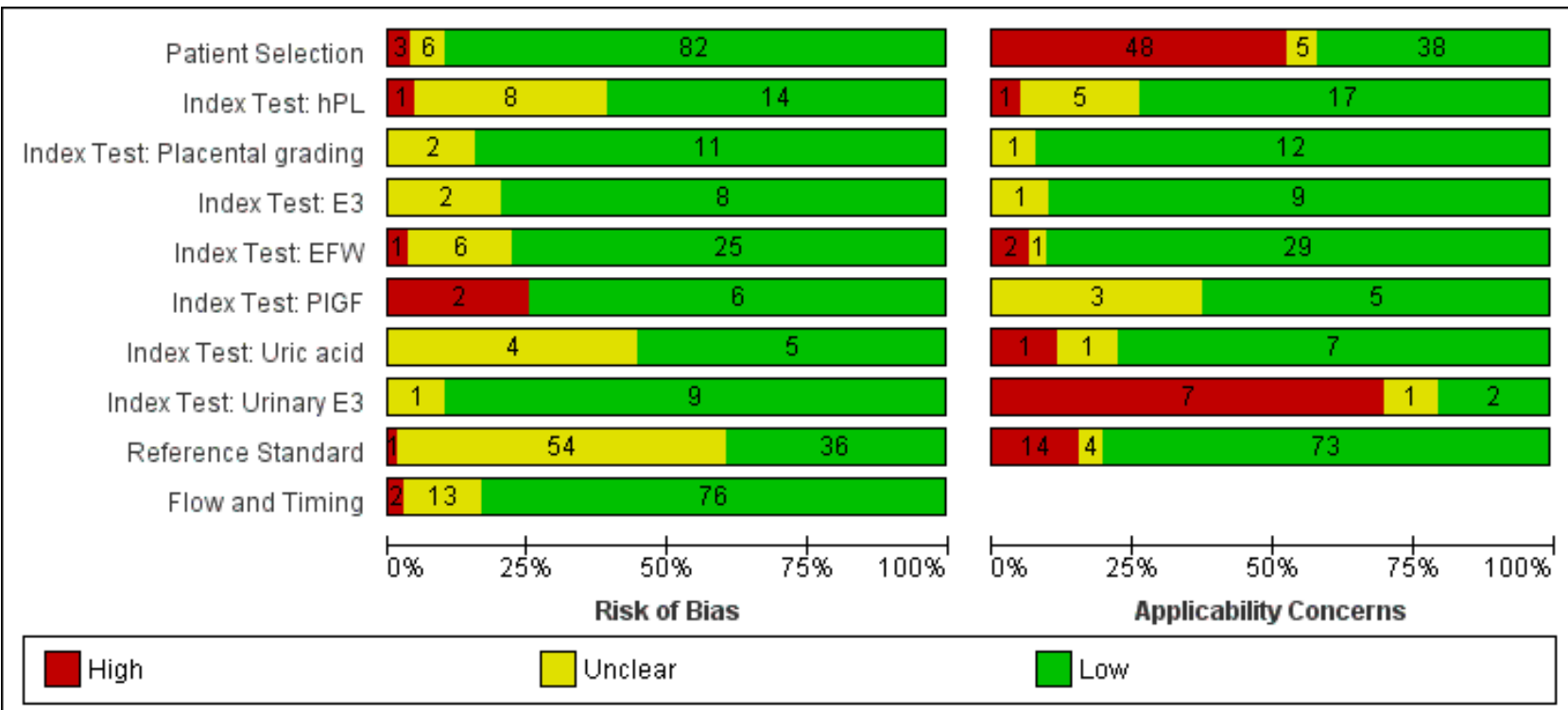

\section{Findings}

\section{Small-for-gestational age (SGA) (birthweight $\leq$ 10th centile)}

The findings are summarised in Summary of findings 1 . SGA was the outcome assessed in 86 studies involving 159,490 pregnancies (included 15,471 SGA infants). The study specific estimates of sensitivity and specificity for each test are shown for structural tests (ultrasound assessment of fetal size and placental grading) in Figure 4, and for biochemical tests (human placental lactogen $(\mathrm{hPL})$, serum oestriol, urinary oestriol, placental growth factor (PIGF), uric acid, and a combination of serum oestriol and $\mathrm{hPL}$ ) in Figure 5. 
Figure 4. Forest plot of structural tests for identifying small-for-gestational age (birthweight stenth centile) infants. EFW = estimated fetal weight; FN = false negative; $F P=$ false positive; $S G A=$ small-for-gestational-age; TN = true negative; TP = true positive. For each test, the forest plot shows the estimates of sensitivity and specificity from each study, the threshold used to define test positivity, risk of SGA pregnancy and whether there was an intervention that may have altered outcome. Studies are sorted by threshold, risk and intervention status.

\begin{tabular}{|c|c|c|c|c|c|c|c|c|c|c|c|}
\hline \multicolumn{12}{|l|}{ EFW and SGA } \\
\hline \multicolumn{2}{|l|}{ Study } & TP & FP & $\mathbf{F N}$ & TN & & & Threshold & & Risk & Intervention \\
\hline \multicolumn{2}{|l|}{ Ott 1984} & 99 & 67 & 12 & 417 & & & $-1.5 \mathrm{SD}$ & & Mixed & Unknown \\
\hline \multicolumn{2}{|l|}{ Mahran 1988} & 88 & 235 & 10 & 495 & & & $-2 \mathrm{SD}$ & & Mixed & Unknown \\
\hline \multicolumn{2}{|l|}{ MacLeod 2013} & 4 & 4 & 4 & 78 & & & $000 \mathrm{~g}(++-10 \%)$ & & Mixed & Unknown \\
\hline \multicolumn{2}{|l|}{ Geerts 2016} & 34 & 0 & 26 & 150 & & Belo & w tenth centile & & High & Unknown \\
\hline \multicolumn{2}{|l|}{ Gupta 2008} & 6 & 3 & 9 & 20 & & Belo & iw tenth centile & & High & Unknown \\
\hline \multicolumn{2}{|l|}{ Griffin 2015} & 88 & 64 & 99 & 335 & & Belo & w tenth centile & & High & Unknown \\
\hline \multicolumn{2}{|l|}{ Christensen 2015} & 6 & 24 & 1 & 126 & & Belo & w tenth centile & & High & Unknown \\
\hline \multicolumn{2}{|l|}{ Palo 1989} & 80 & 8 & 17 & 81 & & Belo & w tenth centile & & High & Unknown \\
\hline \multicolumn{2}{|l|}{ Hatfield 2010} & 15 & 19 & 33 & 592 & & Belo & w tenth centile & & High & Unknown \\
\hline \multicolumn{2}{|l|}{ Baird 2016} & 60 & 16 & 18 & 13 & & Belo & w tenth centile & & High & Unknown \\
\hline \multicolumn{2}{|l|}{ Chauhan 2003} & 40 & 42 & 18 & 164 & & Belo & w tenth centile & & High & Yes \\
\hline \multicolumn{2}{|l|}{ Berkowitz 1988} & 33 & 19 & 9 & 107 & & Belo & w tenth centile & & High & Yes \\
\hline \multicolumn{2}{|l|}{ Hammad 2015} & 6 & 1 & 3 & 61 & & Belo & w tenth centile & & Low & No \\
\hline \multicolumn{2}{|l|}{ Ben-Haroush 2007} & 4 & 8 & 15 & 232 & & Belo & w tenth centile & & Low & Unknown \\
\hline \multirow{2}{*}{\multicolumn{2}{|c|}{ Weiner 2016}} & 26 & 114 & 4 & 261 & & Belo & w tenth centile & & Mixed & No \\
\hline & Sekar 2016 & 14 & 1 & 1 & 134 & & Belo & w tenth centile & & Mixed & No \\
\hline \multicolumn{2}{|c|}{ Gabbay-Benziv 2016} & 441 & 159 & 197 & 5329 & & Belo & w tenth centile & & Mixed & Unknown \\
\hline Freire 2010 & & 18 & 0 & 3 & 101 & & Belo & w tenth centile & & Mixed & Unknown \\
\hline Chauhan 1999 & & 30 & 19 & 14 & 261 & & Belo & w tenth centile & & Mixed & Unknown \\
\hline Chauhan $1999 a$ & & 4 & 8 & 55 & 507 & & Belo & w tenth centile & & Mixed & Unknown \\
\hline Barel 2016 & & 373 & 90 & 845 & 12781 & & Belo & w tenth centile & & Mixed & Unknown \\
\hline Takeuchi 1985 & & 21 & 3 & 18 & 168 & & Belo & w tenth centile & & Mixed & Unknown \\
\hline Skovron 1991 & & 17 & 21 & 52 & 678 & & Belo & w tenth centile & & Mixed & Unknown \\
\hline Sovio 2015 & & 199 & 363 & 153 & 3262 & & Belo & w tenth centile & & Mixed & Unknown \\
\hline Callec 2015 & & 45 & 101 & 111 & 1640 & & Belo & w tenth centile & & Mixed & Yes \\
\hline Valino 2016 & & 104 & 55 & 275 & 3519 & & Belo & w tenth centile & & Mixed & Yes \\
\hline Turitz 2014 & & 593 & 254 & 1283 & 8512 & & Belo & w tenth centile & & Mixed & Yes \\
\hline Roma 2015 & & 52 & 63 & 82 & 918 & & Belo & w tenth centile & & Mixed & Yes \\
\hline Chervenak 1984 & & 14 & 13 & 3 & 149 & & & L99CL & & High & Unknown \\
\hline Laurin 1987 & & 50 & 69 & 28 & $1921 \mathrm{Pre}$ & Prodictad & $B W$ deviation $\mathrm{fc}$ & or $G A$ of $\geq 15 \%$ & & Mixed & Unknown \\
\hline Hendrix 2000 & & 15 & 79 & 7 & 266 & & & $S E F W<2500 \mathrm{~g}$ & & Mixed & No \\
\hline Bikmetova 2013 & & 26 & 38 & 159 & 295 & & & Unknown & Unkn & nown & Unknown \\
\hline Placental gradi & & & & & & & & & & & \\
\hline Study & TP & FP & $\mathbf{F N}$ & TN & Threshold & Risk & Intervention & Sensitivity (95\%) & $\% \mathrm{Cl})$ & Specil & city (95\% Cl) \\
\hline Chen 2012 & 13 & 29 & 10 & 61 & Grade III & High & No & $0.57[0.34,0$ & $0.77]$ & & $.68[0.57,0.77]$ \\
\hline Patterson 1983 & 11 & 166 & 10 & 211 & Grade III & High & Unknown & $0.52[0.30,0$ & $0.74]$ & & $.56[0.51,0$. \\
\hline Geerts 2016 & 21 & 5 & 30 & 132 & Grade III & High & Unknown & $0.41[0.28,0$ & $0.56]$ & & $.96[0.92,0.5$ \\
\hline Estel 1989 & 4 & 14 & 17 & 20 & Grade III & High & Unknown & $0.19[0.05,0$ & $0.42]$ & & $.59[0.41,0.7$ \\
\hline Chen 2012 & 20 & 24 & 16 & 45 & Grade III & High & Unknown & $0.56[0.38,0$ & $0.72]$ & & $.65[0.53,0.7$ \\
\hline n 1978 & 4 & 3 & 2 & 0 & Grade III & High & Unknown & $0.67[0.22,0$ & $0.96]$ & & $.00[0.00,0.7$ \\
\hline Chitlange 1990 & 26 & 38 & 46 & 160 & Grade III & Low & Unknown & $0.36[0.25,0$ & $0.48]$ & & $.81[0.75,0.8$ \\
\hline McKenna 2005 & 12 & 56 & 97 & 1737 & Grade III & Low & Yes & $0.11[0.06,0$ & $0.18]$ & & $.97[0.96,0$. \\
\hline & 3 & 151 & 101 & 1119 & Grade III & II Mixed & Unknown & $0.03[0.01,0$ & 0.0 & & $.99[0.98,0.9$ \\
\hline Montan 1986 & 4 & 84 & 2 & 217 & Grade III & II Mixed & Unknown & $0.67[0.22,0$ & $0.96]$ & & $.72[0.67,0.7$ \\
\hline Miller 1988 & 10 & 87 & 19 & 130 & Grade III & $\|$ Mixed & Unknown & $0.34[0.18,0$ & $0.54]$ & & $.60[0.53,0.6$ \\
\hline Kazzi 1983a & 26 & 18 & 16 & 49 & Grade III & II Mixed & Unknown & $0.62[0.46,0$ & $0.76]$ & & $.73[0.61,0.8$ \\
\hline
\end{tabular}

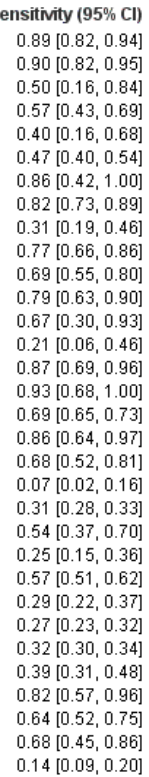

$0.14[0.09,0.20]$
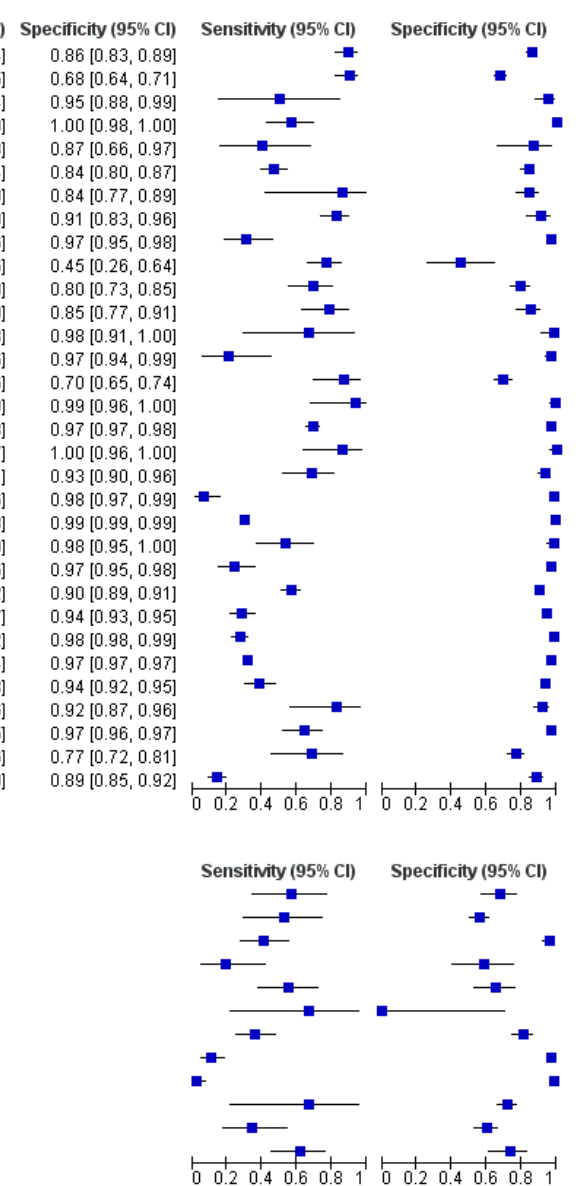

Biochemical tests of placental function versus ultrasound assessment of fetal size for stillbirth and small-for-gestational-age infants 
Figure 5. Forest plot of biochemical tests for identifying small-for-gestational-age (birthweight $\leq$ tenth centile) infants. E3 = oestriol; FN = false negative; FP = false positive; $h P L=$ human placental lactogen; $P I G F=p l a c e n t a l$ growth factor; SGA = small-for-gestational-age; TN = true negative; TP = true positive; UA = uric acid. For each test, the forest plot shows the estimates of sensitivity and specificity from each study, the threshold used to define test positivity, risk of SGA pregnancy and whether there was an intervention that may have altered outcome. Studies are sorted by threshold, risk and intervention status.

\begin{tabular}{|c|c|c|c|c|c|c|c|c|c|}
\hline Study & TP & FP F & FN & TN & Threshold & Risk & Intervention & Sensitivity (95\% Cl) & Specificity $(95 \% \mathrm{Cl})$ \\
\hline Nisbet 1982 & 25 & 134 & 46 & 82 & $-2 S D$ & High & Unknown & $0.35[0.24,0.47]$ & $0.86[0.78,0.93]$ \\
\hline Howell 1985 & 12 & 443 & 38 & 407 & $2.5 \mathrm{\mu g} / \mathrm{ml}$ & Mixed & Unknown & $0.24[0.13,0.38]$ & $0.90[0.87,0.93]$ \\
\hline Obiekwe 1983 & 5 & 502 & 24 & 443 & $4.8 \mathrm{ug} / \mathrm{ml}$ & Mixed & Unknown & $0.17[0.06,0.36]$ & $0.90[0.87,0.92]$ \\
\hline Granat 1977 & 10 & 4 & 0 & 15 & $4 \mu \mathrm{g} / \mathrm{ml}$ & High & No & $1.00[0.69,1.00]$ & $0.79[0.54,0.94]$ \\
\hline Zhang 1990 & 25 & 421 & 13 & 41 & $4 \mu \mathrm{g} / \mathrm{ml}$ & High & No & $0.66[0.49,0.80]$ & $0.49[0.38,0.61]$ \\
\hline Gohari 1978 & 25 & 111 & 13 & 62 & $5 \mathrm{\mu g} / \mathrm{ml}$ & High & Unknown & $0.66[0.49,0.80]$ & $0.85[0.75,0.92]$ \\
\hline Nice 2016 & 10 & 51 & 13 & 49 & $\approx 0.8 \mathrm{MoM}$ & Mixed & No & $0.43[0.23,0.66]$ & $0.91[0.80,0.97]$ \\
\hline Altmann 1978 & 3 & 4 & 3 & 0 & Abnormal value & High & Unknown & $0.50[0.12,0.88]$ & $0.00[0.00,0.60]$ \\
\hline Westergaard 1984 & 15 & 381 & 133 & 326 & Abnormal value & Mixed & Unknown & $0.54[0.34,0.72]$ & $0.90[0.86,0.93]$ \\
\hline Kunz 1976 & 8 & 16 & 7 & 52 & Below fifth centile & High & Unknown & $0.53[0.27,0.79]$ & $0.76[0.65,0.86]$ \\
\hline Klebe 1990 & 1 & 0 & 2 & 10 & Below fifth centile & High & Unknown & $0.33[0.01,0.91]$ & $1.00[0.69,1.00]$ \\
\hline Marin 1979 & 11 & 6 & 2 & 28 & Below fifth centile & Mixed & Unknown & $0.85[0.55,0.98]$ & $0.82[0.65,0.93]$ \\
\hline Odendaal 1981 & 35 & 16 & 8 & 18 & Below tenth centile & High & No & $0.81[0.67,0.92]$ & $0.53[0.35,0.70]$ \\
\hline Steiner 1991 & 25 & 174 & 43 & 28 & Below tenth centile & High & Unknown & $0.37[0.25,0.49]$ & $0.62[0.47,0.76]$ \\
\hline Trudinger 1979 & 10 & 41 & 15 & 30 & Below tenth centile & High & Unknown & $0.40[0.21,0.61]$ & $0.88[0.73,0.97]$ \\
\hline Sagen 1984 & 28 & 61 & 12 & 28 & Below tenth centile & High & Yes & $0.70[0.53,0.83]$ & $0.82[0.65,0.93]$ \\
\hline Siebert 1974 & 1 & 21 & 10 & 54 & Below tenth centile & Low & Yes & $0.09[0.00,0.41]$ & $0.96[0.88,1.00]$ \\
\hline Chard 1985 & 13 & 292 & 263 & 324 & Below tenth centile & Mixed & Unknown & $0.33[0.19,0.50]$ & $0.92[0.88,0.94]$ \\
\hline Lilford 1983 & 15 & 413 & 374 & 429 & Below tenth centile & Mixed & Unknown & $0.29[0.17,0.43]$ & $0.91[0.88,0.94]$ \\
\hline Spernol 1989 & 5 & 31 & 17 & 85 & Below tenth centile & Mixed & Unknown & $0.23[0.08,0.45]$ & $0.97[0.90,0.99]$ \\
\hline
\end{tabular}

E3 and SGA

$\begin{array}{lrrrrrrrrr}\text { Study } & \text { TP FP FN } & \text { TN } & \text { Threshold } & \text { Risk } & \text { Intervention } & \text { Sensitivity }(95 \% \mathrm{Cl}) & \text { Specificity }(95 \% \mathrm{Cl}) \\ \text { Palo 1987 } & 9 & 0 & 31 & 50 & -2 \mathrm{SD} & \text { High } & \text { Unknown } & 0.23[0.11,0.38] & 1.00[0.93,1.00] \\ \text { Nisbet 1982 } & 9 & 4 & 37 & 53 & -2 \mathrm{SD} & \text { High } & \text { Unknown } & 0.20[0.09,0.34] & 0.93[0.83,0.98] \\ \text { Nielsen 1985 } & 11 & 40 & 50 & 917 & \text { Below 2.5th centile } & \text { Mixed } & \text { No } & 0.18[0.09,0.30] & 0.96[0.94,0.97] \\ \text { Spernol 1989 } & 2 & 3 & 20 & 85 & \text { Below fith centile } & \text { Mixed } & \text { Unknown } & 0.09[0.01,0.29] & 0.97[0.90,0.99] \\ \text { Odendaal 1981 } & 13 & 3 & 17 & 20 & \text { Below tenth centile } & \text { High } & \text { No } & 0.43[0.25,0.63] & 0.87[0.66,0.97] \\ \text { Cedard 1979 } & 9 & 13 & 8 & 34 & \text { Below tenth centile } & \text { High } & \text { Unknown } & 0.53[0.28,0.77] & 0.72[0.57,0.84] \\ \text { Sagen 1984 } & 22 & 6 & 18 & 28 & \text { Below tenth centile } & \text { High } & \text { Yes } & 0.55[0.38,0.71] & 0.82[0.65,0.93] \\ \text { Gerhard 1986 } & 18 & 71 & 60 & 720 & \text { Below tenth centile } & \text { Mixed } & \text { No } & 0.23[0.14,0.34] & 0.91[0.89,0.93] \\ \text { Chard 1985 } & 11 & 32 & 28 & 321 & \text { Below tenth centile Mixed } & \text { Unknown } & 0.28[0.15,0.45] & 0.91[0.87,0.94]\end{array}$

Urinary E3 and SGA

\begin{tabular}{|c|c|c|c|c|c|c|c|c|}
\hline Study & TP & FP & FN & TN & Threshold & Risk & Intervention & Sensitivity (95\% Cl) \\
\hline Weerasinghe 1977 & 36 & 98 & 9 & 184 & $-2 \mathrm{SD}$ & High & Unknown & $0.80[0.65,0.90]$ \\
\hline Steiner 1991 & 9 & 17 & 59 & 28 & $8 \mathrm{mg}$ at $30 \mathrm{w}$ to $12 \mathrm{mg}$ at $40 \mathrm{w}$ (per $24 \mathrm{~h}$ ) & High & Unknown & $0.13[0.06,0.24]$ \\
\hline Beischer 1991 & 1454 & 5621 & 3936 & 61051 & $8 \mathrm{mg}$ at $30 \mathrm{w}$ to $12 \mathrm{mg}$ at $40 \mathrm{w}$ (per $24 \mathrm{~h}$ ) & High & Yes & $0.27[0.26,0.28]$ \\
\hline Fliegner 1979 & 22 & 57 & 15 & 235 & $8 \mathrm{mg}$ at $30 \mathrm{w}$ to $12 \mathrm{mg}$ at $40 \mathrm{w}$ (per $24 \mathrm{~h}$ ) & Mixed & No & $0.59[0.42,0.75]$ \\
\hline Oats 1979 & 497 & 2064 & 894 & 15664 & $8 \mathrm{mg}$ at $30 \mathrm{w}$ to $12 \mathrm{mg}$ at $40 \mathrm{w}$ (per $24 \mathrm{~h}$ ) & Mixed & Unknown & $0.36[0.33,0.38]$ \\
\hline Chew 1976 & 0 & 0 & 15 & 28 & Below 2.5 th centile & High & No & $0.00[0.00,0.22]$ \\
\hline Kunz 1976 & 10 & 12 & 5 & 56 & Below fifth centile & High & Unknown & $0.67[0.38,0.88]$ \\
\hline Odendaal 1981 & 6 & 1 & 22 & 17 & Below tenth centile & High & No & $0.21[0.08,0.41]$ \\
\hline Crmonoll 107 & & & & & & & & $0.53[0.42,0.64]$ \\
\hline
\end{tabular}

Campbell 1972

Unknown High

PIGF and SGA

\begin{tabular}{|c|c|c|c|c|c|c|c|c|c|}
\hline tudy & TP & FP & FN & TN & Threshold & Risk & Intervention & Sensitivity (95\% Cl) & Specificity (95\% Cl) \\
\hline Shawkat 2015 & 18 & 43 & 88 & 112 & $12 \mathrm{pg} / \mathrm{ml}$ & High & No & $0.17[0.10,0.26]$ & $0.72[0.65,0.79]$ \\
\hline & 87 & 70 & 72 & 182 & & $\mathrm{Hig}$ & N & & \\
\hline lice 2 & 4 & 4 & 19 & 49 & $2 \mathrm{pg} / \mathrm{ml}$ & Mixed & No & & \\
\hline & 16 & 25 & 6 & 42 & $9: 1$ & & No & & \\
\hline apongsa 201 & 38 & 184 & 70 & 977 & & Mixed & nknown & & \\
\hline Griffin 2015 & 47 & 40 & 145 & 360 & elow fifth centile & High & Unknown & 31] & $0.90[0.87,0$ \\
\hline & 29 & 80 & 11 & 226 & & Mixed & Unknown & & \\
\hline /alino 2016 & 48 & 150 & 331 & 3424 & Below tenth centile & Mixed & Yes & $0.13[0.09,0.16]$ & $0.96[0.95,0.9$ \\
\hline
\end{tabular}

UA and SGA

Study

Hawkins 2012

Amini 2014

Bellomo 2011

Williams 2002

Jauniaux 1996

Odendaal 1997

Yassaee 2003

TP FP FN TN Threstold

TP FN TN

$\begin{array}{rrrr}168 & 621 & 56 & 461 \\ 14 & 89 & 32 & 269\end{array}$

$\begin{array}{rrr} & \text { Threshold } & \text { Risk } \\ +1 \mathrm{SD} & \text { High } \\ +1 \mathrm{SD} & \text { Mixed }\end{array}$

$\begin{array}{rrrrrr}14 & 34 & 7 & 86 & 309 \mu \text { molis } & \text { High } \\ 14 & 42 & 73 & 327 & 450 \mu \text { molil } & \text { High }\end{array}$

$\begin{array}{lllll}7 & 4 & 9 & 21 & 4 \mathrm{mg} / \mathrm{dl} \\ 8 & 13 & 92 & 83 & 520 \mathrm{mh}\end{array}$

$\begin{array}{rrrrrr}8 & 13 & 92 & 83 & 520 u m b l i l & \text { High } \\ 10 & 47 & 20 & 138 & 6 \mathrm{mg} \% & \text { High }\end{array}$

$\begin{array}{lllrlll}41 & 12 & 18 & 32 & 6 \mathrm{mg} \% & \text { High } \\ 4 \mathrm{mg} / \mathrm{dl} & \text { High }\end{array}$

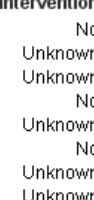

No
nknown
nknown
No
nknown
No
Unknown
Unknown

nsitivity $(95 \% \mathrm{Cl})$ Specificity $(95 \% \mathrm{Cl})$

$0.75[0.69,0.81] \quad 0.43[0.40,0.46]$

$0.30[0.18,0.46] \quad 0.75[0.70,0.80]$

$0.84[0.69,0.93] \quad 0.72[0.63,0.80]$

$0.44[0.20,0.70] \quad 0.84[0.64,0.95]$

$0.08[0.04,0.15] \quad 0.86[0.78,0.93]$

$0.33[0.17,0.53]-0.75[0.68,0.81]$

$0.69[0.56,0.81] \quad 0.73[0.57,0.85]$

E3 AND/OR $h P L$ and SG

Study TP FP FN TN Threshold Risk Intervention Sensitivity $(\mathbf{9 5} \% \mathrm{Cl})$ Specificity $(\mathbf{9 5} \% \mathrm{Cl})$

$\begin{array}{llllllllll}\text { Lenstrup } 1982 & 5 & 4 & 4 & 75 & \text { Below tenth centile Mixed } & \text { No } 0.56[0.21,0.86] & 0.95[0.88,0.99]\end{array}$

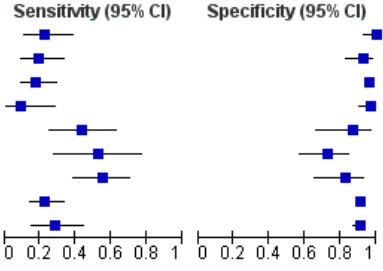

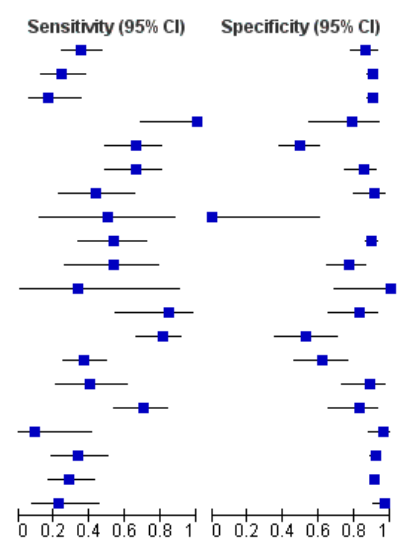

Sensitivity $(95 \% \mathrm{Cl}) \quad$ Specificity $(95 \% \mathrm{Cl})$
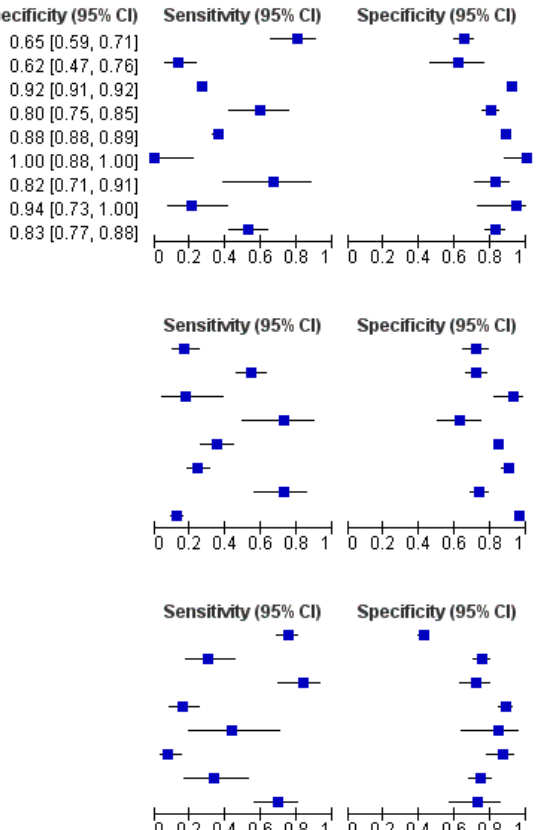

Sensitivity $(95 \% \mathrm{Cl}) \quad$ Specificity $(95 \% \mathrm{Cl})$

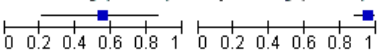

Biochemical tests of placental function versus ultrasound assessment of fetal size for stillbirth and small-for-gestational-age infants 


\section{1) Ultrasound assessment of fetal size (estimated fetal weight (EFW))}

There were 32 studies of estimated fetal weight (EFW) with a total of 51,702 pregnancies involving 6169 SGA infants (Figure 4). Of these, 20 studies (Baird 2016; Barel 2016; Ben-Haroush 2007; Callec 2015; Chauhan 1999; Chauhan 1999a; Chauhan 2003; Christensen 2015; Freire 2010; Gabbay-Benziv 2016; Geerts 2016; Gupta 2008; Hammad 2015; Hendrix 2000; Roma 2015; Sekar 2016; Sovio 2015; Takeuchi 1985; Turitz 2014; Weiner 2016) used the Hadlock formula, two (Laurin 1987; Palo 1989) used the Eik-Nes formula, and four (Berkowitz 1988; Chervenak 1984; Ott 1984; Skovron 1991) used the Shepard formula to estimate fetal weight. The formula used in the remaining six studies (Bikmetova 2013; Griffin 2015; Hatfield 2010; MacLeod 2013; Mahran 1988; Valino 2016) was not stated. There were two, 10 and 19 studies in low-, high- and mixed-risk cohorts; the patient group was unknown in one study. Six (18.8\%) studies (Berkowitz 1988; Callec 2015; Chauhan 2003; Roma 2015;
Turitz 2014; Valino 2016) intervened based on test results, which may have altered the outcome of the pregnancy, while index test results did not affect management in four (12.5\%) studies (Hammad 2015; Hendrix 2000; Sekar 2016; Weiner 2016). The remaining 22 $(68.8 \%)$ studies did not provide information on whether the test results led to intervention(s). Sovio 2015 blinded clinicians to the results of the universal ultrasonography and Weiner 2016 blinded clinicians to results of all ultrasound methods other than the one they conducted, but in the majority of studies clinicians either were not blinded to test results or this was not reported. The same ultrasound threshold (10th centile) was used to determine test positivity in 25 studies, one study did not report the threshold used, and each of the six remaining studies used a different threshold (Figure 4). For the 10th centile ultrasound threshold, the summary sensitivity $(95 \% \mathrm{Cl})$ and specificity $(95 \%)$ were $0.54(0.43$ to 0.65$)$ and 0.95 ( 0.92 to 0.97$)$ from meta-analysis of the 25 studies $(47,057$ pregnancies involving 5650 SGA infants) (Figure 6). 
Figure 6. Summary ROC plot of ultrasound estimated fetal weight (EFW) at a tenth centile threshold for identifying small-for-gestational-age (birthweight stenth centile) infants. The study points are shown using different symbols for the formulas used. The study points were scaled according to the precision of sensitivity and specificity in the studies. The solid circle (summary point) represents the summary estimate of sensitivity and specificity for all 25 studies, and is surrounded by a dotted line representing the $95 \%$ confidence region and a dashed line representing the $95 \%$ prediction region. The $95 \%$ prediction region is the region within which one is $95 \%$ certain the results of a new study will lie.

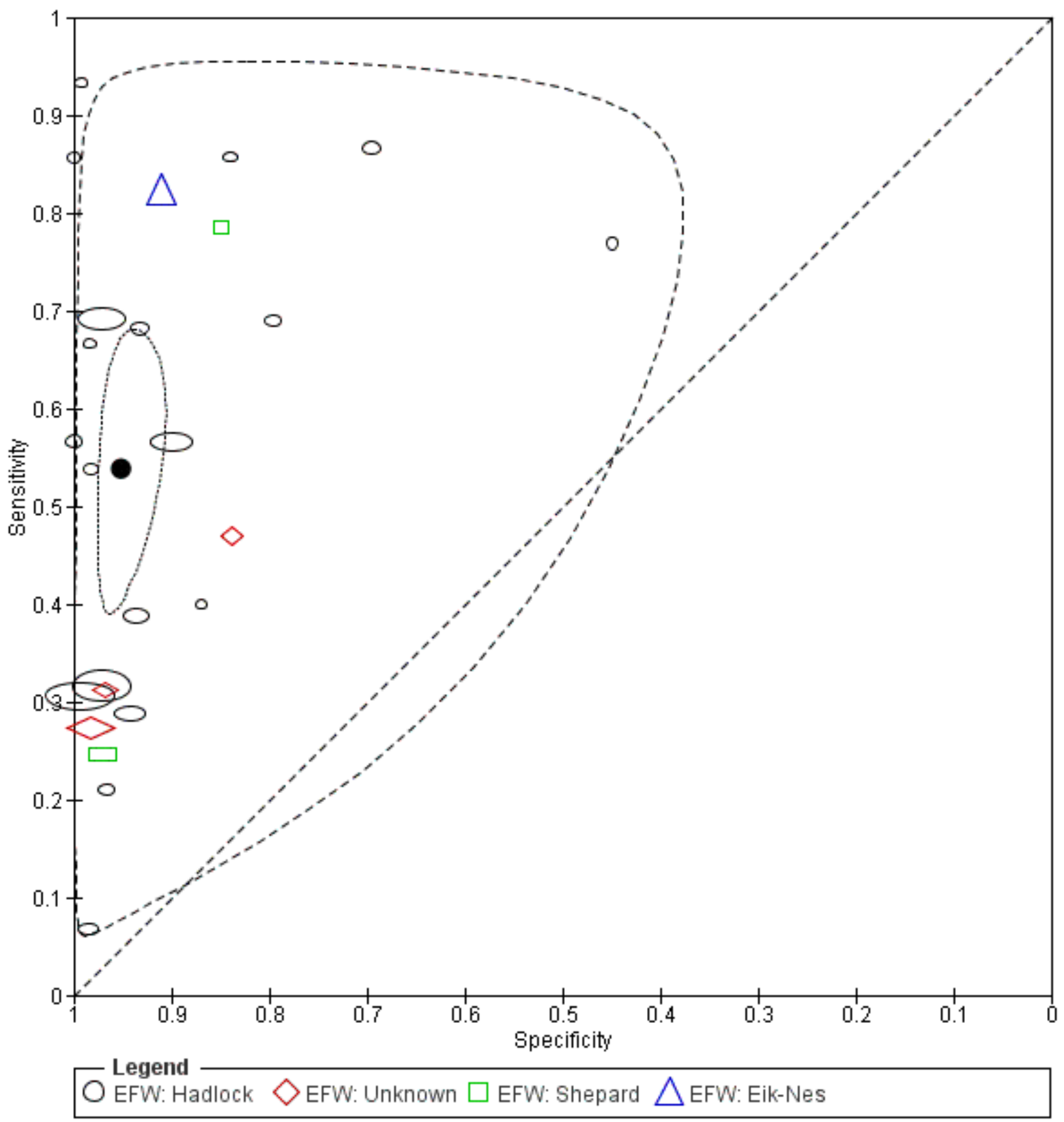

\section{2) Ultrasound placental grading}

Twelve studies assessed placental grading (by ultrasound echogenicity for identifying SGA infants (Figure 4). The studies included 4940 pregnancies involving 520 SGA infants. There were two, six and four studies in low-, high- and mixed-risk cohorts, respectively. One study (McKenna 2005) intervened based on test results, a grade III placenta was used to identify pregnancies to be induced for suspected fetal compromise, and one study did not

Biochemical tests of placental function versus ultrasound assessment of fetal size for stillbirth and small-for-gestational-age infants 19 (Review)

Copyright (C) 2019 The Cochrane Collaboration. Published by John Wiley \& Sons, Ltd. 
(Chen 2012a). Three studies fall beneath the diagonal, two of these are small studies of nine and 55 participants, respectively (Altmann 1978; Estel 1989), while the other study examined placental grading in late pregnancy (36 to 38 weeks) (Miller 1988). The remaining
10 studies did not report this information. All the studies used Grannum grading based on placental calcification and set a grade III threshold; the summary sensitivity $(95 \% \mathrm{Cl})$ and specificity (95\%) were 0.38 ( 0.23 to 0.55 ) and 0.79 (0.62 to 0.90 ) (Figure 7 ).

Figure 7. Summary ROC plot of placental grading for identifying small-for-gestational-age (birthweight stenth centile) infants. The study points are shown using different symbols for different risk groups. The study points were scaled according to the precision of sensitivity and specificity in the studies. The solid circle (summary point) represents the summary estimate of sensitivity and specificity for all 12 studies, and is surrounded by a dotted line representing the $95 \%$ confidence region and a dashed line representing the $95 \%$ prediction region. The $95 \%$ prediction region is the region within which one is $95 \%$ certain the results of a new study will lie.

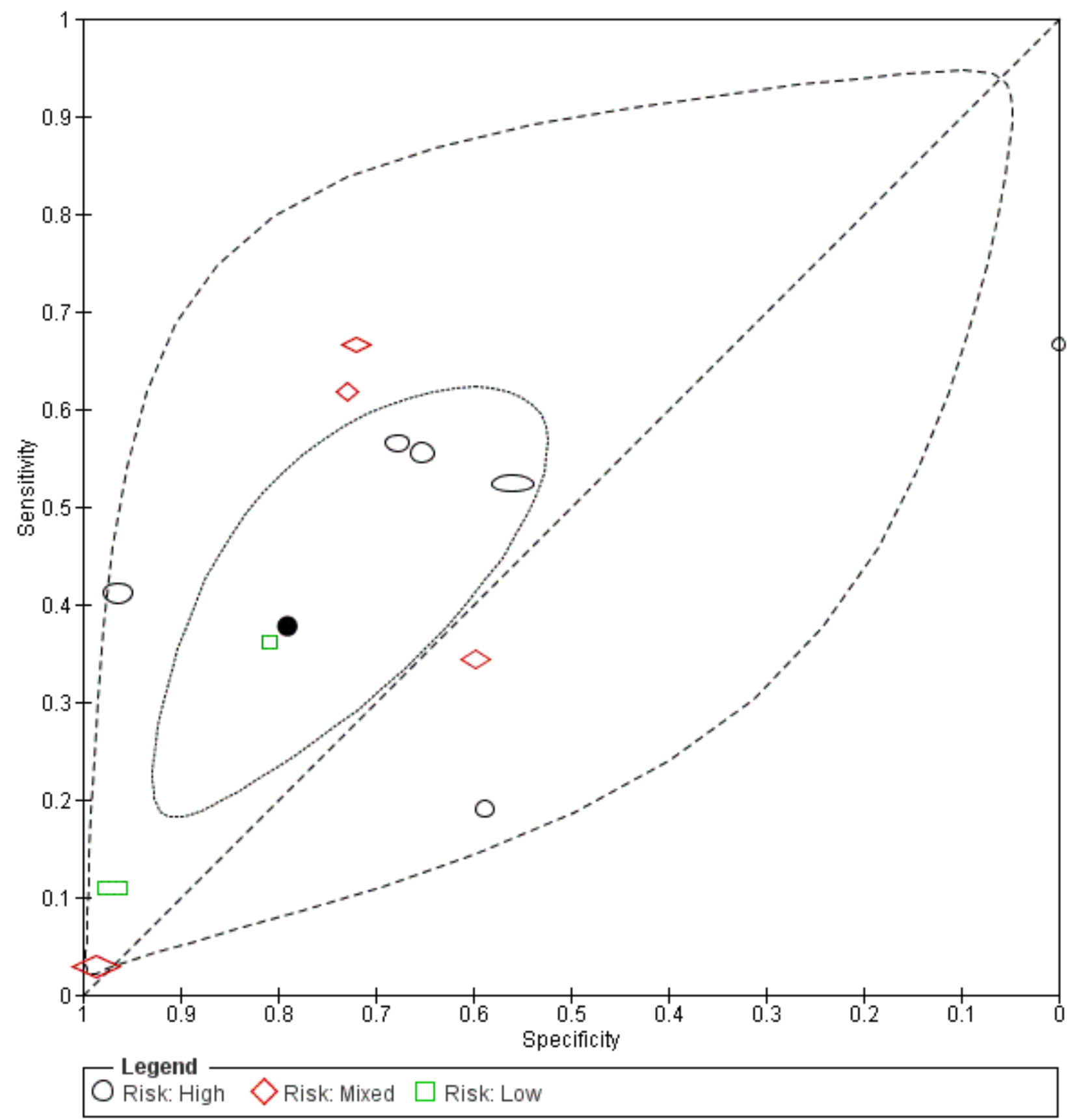

Biochemical tests of placental function versus ultrasound assessment of fetal size for stillbirth and small-for-gestational-age infants 


\section{3) Human placental lactogen (hPL)}

Figure 5 shows the 20 studies that assessed hPL. A total of 3486 pregnancies involving 624 SGA infants were included. There were one, 11, and eight studies in low-, high- and mixed-risk cohorts, respectively. Most of the studies (14/20, 70\%) did not report whether or not interventions were affected by index test results, four (20\%) studies (Granat 1977; Nice 2016; Odendaal 1981;
Zhang 1990) did not intervene based on test results, and in two (10\%) studies (Sagen 1984; Siebert 1974) index test results led to interventions. The studies used different test thresholds (Figure 5), but eight studies used the 10th centile test threshold. The metaanalysis of the eight studies (1124 pregnancies involving 303 SGA infants) gave summary sensitivity $(95 \% \mathrm{Cl})$ and specificity $(95 \% \mathrm{Cl})$ of 0.38 (0.23 to 0.55$)$ and 0.88 (0.78 to 0.94$)$ (Figure 8 ). 
Figure 8. Summary ROC plot of human placental lactogen (hPL) for identifying small-for-gestational-age (birthweight stenth centile) infants. The study points are shown using different symbols for different risk groups. The study points were scaled according to the precision of sensitivity and specificity in the studies. The solid circle (summary point) represents the summary estimate of sensitivity and specificity for all nine studies, and is surrounded by a dotted line representing the $95 \%$ confidence region and a dashed line representing the $95 \%$ prediction region. The $95 \%$ prediction region is the region within which one is $95 \%$ certain the results of a new study will lie.

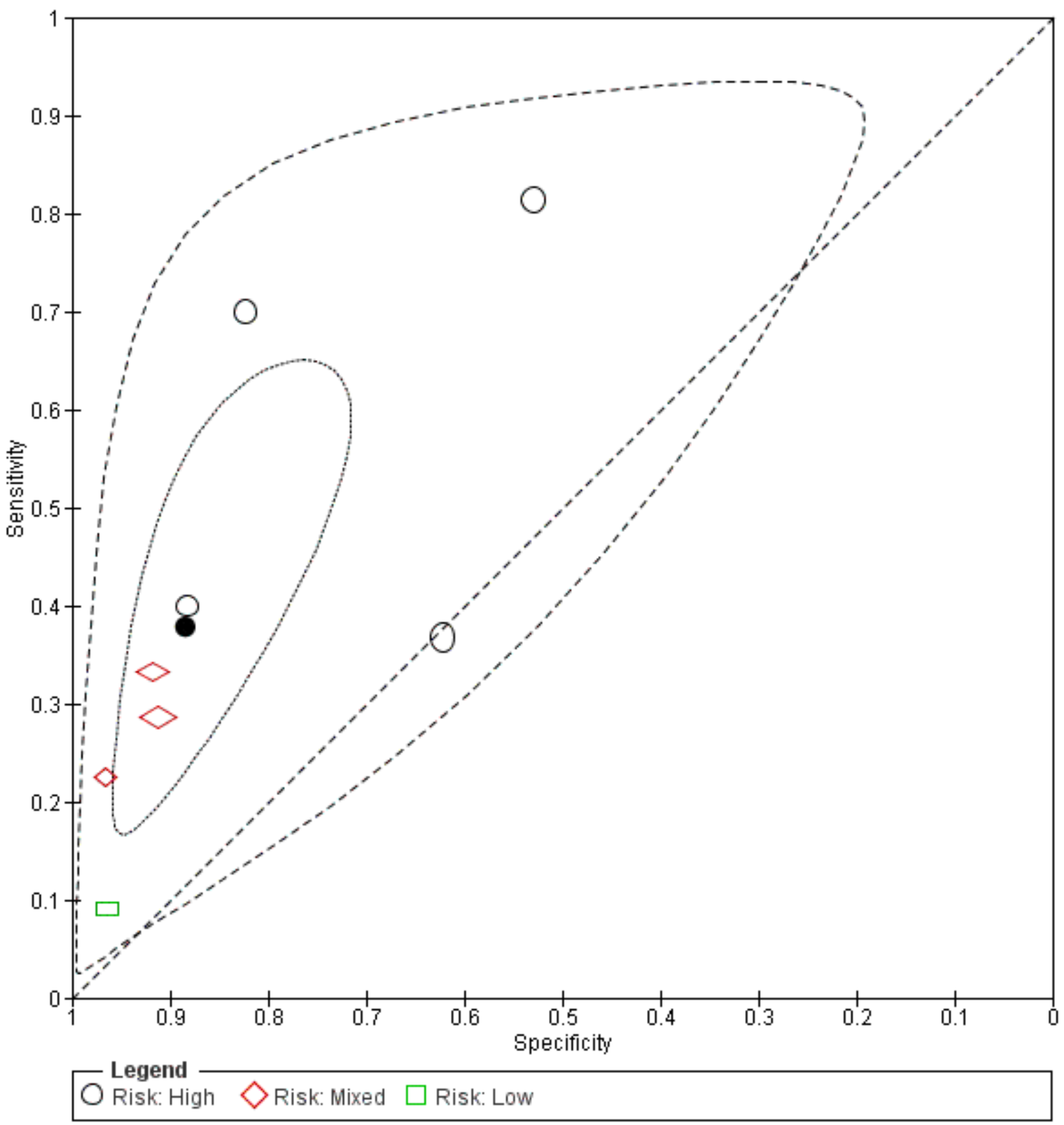

\section{4) Serum oestriol}

Nine studies of 2773 pregnancies involving 373 SGA infants were included (Figure 5). Five of the studies were in high-risk cohorts while the remaining four were in mixed-risk cohorts. Five studies
(Cedard 1979; Chard 1985; Nisbet 1982; Palo 1987; Spernol 1989) did not state whether they intervened based on index test results, three studies (Gerhard 1986; Nielsen 1985; Odendaal 1981) did not intervene based on index test results, while one study (Sagen

Biochemical tests of placental function versus ultrasound assessment of fetal size for stillbirth and small-for-gestational-age infants 22 (Review)

Copyright $\odot 2019$ The Cochrane Collaboration. Published by John Wiley \& Sons, Ltd. 
1984) did, described above. Five studies (Cedard 1979; Chard 1985; Gerhard 1986; Odendaal 1981; Sagen 1984) used the 10th centile test threshold and included a total of 1248 pregnancies (involving 204 SGA infants). Based on the five studies, the summary sensitivity $(95 \% \mathrm{Cl})$ and specificity $(95 \% \mathrm{Cl})$ were $0.39(0.27$ to 0.54$)$ and 0.86 $(0.79,0.91)$.

\section{5) Urinary oestriol}

Urinary oestriol was assessed in nine studies with a total of 92,406 pregnancies involving 7076 SGA infants (Figure 5). Seven of the studies were in high-risk cohorts and two were in mixed-risk cohorts. Five studies (Campbell 1972; Kunz 1976; Oats 1979; Steiner 1991; Weerasinghe 1977) did not state whether or not index test results led to interventions, three studies (Chew 1976; Fliegner 1979; Odendaal 1981) did not intervene based on index test results and one study (Beischer 1991) stated that oestriol levels were an indicator for early delivery, although no numbers were given. Studies used different index test positivity thresholds (Figure 5) but four studies (Beischer 1991; Fliegner 1979; Oats 1979; Steiner 1991) used a threshold of $8 \mathrm{mg}$ per 24 hours (at 30 weeks) to 12 $\mathrm{mg}$ per 24 hours (at 40 weeks). The summary sensitivity $(95 \% \mathrm{CI})$ and specificity $(95 \% \mathrm{Cl})$ from the four studies $(84,737$ pregnancies involving 6886 SGA infants) were $0.31(0.18,0.49)$ and $0.84(0.72$, 0.91).

\section{6) Placental growth factor (PIGF)}

The seven studies of PIGF are shown in Figure 5. A total of 6405 pregnancies (involving 837 SGA infants) were included in the studies. Three of the studies were in high-risk cohorts while four were in mixed-risk cohorts. Two studies (Chaiworapongsa 2013; Kienast 2016) did not state whether index test results led to interventions, four studies (Benton 2016; Molvarec 2013; Nice 2016; Shawkat 2015) did not intervene based on test results and one study (Valino 2016) used the results of the EFW scan to determine whether suspected SGA pregnancies should be delivered by caesarean section. Three studies (Benton 2016; Nice 2016; Shawkat 2015) used a $12 \mathrm{pg} / \mathrm{mL}$ threshold, while each of the four remaining studies used a different threshold (Figure 5). Due to the limited number of studies at a common threshold and substantial heterogeneity, meta-analysis to obtain summary estimates of sensitivity and specificity was not performed.

\section{7) Uric acid}

Eight studies with a total of 2884 pregnancies (involving 605 SGA infants) assessed uric acid (Figure 5). The studies were in high-risk cohorts except for one study in a mixed-risk cohort. Five studies (Amini 2014; Bellomo 2011; Jauniaux 1996; Voto 1988; Yassaee 2003) did not state whether interventions were made based on index test results and three studies (Hawkins 2012; Odendaal 1997; Williams 2002) had no interventions. The studies used various thresholds (Figure 5).

\section{8) Combination of serum oestriol and human placental lactogen ( $h P L)$}

Lenstrup 1982 (88 pregnancies) assessed this combination in a mixed-risk cohort (Figure 5). The sensitivity $(95 \% \mathrm{Cl})$ and specificity (95\%) were 0.56 (0.21 to 0.86 ) and 0.95 (0.88 to 0.99$)$. The specific measurement used as a threshold in this study was not stated; a low $\mathrm{hPL}$ and/or E3 level was classified as a positive test result. In this study, one patient was hospitalised after a cardiotocography (CTG) investigation due to a low plasma oestriol level.

\section{Comparative analyses of seven tests for identifying small-for- gestational-age infants (SGA) (birthweight $\leq 10$ th centile)}

Using all available data (86 studies), we compared the accuracy of $\mathrm{EFW}, \mathrm{hPL}$, serum oestriol, urinary oestriol, PIGF and uric acid in a single model. Based on the preliminary assessments and likelihood ratio tests comparing different HSROC meta-regression models, in the final model fitted, we modelled differences in accuracy and threshold as random effects with symmetric curves for all tests, i.e. parallel SROC curves such that each curve can be described using a diagnostic odds ratio (DOR) (Figure 9, Table 2). There was a statistically significant $(P<0.0001)$ difference in accuracy between the tests, with EFW being more accurate than all the other tests. For example, the DOR $(95 \% \mathrm{Cl})$ of EFW was 21.3 (13.1 to 34.6) while that of $\mathrm{hPL}$, the biochemical test with the highest DOR, was 4.78 (3.21 to 7.13). Comparing EFW to hPL, the ratio of DORs $(95 \% \mathrm{Cl})$ was 4.45 (2.38 to 8.25) with statistical evidence of a difference in accuracy $(P<$ 0.0001). Pairwise comparisons of the seven tests are shown in Table 
Figure 9. Summary ROC plot of structural and biochemical tests for identifying small-for-gestational-age (birthweight stenth centile) infants. E3 = oestriol; EFW = estimated fetal weight; $h \mathrm{PL}=$ human placental lactogen; PIGF = placental growth factor; SGA = small-for-gestational-age; UA =uric acid. The curve for each test is drawn within the range of estimates of specificity from the studies included for the test. Compared to the other curves, the curve for EFW lies closest to the top left hand corner (ideal position where sensitivity and specificity both equal 1). The position of the curves for UA and placental grading is very similar. The SROC curve for UA is the green curve lying above the pink curve for placental grading.

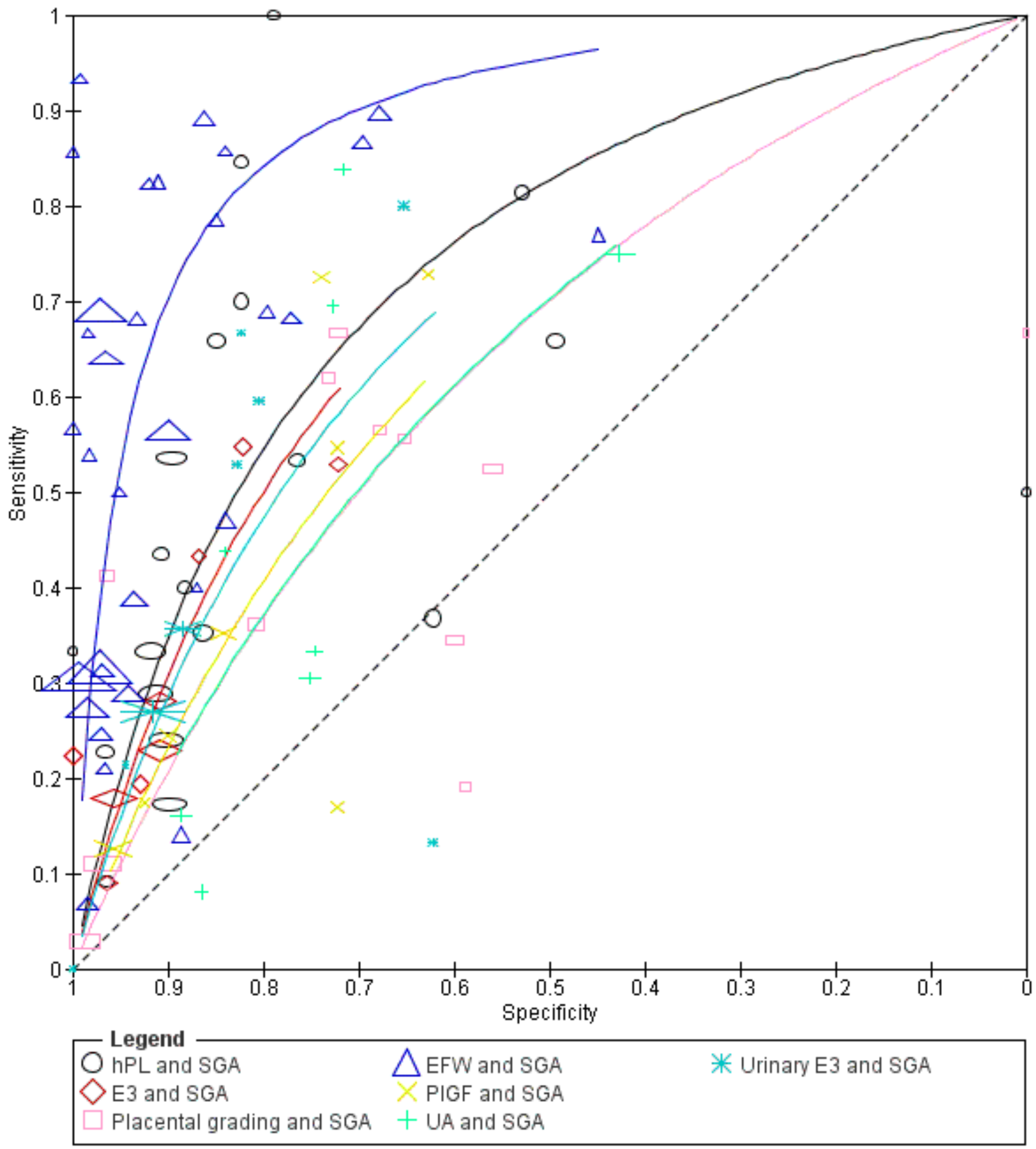

The sensitivities estimated along the SROC curves at fixed values of Table 3 also shows the numbers of missed SGA infants and false specificity are shown in Table 3 for different values of prevalence. positives in a hypothetical cohort of 1000 pregnant women. At the

Biochemical tests of placental function versus ultrasound assessment of fetal size for stillbirth and small-for-gestational-age infants 24 
median specificity of 0.88 and median prevalence of $19 \%, \mathrm{EFW}, \mathrm{hPL}$, oestriol, urinary oestriol, uric acid, PIGF, and placental grading will miss 49, 116, 123, 128, 139, 144, and 145 SGA infants, respectively.

Ten studies (Altmann 1978; Chard 1985; Geerts 2016; Kunz 1976; Nice 2016; Nisbet 1982; Sagen 1984; Spernol 1989; Steiner 1991; Valino 2016) evaluated two tests and one study (Odendaal 1981) evaluated three tests (hPL, serum oestriol, and urinary oestriol). Of the 11 studies, five (Chard 1985; Nisbet 1982; Odendaal 1981; Sagen 1984; Spernol 1989) evaluated hPL and serum oestriol (Figure 10). From the comparative meta-analysis of the five studies, the DOR $(95 \% \mathrm{Cl})$ for $\mathrm{hPL}$ was 5.60 (2.84 to 11.0$)$ and that of serum oestriol was 4.06 (1.81 to 9.07); ratio of the DORs was 1.29 (0.58 to 2.86), $\mathrm{P}=0.40$. Due to limited data we did not perform meta-analyses for other pair-wise comparisons but summarised individual study results in Appendix 6. 
Figure 10. Summary ROC plot of direct comparisons of human placental lactogen and oestriol for identifying smallfor-gestational-age (birthweight $\leq$ tenth centile) infants. E3 = oestriol; hPL = human placental lactogen; SGA = smallfor-gestational-age. Each symbol represents the pair of sensitivity and specificity for one test from a study. The pair of points for the two tests from a study are connected by a dotted line. The size of each symbol was scaled according to the precision of sensitivity and specificity in the study. Each summary curve was restricted to the range of specificities for each test from the five studies that evaluated both tests in the same patients.

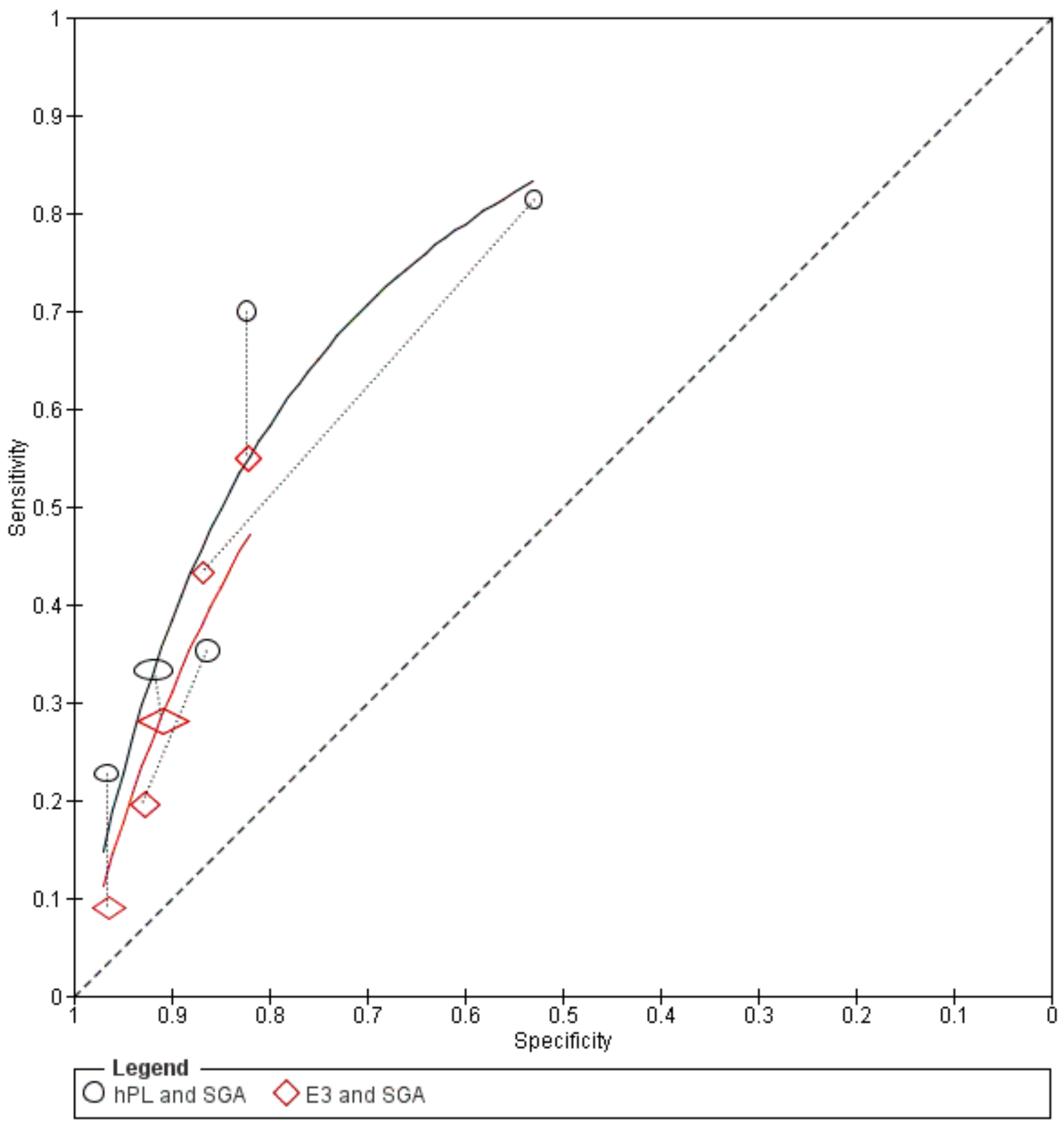

Small-for-gestational age (birthweight < third centile) (SGA3)

SGA3 was evaluated in four studies (Chaiworapongsa 2013; Griffin 2015; Roma 2015; Sovio 2015) involving 6953 pregnancies (235 cases). The four studies assessed PIGF and/or EFW in high- or mixed-risk cohorts (Figure 11). One study (Griffin 2015) of 592 pregnancies evaluated EFW, PIGF, and a combination of the two. The other three studies (5678 pregnancies) assessed EFW and used the 10th centile as the threshold. The summary sensitivity $(95 \% \mathrm{Cl})$ and specificity $(95 \% \mathrm{Cl})$ were $0.66(0.56$ to 0.76$)$ and 0.87 (0.80 to 0.91$)$. The two PIGF studies (1861 pregnancies) used

Biochemical tests of placental function versus ultrasound assessment of fetal size for stillbirth and small-for-gestational-age infants 26 (Review)

Copyright (c) 2019 The Cochrane Collaboration. Published by John Wiley \& Sons, Ltd. 
different thresholds (<0.3 MoM (multiples of the median) and fifth centile); sensitivities were 0.52 ( 0.31 to 0.73 ) and 0.37 (0.26 to 0.49 ) and specificities were 0.83 (0.81 to 0.85$)$ and 0.89 (0.86 to 0.91 ) respectively. The sensitivity $(95 \% \mathrm{Cl})$ and specificity $(95 \% \mathrm{Cl})$ from the single study of the PIGF and EFW combination were $0.69(0.55$ to 0.81 ) and 0.72 (0.67 to 0.77 ).

Figure 11. Forest plot of ultrasound estimated fetal weight (EFW) and placental growth factor (PIGF) for identifying small-for-gestational age (birthweight <third centile) infants. FN = false negative; FP = false positive; SGA3 = smallfor-gestational-age birthweight <third centile; TN = true negative; TP = true positive. For each test, the forest plot shows the estimates of sensitivity and specificity from each study, the threshold used to define test positivity, risk of SGA pregnancy and whether there was an intervention that may have altered outcome. Studies are sorted by threshold, risk and intervention status.

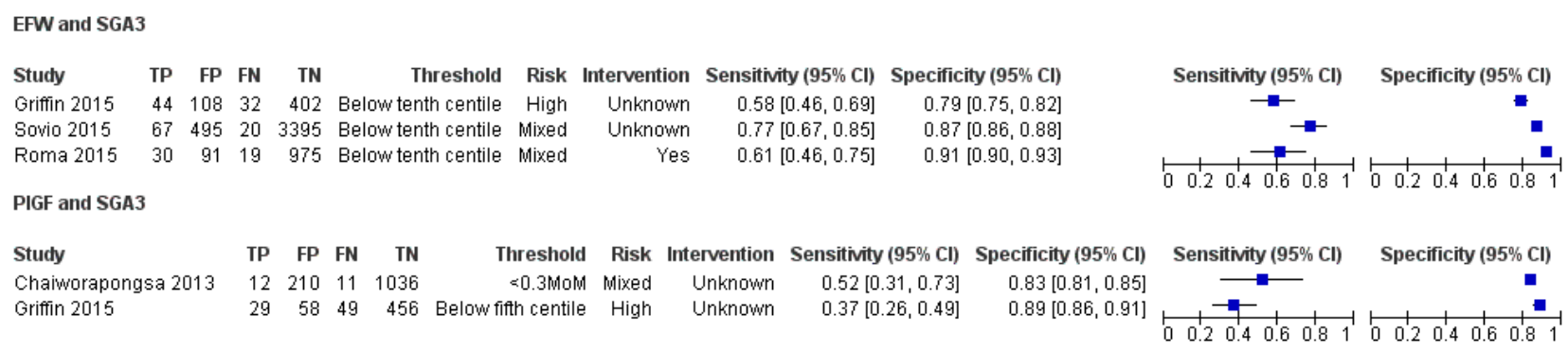

\section{Stillbirth}

\section{1) Ultrasound placental grading}

Three studies assessed placental grading for stillbirth (Figure 12) with a total of 15,2236 pregnancies involving 114 stillbirths. Two of the studies (Altmann 1978; Chen 2012) were in high-risk cohorts and the third (Chen 2015) was in a low-risk cohort. Chen 2015 contributed most of the data $(15,122 / 15,236,99 \%)$. The sensitivity and specificity of placental grading in this study was 0.35 ( 0.26 to 0.46 ) and 0.94 ( 0.93 to 0.94 ). None of the studies stated whether or not there were any interventions based on test results and all used a grade III threshold. 
Figure 12. Forest plot of structural and biochemical tests for predicting stillbirth. E3 = oestriol; $F N=$ false negative; FP = false positive; $\mathrm{hPL}=$ human placental lactogen; PIGF = placental growth factor; $\mathrm{TN}=$ true negative; TP = true positive; UA = uric acid. For each test, the forest plot shows the estimates of sensitivity and specificity from each study, the threshold used to define test positivity, risk of stillbirth and whether there was an intervention that may have altered outcome. Studies are sorted by threshold, risk and intervention.

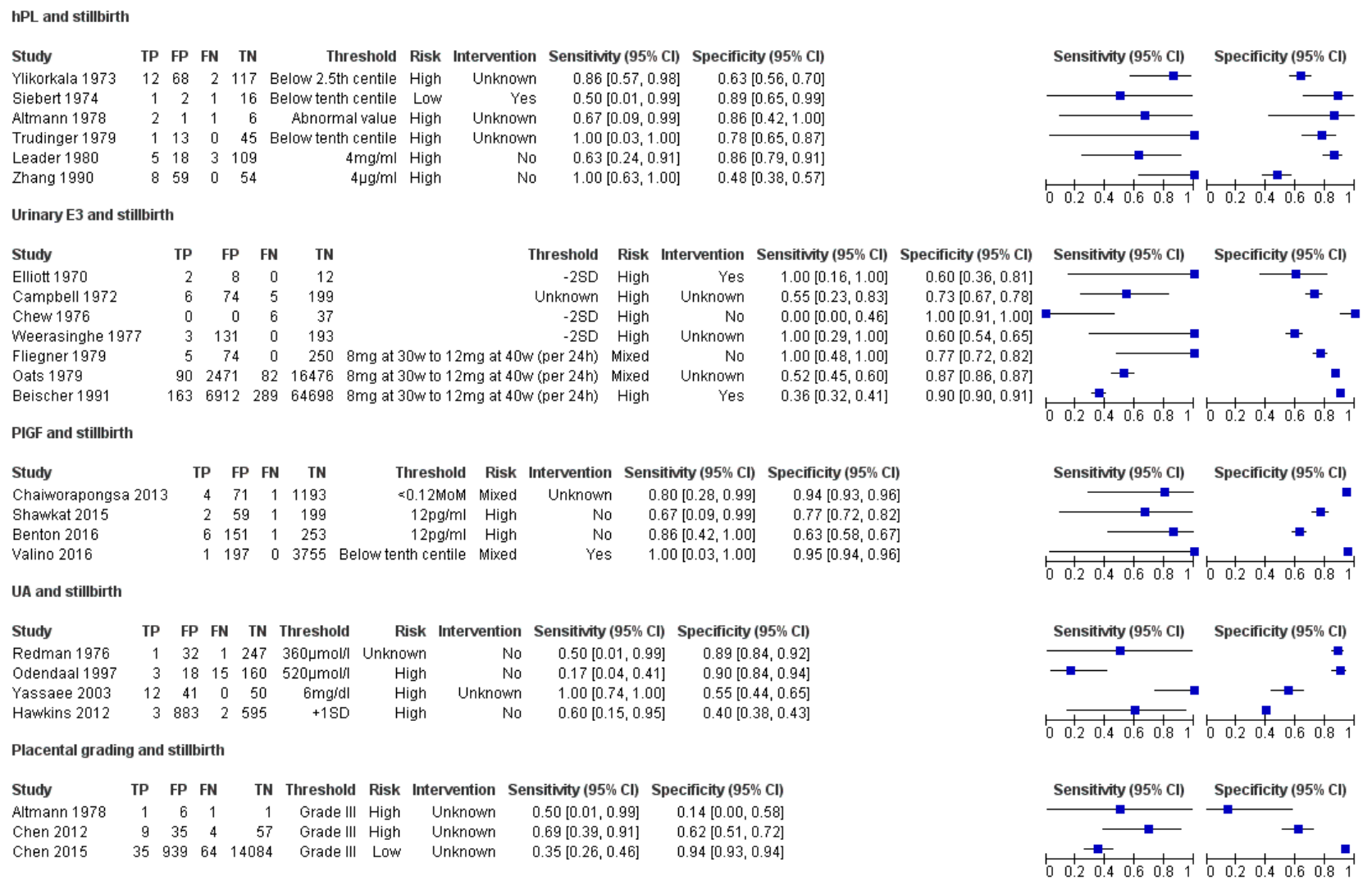

\section{2) Human placental lactogen}

Six studies of 544 pregnancies involving 36 stillbirths were included (Figure 12). One study (Siebert 1974) was in a low-risk cohort while the others were in high-risk cohorts. Three studies (Altmann 1978; Trudinger 1979; Ylikorkala 1973) did not report whether or not there were interventions based on index test results, two studies (Leader 1980; Zhang 1990) did not intervene while one study (Siebert 1974) intervened based on test results; both false positive results were caesarean sections prompted by falling hPL values. The studies used various thresholds with sensitivities ranging from 0.50 to 1.00 , and specificities from 0.48 to 0.89 (Figure 12).

\section{3) Urinary oestriol}

Seven urinary oestriol studies included 92,186 pregnancies involving 651 stillbirths (Figure 12). Five studies were in highrisk cohorts and two were in mixed-risk cohorts. Three studies (Campbell 1972; Oats 1979; Weerasinghe 1977) did not report whether there were any interventions based on index test results, two studies (Chew 1976; Fliegner 1979) did not intervene due to index test results while in two studies (Beischer 1991; Elliott 1970) index test results affected pregnancy management; in the Elliott study there were five caesarean sections that were performed due to greatly reduced oestriol excretion. The studies used different thresholds with sensitivities ranging from 0 to 1 , and specificities from 0.60 to 1.00 .

\section{4) Placental growth factor}

A total of 5894 pregnancies (involving 16 stillbirths) were included in three studies (Figure 12). Two studies were in high-risk cohorts and two were in mixed-risk cohorts. One study (Chaiworapongsa 2013) did not report whether or not index test results could lead to interventions, two studies (Benton 2016; Shawkat 2015) did not intervene based on index test results and one study (Valino 2016) did intervene, described earlier. The studies used different thresholds with sensitivities ranging from 0.67 to 1.00 , and specificities from 0.63 to 0.95 .

\section{5) Uric acid}

Four studies included 2063 pregnancies (involving 37 stillbirths) (Figure 12). Three of the studies were in high-risk cohorts and the remaining study was in a mixed-risk cohort. Intervention status was unknown for one study (Yassaee 2003) while there were no interventions in three studies (Hawkins 2012; Odendaal 1997; Redman 1976). None of the studies used the same threshold. The sensitivities ranged from 0.17 to 1.00 , and specificities ranged from 0.40 to 0.90 . 
Comparative analyses of four biochemical tests for predicting stillbirth

In an indirect test comparison based on 21 studies (including 100,687 pregnancies involving 740 stillbirths), we compared the accuracy of hPL, urinary oestriol, PIGF and uric acid. As there were several tests and only three placental grading studies, to reduce model complexity, we did not include this test in the model. We fitted a model with symmetric curves for the four biochemical tests
(Figure 13) and the DORs and ratio of DORs are shown in Table 4. There was a statistically significant $(P<0.0001)$ difference in accuracy between the tests, with PIGF being the most accurate. For example, the DOR ( $95 \% \mathrm{CI}$ ) of PIGF was 49.2 (12.7 to 191) while that of urinary oestriol was 5.83 (4.91 to 6.92 ). The ratio of the DORs $(95 \% \mathrm{Cl})$ of PIGF and urinary oestriol was 8.44 (2.15 to 33.1$)$ with statistical evidence of a difference in accuracy $(P=0.004)$. Pair-wise comparisons of the four tests are shown in Table 5. 
Figure 13. Summary ROC plot of biochemical tests for predicting stillbirth. $\mathrm{E3}=$ Oestriol; $\mathrm{hPL}=$ human placental lactogen; PIGF = placental growth factor; SGA = small-for-gestational-age; UA =uric acid. The SROC curves for the four tests are parallel. The curve for each test is drawn within the range of estimates of specificity from the studies included for the test. Compared to the other curves, the curve for PIGF lies closest to the top left hand corner (ideal position where sensitivity and specificity both equal 1 ).

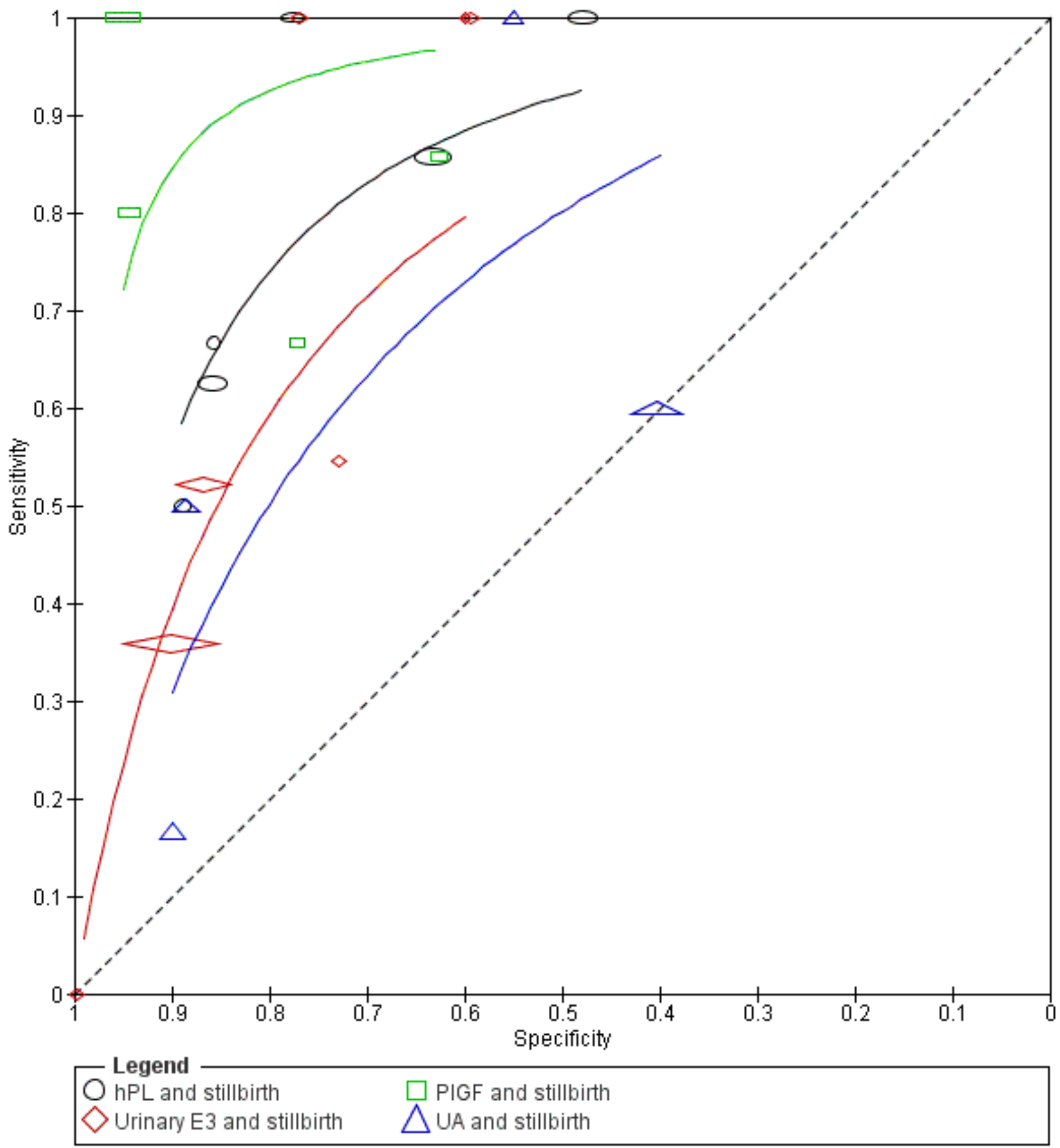

Using sensitivities estimated at fixed values of specificity, Table 5 shows the numbers of missed stillbirths and false positives in a hypothetical cohort of 1000 pregnant women. At the median specificity of 0.78 and median prevalence of $1.7 \%$, PIGF, hPL, urinary oestriol and uric acid will miss 2, 5, 7 and 8 stillbirths, respectively. 
There were no comparative studies of biochemical tests; one study (Altmann 1978) evaluated hPL and placental grading in a small cohort of 10 pregnancies.

\section{Studies with evaluations of both small-for-gestational-age infants (birthweight $\leq 10$ th centile) and stillbirth}

Biochemical tests were assessed for both SGA and stillbirth in 18 studies (Appendix 7). In addition, Chen 2012 assessed placental grading for both outcomes. As it is only possible to show one outcome per study on the forest plot, we chose to display only biochemical tests for clarity. Results for Altmann 1978 and Chen 2012 can be seen in Figure 4 for SGA and in Figure 12 for stillbirth.

\section{Investigation of heterogeneity}

Where the number of studies allowed, we investigated the effect of the formula used to estimate fetal weight based on ultrasound examination on test accuracy in a meta-regression. We compared the 20 studies (41,104 pregnancies) that used the Hadlock formula with the four studies (1710 pregnancies) that used the Shepard formula. The DORs $(95 \% \mathrm{Cl})$ for the Shepard and Hadlock formulas were 28.3 (6.60 to 121 ) and 24.2 (12.3 to 47.7). There was no statistical evidence of a difference in accuracy; the ratio of DORs (95\%) was 1.17 (0.23 to 5.79), $P=0.55$. Due to limited data, we were unable to formally investigate the effect of other potential sources of heterogeneity as outlined in the Secondary objectives.

\section{DISCUSSION}

\section{Summary of main results}

\section{Small-for-gestational age (SGA) (birthweight $\leq 10$ th centile)}

The main findings of this review are that ultrasound estimated fetal weight (EFW) is the most accurate test available to detect an SGA infant, but still only detects about $50 \%$ of infants born SGA. There are more studies of ultrasound EFW than any biochemical marker of placental dysfunction in this review. Overall, ultrasound EFW is better at predicting SGA $<3^{\text {rd }}$ centile than $S G A<10^{\text {th }}$ centile, which suggests that the more severe the phenotype of SGA, the better the accuracy of ultrasound EFW to identify that baby as SGA. Analysis of the biochemical tests found that human placental lactogen (hPL) was best for identifying an infant that would be SGA at birth, although it was inferior to the performance of ultrasound EFW.

\section{Stillbirth}

Fewer studies investigated the prediction of pregnancies that would end in stillbirth and only three studies examined abnormal placental structure or function directly (Benton 2016, Jauniaux 1996, Ylikorkala 1973) by pathological examination.

Placental histopathology data were available for 213 women from the Benton 2016 study; 55 of 94 women with low placental growth factor(PIGF) had Grannum grade II or III placentas, as did one of the 119 with normal PIGF values. Jauniaux 1996 found extended vascular lesions after histopathological examination in 12 complicated cases and Ylikorkala 1973 found evidence of degenerative placental changes and dysmature placenta in $50 \%$ of cases; we did not use data from the entire cohort so cannot know numbers from these but there was no relationship found between placental calcification and serum hPL level.
There were no studies that presented data to allow estimation of the diagnostic accuracy of EFW measurement for stillbirth; Sovio 2015 included stillbirths but data were presented as part of a severe adverse perinatal outcome group meaning that stillbirth could not be assessed separately. Included studies measured hPL, PIGF, placental grading, uric acid, and urinary E3. Of the biochemical tests for detecting pregnancies that would end in stillbirth, PIGF had the best diagnostic accuracy.

Critically, very few studies investigated the accuracy of different tests in the same study population, which would allow direct comparison of diagnostic test accuracy, and only one study (Lenstrup 1982) investigated combinations of biomarkers. Indirect comparison suggests that biochemical tests of placental function performed better in identification of pregnancies that would end in a stillbirth compared to detection of a pregnancy that would end in the birth of an SGA infant.

\section{Strengths and weaknesses of the review}

This review is the first comprehensive review of biochemical markers in maternal blood or serum in late pregnancy in comparison with the performance of ultrasound to detect pregnancies that end in stillbirth and SGA births. We examined papers from different countries and published in languages other than English, allowing us to cover a wide range of populations of pregnant women. We contacted authors where necessary to clarify or obtain data (although this was not always successful) and were able to include unpublished data in some cases. However, some papers were also unobtainable, meaning it is possible that some usable data may not have been included (see Characteristics of studies awaiting classification). Furthermore, the nomenclature of some of the biochemical factors has changed meaning that the search strategies may not have included all possible studies.

There are some limitations which need to be considered.

- Limitations in the availability and variability in reporting of data prevented us from undertaking comparisons and investigations of heterogeneity as originally set out in the protocol. Measurements were taken at many different gestational ages and these were often not comparable. Studies often took measurements over a fixed range of time rather than at one time point so there were few studies that used the exact same gestation; a comparison of studies that tested before and after term ( 37 weeks) was not possible, due to the amount of overlap of this time point.

- Studies used many different measurement techniques for the same index tests, for example measurement of different isoforms of the biochemical factor of interest, which could have had an impact on test performance. Definitions of index test positivity thresholds for individual tests varied and were often not prespecified; they were frequently based on optimally performing thresholds in the study population itself rather than on externally validated thresholds. This meant that it was not practical to perform a formal comparison of all measurements at the 10th centile, for example, as exact measurements differed across studies. If there were common thresholds between studies then these are the ones for which data were extracted, especially if these were in clinical use (e.g. $<12 \mathrm{pg} / \mathrm{mL}$ for PIGF). Defined externally-validated thresholds are needed before recommendations for clinical practice can be made. 
- Few papers made direct comparisons between index tests (comparison of index test in the same population) or investigated the accuracy of testing strategies (combining several index tests for the same woman). Due to differences between study populations, such as risk factors, it is unclear how useful comparisons between studies are.

- Due to variation between study populations we decided to use fairly broad definitions of patient risk; high risk was defined as all women at high risk due to various factors (pre-eclampsia, hypertension, suspected fetal growth restriction (FGR), history of SGA or stillbirth), mixed risk was where some but not all women were affected by these conditions (including unselected populations), and low-risk was where all complications were excluded. It was not possible to look at test performances in only hypertensive women or only women with suspected FGR, for example.

- With the exception of uric acid, the studies of biochemical markers were performed in two distinct time periods, before 1991 (for hPL and E3) and after 2013 (for PIGF), whereas the accuracy of ultrasound scan has been studied continuously since the 1970s. Earlier studies tended to be smaller and less rigorously conducted and reported as required by contemporary standards of study reporting. In addition, methods of biochemical analysis have also developed over the time frame of the review from radioimmunoassay to enzymelinked immunosorbent assay (ELISA) or chemiluminescent assays.

\section{Applicability of findings to the review question}

Ultrasound EFW is a well-established technique in contemporary obstetric practice and is at the centre of screening for FGR (RCOG 2013) and strategies to reduce stillbirth (NHS England 2016). Many of the studies were conducted in women who were at increased risk of FGR or stillbirth, so these findings cannot necessarily be generalised to a mixed- or low-risk population. This is particularly important because the risk status of the woman alters the importance of specific aspects of test performance. In mothers at high risk of stillbirth, a false negative result would potentially deprive the woman of additional monitoring or intervention which may mitigate the increased risk of adverse outcome, thus sensitivity would be prioritised over specificity. However, women in low- or mixed-risk populations, a false positive result may increase monitoring and/or intervention which is unnecessary and could have short- and long-term consequences (Peters 2018). Unfortunately, limitations in data meant that the impact of the potential sources of heterogeneity described above (including risk status of the mother) on test accuracy could not be explored. We were not able to find all of the information we had intended to, particularly about the outcome of testing and potential harms of testing because data were unavailable. The search was completed in October 2016 and it is possible that new studies, particularly regarding PIGF, have been added since then.

\section{AUTHORS' CONCLUSIONS}

\section{Implications for practice}

Ultrasound estimated fetal weight (EFW) appears to be the most accurate method to identify a baby that will be small-forgestational age (SGA) at birth. However, clinicians should be aware that the estimates of sensitivity (the range of sensitivity for included studies was 0.07 to 0.93 ) that ultrasound EFW does not detect a significant proportion of babies who have a birthweight $<10$ th centile. Importantly, EFW has a high specificity (pooled estimate 0.95) which avoids implications of false positive results (e.g. maternal anxiety, further testing, or unwarranted intervention). This review could not find a significant difference between two of the formulae used to derive EFW on diagnostic accuracy (Shepard or Hadlock). This review also suggests that biochemical markers of placental function cannot be used alone to identify which pregnancies will end with the birth of an SGA baby. Biochemical markers show promise in identifying babies who go on to be stillborn, although data are largely confined to women at increased risk of stillbirth. Furthermore, the performance of biochemical markers in comparison to ultrasound EFW for stillbirth is unknown.

\section{Implications for research}

Further research studies of ultrasound are required to determine whether an EFW under a specific threshold, e.g. 10th centile identifies pregnancies that end in stillbirth. This could be achieved by including stillbirth as an outcome measure in all studies; stillbirths were frequently excluded from many of the studies examining the accuracy of ultrasound EFW. While individual studies of the accuracy of ultrasound EFW are likely to be underpowered to evaluate the prediction of a pregnancy that ends in stillbirth, this aim could be achieved by meta-analysis of such studies. Further studies are also needed of biochemical markers alone and in combination with ultrasound EFW. Such studies would facilitate direct comparison of test performance and whether a combination of tests would be more effective than a single means of assessment for detection of SGA infants at birth and pregnancies that end in stillbirth.

Ideally, future studies should have an adequate sample size to study their outcome of interest or when this is unlikely to be possible, e.g. in studies of stillbirth a range of important pregnancy outcomes should be reported to facilitate future meta-analyses. Similarly, studies should also have standardised reporting using the STARD guidelines (Bossuyt 2015) to ensure that information can be extracted for future meta-analyses. In addition, researchers should consider using direct assessment of placental pathology as the reference standard. For practical reasons, this review used two clinical endpoints which are associated with placental pathology. However, the use of clinical endpoints rather than evidence of placental pathology could account for the apparent suboptimal test performance. For example, 70\% of SGA infants $\left(<10^{\text {th }}\right.$ percentile) are "constitutionally small", with no evidence of underlying placental dysfunction, so would not be expected to have a positive test result. This may also explain why biochemical markers of placental function appear to have a greater accuracy in predicting stillbirth compared to SGA, as stillbirth is more frequently associated with placental abnormalities (in up to $60 \%$ of cases). Further studies are needed to determine whether ultrasound EFW, biochemical markers of placental function, and other measurements such as fetal and maternal Doppler measurements accurately identify placental pathology.

Initial research studies may wish to focus on women at highest risk of placental dysfunction, and by association the birth of an SGA infant and stillbirth, e.g. women who are suspected to have a SGA infant by symphysis-fundal height (SFH) measurement, or who present with reduced fetal movements or have hypertension. Studies could then explore the diagnostic accuracy of biochemical factors alone, or in association with ultrasound measurements, in a

Biochemical tests of placental function versus ultrasound assessment of fetal size for stillbirth and small-for-gestational-age infants 32 (Review) 
low- or mixed-risk population where the background risk of adverse outcome is lower.

Test evaluation studies need to consider the implications of revealing index test results as this could have adverse consequences such as increased intervention by induction of labour or increased frequency of birth by caesarean section and admission to neonatal units, all of which may impact upon mothers' experience of care and fetal outcome. The clinical role of biochemical markers of placental dysfunction needs to be revisited using robust study designs with adequate sample sizes and standardised reporting. Ultimately, clinical efficacy will need to be demonstrated by intervention studies before any test is adopted into clinical practice.

\section{ACK N O WLEDGEMENTS}

Alexander Heazell is supported by a Clinician Scientist Fellowship (CS-2013-009) from the National Institute for Health Research (NIHR).
The authors would like to thank the patient participant involvement group chaired by Claire Storey for the Placental Assessment Predicting Pregnancy Outcome (PAPPO) study for their assistance with preparing the Plain language summary. We are also very grateful to everyone who has helped with translations at any point during this review: Laura Avagliano, Lauren Baker, Sandor Bako, Janine Dretske, Rui Duarte, Filip Ericsson, Claudia Ravaldi, Michael Robinson, Katalin Wilkinson and Yu-Tian Xiao.

As part of the pre-publication editorial process, this review has been commented on by three peers (an editor and two referees who are external to the editorial team). The authors are grateful to the following peer reviewers for their time and comments: Professor GC Smith, Helen Sassoon.

This project was supported by the National Institute for Health Research, via Cochrane Infrastructure funding to Cochrane Pregnancy and Childbirth. The views and opinions expressed therein are those of the authors and do not necessarily reflect those of the Systematic Reviews Programme, NIHR, NHS or the Department of Health. 


\section{RE F E R E N C E S}

\section{References to studies included in this review}

\section{Altmann 1978 \{published data only\}}

Altmann P, Janisch H, Muller-Tyl E, Reinold E, Spona J, Havelec L. Serum oestriol: a parameter of the function of the feto-placental unit. Wiener Klinische Wochenschrift 1978;90:121-7.

\section{Amini 2014 \{published data only\}}

Amini E, Sheikh M, Hantoushzadeh S, Shariat M, Abdollahi A, Kashanian M. Maternal hyperuricemia in normotensive singleton pregnancy, a prenatal finding with continuous perinatal and postnatal effects, a prospective cohort study. BMC Pregnancy \& Childbirth 2014;14:104.

\section{Baird 2016 \{published data only\}}

Baird SM, Davies-Tuck M, Coombs P, Knight M, Wallace EM. Detection of the growth-restricted fetus: which centile charts? Sonography 2016;3:81-6.

\section{Barel 2016 \{published data only\}}

Barel O, Maymon R, Elovits M, Smorgick N, Tovbin J, Vaknin Z. Evaluation of fetal weight estimation formulas in assessing small-for-gestational-age fetuses. Ultraschall in der Medizin 2016;37:283-9.

\section{Beischer 1991 \{published data only\}}

Beischer N, Brown J, Parkinson P, Walstab J. Urinary oestriol assay for monitoring fetoplacental function. Australian \& New Zealand Journal of Obstetrics \& Gynaecology 1991;31:1-8.

Bellomo 2011 \{published data only\}

Bellomo G, Venanzi S, Saronio P, Verdura C, Narducci PL. Prognostic significance of serum uric acid in women with gestational hypertension. Hypertension 2011;58:704-8.

\section{Ben-Haroush 2007 \{published data only\}}

Ben-Haroush A, Yogev Y, Hod M, Bar J. Predictive value of a single early fetal weight estimate in normal pregnancies. European Journal of Obstetrics Gynecology and Reproductive Biology 2007;130:187-92.

\section{Benton 2016 \{published data only\}}

Benton SJ, McCowan LM, Heazell AE, Grynspan D, Hutcheon JA, Senger $\mathrm{C}$, et al. Placental growth factor as a marker of fetal growth restriction caused by placental dysfunction. Placenta 2016;42:1-8.

\section{Berkowitz 1988 \{published data only\}}

Berkowitz GS, Chitkara U, Rosenberg J, Cogswell C, Walker B, Lahman EA, et al. Sonographic estimation of fetal weight and Doppler analysis of umbilical artery velocimetry in the prediction of intrauterine growth retardation: a prospective study. American Journal of Obstetrics \& Gynecology 1988; Vol. 158:1149-53.
Bikmetova 2013 \{published data only\}

Bikmetova E, Trishkin A, Artymuk N. Fetal growth restriction: Informativity of modern diagnosis methods. Journal of Perinatal Medicine 2013;41:85.

\section{Callec 2015 \{published data only\}}

Callec R, Lamy C, Perdriolle-Galet E, Patte C, Heude B, Morel O. Impact on obstetric outcome of third-trimester screening for small-for-gestational-age fetuses. Ultrasound in Obstetrics \& Gynecology 2015;46:216-20.

\section{Campbell 1972 \{published data only\}}

Campbell S, Kurjak A. Comparison between urinary oestrogen assay and serial ultrasonic cephalometry in assessment of fetal growth retardation. British Medical Journal 1972;4:336-40.

\section{Cedard 1979 \{published data only\}}

Cedard L, Bedin M, Leblond J, Tanguy G, Kaminski M. Maternal plasma total oestriol and dehydroepiandrosterone sulfate loading test as indicators of feto-placental function or placental sulfatase deficiency. Journal of Steroid Biochemistry 1979;11:501-7.

Chaiworapongsa 2013 \{published data only\}

Chaiworapongsa T, Romero R, Korzeniewski SJ, Kusanovic JP, Soto E, Lam J, et al. Maternal plasma concentrations of angiogenic/antiangiogenic factors in the third trimester of pregnancy to identify the patient at risk for stillbirth at or near term and severe late preeclampsia. American Journal of Obstetrics \& Gynecology 2013;208:287.e1-287.e15.

Chard 1985 \{published data only\}

Chard T, Sturdee J, Cockrill B, Obiekwe BC. Which is the best placental function test? A comparison of placental lactogen and unconjugated oestriol in the prediction of intrauterine growth retardation. European Journal of Obstetrics, Gynecology, \& Reproductive Biology 1985;19:13-7.

Chauhan 1999 \{published data only\}

Chauhan SP, Scardo JA, Hendrix NW, Magann EF, Morrison JC. Accuracy of sonographically estimated fetal weight with and without oligohydramnios. A case-control study. Journal of Reproductive Medicine 1999;44:969-73.

Chauhan 1999a \{published data only\}

Chauhan SP, Scardo JA, Magann EF, Devoe LD, Hendrix NW, Martin JN Jr. Detection of growth-restricted fetuses in preeclampsia: a case-control study. Obstetrics \& Gynecology 1999;93:687-91.

\section{Chauhan 2003 \{published data only\}}

Chauhan SP, Magann EF, Velthius S, Nunn SL, Reynolds D, Scardo JA, et al. Detection of fetal growth restriction in patients with chronic hypertension: is it feasible?. Journal of MaternalFetal \& Neonatal Medicine 2003;14:324-8.

\section{Chen 2012 \{published data only\}}

Chen KH, Chen LR. PP096. The effect of preterm placental calcification on uteroplacental blood flow, fetal growth and

Biochemical tests of placental function versus ultrasound assessment of fetal size for stillbirth and small-for-gestational-age infants 
perinatal outcome in hypertension complicating pregnancy. Pregnancy Hypertension 2012;2:292.

\section{Chen 2012a \{published data only\}}

Chen $\mathrm{KH}$, Chen LR, Lee YH. The role of preterm placental calcification in high-risk pregnancy as a predictor of poor uteroplacental blood flow and adverse pregnancy outcome. Ultrasound in Medicine \& Biology 2012;38(6):1011-8.

\section{Chen 2015 \{published data only\}}

Chen KH, Seow KM, Chen LR. The role of preterm placental calcification on assessing risks of stillbirth. Placenta 2015;36:1039-44

\section{Chervenak 1984 \{published data only\}}

Chervenak FA, Romero R, Berkowitz RL, Scott D, Tortora M, Hobbins JC. Use of sonographic estimated fetal weight in the prediction of intrauterine growth retardation. American Journal of Perinatology 1984; Vol. 1, issue 4:298-301.

Chew 1976 \{published data only\}

Chew PC, Ratnam SS. Plasma estradiol-17 beta as an index of fetoplacental function. International Journal of Gynaecology \& Obstetrics 1976;14:445-8.

\section{Chitlange 1990 \{published data only\}}

Chitlange SM, Hazari KT, Joshi JV, Shah RK, Mehta AC. Ultrasonographically observed preterm grade III placenta and perinatal outcome. International Journal of Gynaecology \& Obstetrics 1990;31:325-8.

\section{Christensen 2015 \{published data only\}}

Christensen KM, Heilbrun ME, Patel N, Woodward PJ, Kennedy A. Estimated fetal weight and birth weight associated with isolated single umbilical artery: the University of Utah experience. Ultrasound Quarterly 2015;31:19-22.

\section{Elliott 1970 \{published data only\}}

Elliott PM. Urinary oestriol excretion in retarded intrauterine fetal growth. Australian \& New Zealand Journal of Obstetrics \& Gynaecology 1970;10(1):18-21.

\section{Estel 1989 \{published data only\}}

Estel C, Eichhorn KH. [The correlation of reduced amniotic fluid volume, placental maturity and morphologic placental changes in placental insufficiency]. Zentralblatt fur Gynakologie 1989;111:891-6.

\section{Fliegner 1979 \{published data only\}}

Fliegner JR. Comparison of urinary pregnanediol and estriol excretion as indexes of placental function. Obstetrics \& Gynecology 1979;53(1):93-8.

\section{Freire 2010 \{published data only\}}

Freire DM, Cecatti JG, Paiva CS. Correlation between estimated fetal weight by ultrasound and neonatal weight [Correlacao entre peso fetal estimado por ultrassonografia e peso neonatal]. Revista Brasileria de Ginecologia e Obstetricia 2010; Vol. 32:4-10

\section{Gabbay-Benziv 2016 \{published data only\}}

Gabbay-Benziv R, Aviram A, Bardin R, Ashwal E, Melamed N, Hiersch $L$, et al. Prediction of small for gestational age: accuracy of different sonographic fetal weight estimation formulas. Fetal Diagnosis \& Therapy 2016;40:205-13.

Geerts 2016 \{published data only\}

Geerts L, Van der ME, Theron A, Rademan K. Placental insufficiency among high-risk pregnancies with a normal umbilical artery resistance index after 32 weeks. International Journal of Gynaecology \& Obstetrics 2016;135:38-42.

\section{Gerhard 1986 \{published data only\}}

Gerhard I, Fitzer C, Klinga K, Rahman N, Runnebaum B. Estrogen screening in evaluation of fetal outcome and infant's development. Journal of Perinatal Medicine 1986;14:279-91.

Gohari 1978 \{published data only\}

Gohari P, Hobbins JC, Berkowtiz R. Use of hPL in the diagnosis of intrauterine growth retardation. Obstetrics \& Gynecology 1978;52:127-8.

\section{Granat 1977 \{published data only\}}

Granat M, Sharf M, Diengott D, Spindel A, Kahana L, Elrad H. Further investigation on the predictive value of human placental lactogen in high-risk pregnancies. American Journal of Obstetrics and Gynecology 1977; Vol. 129:647-54.

\section{Griffin 2015 \{published data only\}}

Griffin M, Seed PT, Webster L, Myers J, MacKillpo L, Simpson N, et al. Diagnostic accuracy of placental growth factor and ultrasound parameters to predict the small-for-gestational-age infant in women presenting with reduced symphisis-fundus height. Ultrasound in Obstetrics \& Gynecology 2015;46:182-90

Gupta 2008 \{published data only\}

Gupta LM, Gaston L, Chauhan SP. Detection of fetal growth restriction with preterm severe preeclampsia: experience at two tertiary centers. American Journal of Perinatology 2008;25:247-9.

\section{Hammad 2015 \{published data only\}}

Hammad IA, Chauhan SP, Mlynarczyk M, Rabie N, Goodie C, Chang E, et al. Uncomplicated pregnancies and ultrasounds for fetal growth restriction: a pilot randomized clinical trial. AJP Reports 2015;6:e83-90.

\section{Hatfield 2010 \{published data only\}}

Hatfield T, Caughey AB, Lagrew DC, Heintz R, Chung JH. The use of ultrasound to detect small-for-gestational-age infants in patients with elevated human chorionic gonadotropin on maternal serum screening. American Journal of Obstetrics and Gynecology 2010; Vol. 27:173-80.

\section{Hawkins 2012 \{published and unpublished data\}}

Hawkins TL, Roberts JM, Mangos GJ, Davis GK, Roberts LM, Brown MA. Plasma uric acid remains a marker of poor outcome in hypertensive pregnancy: a retrospective cohort study. BJOG: an international journal of obstetrics and gynaecology 2012;119:484-92

Biochemical tests of placental function versus ultrasound assessment of fetal size for stillbirth and small-for-gestational-age infants 
Hendrix 2000 \{published data only\}

Hendrix NW, Grady CS, Chauhan SP. Clinical vs. sonographic estimate of birth weight in term parturients: a randomized clinical trial. Journal of Reproductive Medicine for the Obstetrician and Gynecologist 2000;45:317-22.

Howell 1985 \{published data only\}

Howell RJ, Perry LA, Ghoglay NS. Placental protein 12 (PP12): a new test for the prediction of the small-for-gestationalage infant. British Journal of Obstetrics and Gynaecology 1985;92:1141-4.

\section{Jauniaux 1996 \{published data only\}}

Jauniaux E, Gulbis B, Tunkel S, Ramsay B, Campbell S, Meuris S. Maternal serum testing for alpha-fetoprotein and human chorionic gonadotropin in high-risk pregnancies. Prenatal Diagnosis 1996;16:1129-35.

\section{Kazzi 1983a \{published data only\}}

Kazzi GM, Gross TL, Sokol RJ, Kazzi NJ. Detection of intrauterine growth retardation: a new use for sonographic placental grading. American Journal of Obstetrics and Gynecology 1983;145:733-7.

\section{Kienast 2016 \{published data only\}}

Kienast C, Moya W, Rodriguez O, Jijon A, Geipel A. Predictive value of angiogenic factors, clinical risk factors and uterine artery Doppler for pre-eclampsia and fetal growth restriction in second and third trimester pregnancies in an Ecuadorian population. Journal of Maternal-Fetal \& Neonatal Medicine 2016;29:537-43.

\section{Klebe 1990 \{published data only\}}

Klebe JG, Marushak A, Bock J. Human placental lactogenic hormone as a parameter for placental function in renal transplanted women. Acta Obstetricia et Gynecologia Scandinavica 1990;69:41-3.

\section{Kunz 1976 \{published data only\}}

Kunz J, Keller PJ. Ultrasound and biochemical findings in intrauterine growth retardation. Journal of Perinatal Medicine 1976;4:85-94.

\section{Laurin 1987 \{published data only\}}

Laurin J, Persson PH. Ultrasound screening for detection of intra-uterine growth retardation. Acta Obstetricia et Gynecologica Scandinavica 1987; Vol. 66:493-500.

\section{Leader 1980 \{published data only\}}

Leader LR, Baillie P. Comparison of fetal movements and human placental lactogen as predictors of fetal outcome. A prospective study. South African Medical Journal 1980;58:609-10.

\section{Lenstrup 1982 \{published data only\}}

Lenstrup C. Predictive value of a single unstressed antepartum cardiotocogram in apparently uncomplicated pregnancy. Introduction of a new cardiotocography score. Acta Obstetricia et Gynecologica Scandinavica 1982; Vol. 61:177-82.

\section{Lilford 1983 \{published data only\}}

Lilford RJ, Obiekwe BC, Chard T. Maternal blood levels of human placental lactogen in the prediction of fetal growth retardation: choosing a cut-off point between normal and abnormal. British Journal of Obstetrics and Gynaecology 1983;90:511-5.

MacLeod 2013 \{published data only\}

MacLeod K, Sandercombe N, Barrett A, Heffernan E, Kalema H, Ngonzi J, et al. Clinical relevance of fetal weight estimation in Southwest Uganda. Archives of Disease in Childhood: Fetal and Neonatal Edition 2013;98:A15.

Mahran 1988 \{published data only\} Mahran M, Omran M. The impact of diagnostic ultrasound on the prediction of intrauterine growth retardation in developing countries. International Journal of Gynaecology and Obstetrics 1988;26:375-8.

Marin 1979 \{published data only\}

Marin RD, Hood W. Significance of amniotic fluid glucose in late pregnancy. Australian \& New Zealand Journal of Obstetrics \& Gynaecology 1979;19:91-4.

McKenna 2005 \{published data only\}

McKenna D, Tharmaratnam S, Mahsud S, Dornan J. Ultrasonic evidence of placental calcification at 36 weeks' gestation: maternal and fetal outcomes. Acta Obstetricia et Gynecologica Scandinavica 2005;84:7-10.

Miller 1988 \{published data only\}

Miller JM Jr, Brown HL, Kissling GA, Gabert HA. The relationship of placental grade to fetal size and growth at term. American Journal of Perinatology 1988;5:19-21.

Molvarec 2013 \{published data only\}

Molvarec A, Gullai N, Stenczer B, Fugedi G, Nagy B, Rigo J. Comparison of placental growth factor and fetal flow Doppler ultrasonography to identify fetal adverse outcomes in women with hypertensive disorders of pregnancy: an observational study. BMC Pregnancy and Childbirth 2013;13:161.

\section{Montan 1986 \{published data only\}}

Montan S, Jorgensen C, Svalenius E, Ingemarsson I. Placenta grading with ultrasound in hypertensive and normotensive pregnancies. A prospective, consecutive study. Acta Obstetrica et Gynecologica Scandinavica 1986; Vol. 65:477-80.

Nice 2016 \{published and unpublished data\}

Nice D, Hayden K, Higgins L, Garrod A, Johnstone E, Heazell A. Human placental lactogen and placental growth factor differentiate adverse pregnancy outcome from healthy outcomes in high-risk pregnancies. BJOG: an international journal of obstetrics and gynaecology 2016;123:44-5.

Nielsen 1985 \{published data only\}

Nielsen PV, Schultz-Larsen P, Schioeler V. Screening in pregnancy with unconjugated estriol compared with total estriol. Acta Obstetricia et Gynecologica Scandinavica 1985;64:297-301.

Biochemical tests of placental function versus ultrasound assessment of fetal size for stillbirth and small-for-gestational-age infants 
Nisbet 1982 \{published data only\}

Nisbet AD, Horne CH, Jandial V, Bremner RD, Cruickshank N, Sutcliffe RG. Measurement of plasma placental proteins and estriol in the detection of intrauterine growth retardation. European Journal of Obstetrics, Gynecology, \& Reproductive Biology 1982;13:333-42.

\section{Oats 1979 \{published data only\}}

Oats JJ, Beischer NA. The recurrence rate and significance of low oestriol excretion in successive pregnancies. British Journal of Obstetrics and Gynaecology 1979;86:15-8.

Obiekwe 1983 \{published data only\}

Obiekwe BC, Chard T. A comparative study of the clinical use of four placental proteins in the third trimester. Journal of Perinatal Medicine 1983;11:121-6.

Odendaal 1981 \{published data only\}

Odendaal HJ, Malan C, Oosthuizen J. Hormonal placental functions and intrauterine growth retardation in patients with positive contraction stress tests. South African Medical Journal 1981;59:822-4

\section{Odendaal 1997 \{published data only\}}

Odenaal HJ, Pienaar ME. Are high uric acid levels in patients with early preeclampsia an indication for delivery?. South African Medical Journal 1997;87:213-8.

\section{Ott 1984 \{published data only\}}

Ott WJ, Doyle S. Ultrasonic diagnosis of altered fetal growth by use of a normal ultrasonic fetal weight curve. Obstetrics \& Gynecology 1984;63:201-4.

\section{Palo 1987 \{published data only\}}

Palo P, Erkkola R, Irjala K, Taina E. Serum free estriol inefficient in the detection of intrauterine growth retardation. Annales Chirurgiae et Gynaecologiae 1987;Suppl 202:20-2.

\section{Palo 1989 \{published data only\}}

Palo P, Erkkola R, Piiroinen O, Ruotsalainen P. Accuracy of ultrasonic fetal weight estimation and detection of small for gestational age fetuses. American Journal of Perinatology 1989; Vol. 6:400-4.

\section{Patterson 1983 \{published data only\}}

Patterson RM, Hayashi RH, Cavazos D. Ultrasonographically observed early placental maturation and perinatal outcome. American Journal of Obstetrics and Gynecology 1983;147:773-7.

\section{Redman 1976 \{published data only\}}

Redman CW, Beckin LJ, Bonnar J, Wilkinson RH. Plasma urate measurements in predicting fetal death in hypertensive pregnancy. Lancet 1976;307:1370-3.

\section{Roma 2015 \{published data only\}}

Roma E, Arnau A, Berdala R, Bergos C, Montesinos J, Figueras F. Ultrasound screening for fetal growth restriction at 36 vs 32 weeks' gestation: a randomized trial (ROUTE). Ultrasound in Obstetrics \& Gynecology 2015;46:391-7.

\section{Sagen 1984 \{published data only\}}

Sagen N, Nilsen ST, Kim HC, Koller O, Bergsjo P. The predictive value of total estriol; $\mathrm{HPL}$ and $\mathrm{Hb}$ on perinatal outcome in severe pre-eclampsia. Acta Obstetricia et Gynecologica Scandinavica 1984; Vol. 63:603-8.

\section{Sekar 2016 \{published data only\}}

Sekar R, Khatun M, Barrett HL, Duncombe G. A prospective pilot study in assessing the accuracy of ultrasound estimated fetal weight prior to delivery. Australian \& New Zealand Journal of Obstetrics \& Gynaecology 2016;56:49-53.

\section{Shawkat 2015 \{published and unpublished data\}}

Shawkat E, Johnstone E, Nice D, Sayce A, Hayden K, Myers J. [105-POS] : Clinical evaluation of placental growth factor (PIGF) for the management of suspected placental pathology in highrisk pregnancies. Pregnancy Hypertension 2015;5:57.

\section{Siebert 1974 \{published data only\}}

Siebert W, Meitinger C, Vogt W, Sandel P. [HPL serum levels in intrauterine retardation of fetal growth during late pregnancy (author's transl)]. Geburtshilfe und Frauenheilkunde 1974;34:520-4.

\section{Skovron 1991 \{published data only\}}

Skovron ML, Berkowitz GS, Lapinski RH, Kim JM, Chitkara U. Evaluation of early third-trimester ultrasound screening for intrauterine growth retardation. Journal of Ultrasound in Medicine 1991;10:153-9.

\section{Sovio 2015 \{published data only\}}

Sovio U, Smith G, Dacey A, Pasupathy D, White I. Screening for fetal growth restriction (FGR) using universal third trimester ultrasonography: A prospective cohort study of 3,977 nulliparous women. American Journal of Obstetrics and Gynecology 2015;1:S92.

\section{Spernol 1989 \{published data only\}}

Spernol R, Hecher K, Szalay S. [The value of fetal blood flow measurements in intrauterine growth retardation in comparison with E3 and human placental lactogen determinations]. Geburtshilfe und Frauenheilkunde 1989;49:463-5.

\section{Steiner 1991 \{published data only\}}

Steiner H, Schaffer H, Lassmann R, Staudach A, Batka M. [Comparison of biochemical and Doppler sonographic monitoring of high-risk pregnancies]. Geburtshilfe und Frauenheilkunde 1991;51:540-3.

\section{Takeuchi 1985 \{published data only\}}

Takeuchi K. [Antenatal assessment of intrauterine growth retardation by ultrasonic fetal biometry and non-stress fetal heart rate testing]. Nippon Sanka Fujinka Gakkai Zasshi - Acta Obstetrica et Gynaecologica Japonica 1985;37:2376-84.

\section{Trudinger 1979 \{published data only\}}

Trudinger BJ, Gordon YB, Grudzinskas JG, Hull MG, Lewis PJ, Arrans ME. Fetal breathing movements and other tests of fetal wellbeing: a comparative evaluation. British Medical Journal $1979 ; 2: 577-9$

Biochemical tests of placental function versus ultrasound assessment of fetal size for stillbirth and small-for-gestational-age infants 
Turitz 2014 \{published data only\}

Turitz AL. Isolated abdominal circumference $<5 \%$ or estimated fetal weight 10 to $19 \%$ as predictors of small for gestational age infants. American Journal of Perinatology 2014; Vol. 31:469-76.

\section{Valino 2016 \{published data only\}}

Valino N, Giunta G, Gallo DM, Akolekar R, Nicolaides KH. Biophysical and biochemical markers at 35-37 weeks' gestation in the prediction of adverse perinatal outcome. Ultrasound in Obstetrics \& Gynecology 2016;47:203-9.

\section{Voto 1988 \{published data only\}}

Voto LS, Ilia R, Darbon-Grosso A, Uranga Imaz F, Marguiles M. Uric acid levels: a useful index of the severity of preeclampsia and perinatal prognosis. Journal of Perinatal Medicine 1988;16:123-6

\section{Walker 2010 \{published data only\}}

Walker GM, Hindmarsh, PC, Geary M, Kingdom JC. Sonographic maturation of the placenta at 30 to 34 weeks is not associated with second trimester markers of placental insufficiency in lowrisk pregnancies. Journal of Obstetrics and Gynaecology Canada 2010;32(12):1134-9.

\section{Weerasinghe 1977 \{published data only\}}

Weerasinghe DS, Legge M, Aickin DR. The clinical significance of low urine oestriol values. New Zealand Medical Journal 1977;86:383-4.

\section{Weiner 2016 \{published data only\}}

Weiner E, Fainstein N, Mizrachi Y, Elyashiv O, MevorachZussman N, Bar J, et al. Comparison between three methods for the detection of macrosomia and growth restriction in patients presenting in active labor-a prospective study. American Journal of Obstetrics and Gynecology 2016;1:S225-6.

\section{Westergaard 1984 \{published data only\}}

Westergaard JG, Teisner B, Hau J, Grudzinskas JG. Placental protein measurements in complicated pregnancies. I. Intrauterine growth retardation. British Journal of Obstetrics and Gynaecology 1984;91:1216-23.

\section{Williams 2002 \{published data only\}}

Williams KP, Galerneau F. The role of serum uric acid as a prognostic indicator of the severity of maternal and fetal complications in hypertensive pregnancies. Journal of Obstetrics \& Gynaecology Canada: JOGC 2002;24:628-32.

\section{Yassaee 2003 \{published data only\}}

Yassaee F. Hyperuricaemia and perinatal outcomes in patients with severe preeclampsia. Iranian Journal of Medical Sciences 2003;28(4):198-9.

\section{Ylikorkala 1973 \{published data only\}}

Ylikorkala O. Maternal serum HPL levels in normal and complicated pregnancy as an index of placental function. Acta Obstetricia et Gynecologica Scandinavica - Supplement 1973;26:1-52.

\section{Zhang 1990 \{published data only\}}

Zhang WY. [Single radial immunodiffusion of human placental lactogen and its clinical uses]. Chung-Hua Fu Chan Ko Tsa Chih [Chinese Journal of Obstetrics \& Gynecology] 1990;25:278-81, 316.

\section{References to studies excluded from this review}

\section{Adekanle 2013 \{published data only\}}

Adekanle DA, Oparinde DP, Atiba AS, Akintayo AA. Effect of different modes of delivery on cord blood oxidative stress markers. International Journal of Biomedical Science 2013;9:249-54.

\section{Agboola 1978 \{published data only\}}

Agboola A. The effect of low haematocrit on serum human placental lactogen values. British Journal of Obstetrics \& Gynaecology 1978; Vol. 85, issue 10:758-60.

Aggarwal 2006 \{published data only\}

Aggarwal PK, Jain V, Sakhuja V, Karumanchi SA, Jha V. Low urinary placental growth factor is a marker of pre-eclampsia. Kidney International 2006;69:621-4.

\section{Agorastos 2014 \{published data only\}}

Agorastos T. Biomarkers of endothelial dysfunction in preeclampsia and neonatal morbidity: a case-control study. European Journal of Obstetrics, Gynecology, and Reproductive Biology 2014;175:119-23.

\section{Ahmad 1979 \{published data only\}}

Ahmad T, Rahat T. Diagnostic evaluation of pregnancy urinary oestriol for foeto-placental function. JPMA - Journal of the Pakistan Medical Association 1979; Vol. 29, issue 10:209-11.

\section{Aickin 1983 \{published data only\}}

Aickin DR, Duff GB, Evans JJ, Legge M. Antenatal biochemical screening to predict low birthweight infants. British Journal of Obstetrics and Gynaecology 1983;90:129-33.

\section{Alahakoon 2014 \{published data only\}}

Alahakoon TI, Zhang WY, Trudinger B, Lee V. Discordant clinical presentations of preeclampsia and intrauterine fetal growth restriction with similar pro and anti-angiogenic profiles. Reproductive Sciences 2014;1:185A.

\section{Al-Amin 2015 \{published data only\}}

Al-Amin A, Hingston T, Mayall P, Araujo E, Fabricio Da Silva C, Friedman $D$. The utility of ultrasound in late pregnancy compared with clinical evaluation in detecting small and large for gestational age fetuses in low-risk pregnancies. Journal of Maternal-Fetal and Neonatal Medicine 2015;28:1495-9.

\section{Alberry 2009 \{published data only\}}

Alberry MS, Maddocks DG, Hadi MA, Metawi H, Hunt LP, Abdel-Fattah SA, et al. Quantification of cell free fetal DNA in maternal plasma in normal pregnancies and in pregnancies with placental dysfunction. American Journal of Obstetrics and Gynecology 2009;200:98.e1-6. 
Algeri 2013 \{published data only\}

Algeri P, Ornaghi S, Bernasconi D, Cappellini F, Signorini S, Brambilla $\mathrm{P}$, et al. The role of placental dysfunction in the pathogenesis of IUGR. American Journal of Obstetrics and Gynecology 2013;208 (1 Suppl 1):S192-3.

\section{Alvarez-Fernandez 2014 \{published data only\}}

Alvarez-Fernandez I, Prieto B, Rodriguez V, Ruano Y, Escudero Al, Alvarez FV. New biomarkers in diagnosis of early onset preeclampsia and imminent delivery prognosis. Clinical Chemistry \& Laboratory Medicine 2014; Vol. 52:1159-68.

\section{Alwasel 2013 \{published data only\}}

Alwasel SH, Harrath AH, Aljarallah JS, Abotalib Z, Osmond C, Al Omar SY, et al. The velocity of fetal growth is associated with the breadth of the placental surface, but not with the length. American Journal of Human Biology 2013;25:534-7.

\section{Anastasakis 2008 \{published data only\}}

Anastasakis E, Papantoniou N, Daskalakis G, Mesogitis S, Antsaklis A. Screening for pre-eclampsia by oxidative stress markers and uteroplacental blood flow. Journal of Obstetrics and Gynaecology 2008;28:285-9.

\section{Anderson 1978 \{published data only\}}

Anderson SG. Real-time sonography in obstetrics. Obstetrics \& Gynecology 1978;51:284-7.

\section{Arabin 1993 \{published data only\}}

Arabin B, Snyders R, Nicolaides KH, Versmold HK, Weitzel HK, Giffei J, et al. Systematic antepartum fetal evaluation ("Safe"). A concept for diagnosis of fetal function in threatened hypoxia. Geburtshilfe und Frauenheilkunde 1993; Vol. 53, issue 12:835-42.

\section{Arabin 1995 \{published data only\}}

Arabin B, Ragosch V, Mohnhaupt A. From biochemical to biophysical placental function tests in fetal surveillance. American Journal of Perinatology 1995; Vol. 12, issue 3:168-71.

\section{Arias 1977 \{published data only\}}

Arias $F$. The diagnosis and management of intrauterine growth retardation. Obstetrics \& Gynecology 1977;49:293-8.

\section{Ariyuki 1995 \{published data only\}}

Ariyuki Y, Hata T, Kitao M. Evaluation of perinatal outcome using individualized growth assessment: comparison with conventional methods. Pediatrics 1995;96:36-42.

\section{Atzeni 2012 \{published data only\}}

Atzeni I, Paoletti AM, Deiana SF, Meloni A, Guerriero S, Parodo G, et al. Placental growth factor (PLGF): Correlations with placental function. International Journal of Gynecology and Obstetrics 2012;119:S782-3.

\section{Aviram 2015 \{published data only\}}

Aviram A, Yogev Y, Bardin R, Meizner I, Wiznitzer A, Hadar E. Small for gestational age newborns - Does pre-recognition make a difference in pregnancy outcome?. Journal of Maternalfetal \& Neonatal Medicine 2015;28:1520-4.

\section{Axelsson 1978 \{published data only\}}

Axelsson O, Nilsson BA, Johansson ED. Assessment of placental function in uncomplicated and complicated late pregnancy by estimation of unconjugated oestrogens in plasma after an intravenous injection of dehydroepiandrosterone sulphate. Acta Endocrinologica 1978;89:359-71.

\section{Baeza Valenzuela1995 \{published data only\}}

Baeza Valenzuela A, Garcia Mendez A. Premature aging of the placenta. Ultrasonic diagnosis. [Spanish]. Ginecologia y Obstetricia de Mexico 1995;63:287-92.

Bahado-Singh 1998 \{published data only\}

Bahado-Singh RO, Dashe J, Deren O, Daftary G, Copel JA, Ehrenkranz RA. Prenatal prediction of neonatal outcome in the extremely low-birth-weight infant. American Journal of Obstetrics and Gynecology 1998;178:462-8.

Bainbridge 2008 \{published data only\}

Bainbridge SA, Roberts JM. Uric acid as a pathogenic factor in preeclampsia. Placenta 2008;29 Suppl A:S67-S72.

Bakketeig 1984 \{published data only\}

Bakketeig LS, Eik-Nes SH, Jacobsen G. Randomised controlled trial of ultrasonographic screening in pregnancy. Lancet 1984;2:207-11.

\section{Baltajian 2016 \{published data only\}}

Baltajian K, Bajracharya S, Salahuddin S, Berg AH, Geahchan C, Wenger JB, et al. Sequential plasma angiogenic factors levels in women with suspected preeclampsia. American Journal of Obstetrics \& Gynecology 2016;215:89.e1-89.e10.

Barden 1999 \{published data only\}

Barden AE, Beilin LJ, Ritchie J, Walters BN, Graham D, Michael CA. Is proteinuric pre-eclampsia a different disease in primigravida and multigravida?. Clinical Science 1999;97:475-83.

Bardien 2016 \{published data only\}

Bardien N, Whitehead CL, Tong S, Ugoni A, McDonald S, Walker SP. Placental insufficiency in fetuses that slow in growth but are born appropriate for gestational age: a prospective longitudinal study. PLOS One 2016;11:e0142788.

\section{Baron 1996 \{published data only\}}

Baron F, Graham D. Age-independent assessment of abnormal fetal growth in the third trimester. Journal of Ultrasound in Medicine 1996;15:381-4.

\section{Barrilleaux 2007 \{published data only\}}

Barrilleaux PS, Magann EF, Chauhan SP, York BM, Philibert L, Lewis DF. Amniotic fluid index as a predictor of adverse perinatal outcome in the HELLP syndrome. Journal of Reproductive Medicine 2007;52:293-8.

\section{Bartha 2003 \{published data only\}}

Bartha JL, Romero-Carmona R, Escobar-Llompart M, Paloma-Castro O, Comino-Delgado R. Human chorionic gonadotropin and vascular endothelial growth factor in normal and complicated pregnancies. Obstetrics and Gynecology 2003;102:995-9.

Biochemical tests of placental function versus ultrasound assessment of fetal size for stillbirth and small-for-gestational-age infants 
Bashir 1982 \{published data only\}

Bashir T, Brash JH, Buchan PC, Bevis DC, Clayden AD. Screening for the small-for-dates: a clinical and biochemical appraisal. European Journal of Obstetrics, Gynecology, \& Reproductive Biology 1982;13:61-6.

\section{Bastek 2009 \{published data only\}}

Bastek JA, Parr E, Wang E, Elovitz MA, Srinivas SK. Limitations of ultrasound in diagnosing intrauterine growth restriction in severe preeclampsia. Journal of Maternal-fetal \& Neonatal Medicine 2009;22:1039-44.

\section{Battaglia 1995 \{published data only\}}

Battaglia C, Artini PG, Ballestri M, Bonucchi D, Galli PA, Bencini S, et al. Hemodynamic, hematological and hemorrheological evaluation of post-term pregnancy. Acta Obstetricia et Gynecologica Scandinavica 1995;74:336-40.

\section{Beischer 1975 \{published data only\}}

Beischer NA. Low oestriol excretion: incidence, significance and treatment in an obstetric population. Medical Journal of Australia 1975;2:379-81.

\section{Bell 1967 \{published data only\}}

Bell ET, Loraine JA, McEwan HP, Charles D. Serial hormone assays in patients with uteroplacental insufficiency. American Journal of Obstetrics and Gynecology 1967;97:562-70.

\section{Benton 2010 \{published data only\}}

Benton S, Hu Y, Fang X, Knudsen AB, Kronborg CS, Vittinghus E, et al. Placental growth factor as a diagnostic for early onset preeclampsia and normotensive intrauterine growth restriction of placental origin. Placenta 2010; Vol. 1:S24.

\section{Benton 2011 \{published data only\}}

Benton S, Hu Y, Xie F, Kupfer K, Lee SW, Magee L, et al. Can placental growth factor identify placental intra-uterine growth restriction in fetuses who are antenatally identified as being small for gestational age?. Placenta 2011;32(9):A100.

\section{Benton 2011a \{published data only\}}

Benton S, Hu Y, Xie F, Kupfer K, Lee SW, Magee L, et al. Placental growth factor quantified on rapid assay as a diagnostic test for early-onset pre-eclampsia. Placenta 2011;32(9):A84.

\section{Benton 2012 \{published data only\}}

Benton S, Knudsen U, Hu Y, Vittinghus E, Allen J, Konborg C, et al. Angiogenic factor imbalance is not specific to the maternal syndrome of pre-eclampsia. Reproductive Sciences 2012;1:317A-8A.

\section{Benton 2012a \{published data only\}}

Benton SJ, Hu X, Xie F, Kupfer K, Lee SW, Magee LA, et al. Can placental growth factor in maternal circulation identify fetuses with placental intrauterine growth restriction?. American Journal of Obstetrics and Gynecology 2012;206(2):163.

\section{Benton 2014 \{published data only\}}

Benton S, Hu Y, Magee L, Von Dadelszen P. Angiogenic factors and the prediction of complications in a high-risk pregnancy cohort. Reproductive Sciences 2014;1:186A-187A.

\section{Benton 2014a \{published data only\}}

Benton S, Yockell-Lelievre J, Grynspan D, Magee L, Hu Y, Gruslin A, et al. Low maternal placental growth factor is associated with abnormal placental morphology in fetuses with suspected intrauterine growth restriction. Placenta 2014;35(9):A44

\section{Benz 1980 \{published data only\}}

Benz J, Ingold W, Landolt A, Keller PJ. [Hormonal diagnosis in fetal intrauterine retardation]. Gynakologische Rundschau 1980;20 Suppl 1:74-6.

\section{Berendtsen 1985 \{published data only\}}

Berendtsen $\mathrm{H}$, Klunder KB, Norskov O. Biparietal measurements, human placental-lactogenic hormone and oestriol in assessment of foetal condition. Ugeskrift for Laeger 1985; Vol. 147, issue 38:2984-6.

\section{Bergsjo 1973 \{published data only\}}

Bergsjo P, Bakke T, Salamonsen LA, Stoa KF, Thorsen T. Urinary oestriol in pregnancy, daily fluctuation, and correlation with fetal growth. Journal of Obstetrics \& Gynaecology of the British Commonwealth 1973;80:305-10.

Berle 1973 \{published data only\}

Berle P. [Value of hormone analysis for the assessment of placenta function in late pregnancy]. Deutsche Medizinische Wochenschrift 1973;98:2146-50

\section{Berle 1973a \{published data only\}}

Berle P. Maternal serum levels of human placental lactogen in placental insufficiency. Geburtshilfe und Frauenheilkunde 1973; Vol. 33, issue 6:455-9.

\section{Berle 1973b \{published data only\}}

Berle P, van Leyen H, Rossler H. [Proceedings: Diagnosis of placenta insufficiency by determination of placental lactogen in maternal blood]. Archiv fur Gynakologie 1973;214:213-5.

\section{Berle 1975 \{published data only\}}

Berle P, Haselmayer B, Plambeck H. [Comparative studies on CTG and hormonal parameters in the diagnosis of placenta insufficiency]. Archiv fur Gynakologie 1975;219:426-8.

\section{Bernardes 2013 \{published data only\}}

Bernardes LS, Francisco RP, Dourado RM, Doro GF, Zugaib M. Ultrasound evaluation of the placenta in fetuses of IUGR. Placenta 2013;34:A92.

\section{Bernatavicius 2013 \{published data only\}}

Bernatavicius G, Roberts S, Garrod A, Whitworth MK, Johnstone ED, Gillham JC, et al. A feasibility study for a randomised controlled trial of management of reduced fetal movements after 36 weeks gestation. Archives of Disease in Childhood: Fetal and Neonatal Edition 2013;98:35.

\section{Bersinger 2004 \{published data only\}}

Bersinger NA, Odegard RA. Second- and third-trimester serum levels of placental proteins in preeclampsia and small-forgestational age pregnancies. Acta Obstetricia et Gynecologica Scandinavica 2004;83:37-45.

Biochemical tests of placental function versus ultrasound assessment of fetal size for stillbirth and small-for-gestational-age infants 


\section{Bersinger 2005 \{published data only\}}

Bersinger NA, Odegard RA. Serum levels of macrophage colony stimulating, vascular endothelial, and placenta growth factor in relation to later clinical onset of pre-eclampsia and a smallfor-gestational age birth. American Journal of Reproductive Immunology 2005;54:77-83.

\section{Bhansali 1975 \{published data only\}}

Bhansali KG. Placental function tests by blood analysis. Journal of the National Medical Association 1975;67:137-9.

\section{Bian 1992 \{published data only\}}

Bian XM. [Choice of ultrasound fetal weight estimation formulae]. Chung-Hua i Hsueh Tsa Chih [Chinese Medical Journal] 1992;72:677-9, 703.

\section{Biberoglu 2016 \{published data only\}}

Biberoglu E, Kirbas A, Daglar K, Biberoglu K, Timur H, Demirtas $C$, et al. Serum angiogenic profile in abnormal placentation. Journal of Maternal-Fetal \& Neonatal Medicine 2016;29:3193-7.

\section{Bieglmayer 1981 \{published data only\}}

Bieglmayer C, Spona J. [Monitoring of at-risk pregnancies through E3 and HPL]. Acta Universitatis Palackianae Olomucensis Facultatis Medicae 1981;101:38-42.

\section{Bila 1980 \{published data only\}}

Bila S, Sulovic V, Genbacev O. [Human placental lactogen in the blood in fetal growth retardation]. Srpski Arhiv Za Celokupno Lekarstvo 1980;108:317-24.

\section{Bitzer 1985 \{published data only\}}

Bitzer J, Hendry M, Richter R. [Detection of intrauterine growth retardation within the scope of routine prenatal care]. Geburtshilfe und Frauenheilkunde 1985; Vol. 45, issue 2:79-82.

\section{Blaskova 1977 \{published data only\}}

Blaskova O, Sasko A, Pont'uch A, Chabada J. The value of estriol determination, and cytologic, ultrasound, and amnioscopic investigation in high-risk pregnancy with a view to placental insufficiency (author's transl). [Slovak]. Ceskoslovenska Gynekologie 1977;42:411-4.

\section{Bligh 2015 \{published data only\}}

Bligh L, Al Solai A, Greer RM, Kumar S. Intrapartum fetal compromise is associated with lower maternal placental growth factor (PIGF) levels at term. BJOG: an international journal of obstetrics and gynaecology 2015;122:162-3.

\section{Blitz 2016 \{published data only\}}

Blitz MJ, Rochelson B, Vohra N. Maternal serum analyses as predictors of fetal growth restriction with different degrees of placental vascular dysfunction. Clinics in Laboratory Medicine 2016;36:353-67.

\section{Blumenfeld 2007 \{published data only\}}

Blumenfeld Y, Lee H, Pullen K, Wong A, Pettit K, Taslimi M. Ultrasound accuracy of estimated fetal weight in pregnancies complicated by intra-uterine growth restriction. American Journal of Obstetrics and Gynecology 2007;197:S59.

\section{Bobrow 2002 \{published data only\}}

Bobrow CS, Holmes RP, Muttukrishna S, Mohan A, Groome N, Murphy DJ, et al. Maternal serum activin A, inhibin A, and follistatin in pregnancies with appropriately grown and smallfor-gestational-age fetuses classified by umbilical artery Doppler ultrasound. American Journal of Obstetrics and Gynecology 2002;186:283-7.

Bock 1976 \{published data only\}

Bock JE, Gaede P, Trolle D. Human placental lactogen hormone in serum from pregnant women with rhesus (anti-D) isoimmunization. Acta Obstetricia et Gynecologica Scandinavica - Supplement 1976; Vol. 53:14-9.

Boij 2012 \{published data only\}

Boij R, Svensson J, Nilsson-Ekdahl K, Sandholm K, Lindahl TL, Palonek E, et al. Biomarkers of coagulation, inflammation, and angiogenesis are independently associated with preeclampsia. American Journal of Reproductive Immunology 2012;68:258-70.

Borges 2005 \{published data only\}

Borges MH, Zamudio S, Pullockaran J, Belliappa S, Albieri A, Catalano PM, et al. Fetal circulating growth factors in diabetic and normal pregnancy: relationship to placental and fetal growth. Journal of the Society for Gynecologic Investigation 2005; Vol. 12:299A.

\section{Botasheva 2016 \{published data only\}}

Botasheva TL, Linde VA, Ermolova NV, Palieva NV, Sargsyan OD, Barinova VV. Peculiarities of angiogenic factors and cytokines in the physiological and complicated pregnancy, depending on the sex of the fetus. Journal of Maternal-Fetal and Neonatal Medicine 2016;29:134.

\section{Boucoiran 2012 \{published data only\}}

Boucoiran I, Thissier-Levy S, Wu Y, Wei SQ, Zhong-Cheng L, Delvin $\mathrm{E}$, et al. Risk for preeclampsia and intrauterine growth restriction: Effective value of PIGF, Sflt-1 and Inhibin A in singleton and multiple pregnancies. American Journal of Obstetrics and Gynecology 2012;1:S336-7.

\section{Branconi 1981 \{published data only\}}

Branconi F, Cariati E, Cappelli G, Paladini S, Scarselli G. Plasma hormone assay in pregnancy. International Journal of Biological Research in Pregnancy 1981;2:146-8.

\section{Brush 1970 \{published data only\}}

Brush MG, Maxwell R, Scherer J, Taylor RW, Tye G. Placental failure in the small-for-dates syndrome. Proceedings of the Royal Society of Medicine 1970; Vol. 63:1098-9.

\section{Bukowski 2014 \{published data only\}}

Bukowski R, Hansen NI, Willinger M, Reddy UM, Parker CB, Pinar $\mathrm{H}$, et al. Fetal growth and risk of stillbirth: a populationbased case-control study. PLOS Medicine 2014;11:e1001633.

\section{Butcher 2012 \{published data only\}}

Butcher I, Whatmore A, Bonshek C, Shaikh G, Dunn W, Brown M, et al. Metabolic profiles identify markers of catch-up growth in children born small for gestational age (SGA). Archives of Disease in Childhood 2012;97:A102.

Biochemical tests of placental function versus ultrasound assessment of fetal size for stillbirth and small-for-gestational-age infants 
Buyon 2011 \{published data only\}

Buyon JP, Garabet L, Kim M, Reeves ER, Guerra MM, Lockshin MD, et al. Favorable prognosis in a large, prospective multicenter study of lupus pregnancies. Arthritis and Rheumatism 2011;63(S10):1707.

\section{Cage 2009 \{published data only\}}

Cage CR, Kreither M, Coussons-Read M, Cole S, Brandt C, Lobel M. Pregnancy-related stress influences maternal corticotropin-releasing factor and estriol concentrations affecting birth outcome. Brain, Behavior, and Immunity 2009;23:S29-30.

\section{Calabrese 2012 \{published data only\}}

Calabrese S, Cardellicchio M, Mazzocco M, Taricco E, Martinelli A, Cetin I. Placental growth factor (PLGF) maternal circulating levels in normal pregnancies and in pregnancies at risk of developing placental insufficiency complications. Reproductive Sciences 2012; Vol. 1:211A-2A.

\section{Calderon 2011 \{published data only\}}

Calderon AC, Berezowski AT, Marcolin AC, Martins WP, Duarte G, Cavalli RC. Ultrasonography in pregnant women with antiphospholipid syndrome using salicylic acid and heparin. Archives of Gynecology \& Obstetrics 2011;284:79-84.

\section{Campobasso 1967 \{published data only\}}

Campobasso M, Pontrelli VC, Longo M. [Chorionic gonadotropins as an index of placental function in normal and pathological pregnancy]. Minerva Ginecologica 1967;19:133-8.

\section{Camus-Bablon 1990 \{published data only\}}

Camus-Bablon F, Cohen RM, Berk MA, Perisutti G, Hunter K, Frohman LA. Alterations in circulating human chorionic gonadotropin free alpha-subunit in insulin-dependent diabetic pregnancy: correlation with maternal characteristics. Journal of Clinical Endocrinology \& Metabolism 1990; Vol. 71:46-52.

\section{Carne 1987 \{published data only\}}

Carne RJ, Drew JH. Infant development following the use of intravenous nutrition to women with persistently low urinary oestriol excretion. Australian \& New Zealand Journal of Obstetrics \& Gynaecology 1987;27:30-6.

\section{Castren 1966 \{published data only\}}

Castren O, Rauramo L, Pekkarinen A. Excretion of oestriol and pregnanediol in placental insufficiency. Acta Obstetricia et Gynecologica Scandinavica 1966;45(Suppl 9):66-7.

\section{Cavazza 2015 \{published data only\}}

Cavazza MC, Pinto L, Graca L. Intrauterine growth restrictiona three-year experience at a tertiary care hospital in Portugal. Journal of Perinatal Medicine. Conference: 12th World Congress of Perinatal Medicine 2015;43:639.

\section{Ceccarello 1980 \{published data only\}}

Ceccarello PL, Calcagnile F, Varagnolo C, Castello C, Destro F. [Fetal ultrasonic biometry of the small-for-date fetus]. Minerva Ginecologica 1980;32:107-12.

\section{Cefalo 2005 \{published data only\}}

Cefalo RC. [Commentary on] Value of biochemical markers for outcome in term infants with asphyxia. Obstetrical \& Gynecological Survey 2005;60:293-5.

\section{Cetin 2014 \{published data only\}}

Cetin I, Mazzocco M, Giardini V, Calabrese S, Algeri P, Martinelli A, et al. Placental growth factor for the prediction of fetal outcomes in pregnancies at risk and in IUGR. Journal of Maternal-Fetal and Neonatal Medicine 2014; Vol. 27:135

\section{Cetin 2016 \{published data only\}}

Cetin I, Mazzocco MI, Giardini V, Cardellicchio M, Calabrese S, Algeri P, et al. PIGF in a clinical setting of pregnancies at risk of preeclampsia and/or intrauterine growth restriction. Journal of Maternal-Fetal and Neonatal Medicine 2016;30(2):144-9.

\section{Chaiworapongsa 2008 \{published data only\}}

Chaiworapongsa T, Espinoza J, Gotsch F, Kim YM, Kim GJ, Goncalves LF, et al. The maternal plasma soluble vascular endothelial growth factor receptor-1 concentration is elevated in SGA and the magnitude of the increase relates to Doppler abnormalities in the maternal and fetal circulation. Journal of Maternal-Fetal \& Neonatal Medicine 2008;21:25-40.

\section{Chaiworapongsa 2012 \{published data only\}}

Chaiworapongsa T, Romero R, Korzeniewski SJ, Kusanovic JP, Soto E, Hernandez-Andrade E, et al. Prediction of stillbirth and late-onset preeclampsia. Reproductive Sciences 2012;1:90A-1A.

\section{Chaiworapongsa 2013a \{published data only\}}

Chaiworapongsa T, Whitten AE, Romero R, Korzeniewski SJ, Schwartz A, Chaemsaithong P, et al. Biomarkers identify mothers with small for gestational age fetuses who will develop preeclampsia or require an indicated early preterm delivery. Journal of Perinatal Medicine 2013;41(S1):1.

\section{Chaiworapongsa 2013b \{published data only\}}

Chaiworapongsa T, Whitten AE, Romero R, Korzeniewski SJ, Schwartz A, Cortez J C, et al. Biomarkers in maternal blood predict neonatal morbidity. Journal of Perinatal Medicine 2013;41(S1):1.

\section{Chambers 1989 \{published data only\}}

Chambers SE, Hoskins PR, Haddad NG, Johnstone FD, McDicken WN, Muir BB. A comparison of fetal abdominal circumference measurements and Doppler ultrasound in the prediction of small-for-dates babies and fetal compromise. British Journal of Obstetrics and Gynaecology 1989;96:803-8.

\section{Chang 1993 \{published data only\}}

Chang TC, Robson SC, Spencer JA, Gallivan S. Identification of fetal growth retardation: comparison of Doppler waveform indices and serial ultrasound measurements of abdominal circumference and fetal weight. Obstetrics \& Gynecology 1993;82:230-6.

\section{Chang 1994 \{published data only\}}

Chang TC, Robson SC, Spencer JA, Gallivan S. Prediction of perinatal morbidity at term in small fetuses: comparison of fetal 
growth and Doppler ultrasound. British Journal of Obstetrics and Gynaecology 1994;101:422-7.

\section{Chapman 1978 \{published data only\}}

Chapman MG, Jones WR. Pregnancy-specific beta-1 glycoprotein (SP-1) in normal and abnormal pregnancy. Australian \& New Zealand Journal of Obstetrics \& Gynaecology 1978;18:172-5.

\section{Chapman 1981 \{published data only\}}

Chapman MG, O'Shea RT, Jones WR, Hillier R. Pregnancyspecific beta 1-glycoprotein as a screening test for at-risk pregnancies. American Journal of Obstetrics and Gynecology 1981; Vol. 141:499-502.

\section{Chappell 2002 \{published data only\}}

Chappell LC, Seed PT, Briley A, Kelly FJ, Hunt BJ, CharnockJones DS, et al. A longitudinal study of biochemical variables in women at risk of preeclampsia. American Journal of Obstetrics and Gynecology 2002;187:127-36.

\section{Chard 1982 \{published data only\}}

Chard T. Human placental lactogen in the monitoring of high-risk pregnancy. Ricerca in Clinica e in Laboratorio 1982;12:207-20.

\section{Chauhan 2012 \{published data only\}}

Chauhan S, Tajik P, Boers K, Wyk L, Mol BW, Scherjon S. Differentiating newborns with birth weight $<v s>3$ percentiles for gestational age: Secondary analysis of a randomized clinical trial (DIGITAT). American Journal of Obstetrics and Gynecology 2012; Vol. 1:S177-s178.

\section{Chawengsettakul 2015 \{published data only\}}

Chawengsettakul S, Russameecharoen K, Wanitpongpan P. Fetal cardiac function measured by myocardial performance index of small-for-gestational age fetuses. Journal of Obstetrics and Gynaecology Research 2015;41:222-8.

\section{Chew 2014 \{published data only\}}

Chew C, Crocker I, Kiss O, Allibone A, Tower C, Bruce IN. Placental growth factor is reduced in lupus patients with adverse pregnancy outcomes. Rheumatology 2014;53:i182.

\section{Church 2016 \{published data only\}}

Church E, Bellis A. Impact of education of pregnant women regarding fetal movements and improved detection and assessment of small-for-gestational-age babies over a year in a District General Hospital. BJOG: an international journal of obstetrics and gynaecology 2016;123:88.

\section{Clelia 2013 \{published data only\}}

Cabo Fustaret MC, Escobar A, Illia R, Uranga M, Rivas C, Lobenstein G, et al. NT-Pro-BNP: Correlation with adverse outcome markers in hypertensive gestational syndromes. Pregnancy Hypertension 2013;3(2):84-5.

Clowse 2011 \{published data only\}

Clowse ME, Criscione-Schreiber LG, Pisetsky DS. Predictors of preterm birth and preeclampsia in systemic lupus erythematosus. Arthritis and Rheumatism 2011;63(S1):2278.

\section{Cody 2013 \{published data only\}}

Cody F, Unterscheider J, Daly S, Geary MP, Kennelly MM, McAuliffe FM, et al. Impact of maternal obesity on accuracy of sonographic fetal weight estimation in IUGR. Archives of Disease in Childhood: Fetal and Neonatal Edition 2013;98(S1):A30.

\section{Cody 2016 \{published data only\}}

Cody F, Unterscheider J, Daly S, Geary MP, Kennelly MM, McAuliffe FM, et al. The effect of maternal obesity on sonographic fetal weight estimation and perinatal outcome in pregnancies complicated by fetal growth restriction. Journal of Clinical Ultrasound 2016;44:34-9.

\section{Cooley 2011 \{published data only\}}

Cooley SM, Donnelly JC, Walsh T, McMahon C, Gillan J, Geary MP. The impact of ultrasonographic placental architecture on antenatal course, labor and delivery in a low-risk primigravid population. Journal of Maternal-Fetal \& Neonatal Medicine 2011;24:493-7.

Cordano 1988 \{published data only\}

Cordano MC, Comte E, Bessis R, Papiernik E. Longitudinal follow-up of 100 patients at risk of intrauterine growth retardation: comparison of diagnosis in two periods. Journal of Perinatal Medicine 1988;16:61-6.

\section{Craigo 1996 \{published data only\}}

Craigo SD, Beach ML, Harvey-Wilkes KB, D'Alton ME. Ultrasound predictors of neonatal outcome in intrauterine growth restriction. American Journal of Perinatology 1996; Vol. 13, issue 8:465-71.

\section{Crane 1979 \{published data only\}}

Crane JP, Kopta MM. Prediction of intrauterine growth retardation via ultrasonically measured head/abdominal circumference ratios. Obstetrics \& Gynecology 1979;54:597-601.

Crawford 1985 \{published data only\} Crawford DC, Fenton DW, Price WI. Ultrasonic tissue characterization of the placenta: Is it of clinical value?. Journal of Clinical Ultrasound 1985;13:533-7.

D'Anna 2000 \{published data only\}

D'Anna R, Baviera G, Scilipoti A, Leonardi I, Leo R. The clinical utility of serum uric acid measurements in pre-eclampsia and transient hypertension in pregnancy. Panminerva Medica 2000;42:101-3.

\section{Daikoku 1979 \{published data only\}}

Daikoku NH, Tyson JE, Graf C, Scott R, Smith B, Johnson JW, et al. The relative significance of human placental lactogen in the diagnosis of retarded fetal growth. American Journal of Obstetrics \& Gynecology 1979; Vol. 135, issue 4:516-21.

\section{Darling 2014 \{published data only\}}

Darling AM, McDonald CR, Conroy AL, Hayford KT, Liles WC, Wang $M$, et al. Angiogenic and inflammatory biomarkers in midpregnancy and small-for-gestational-age outcomes in Tanzania. American Journal of Obstetrics and Gynecology 2014;211:509.e1-8.

Biochemical tests of placental function versus ultrasound assessment of fetal size for stillbirth and small-for-gestational-age infants 


\section{Dave 2016 \{published data only\}}

Dave A, Maru L, Jain A. LDH (lactate dehydrogenase): a biochemical marker for the prediction of adverse outcomes in pre-eclampsia and eclampsia. Journal of Obstetrics \& Gynaecology of India 2016;66:23-9.

Dawood 1976 \{published data only\} Dawood MY. Circulating maternal serum progesterone in highrisk pregnancies. American Journal of Obstetrics and Gynecology 1976;125:832-40.

\section{Del Moral 2015 \{published data only\}}

Del Moral R, Gozalo M, Spies K, Joigneau L, Martinez R. Diagnosis and follow-up of in patients diagnosed with intrauterine growth restriction in our center. Journal of Perinatal Medicine. Conference: 12th World Congress of Perinatal Medicine 2015;43:1.

\section{De Marchi 1977 \{published data only\}}

De Marchi C, Santi F, Zauli F, Roberti L, Perolo F. [Fetal growth studied by echographic evaluation and by placental lactogen and estradiol levels]. Rivista Italiana di Ginecologia 1977:58:287-93.

\section{Deter 2016 \{published data only\}}

Deter RL, Levytska K, Melamed N, Lee W, Kingdom JC. Classifying neonatal growth outcomes: use of birth weight, placental evaluation and individualized growth assessment. Journal of Maternal-Fetal \& Neonatal Medicine 2016;29:3939-49.

\section{Di Lorenzo 2013 \{published data only\}}

Di Lorenzo G, Monasta L, Ceccarello M, Cecotti V, D'Ottavio G. Third trimester abdominal circumference, estimated fetal weight and uterine artery doppler for the identification of newborns small and large for gestational age. European Journal of Obstetrics, Gynecology, \& Reproductive Biology 2013;166:133-8.

\section{Dombrowski 1992 \{published data only\}}

Dombrowski MP, Saleh AA, Berry SM, Cotton DB. Perinatal outcome with sonographically thin placentas. Journal of Maternal-Fetal Medicine 1992;1:137-9.

\section{Dombrowski 1992a \{published data only\}}

Dombrowski MP, Wolfe HM, Saleh A, Evans MI, O'Brien J. The sonographically thick placenta: a predictor of increased perinatal morbidity and mortality. Ultrasound in Obstetrics \& Gynecology 1992;2:252-5.

\section{Ducarme 2012 \{published data only\}}

Ducarme G, Seguro E, Chesnoy V, Davitian C, Luton D. [Estimation of fetal weight by external abdominal measurements and fundal height measurement near term for the detection of intra-uterine growth retardation]. Gynecologie, Obstetrique \& Fertilite 2012;40:642-6.

\section{Duff 1986 \{published data only\}}

Duff GB. The realities of screening for the small for dates fetus using ultrasound measurement. Australian \& New Zealand Journal of Obstetrics \& Gynaecology 1986;26:102-5.

\section{Dutton 2012 \{published data only\}}

Dutton P, Warrander L, Bernatavicius G, Kroll J, Gaze D, Jones R, et al. Placentally-derived factors in women with reduced fetal movements and their relationship to pregnancy outcome. BJOG: an international journal of obstetrics and gynaecology 2012;119(6):e3.

Dutton 2012a \{published data only\}

Dutton PJ, Warrander LK, Roberts SA, Bernatavicius G, Byrd LM, Gaze D, et al. Predictors of poor perinatal outcome following maternal perception of reduced fetal movements - a prospective cohort study. PLOS One 2012;7:7.

Eik-Nes 1984 \{published data only\}

Eik-Nes SH, Okland O, Aure JC, Ulstein M. Ultrasound screening in pregnancy: a randomised controlled trial. Lancet 1984; Vol. $1: 1347$.

\section{El-Ahmady 1997 \{published data only\}}

El-Ahmady O, Halim AB, Saleh AA, Ismail MT, Amin AF. Serum alpha-fetoprotein (AFP) and beta-human chorionic gonadotropin (beta-hCG) in normal and high risk pregnancy. Clinical Chemistry and Enzymology Communications 1997;7:341-7.

\section{Elchalal 2000 \{published data only\}}

Elchalal U, Ezra Y, Levi Y, Bar-Oz B, Yanai N, Intrator O, et al. Sonographically thick placenta: a marker for increased perinatal risk--a prospective cross-sectional study. Placento 2000;21:268-72.

\section{Ernst 2016 \{published data only\}}

Ernst SA, Brand T, Zeeb H. Antenatal detection of intrauterine growth restriction: A case-control study. European Journal of Epidemiology 2016;31:S50-1.

Fadigas 2015 \{published data only\}

Fadigas C, Peeva G, Mendez O, Poon L C, Nicolaides KH. Prediction of small-for-gestational-age neonates: screening by placental growth factor and soluble fms-like tyrosine kinase-1 at 35-37 weeks. Ultrasound in Obstetrics \& Gynecology 2015;46:191-7.

\section{Falkner 1995 \{published data only\}}

Falkner F. Ultrasonography and fetal growth: key perinatal factors. Journal of Perinatology 1995;15:114-8.

\section{Ferrazzi 1986 \{published data only\}}

Ferrazzi E, Nicolini U, Kustermann A, Pardi G. Routine obstetric ultrasound: effectiveness of cross-sectional screening for fetal growth retardation. Journal of Clinical Ultrasound 1986;14:17-22

\section{Fioretti 1986 \{published data only\}}

Fioretti P, Melis GB, Paoletti AM. Ultrasound and human placental lactogen in the diagnosis of intrauterine growth retardation. New Trends in Gynaecology and Obstetrics 1986;2:59-64.

Biochemical tests of placental function versus ultrasound assessment of fetal size for stillbirth and small-for-gestational-age infants 
Fischer-Rasmussen 1971 \{published data only\}

Fischer-Rasmussen W. Plasma oestrogens and the fetal outcome. Acta Obstetricia et Gynecologica Scandinavica 1971; Vol. 50, issue 4:301-9.

\section{Fisteag-Kiprono 2006 \{published data only\}}

Fisteag-Kiprono L, Neiger R, Sonek JD, Croom CS, McKenna DS, Ventolini G. Perinatal outcome associated with sonographically detected globular placenta. Journal of Reproductive Medicine 2006;51:563-6.

\section{Forger 2016 \{published data only\}}

Forger F, Baumann M, Risch L, Raio L, Surbek D, Wiedemann U, et al. Angiogenic placental factors during pregnancy in rheumatoid arthritis. Annals of the Rheumatic Diseases 2016;75:474

\section{Fotiou 2015 \{published data only\}}

Fotiou M, Michaelidou AM, Athanasiadis AP, Menexes G Symeonidou M Koulourida V, et al. Second trimester amniotic fluid glucose, uric acid, phosphate, potassium, and sodium concentrations in relation to maternal pre-pregnancy BMI and birth weight centiles. Journal of Maternal-Fetal \& Neonatal Medicine 2015;28:910-5.

\section{Furuhashi 1984 \{published data only\}}

Furuhashi N, Tachibana Y, Shinkawa O, Hiruta M, Takahashi T, Tanaka M. Simultaneous and serial measurement of serum levels of human placental lactogen, beta-human chorionic gonadotropin and unconjugated estriol levels in pregnant women. Tohoku Journal of Experimental Medicine 1984;144:211-5.

\section{Gabbay-Benziv 2016a \{published data only\}}

Gabbay-Benziv R, Aviram A, Ashwal E, Hiersch L, Melamed N, Hadar E, et al. Sonographic prediction of small for gestational age-which formula is more accurate?. American Journal of Obstetrics and Gynecology 2016;1:S356.

\section{Gabbay-Benziv 2017 \{published data only\}}

Gabbay-Benziv R, Aviram A, Hadar E, Chen R, Bardin R, Wiznitzer A, et al. Pregnancy outcome after false diagnosis of fetal growth restriction. Journal of Maternal-Fetal and Neonatal Medicine 2017;30(16):1916-9.

\section{Gaillard 2014 \{published data only\}}

Gaillard R, Steegers EA, de Jongste JC, Hofman A, Jaddoe VW. Tracking of fetal growth characteristics during different trimesters and the risks of adverse birth outcomes. International Journal of Epidemiology 2014;43:1140-53.

\section{Gao 2008 \{published data only\}}

Gao T, Zablith NR, Burns DH, Skinner CD, Koski KG. Second trimester amniotic fluid transferrin and uric acid predict infant birth outcomes. Prenatal Diagnosis 2008;28:810-4.

\section{Garcia-Flores 2015 \{published data only\}}

Garcia-Flores J, Cruceyra M, Canamares M, Garicano A, Nieto O, Lopez A, et al. Fetal limb soft tissue assessment for prediction of birth weight and umbilical cord blood analytes in gestational diabetes. Prenatal Diagnosis 2015;35:1187-96.

\section{Garoff 1976 \{published data only\}}

Garoff L. Prediction of fetal outcome by urinary estriol, maternal serum placental lactogen, and alpha-fetoprotein in diabetes and hepatosis of pregnancy. Obstetrics \& Gynecology 1976;48:659-66.

\section{Gaziano 1988 \{published data only\}}

Gaziano E, Knox GE, Wager GP, Bendel RP, Boyce DJ, Olson J. The predictability of the small-for-gestational-age infant by real-time ultrasound-derived measurements combined with pulsed Doppler umbilical artery velocimetry. American Journal of Obstetrics and Gynecology 1988; Vol. 158, issue 6:1431-9.

\section{Geerts 2007 \{published data only\}}

Geerts L, Odendaal HJ. Severe early onset pre-eclampsia: prognostic value of ultrasound and Doppler assessment. Journal of Perinatology 2007;27:335-42.

\section{Gerhard 1987 \{published data only\}}

Gerhard I, Vollmar B, Runnebaum B, Klinga K, Haller U, Kubli F. Weight percentile at birth. II. Prediction by endocrinological and sonographic measurements. European Journal of Obstetrics, Gynecology, \& Reproductive Biology 1987;26:313-28.

\section{Gernand 2015 \{published data only\}}

Gernand AD, Schulze KJ, Nanayakkara-Bind A, Arguello M, Shamim AA, Ali $\mathrm{H}$, et al. Effects of prenatal multiple micronutrient supplementation on fetal growth factors: a cluster-randomized, controlled trial in rural Bangladesh. PLOS One 2015;10(10):e0137269.

\section{Gherzi 1981 \{published data only\}}

Gherzi R, Pastore M, Labate D. [Monitoring of HPL, estriol and estetrol in high-risk pregnancy]. Minerva Ginecologica 1981;33:911-6.

\section{Giambanco 1986 \{published data only\}}

Giambanco V, Germana CF, Esposito S. Ultrasonographic assessment of fetal growth retardation. [Italian]. Ultrasuoni in Ostetricia e Ginecologia 1986;4:284-8.

\section{Giardini 2014 \{published data only\}}

Giardini V, Algeri P, Todyrenchuk L, Pellizzoni F, Callegari C, D'Arcangelo $F$, et al. A longitudinal study of serum placental growth factor levels in normal pregnancy and women at high risk for preeclampsia and/or intrauterine growth restriction. Reproductive Sciences 2014;1:191A-2A.

\section{Gloning 1991 \{published data only\}}

Gloning KP, Papaioannou A, Kuss E. The validity of CTG and estriol as predictors of intrauterine death. [German]. Archives of Gynecology and Obstetrics 1991;250:1184-5.

\section{Goetzinger 2013 \{published data only\}}

Goetzinger KR, Tuuli MG, Odibo AO, Roehl KA, Macones GA, Cahill AG. Screening for fetal growth disorders by clinical exam in the era of obesity. Journal of Perinatology 2013;33:352-7.

\section{Goldenberg 1993 \{published data only\}}

Goldenberg RL, Davis RO, Cliver CP, Cutter GR, Hoffman HJ, Dubard MB, et al. Maternal risk factors and their influence

Biochemical tests of placental function versus ultrasound assessment of fetal size for stillbirth and small-for-gestational-age infants 
on fetal anthropometric measurements. American Journal of Obstetrics and Gynecology 1993;168:1197-205.

\section{Goldenberg 1997 \{published data only\}}

Goldenberg RL, Cliver SP, Neggers Y, Copper RL, DuBard MD, Davis RO, et al. The relationship between maternal characteristics and fetal and neonatal anthropometric measurements in women delivering at term: a summary. Acta Obstetricia et Gynecologica Scandinavica. Supplement 1997;165:8-13.

\section{Gomez-Roig 2015 \{published data only\}}

Gomez-Roig MD, Mazarico E, Sabria J, Parra J, Oton L, Vela A. Use of placental growth factor and uterine artery doppler pulsatility index in pregnancies involving intrauterine fetal growth restriction or preeclampsia to predict perinatal outcomes. Gynecologic and Obstetric Investigation 2015;80:99-105.

\section{Gordon 1978 \{published data only\}}

Gordon YB, Lewis JD, Pendlebury DJ. Is measurement of placental function and maternal weight worth while?. Lancet 1978;1:1001-3.

\section{Grantz 2016 \{published data only\}}

Grantz K, Kim S, Grobman W, Newman R, Owen J, Skupski D, et al. Does the addition of fetal growth velocity improve the precision of sonographic birthweight estimation?. American Journal of Obstetrics and Gynecology 2016;1:S78.

\section{Gravett 2015 \{published data only\}}

Gravett M. Maternal serum biomarkers for assessment of preeclampsia: Glycosylated fibronectin as a point-of-care biomarker. Journal of Perinatal Medicine. Conference: 12th World Congress of Perinatal Medicine 2015;43(S1):73.

\section{Griffin 2014 \{published data only\}}

Griffin M, Duckworth S, Webster L, Seed P, Chappell L, Shennan A. Comparison of PIGF and other biomarkers against current ultrasound parameters for predicting delivery of small for gestational age (SGA) infants in women with suspected preeclampsia: the PELICAN study. BJOG: an international journal of obstetrics and gynaecology 2014;121(7):e6.

\section{Gris 2015 \{published data only\}}

Gris JC, Bouvier S, Lavigne G, Nouvellon E, Mercier E, Galanaud JP, et al. Obstetric antiphospholipid syndrome: Early Imwh induced variations of angiogenic factors predict pregnancy loss. Journal of Thrombosis and Haemostasis 2015;13:167.

\section{Habib 2002 \{published data only\}}

Habib FA. Prediction of low birth weight infants from ultrasound measurement of placental diameter and placental thickness. Annals of Saudi Medicine 2002;22:312-4.

\section{Hargreaves 2011 \{published data only\}}

Hargreaves K, Cameron M, Edwards H, Gray R, Deane K. Is the use of symphysis-fundal height measurement and ultrasound examination effective in detecting small or large fetuses?. Journal of Obstetrics \& Gynaecology 2011;31:380-3.

\section{Harper 2014 \{published data only\}}

Harper LM, Jauk VC, Owen J, Biggio RR. The utility of ultrasound surveillance of fluid and growth in obese women. American Journal of Obstetrics and Gynecology 2014;211:524.e1-8.

\section{Hassan 1987 \{published data only\}}

Hassan MM, Bottoms SF, Mariona FG, Syner FN, Simkowski KM, Sokol RJ. The use of clinical, biochemical, and ultrasound parameters for the diagnosis of intrauterine growth retardation. American Journal of Perinatology 1987;4:191-4.

\section{Hawkins 2014 \{published data only\}}

Hawkins LK, Schnettler WT, Modest AM, Hacker MR, Rodriguez D. Association of third-trimester abdominal circumference with provider-initiated preterm delivery. Journal of Maternal-Fetal \& Neonatal Medicine 2014;27:1228-31.

Heazell 2014 \{published data only\}

Heazell A. A kick in the right direction-reduced fetal movements and stillbirth prevention. BMC Pregnancy and Childbirth 2014;15(Supp 1):A7.

\section{Henrichs 2016 \{published data only\}}

Henrichs J, Verfaille V, Viester L, Westerneng M, Molewijk B, Franx $A$, et al. Effectiveness and cost-effectiveness of routine third trimester ultrasound screening for intrauterine growth restriction: study protocol of a nationwide stepped wedge cluster-randomized trial in The Netherlands (The IRIS Study). BMC Pregnancy \& Childbirth 2016;16(1):310.

\section{Hensleigh 1977 \{published data only\}}

Hensleigh PA, Cheatum SG, Spellacy N. Oxytocinase and human placental lactogen for the prediction of intrauterine growth retardation. American Journal of Obstetrics and Gynecology 1977; Vol. 129:675-8.

\section{Herraiz 2014 \{published data only\}}

Herraiz I, Droge LA, Gomez-Montes E, Henrich W, Galindo A, Verlohren S. Characterization of the soluble fms-like tyrosine kinase-1 to placental growth factor ratio in pregnancies complicated by fetal growth restriction. Obstetrics \& Gynecology 2014;124:265-73.

\section{Hinkle 2015 \{published data only\}}

Hinkle SN, Johns AM, Albert PS, Kim S, Grantz KL. Longitudinal changes in gestational weight gain and the association with intrauterine fetal growth. European Journal of Obstetrics Gynecology and Reproductive Biology 2015;190:41-7.

\section{Hughes 1980 \{published data only\}}

Hughes G, Bischof P, Wilson G, Smith R, Klopper A. Tests of fetal wellbeing in the third trimester of pregnancy. British Journal of Obstetrics and Gynaecology 1980;87:650-6.

\section{Husse 2014 \{published data only\}}

Husse S, Gottschlich A, Schrey S, Stepan H, Hoffmann J. [Predictive value of the sFlt1/PIGF ratio for the diagnosis of preeclampsia in high-risk patients]. Zeitschrift fur Geburtshilfe und Neonatologie 2014;218:34-41.

Biochemical tests of placental function versus ultrasound assessment of fetal size for stillbirth and small-for-gestational-age infants 
Jabeen 1999 \{published data only\}

Jabeen S, Sabrina, Ahmad S. Screening for intra-uterine growth retardation. Journal of the College of Physicians and Surgeons Pakistan 1999;9:17-9.

\section{James-Todd 2015 \{published data only\}}

James-Todd T, Cohen A, Wenger J, Brown FM. Placental-like growth factor (PIGF) and infant birth weight in women with preexisting diabetes. Diabetes 2015;64:A378.

\section{Johnson 2011 \{published data only\}}

Johnson RJ, Kanbay M, Kang DH, Sanchez-Lozada LG, Feig D. Uric acid: A clinically useful marker to distinguish preeclampsia from gestational hypertension. Hypertension 2011;58:548-9.

\section{Johnstone 2015 \{published data only\}}

Johnstone ED, Higgins L, Myers J, Simcos L, Heazell A. Exclusion of early onset fetal growth restriction using a combination placental and uterine artery doppler screening. Reproductive Sciences 2015;22:383A-4A.

\section{Karjalainen 1975 \{published data only\}}

Karjalainen O, Stenman U, Widholm O. Urinary oestriol and serum activities of human placental lactogen and heat stable alkaline phosphatase as indicators of fetoplacental function. Annales Chirurgiae et Gynaecologiae Fenniae 1975;64:50-4.

\section{Karlsen 2016 \{published data only\}}

Karlsen HO, Johnsen SL, Rasmussen S, Kiserud T. Prediction of adverse perinatal outcome of small-for-gestational-age pregnancy using size centiles and conditional growth centiles. Ultrasound in Obstetrics \& Gynecology 2016;48:217-23.

Kase 2012 \{published data only\}

Kase B, Blackwell SC. Ultrasound derived estimated fetal weight using customized standards: Does it improve prediction of adverse pregnancy outcomes?. American Journal of Obstetrics and Gynecology 2012;1:S158.

\section{Kase 2012a \{published data only\}}

Kase BA, Carreno CA, Blackwell SC. Customized estimated fetal weight: a novel antenatal tool to diagnose abnormal fetal growth. American Journal of Obstetrics and Gynecology 2012;207:218.e1-5.

\section{Kazzi 1983 \{published data only\}}

Kazzi GM, Gross TL, Sokol RJ. Fetal biparietal diameter an placental grade: predictors of intrauterine growth retardation. Obstetrics \& Gynecology 1983;62:755-9.

\section{Khalil 2015 \{published data only\}}

Khalil AA, Morales-Rosello J, Elsaddig M, Khan N, Papageorghiou A, Bhide A, et al. The association between fetal Doppler and admission to neonatal unit at term. American Journal of Obstetrics and Gynecology 2015;213:57.e1-7.

\section{Khalil 2016 \{published data only\}}

Khalil A, Morales-Rosello J, Townsend R, Morlando M, Papageorghiou A, Bhide A, et al. Value of third-trimester cerebroplacental ratio and uterine artery Doppler indices as predictors of stillbirth and perinatal loss. [Erratum appears in Ultrasound Obstet Gynecol. 2016 Apr;47(4):526; PMID: 27062979]. Ultrasound in Obstetrics \& Gynecology 2016;47:74-80.

Kihaile 1988 \{published data only\}

Kihaile PE. Ultrasonic grey-level histograms of prenatal placenta and its relation to fetal well-being. Yonago Acta Medica 1988;31:139-46.

Kim 2009 \{published data only\}

Kim YN, Lee DS, Jeong DH, Sung MS, Kim KT. The relationship of the level of circulating antiangiogenic factors to the clinical manifestations of preeclampsia. Prenatal Diagnosis 2009;29(5):464-70.

\section{Kim 2014 \{published data only\}}

Kim JW, Kim YH, Song TB. The usefulness of gestation corrected hyperuricemia as predictors of the recurrence of preeclampsia and obstetric outcomes on subsequent pregnancy. Journal of Maternal-Fetal and Neonatal Medicine 2014;27:355-6.

Kim 2016 \{published data only\}

Kim MY, Buyon JP, Guerra MM, Rana S, Zhang D, Laskin CA, et al. Angiogenic factor imbalance early in pregnancy predicts adverse outcomes in patients with lupus and antiphospholipid antibodies: results of the PROMISSE study. American Journal of Obstetrics and Gynecology 2016;214:108.e1-108.e14.

Kjos 2015 \{published data only\}

Kjos K, Ghashghaei R, Klisser K, Woelkers D. Prediction of adverse outcomes with mid-pregnancy serum placental growth factor levels and uterine artery Dopplers in high risk pregnancies. Pregnancy Hypertension 2015;5(1):80.

\section{Kneitel 2016 \{published data only\}}

Kneitel AW, Treadwell MC, O'Brien LM. Effects of maternal sleep apnea on fetal growth. American Journal of Obstetrics and Gynecology 2016;1:S250.

\section{Kolovetsiou-Kreiner 2014 \{published data only\}}

Kolovetsiou-Kreiner V, Stern EC, Mayer-Pickel K, Lakovschek I, Ulrich $\mathrm{D}$, Lang $\mathrm{U}$, et al. Predictive value of gestational angiogenic biomarkers SFLT-1 and PIGF in high-risk women. Reproductive Sciences 2014;1:300A.

\section{Kolovetsiou-Kreiner 2015 \{published data only\}}

Kolovetsiou-Kreiner V, Stern EC, Mayer-Pickel K, Lakovschek I, Lang U, Cervar-Zivkovic M. Repeated controls of gestational angiogenic biomarkers in high-risk pregnancies-do they derive a clinical benefit?. Journal of Perinatal Medicine. Conference: 12th World Congress of Perinatal Medicine 2015;43:300A

Krochik 2010 \{published data only\}

Krochik AG, Chaler EA, Maceiras M, Aspres N, Mazza CS. Presence of early risk markers of metabolic syndrome in prepubertal children with a history of intrauterine growth restriction. [Spanish]. Archivos Argentinos de Pediatria 2010;108:10-6.

Biochemical tests of placental function versus ultrasound assessment of fetal size for stillbirth and small-for-gestational-age infants 
Kulkarni 1981 \{published data only\}

Kulkarni BD, O'Leary JA, Takagi RL, Avila TD, Jabamoni R. Plasma estrogens in the assessment of fetoplacental function. Clinical Biochemistry 1981;14:108-12.

\section{Kulkarni 2010 \{published data only\}}

Kulkarni AV, Mehendale SS, Yadav HR, Kilari AS, Taralekar VS, Joshi SR. Circulating angiogenic factors and their association with birth outcomes in preeclampsia. Hypertension Research Clinical \& Experimental 2010;33:561-7.

\section{Kullander 1982 \{published data only\}}

Kullander S, Marsal K, Persson PH. Human placental lactogen and ultrasonic screening for the detection of placental insufficiency. Contributions to Gynecology \& Obstetrics 1982;9:129-44.

\section{Kundu 1978 \{published data only\}}

Kundu N, Carmody PJ, Didolkar SM, Petersen LP. Sequential determination of serum human placental lactogen, estriol, and estetrol for assessment of fetal morbidity. Obstetrics \& Gynecology 1978;52:513-20.

\section{Kunzig 1975 \{published data only\}}

Kunzig HJ, Geiger W, Schlensker KH. [Serum estriol and HPL concentration as well as echographic maturity diagnosis as parameters of placental function]. Archiv fur Gynakologie 1975;219:443-5.

\section{Kunzig 1980 \{published data only\}}

Kunzig HJ. [Diagnosis and monitoring of risk pregnancies. Serum estrone, estradiol-17 beta and estradiol determination in normal and risk pregnancies. Methods and results of radioimmunologic studies]. Fortschritte der Medizin 1980;98:626-31.

\section{Lai 2014 \{published data only\}}

Lai J, Garcia-Tizon Larroca S, Peeva G, Poon LC, Wright D, Nicolaides KH. Competing risks model in screening for preeclampsia by serum placental growth factor and soluble fms-like tyrosine kinase-1 at 30-33 weeks' gestation. Fetal Diagnosis and Therapy 2014;35(4):240-8.

\section{Larkin 2015 \{published data only\}}

Larkin J, Chauhan S, Simhan H. Small for gestational age: The differential mortality when detected versus undetected antenatally. American Journal of Obstetrics and Gynecology 2015;1:S44.

\section{Larsen 1992 \{published data only\}}

Larsen T, Larsen JF, Petersen S, Greisen G. Detection of smallfor-gestational-age fetuses by ultrasound screening in a high risk population: a randomized controlled study. British Journal of Obstetrics and Gynaecology 1992;99:469-74.

\section{Larsen 1997 \{published data only\}}

Larsen T, Greisen G, Petersen S. Intrauterine growth correlation to postnatal growth--influence of risk factors and complications in pregnancy. Early Human Development 1997;47:157-65.

\section{Laurin 1987a \{published data only\}}

Laurin J, Persson PH, Fernlund P. The efficacy of biochemical assays in assessing an IUGR risk-group, preselected with ultrasound fetometry. European Journal of Obstetrics, Gynecology, \& Reproductive Biology 1987;24:177-87.

\section{Lean 2016 \{published data only\}}

Lean S, Heazell A, Peacock L, Lodge K, Roberts S, Jones R. Manchester Advanced Maternal Age Study (MAMAS): A prospective observational cohort study to identify risk factors and markers of adverse pregnancy outcome. BJOG: an international journal of obstetrics and gynaecology 2016;123:41.

\section{Leanos-Miranda 2013 \{published data only\}}

Leanos-Miranda A, Campos-Galicia I, Ramirez-Valenzuela KL, Chinolla-Arellano ZL, Isordia-Salas I. Circulating angiogenic factors and urinary prolactin as predictors of adverse outcomes in women with preeclampsia. Hypertension 2013;61:1118-25.

\section{Lechner 1987 \{published data only\}}

Lechner W, Heim K, Zech J, Daxenbichler G, Marth C. The relation between saliva estriol levels in pregnancy and infant birth weight. Archives of Gynecology and Obstetrics 1987;241:9-12.

\section{Levine 2005 \{published data only\}}

Levine RJ, Thadhani R, Oian C, Lam C, Lim KH, Yu KF, et al. Urinary placental growth factor and risk of preeclampsia. JAMA 2005;293:77-85.

\section{Li 2014 \{published data only\}}

Li SW, Ling Y, Jin S, Lin YF, Chen ZJ, Hu CX, et al. Expression of soluble vascular endothelial growth factor receptor-1 and placental growth factor in fetal growth restriction cases and intervention effect of tetramethylpyrazine. Asian Pacific Journal of Tropical Medicine 2014;7:663-7.

\section{Little 2016 \{published data only\}}

Little J, Chew C, Kither H, Kiss O, Allibone A, Bruce IN, et al. Circulating placental growth factor, measured at 28 weeks of gestation, may hold limited prognostic value in predicting poor pregnancy outcome in patients with systemic lupus erythematosus. BJOG: an international journal of obstetrics and gynaecology 2016;123:51-2.

\section{Lobmaier 2014 \{published data only\}}

Lobmaier SM, Figueras F, Mercade I, Perello M, Peguero A, Crovetto F, et al. Angiogenic factors vs Doppler surveillance in the prediction of adverse outcome among late-pregnancy small-for- gestational-age fetuses. Ultrasound in Obstetrics \& Gynecology 2014;43:533-40.

\section{London 1983 \{published data only\}}

London R, Vallejos J, Baer D. Serum unconjugated estriol concentrations before and after the oxytocin challenge test: An index of fetal well-being. American Journal of Obstetrics and Gynecology 1983;146:630-2.

\section{MacDonald 1983 \{published data only\}}

MacDonald DJ, Scott JM, Gemmell RS, Mack DS. A prospective study of three biochemical fetoplacental tests: serum human

Biochemical tests of placental function versus ultrasound assessment of fetal size for stillbirth and small-for-gestational-age infants 
placental lactogen, pregnancy-specific beta 1-glycoprotein, and urinary estrogens, and their relationship to placental insufficiency. American Journal of Obstetrics and Gynecology 1983;147:430-6.

\section{Macmillian 1976 \{published data only\}}

Macmillian DR, Hawkins R, Collier RN. Chorionic somatomammotrophin as index of fetal growth. Archives of Disease in Childhood 1976;51(2):120-3.

Maly 1987 \{published data only\}

Maly Z, Cupr Z, Kadrnkova M. [Evaluation of fetal hypotrophy by examining placental structure using ultrasonography and urinary estriol levels]. Ceskoslovenska Gynekologie 1987;52:179-82.

\section{March 2015 \{published data only\}}

March M I, Geahchan C, Wenger J, Raghuraman N, Berg A, Haddow $\mathrm{H}$, et al. Circulating angiogenic factors and the risk of adverse outcomes among Haitian women with preeclampsia. PLOS One 2015;10(5):e0126815.

\section{Margossian 2016 \{published data only\}}

Margossian A, Boisson-Gaudin C, Subtil F, Rudigoz RC, Dubernard G, Allias F, et al. [Intra-uterine growth restriction impact on maternal serum concentration of PIGF (placental growth factor): A case control study]. Gynecologie, Obstetrique \& Fertilite 2016;44:23-8.

\section{Markestad 1997 \{published data only\}}

Markestad T. Prediction of fetal growth based on maternal serum concentrations of human chorionic gonadotropin, human placental lactogen and estriol. Acta Obstetricia et Gynecologica Scandinavica, Supplement 1997;76:50-5.

\section{Martins 2005 \{published data only\}}

Martins MM, Tedesco JJ. Early diagnosis of intra-uterine growth restriction by ultrasonographic estimation of fetal weight. Revista Da Associacao Medica Brasileira 2005; Vol. 51, issue $1: 41-5$.

\section{Masoura 2014 \{published data only\}}

Masoura S, Kalogiannidis I, Makedou K, Theodoridis T, Koiou K, Gerou S, et al. Biomarkers of endothelial dysfunction in preeclampsia and neonatal morbidity: a case-control study. [Erratum appears in Eur J Obstet Gynecol Reprod Biol. 2014 Sep;180:209]. European Journal of Obstetrics, Gynecology, \& Reproductive Biology 2014;175:119-23.

\section{Matthews 2017 \{published data only\}}

Matthews KC, Williamson J, Gupta S, Lam-Rachlin J, Saltzman DH, Rebarber A, et al. The effect of a sonographic estimated fetal weight on the risk of cesarean delivery in macrosomic and small for gestational-age infants. Journal of Maternal-Fetal and Neonatal Medicine 2017;30(10):1172-6.

\section{Mazzocco 2014 \{published data only\}}

Mazzocco MI, Calabrese S, Cardellicchio M, Martinelli A, Cetin I. Could PLGF be a useful marker to predict fetal outcomes in pregnancies at risk?. Reproductive Sciences 2014;1:304A-5A.

\section{McKenna 2003 \{published data only\}}

McKenna D, Tharmaratnam S, Mahsud S, Bailie C, Harper A, Dornan J. A randomized trial using ultrasound to identify the high-risk fetus in a low-risk population. Obstetrics \& Gynecology 2003;101:626-32.

\section{Melamed 2015 \{published data only\}}

Melamed N, Kingdom J. Sonographic weight estimation of small for gestational age fetuses: Is the optimal model related to fetal body proportions?. American Journal of Obstetrics and Gynecology 2015;1:S263-4.

\section{Melamed 2016 \{published data only\}}

Melamed N, Pittini A, Kingdom J, Barrett J. Sonographic factors distinguishing late intrauterine growth restriction from late small for gestational age fetuses. American Journal of Obstetrics and Gynecology 2016;1:S104-5.

\section{Melamed 2016a \{published data only\}}

Melamed N, Ryan G, Windrim R, Toi A, Kingdom J. Choice of formula and accuracy of fetal weight estimation in small-forgestational-age fetuses. Journal of Ultrasound in Medicine 2016;35:71-82.

\section{Merriam 2014 \{published data only\}}

Merriam A, Jain V, Shlossman P, Hoffman M. Does abdominal circumference less than the 5 percentile improve detection of fetal growth restriction?. American Journal of Obstetrics and Gynecology 2014;1:S102.

\section{Mertens 1975 \{published data only\}}

Mertens H, Puder H. [Diagnosis of placental insufficiency through HPL studies]. Archiv fur Gynakologie 1975; Vol. 219:428-30.

\section{Mirza 2015 \{published data only\}}

Mirza FG, Bauer ST, Van Der Veer A, Simpson LL. Gastroschisis: Incidence and prediction of growth restriction. Journal of Perinatal Medicine 2015;43:605-8.

\section{Miwa 2014 \{published data only\}}

Miwa I, Sase M, Torii M, Sanai H, Nakamura Y, Ueda K. A thick placenta: a predictor of adverse pregnancy outcomes. Springerplus 2014;3:353.

\section{Mlynarczyk 2015 \{published data only\}}

Mlynarczyk M, Chauhan S, Baydoun H, Wilkes C, Earhart K, Goodier C, et al. Fetal growth restriction < $5 \%$ versus $5-9 \%$ : Multi-center study for comparison of neonatal morbidity (ULTRA TOT). American Journal of Obstetrics and Gynecology 2015;1:S109.

\section{Mlynarczyk 2015a \{published data only\}}

Mlynarczyk M, Chauhan SP, Wilkes CM, Earhart KR, Lee NM, Owens M, et al. Accuracy of sonographic estimation of fetal weight (SEFW) as a predictor of birth weight (BW) in growthrestricted fetuses; A large multicenter study. Ultrasound in Medicine and Biology 2015;1:S131. 
Mone 2016 \{published data only\}

Mone F, Hartigan L, Ali F, Neville G, Mahony R, Carroll S, et al. How accurately do we predict birthweight in the smallfor-gestational-age fetus?. BJOG: an international journal of obstetrics and gynaecology 2016;123:76.

\section{Moore 2012 \{published data only\}}

Moore A, Young H, Keller J, Ojo L, Yan J, Simas TM, et al. Angiogenic biomarkers for the prediction of pregnancy complications in women with suspected preeclampsia. American Journal of Obstetrics and Gynecology 2012;1:S326-7.

Morrison 1980 \{published data only\}

Morrison I, Green P, Oomen B. The role of human placental lactogen assays in antepartum fetal assessment. American Journal of Obstetrics \& Gynecology 1980; Vol. 136, issue 8:1055-60.

\section{Muraguchi 1981 \{published data only\}}

Muraguchi K, Takahashi K, Suzuki M, Ikeno N. [The concentration of serum unconjugated estradiol, estriol and estetrol in pregnant women, and the significance of these hormones in pregnancy (author's transl)]. Nippon Naibunpi Gakkai Zasshi - Folia Endocrinologica Japonica 1981;57:974-82.

Myatt 2013 \{published data only\}

Myatt L. Association of maternal biomarkers with obstetric outcomes. Reproductive Sciences 2013; Vol. 1:330A.

\section{Nadal 2015 \{published data only\}}

Nadal A, Parra-Saavedra M, Crovetto F, Triunfo S, Savchev S, Peguero A, et al. A comprehensive analysis of placental insufficiency in late-onset small for gestational age births. Laboratory Investigation 2015;95:299A.

\section{Nair 2016 \{published data only\}}

Nair A, Savitha C. Estimation of serum uric acid as an indicator of severity of preeclampsia and perinatal outcome. Journal of Obstetrics and Gynecology of India 2016;67(2):1-10.

\section{Nelson 2015 \{published data only\}}

Nelson DB, Martin R, Twickler DM, Santiago-Munoz PC, McIntire DD, Dashe JS. Sonographic detection and clinical importance of growth restriction in pregnancies with gastroschisis sonographic detection and clinical importance of growth restriction in pregnancies with gastroschisis. Journal of Ultrasound in Medicine 2015;34(12):2217-23.

\section{Nice 2014 \{published data only\}}

Nice D, Hayden K, Higgins L, Johnstone E, Heazell A. Human placental lactogen and placental growth factor can differentiate small for gestational age from appropriately grown infants. Placenta 2014;35(9):A19.

\section{Nice 2014a \{published data only\}}

Nice DB, Hayden K, Higgins L, Johnstone E, Heazell AE. The measurement of placental biomarkers in the detection of compromised pregnancies. Clinical Chemistry and Laboratory Medicine 2014;52(11):eA372.

\section{Nieder 1976 \{published data only\}}

Nieder J, Kapitza W. [The determination of human placental lactogen (HPL) for hormonal supervision in late pregnancy]. Zentralblatt fur Gynakologie 1976;98:1129-36.

\section{Nielsen 1981 \{published data only\}}

Nielsen PV, Schioler V. Ratio of human placental lactogenic hormone (hPL) in amniotic fluid/maternal serum. Acta Obstetricia et Gynecologica Scandinavica 1981; Vol. 60, issue 1:9-12

\section{Niknafs 2001 \{published data only\}}

Niknafs P, Sibbald J. Accuracy of single ultrasound parameters in detection of fetal growth restriction. American Journal of Perinatology 2001; Vol. 18, issue 6:325-34.

O'Connor 2015 \{published data only\}

O'Connor H, Unterscheider J, Daly S, Geary M, Kennelly M, McAuliffe $F$, et al. Comparison of asymmetric versus symmetric IUGR - results from a national prospective trial. American Journal of Obstetrics and Gynecology 2015;212(1):S173-S174.

\section{Obiekwe 1982 \{published data only\}}

Obiekwe BC, Chard T. Human chorionic gonadotropin levels in maternal blood in late pregnancy: relation to birthweight, sex and condition of the infant at birth. British Journal of Obstetrics \& Gynaecology 1982;89:543-6.

\section{Odibo 2014 \{published data only\}}

Odibo AO. Routine ultrasound examination at 41 weeks of gestation does not improve perinatal outcomes. BJOG: an international journal of obstetrics and gynaecology 2014;121:1116.

\section{Okonofua 1986 \{published data only\}}

Okonofua FE, Ayangade SO, Chan RC, O'Brien PM. A prospective comparison of clinical and ultrasonic methods of predicting normal and abnormal fetal growth. International Journal of Gynaecology \& Obstetrics 1986;24:447-51.

\section{Pal 2015 \{published data only\}}

Pal A, Rajoria L. Hyperuricemia and preeclampsia: evaluation of uric acid as predictor of adverse perinatal outcome. International Journal of Gynecology and Obstetrics 2015;131:E244

\section{Palomaki 2015 \{published data only\}}

Palomaki GE, Haddow JE, Haddow H, Salahuddin S, Geahchan C, Cerdeira AS, et al. Modeling risk for adverse outcomes in women with suspected preterm preeclampsia using angiogenic factor measurements. Pregnancy Hypertension 2015;5(1):12.

\section{Palomaki 2015a \{published data only\}}

Palomaki GE, Haddow JE, Haddow HR, Salahuddin S, Geahchan C, Cerdeira AS, et al. Modeling risk for severe adverse outcomes using angiogenic factor measurements in women with suspected preterm preeclampsia. Prenatal Diagnosis 2015;35:386-93. 


\section{Papastefanou 2014 \{published data only\}}

Papastefanou I, Pilalis A, Chrelias C, Kassanos D, Souka AP. Screening for birth weight deviations by second and third trimester ultrasound scan. Prenatal Diagnosis 2014;34:759-64.

\section{Papastefanou 2015 \{published data only\}}

Papastefanou I, Souka AP, Eleftheriades M, Pilalis A, Chrelias C, Kassanos D. Predicting fetal growth deviation in parous women: combining the birth weight of the previous pregnancy and third trimester ultrasound scan. Journal of Perinatal Medicine 2015; Vol. 43, issue 4:485-92.

\section{Parra Saavedra 2015 \{published data only\}}

Parra Saavedra MA, Triunfo S, Crovetto F, Gratacos E, Figueras F. OP14.02: Ultrasound and Doppler evaluation at routine third trimester scan to detect late pregnancy (SGA) in adequate-forgestational age (AGA) pregnancies. Journal of Perinatal Medicine 2015;46(S1):93-4.

\section{Parrish 2010 \{published data only\}}

Parrish M, Griffin M, Morris R, Darby M, Owens MY, Martin JN Jr. Hyperuricemia facilitates the prediction of maternal and perinatal adverse outcome in patients with severe/ superimposed preeclampsia. Journal of Maternal-Fetal \& Neonatal Medicine 2010;23:1451-5.

\section{Partap 2015 \{published data only\}}

Partap U, Sovio U, Smith G. Fetal growth and the risk of spontaneous preterm birth. American Journal of Obstetrics and Gynecology 2015;1:S208.

\section{Pavelka 1982 \{published data only\}}

Pavelka R, Schmid R, Reinold E. Evaluation of various monitoring techniques in late pregnancy to detect poor intrauterine fetal growth. Gynecologic \& Obstetric Investigation 1982; Vol. 13:65-75.

\section{Pecks 2015 \{published data only\}}

Pecks U, Kleine-Eggebrecht N, Winkler BS, Mohaupt M, Escher G, Rath W. Maternal lipid-and steroid hormone concentrations during the course of pregnancy and in pregnancy pathologies. Pregnancy Hypertension 2015;5(1):99-100.

\section{Peixoto 2016 \{published data only\}}

Peixoto AB, Rodrigues da Cunha Caldas TM, Godoy Silva TA, Silva Gomes Caetano MS, Martins WP, Martins Santana EF, et al. Assessment of ultrasound and Doppler parameters in the third trimester of pregnancy as predictors of adverse perinatal outcome in unselected pregnancies. Ginekologia Polska 2016;87(7):510-5.

\section{Perez-Cruz 2015 \{published data only\}}

Perez-Cruz M, Cruz-Lemini M, Fernandez MT, Parra JA, Bartrons J, Gomez-Roig MD, et al. Fetal cardiac function in lateonset intrauterine growth restriction vs small-for-gestational age, as defined by estimated fetal weight, cerebroplacental ratio and uterine artery Doppler. Ultrasound in Obstetrics \& Gynecology 2015;46:465-71.
Perry 1986 \{published data only\}

Perry L, Hickson R, Obiekwe BC, Chard T. Maternal oestriol levels reflect placental function rather than foetal function. Acta Endocrinologica 1986;111:563-6.

\section{Persson 1978 \{published data only\}}

Persson PH, Marsal K. Monitoring of fetuses with retarded BPD growth. Acta Obstetricia et Gynecologica Scandinavica. Supplement 1978; Vol. 78:49-55.

\section{Persson 1980 \{published data only\}}

Persson PH, Grennert L, Gennser G, Eneroth P. Fetal biparietal diameter and maternal plasma concentrations of placental lactogen, chorionic gonadotrophin, oestriol, and alphafetoprotein in normal and pathological pregnancies. British Journal of Obstetrics and Gynaecology 1980;87:25-32.

\section{Peyronnet 2016 \{published data only\}}

Peyronnet V, Kayem G, Mandelbrot L, Sibiude J. [Detection of small for gestational age fetuses during third trimester ultrasound. A monocentric observational study]. Gynecologie, Obstetrique \& Fertilite 2016;44:531-6.

Pfeiffer 1990 \{published data only\}

Pfeiffer KH. [Detection of fetal growth retardation by instrumental and biochemical monitoring methods]. Zeitschrift fur Geburtshilfe und Perinatologie 1990;194:99-103.

Pinheiro 2014 \{published data only\} Pinheiro CC, Rayol P, Gozzani L, Reis LM, Zampieri G, Dias CB, et al. The relationship of angiogenic factors to maternal and neonatal manifestations of early-onset and late-onset preeclampsia. Prenatal Diagnosis 2014;34:1084-92.

\section{Pledger 1984 \{published data only\}}

Pledger DR, Belfield A, Calder AA, Wallace AM. The predictive value of three pregnancy-associated proteins in the detection of the light-for-dates baby. British Journal of Obstetrics and Gynaecology 1984; Vol. 91, issue 9:870-4.

\section{Pluta 1979 \{published data only\}}

Pluta M, Hardt W, Schmidt-Gollwitzer K, Schmidt-Gollwitzer M. Radioimmunoassay of serum SP 1 and HPL in normal and abnormal pregnancies. Archives of Gynecology 1979;227:327-36.

\section{Ponce 1995 \{published data only\}}

Ponce J, Boguna JM, Salvador C, Borras M, Lailla JM. Value of hyperuricemia as biological marker in hypertensive disorders of pregnancy. [Spanish]. Progresos en Obstetricia y Ginecologia 1995;38:244-50.

\section{Powers 2010 \{published data only\}}

Powers R, Roberts J, Plymire D, Pucci D, Datwyler S, Laird D, et al. Low maternal PIGF across pregnancy identifies a subset of women with preterm preeclampsia; Type 1 vs. type 2 preeclampsia?. Pregnancy Hypertension 2010;1:S14.

\section{Prakash 2012 \{published data only\}}

Prakash S, Sharma N, Kumari P, Kumar A. Serum uric acid as marker for diagnosing preeclampsia. International Journal of Pharmaceutical Sciences and Research 2012;3:2669-75. 
Qublan 2005 \{published data only\}

Qublan HS, Ammarin V, Bataineh O, Al-Shraideh Z, Tahat Y, Awamleh I, et al. Lactic dehydrogenase as a biochemical marker of adverse pregnancy outcome in severe pre-eclampsia. Medical Science Monitor 2005;11:CR393-7.

\section{Raghuramulu 1978 \{published data only\}}

Raghuramulu N. Plasma placental lactogen in pregnancy. Nutrition \& Metabolism 1978;22:160-6.

\section{Rajasingam 2009 \{published data only\}}

Rajasingam D, Seed PT, Briley AL, Shennan AH, Poston L. A prospective study of pregnancy outcome and biomarkers of oxidative stress in nulliparous obese women. American Journal of Obstetrics \& Gynecology 2009;200:395.e1-9.

\section{Rasanen 2015 \{published data only\}}

Rasanen J, Quinn MJ, Laurie A, Bean E, Roberts CT, Nagalla SR, et al. Maternal serum glycosylated fibronectin as a point-of-care biomarker for assessment of preeclampsia. American Journal of Obstetrics and Gynecology 2015;212:82.e1-82e9.

\section{Reck 1987 \{published data only\}}

Reck G, Kronitz B, Breckwoldt M. [Significance of the estriol profile as an endogenous function test of the fetoplacental unit]. Geburtshilfe und Frauenheilkunde 1987;47:774-80.

\section{Riss 1982 \{published data only\}}

Riss P, Bartl W. Placental function, fetal distress, and the fetal/ placental weight ratio in normal and gestotic pregnancies. International Journal of Biological Research in Pregnancy 1982;3:10-3.

\section{Ris-Stalpers 2012 \{published data only\}}

Ris-Stalpers C, Hassani Lahsinoui H, Boussata S, Am Van Der Post J. Placental growth factor as a diagnostic and prognostic test for placental complications of pregnancy. Pregnancy Hypertension 2012;2(3):212.

\section{Rizos 2013 \{published data only\}}

Rizos D, Eleftheriades M, Karampas G, Rizou M, Haliassos A, Hassiakos D, et al. Placental growth factor and soluble fmslike tyrosine kinase-1 are useful markers for the prediction of preeclampsia but not for small for gestational age neonates: a longitudinal study. European Journal of Obstetrics, Gynecology, \& Reproductive Biology 2013;171:225-30.

\section{Rocca 1995 \{published data only\}}

Rocca MM, Said MS, Khamis MY, Ghanem IA, Karkour TA. The value of Doppler study of the umbilical artery in predicting perinatal outcome in pre-eclamptic patients. Journal of Obstetrics and Gynaecology 1995;21:427-31.

\section{Romero 2008 \{published data only\}}

Romero R, Nien JK, Espinoza J, Todem D, Fu W, Chung H, et al. A longitudinal study of angiogenic (placental growth factor) and anti-angiogenic (soluble endoglin and soluble vascular endothelial growth factor receptor-1) factors in normal pregnancy and patients destined to develop preeclampsia and deliver a small for gestational age neonate. Journal of MaternalFetal \& Neonatal Medicine 2008:21:9-23.

\section{Ronin-Walknowska 1984 \{published data only\}}

Ronin-Walknowska E, Holmgren PA, von Schoultz B, Stigbrand T. Placental alkaline phosphatase compared with human placental lactogen and oestriol in high-risk pregnancies. Gynecologic \& Obstetric Investigation 1984;18:206-11.

\section{Rosendahl 1988 \{published data only\}}

Rosendahl H, Kivinen S. Routine ultrasound screening for early detection of small for gestational age fetuses. Obstetrics and Gynecology 1988;71:518-21.

\section{Rosendahl 1991 \{published data only\}}

Rosendahl H, Kivinen S. Detection of small for gestational age fetuses by the combination of clinical risk factors and ultrasonography. European Journal of Obstetrics, Gynecology, and Reproductive Biology 1991;39:7-11.

Rothenbacher 2016 \{published data only\}

Rothenbacher D, Braig S, Muller M, Koenig W, Reister F, Genuneit J. Maternal uric acid serum concentrations, renal function at delivery and health-related pregnancy outcomes in neonates: The Ulm SPATZ Health Study. European Journal of Epidemiology 2016;31:S166.

\section{Ruozi Berretta 1967 \{published data only\}}

Ruozi Berretta L, Avitto P. [Estriol and pregnanediol as indices of placental function in normal and pathological pregnancy]. Minerva Ginecologica 1967;19:138-41.

Sabbagha 1979 \{published data only\} Sabbagha RE, Tamura RK. Antenatal ultrasound diagnosis of intrauterine growth retardation. Perinatology Neonatology 1979;3:33-6.

Salahuddin 2016 \{published data only\} Salahuddin S, Wenger JB, Zhang D, Thadhani R, Karumanchi SA Rana S. KRYPTOR-automated angiogenic factor assays and risk of preeclampsia-related adverse outcomes. Hypertension in Pregnancy 2016;35:330-45.

Salas 1993 \{published data only\} Salas SP, Rosso P, Espinoza R, Robert JA, Valdes G, Donoso E. Maternal plasma volume expansion and hormonal changes in women with idiopathic fetal growth retardation. Obstetrics and Gynecology 1993;81:1029-33.

\section{Salas 1998 \{published data only\}}

Salas SP, Rosso P. Plasma volume, renal function, and hormonal levels in pregnant women with idiopathic fetal growth restriction or preeclampsia. Hypertension in Pregnancy 1998;17:69-79.

\section{Salas 2006 \{published data only\}}

Salas SP, Marshall G, Gutierrez BL, Rosso P. Time course of maternal plasma volume and hormonal changes in women with preeclampsia or fetal growth restriction. Hypertension 2006;47:203-8

\section{Saleh 2015 \{published data only\}}

Saleh L, Verdonk K, Danser AH, Steegers EA, Russcher H, Van Den Meiracker AH, et al. The preratio study: Is the SFLT-1/PLGF

Biochemical tests of placental function versus ultrasound assessment of fetal size for stillbirth and small-for-gestational-age infants 
ratio a suitable marker to diagnose preeclampsia and to predict adverse maternal/neonatal pregnancy outcome?. Journal of Hypertension 2015;33:e347-8.

Salkie 1977 \{published data only\}

Salkie ML, Hannah CL. Maternal serum hyaluronidase activity in pregnancy. Enzyme 1977;22:52-9.

Samanta 1989 \{published data only\}

Samanta B, Dutta GP. Study on blood level of human placental lactogen in abnormal pregnancy. Journal of the Indian Medical Association 1989;87:205-7.

\section{Sanchez Fernandez 2015 \{published data only\}}

Sanchez Fernandez M, De La Fuente Pedrosa ER, Garcia Cotes AE, Sanchez Barroso MT, Mozas Moreno J, JimenezMoleon JJ. Ultrasound scan error associated factors on fetal weight measurement. Journal of Perinatal Medicine 2015;43:908

\section{Sarandakou 1989 \{published data only\}}

Sarandakou A, Rizos D, Phocas I. Comparative study of four hormonal parameters in pregnancies with low-birthweight infants. Clinical Chemistry and Enzymology Communications 1989;1:159-69.

\section{Sato 1974 \{published data only\}}

Sato Y, Arai S, Takeuchi S, Hiroi M. [Feto-placental function tests based on the ratio of alpha-fetoprotein and HPL of the maternal blood]. Horumon to Rinsho - Clinical Endocrinology 1974;22:1061-5.

\section{Secher 1986 \{published data only\}}

Secher NJ, Hansen PK, Lenstrup C, Eriksen PS. Controlled trial of ultrasound screening for light for gestational age (LGA) infants in late pregnancy. European Journal of Obstetrics, Gynecology, and Reproductive Biology 1986;23:307-13.

\section{Secher 1987 \{published data only\}}

Secher NJ, Kern Hansen P, Lenstrup C, Sindberg Eriksen P, Morsing $\mathrm{G}$. A randomized study of fetal abdominal diameter and fetal weight estimation for detection of light-for-gestation infants in low-risk pregnancies. British Journal of Obstetrics and Gynaecology 1987;94:105-9.

\section{Sekar 2015 \{published data only\}}

Sekar R, Duncombe G. Fetalweight study - Single centre experience. BJOG: an international journal of obstetrics and gynaecology 2015;122:111.

\section{Selbing 1984 \{published data only\}}

Selbing A, Wichman K, Ryden G. Screening for detection of intra-uterine growth retardation by means of ultrasound. Acta Obstetricia et Gynecologica Scandinavica 1984;63:543-8.

\section{Semczuk-Sikora 2007 \{published data only\}}

Semczuk-Sikora A, Krzyzanowski A, Stachowicz N, Robak J, Kraczkowski J, Kwiatek M, et al. [Maternal serum concentration of angiogenic factors: PIGF, VEGF and VEGFR-1 and placental volume in pregnancies complicated by intrauterine growth restriction]. Ginekologia Polska 2007;78:783-6.

\section{Shaarawy 2001 \{published data only\}}

Shaarawy M, El Meleigy M, Rasheed K. Maternal serum transforming growth factor beta-2 in preeclampsia and eclampsia, a potential biomarker for the assessment of disease severity and fetal outcome. Journal of the Society for Gynecologic Investigation 2001;8:27-31.

Shah 1996 \{published data only\}

Shah DM, Reed G. Parameters associated with adverse perinatal outcome in hypertensive pregnancies. Journal of Human Hypertension 1996;10:511-5.

\section{Sharf 1984 \{published data only\}}

Sharf M, Eibschitz I, Hakim M, Degani S, Rosner B. Is serum free estriol measurement essential in the management of hypertensive disorders during pregnancy?. European Journal of Obstetrics, Gynecology, and Reproductive Biology 1984;17:365-75.

\section{Sheth 2016 \{published data only\}}

Sheth T, Glantz JC. Third-trimester fetal biometry and neonatal outcomes in term and preterm deliveries. Journal of Ultrasound in Medicine 2016;35:103-10.

\section{Shibata 2005 \{published data only\}}

Shibata E, Rajakumar A, Powers RW, Larkin RW, Gilmour C, Bodnar LM, et al. Soluble fms-like tyrosine kinase 1 is increased in preeclampsia but not in normotensive pregnancies with small-for-gestational-age neonates: relationship to circulating placental growth factor. Journal of Clinical Endocrinology \& Metabolism 2005;90:4895-903.

Sibiude 2012 \{published data only\}

Sibiude J, Guibourdenche J, Dionne MD, Le Ray C, Anselem O, Serreau R, et al. Placental growth factor for the prediction of adverse outcomes in patients with suspected preeclampsia or intrauterine growth restriction. PLOS One 2012;7:e50208.

\section{Sichinava 2014 \{published data only\}}

Sichinava L, Gugushvili N. Fetal growth restriction and placental growth factor. Journal of Maternal-Fetal and Neonatal Medicine 2014;27:120

\section{Singer 1970 \{published data only\}}

Singer W, Desjardins P, Friesen HG. Human placental lactogen. An index of placental function. Obstetrics and Gynecology 1970;36:222-32.

\section{Smith 2014 \{published data only\}}

Smith NA, Bukowski R, Thomas AM, Cantonwine D, Zera C, Robinson JN. Identification of pathologically small fetuses using customized, ultrasound and population-based growth norms. Ultrasound in Obstetrics and Gynecology 2014;44:595-9.

\section{Smith-Bindman 2002 \{published data only\}}

Smith-Bindman R, Chu PW, Ecker JL, Feldstein VA, Filly RA, Bacchetti P. US evaluation of fetal growth: prediction of neonatal outcomes. Radiology 2002;223:153-61.

Biochemical tests of placental function versus ultrasound assessment of fetal size for stillbirth and small-for-gestational-age infants 
Smith-Bindman 2003 \{published data only\}

Smith-Bindman R, Chu PW, Ecker J, Feldstein VA, Filly RA, Bacchetti P. Adverse birth outcomes in relation to prenatal sonographic measurements of fetal size. Journal of Ultrasound in Medicine 2003;22:347-56; quiz 357-8.

\section{Soler 1975 \{published data only\}}

Soler NG, Nicholson HO, Malins JM. Serial determinations of human placental lactogen in the management of diabetic pregnancy. Lancet 1975;2:54-7.

\section{Sood 1988 \{published data only\}}

Sood M, Hingorani V, Kashyap N, Kumar S, Berry M, Bhargava S. Ultrasonic measurement of foetal parameters in normal pregnancy \& in intrauterine growth retardation. Indian Journal of Medical Research 1988;87:453-8.

\section{Sorensen 2000 \{published data only\}}

Sorensen S, von Tabouillot D, Schioler V, Greisen G, Petersen S Larsen T. Serial measurements of serum human placental lactogen (hPL) and serial ultrasound examinations in the evaluation of fetal growth. Early Human Development 2000;60:25-34

\section{Souka 2012 \{published data only\}}

Souka AP, Papastefanou I, Pilalis A, Michalitsi V, Kassanos D. Performance of third-trimester ultrasound for prediction of small-for-gestational-age neonates and evaluation of contingency screening policies. Ultrasound in Obstetrics and Gynecology 2012;39:535-42.

\section{Souka 2013 \{published data only\}}

Souka AP, Papastefanou I, Pilalis A, Michalitsi V, Panagopoulos P, Kassanos D. Performance of the ultrasound examination in the early and late third trimester for the prediction of birth weight deviations. Prenatal Diagnosis 2013;33:915-20.

\section{Sovio 2014 \{published data only\}}

Sovio U, Smith G, Dacey A. Level 1 evidence for the diagnostic effectiveness of routine sonography as a screening test for small for gestational age (SGA) infants. American Journal of Obstetrics and Gynecology 2014;1:S408

\section{Spellacy 1967 \{published data only\}}

Spellacy WN, Cohen WD, Carlson KL. Human placental lactogen levels as a measure of placental function. American Journal of Obstetrics and Gynecology 1967;97:560-1.

\section{Spellacy 1975 \{published data only\}}

Spellacy WN, Buhi WC, Birk SA. The effectiveness of human placental lactogen measurements as an adjunct in decreasing perinatal deaths. Results of a retrospective and a randomized controlled prospective study. American Journal of Obstetrics and Gynecology 1975; Vol. 121, issue 6:835-44.

\section{Spellacy 1976 \{published data only\}}

Spellacy WN, Buhi WC, Birk SA. Human placental lactogen and intrauterine growth retardation. Obstetrics and Gynecology 1976;47:446-8

\section{Spona 1971 \{published data only\}}

Spona J, Janisch H. Serum placental lactogen (HPL) as index of placental function. Acta Endocrinologica 1971;68:401-12.

Spona 1972 \{published data only\}

Spona J, Janisch H. [Diagnosis of placental insufficiency by radioimmunoassay of serum HCG and HPL]. Wiener Klinische Wochenschrift 1972;84:385-9.

\section{Stefanelli 2014 \{published data only\}}

Stefanelli S, Groom KM. The accuracy of ultrasound-estimated fetal weight in extremely preterm infants: a comparison of small for gestational age and appropriate for gestational age. Australian \& New Zealand Journal of Obstetrics \& Gynaecology 2014;54:126-31.

\section{Stefanidis 1998 \{published data only\}}

Stefanidis K, Solomou E, Mouzakioti E, Stefos T, Farmakides G. Comparison of somatomedin-C (SMC/IGF-I), human placental lactogen and Doppler velocimetry between appropriate and small-for-gestational-age pregnancies. Clinical \& Experimental Obstetrics \& Gynecology 1998;25:20-2.

Strizhakov 2013 \{published data only\}

Strizhakov A, Timokhina E, Ignatko I. The value of pathogenetic factors of fetal growth retardation in the early diagnosis, prevention and treatment of the placental insufficiency. Journal of Perinatal Medicine 2013;41:1

Strom 1983 \{published data only\}

Strom H, Berg B, Jacobson L. Plasma estriol in late pregnancy in relation to fetal outcome. Acta Obstetricia et Gynecologica Scandinavica 1983;62:355-7.

Sucak 2010 \{published data only\}

Sucak A, Kanat-Pektas M, Gungor T, Mollamahmutoglu L. Leptin levels and antihypertensive treatment in preeclampsia. Singapore Medical Journal 2010;51:39-43.

\section{Sudik 1982 \{published data only\}}

Sudik R. [Results of an ultrasonic screening programme in the detection of intrauterine growth retardation]. Zeitschrift fur Geburtshilfe und Perinatologie 1982;186:119-24.

Sundrani 2013 \{published data only\}

Sundrani D, Khot V, Pisal H, Mehendale S, Wagh G, Joshi A, et al. Gestation dependant changes in angiogenic factors and their associations with fetal growth measures in normotensive pregnancy. PLOS One 2013;8:e54153.

Tajik 2012 \{published data only\}

Tajik P, Boers K, Wyk L, Mol B, Sicco S. Evaluation of markers guiding management decision for intrauterine growth restriction: A sub-analysis of a randomized trial, DIGITAT. American Journal of Obstetrics and Gynecology 2012, issue 1:S199-S200.

Takeuchi 1988 \{published data only\}

Takeuchi M, Morikawa H, Ueda Y, Mochizuki M. [Studies on the roles of insulin-like growth factor-1 (IGF-1)/somatomedin C 
(SMC) during pregnancy]. Nippon Naibunpi Gakkai Zasshi - Folia Endocrinologica Japonica 1988;64:489-505.

\section{Tammemae 2016 \{published data only\}}

Tammemae L, Angerjas T, Szirko F. 5 Years of ERT-quality assurance in East-Tallinn Central Hospital, SGA. Journal of Maternal-Fetal and Neonatal Medicine 2016;29:306-7.

\section{Tayama 1983 \{published data only\}}

Tayama C, Ichimaru S, Ito M, Nakayana M, Maeyama M, Miyakawa I. Unconjugated estradiol, estriol and total estriol in maternal peripheral vein, cord vein, and cord artery serum at delivery in pregnancies with intrauterine growth retardation. Endocrinologia Japonica 1983;30:155-62.

\section{Taylor 2003 \{published data only\}}

Taylor RN, Grimwood J, Taylor RS, McMaster MT, Fisher SJ, North RA. Longitudinal serum concentrations of placental growth factor: evidence for abnormal placental angiogenesis in pathologic pregnancies. American Journal of Obstetrics and Gynecology 2003;188:177-82.

\section{Teoh 1971 \{published data only\}}

Teoh ES, Spellacy WN, Buhi WC. Human chorionic somatomammotrophin (HCS): a new index of placental function. Journal of Obstetrics \& Gynaecology of the British Commonwealth 1971;78:673-85.

\section{Tonari 1987 \{published data only\}}

Tonari M. Studies on the relation between fetal heart rate change, placental finding and fetal outcome. [Japanese]. Acta Obstetrica et Gynaecologica Japonica 1987;39:751-9.

\section{Torok 1987 \{published data only\}}

Torok A, Csernus V, Csaba I. Diagnostic value of serum estriol determination in placental insufficiency. [Hungarian]. Orvosi Hetilap 1987;128(52):2731-2, 2735.

\section{Triunfo 2014 \{published data only\}}

Triunfo S, Lobmaier S, Parra-Saavedra M, Crovetto F, Peguero A, Nadal A, et al. Angiogenic factors at diagnosis of lateonset small-for-gestational age and histological placental underperfusion. Placenta 2014;35:398-403.

\section{Triunfo 2016 \{published data only\}}

Triunfo S, Parra-Saavedra M, Rodriguez-Sureda V, Crovetto F, Dominguez C, Gratacos E, et al. Angiogenic factors and Doppler evaluation in normally growing fetuses at routine thirdtrimester scan: prediction of subsequent low birth weight. Fetal Diagnosis and Therapy 2016;40:13-20.

\section{Triunfo 2016a \{published data only\}}

Triunfo S, Crovetto F, Scazzocchio E, Parra-Saavedra M, Gratacos E, Figueras F. Contingent versus routine third-trimester screening for late fetal growth restriction. Ultrasound in Obstetrics and Gynecology 2016;47:81-8.

Tsiakkas 2015 \{published data only\}

Tsiakkas A, Duvdevani N, Wright A, Wright D, Nicolaides KH. Serum placental growth factor in the three trimesters of pregnancy: effects of maternal characteristics and medical history. Ultrasound in Obstetrics \& Gynecology 2015;45:591-8.

Tsiakkas 2016 \{published data only\}

Tsiakkas A, Saiid Y, Wright A, Wright D, Nicolaides KH. Competing risks model in screening for preeclampsia by maternal factors and biomarkers at 30-34 weeks' gestation. American Journal of Obstetrics and Gynecology 2016;215:87.e1-87.e17.

Turpin 2015 \{published data only\}

Turpin CA, Sakyi SA, Owiredu WK, Ephraim RK, Anto EO. Association between adverse pregnancy outcome and imbalance in angiogenic regulators and oxidative stress biomarkers in gestational hypertension and preeclampsia. BMC Pregnancy and Childbirth 2015;15:189.

\section{Van Rijn 2015 \{published data only\}}

Van Rijn BB, Maguire P, Clarke S, Roland A, Reading IC, Cameron IT, et al. Salivary uric acid levels in women destined to develop preeclampsia: Longitudinal prospective study. Reproductive Sciences 2015;22:93A-4A.

Varma 1979 \{published data only\} Varma TR, Taylor H, Bridges C. Ultrasound assessment of fetal growth. British Journal of Obstetrics and Gynaecology 1979;86:623-32.

\section{Varma 1982 \{published data only\}}

Varma TR. Serum uric acid levels as an index of fetal prognosis in pregnancies complicated by preexisting hypertension and preeclampsia of pregnancy. International Journal of Gynaecology and Obstetrics 1982;20:401-8.

\section{Vatten 2012 \{published data only\}}

Vatten LJ, Asvold BO, Eskild A. Angiogenic factors in maternal circulation and preeclampsia with or without fetal growth restriction. Acta Obstetricia et Gynecologica Scandinavica 2012;91:1388-94.

\section{Vinayagam 2015 \{published data only\}}

Vinayagam V, Bobby Z, Habeebullah S, Chaturvedula L, Bharadwaj SK. Impaired angiogenesis and pregnancy outcome in patients with hypertensive disorders of pregnancy: A pilot study in an Indian population. Indian Journal of Clinical Biochemistry 2015;30:S117.

Wallner 2007 \{published data only\}

Wallner W, Sengenberger R, Strick R, Strissel PL, Meurer B, Beckmann MW, et al. Angiogenic growth factors in maternal and fetal serum in pregnancies complicated by intrauterine growth restriction. Clinical Science 2007;112:51-7.

\section{Watson 1973 \{published data only\}}

Watson D, Siddiqui SA, Stafford JE, Gibbard S, Hewitt V. A comparative study of five laboratory tests for foeto-placental dysfunction in late pregnancy. Journal of Clinical Pathology 1973;26:249-300. 
Weissbach 1985 \{published data only\}

Weissbach A, Freymann E, Hubl W, Seefried W, Neef B, Thiele HJ. Enzymeimmunoassay of unconjugated estriol in serum and saliva during pregnancy. Experimental \& Clinical Endocrinology 1985;86:178-84.

\section{Whigham 1980 \{published data only\}}

Whigham KA, Howie PW, Shah MM, Prentice CR. Factor VIII related antigen/coagulant activity ratio as a predictor of fetal growth retardation: a comparison with hormone and uric acid measurements. British Journal of Obstetrics and Gynaecology 1980;87:797-803.

White 2016 \{published data only\}

White SW, Marsh JA, Lye SJ, Briollais L, Newnham JP, Pennell CE. Improving customized fetal biometry by longitudinal modelling. Journal of Maternal-Fetal \& Neonatal Medicine 2016;29:1888-94.

\section{Woelkers 2016 \{published data only\}}

Woelkers DA, Von Dadelszen P, Sibai B. Placenta Growth Factor (PLGF) predicts time to delivery in women with signs or symptoms of early preterm preeclampsia. American Journal of Obstetrics and Gynecology 2016;1:S25-6.

\section{Woo 2016 \{published data only\}}

Woo I, Ingles S, Sriprasert I, Paulson R, Stanczyk F, Chung K. The role of angiogenic markers in adverse perinatal outcomes: Fresh vs frozen embryo transfers. Fertility and Sterility 2016;1:e7.

\section{Woods 2015 \{published data only\}}

Woods A, Dekker G. Placental growth factor measurement as a marker of subsequent disease and harm in placental insufficiency conditions. Pregnancy Hypertension 2015;5(1):50.

\section{Wurz 1983 \{published data only\}}

Wurz H, Luben G, Bohn H, Kunzig HJ, Geiger W. Concentration of placental protein 10 (PP10) in maternal serum and amniotic fluid throughout normal gestation and in pregnancy complicated by fetal growth retardation. Archives of Gynecology 1983;233:165-74.

\section{Xing 2016 \{published data only\}}

Xing Y, Chang RJ, Du XN, Chen D. Placental growth factor, an index for detection of women with preeclampsia. International Journal of Clinical and Experimental Medicine 2016;9:11348-54.

\section{Xu 2015 \{published data only\}}

Xu Y, Lek N, Cheung YB, Biswas A, Su LL, Kwek KY, et al. Unconditional and conditional standards for fetal abdominal circumference and estimated fetal weight in an ethnic Chinese population: a birth cohort study. BMC Pregnancy \& Childbirth 2015;15:141.

\section{Yamaguchi 1979 \{published data only\}}

Yamaguchi H, Nishiyama Y, Nose Y, Sugiyama Y. [Usefulness of serum HPL determination as an indicator of placental function and fetal growth]. Horumon to Rinsho - Clinical Endocrinology 1979;27:191-6.
Yanaihara 1984 \{published data only\}

Yanaihara T, Hirato K, Seo F, Mitsukawa G, Kojima S, Maruyama S, et al. [Prenatal diagnosis of IUGR by assessing the multiple hormone concentration in maternal peripheral blood]. Nippon Sanka Fujinka Gakkai Zasshi - Acta Obstetrica et Gynaecologica Japonica 1984;36:182-8.

Zail 1975 \{published data only\}

Zail SS, Safro IL. Serum human placental lactogen levels in intra-uterine fetal growth retardation. South African Medical Journal. Suid-Afrikaanse Tydskrif Vir Geneeskunde 1975;49:2022-4.

\section{Zera 2011 \{published data only\}}

Zera C, Smith NA, Robinson JN, Bukowski RK. Improved identification of pregnancies at risk for stillbirth with ultrasound based estimates of individualized fetal growth potential. American Journal of Obstetrics and Gynecology 2011;204:S150-1.

\section{Zhang 2011 \{published data only\}}

Zhang J, Mikolajczyk R, Grewal J, Neta G, Klebanoff M. Prenatal application of the individualized fetal growth reference. American Journal of Epidemiology 2011; Vol. 173, issue 5:539-43.

Zhao 2010 \{published data only\}

Zhao W, Qiao J, Zhang Q, Zhao Y, Chen Q. Levels of antiangiogenic factors in preeclamptic pregnancies. Growth Factors 2010;28:293-8.

\section{Zlatnik 1979 \{published data only\}}

Zlatnik FJ, Varner MW, Hauser KS. Human placental lactogen: a predictor of perinatal outcome?. Obstetrics and Gynecology 1979;54:205-10.

\section{Zuckerman 1974 \{published data only\}}

Zuckerman H, Gendler L, Schwarz M, Harpaz S. Human placental lactogen as an index of placental function. Israel Journal of Medical Sciences 1974;10:490-4.

\section{References to studies awaiting assessment}

Bracali 1968 \{published data only\}

Bracali R, Corrado F. Clinical value of urinary estriol as an index of placental function and of fetal vitality in some pathological conditions of pregnancy. [Italian]. Quaderni di Clinica Ostetrica e Ginecologica 1968;23:1534-52.

Fuks 1990 \{published data only\}

Fuks MA, Milovanov AP, Chekhonatskaia ML. Prognostic value of placental maturity staging for pregnancy outcome of the fetus and newborn infant. Akusherstvo i Ginekologiia 1990;7(3):19-22.

Jain 2000 \{published data only\}

Jain A, Kumar G, Gupta AK. Relationship of placental grades to gestational age and early grade III placenta and its relation with growth retardation. Ultrasound International 2000;6:112-20. 
Khan 2004 \{published data only\}

Khan DB, Bari V, Chishty IA. Ultrasound in the diagnosis and management of intrauterine growth retardation. Journal of the College of Physicians and Surgeons Pakistan 2004;14:601-4.

\section{Ruseva 1983 \{published data only\}}

Ruseva R, Marinov B. [Prognostic potentials of certain parameters in fetal growth retardation]. Akusherstvo $i$ Ginekologiia 1983;22:367-72.

\section{Ruseva 1985 \{published data only\}}

Ruseva R, Katsulov A, Marinov B, Atanasov B, Milkov V. [The placenta. Ultrasonic and hormonal changes in fetal growth retardation]. Akusherstvo i Ginekologiia 1985;24:16-9.

\section{Ruseva 1985a \{published data only\}}

Ruseva R, Khadzhiev A, Marinov B. [Ultrasonic study of placental intrauterine growth]. Akusherstvo i Ginekologiia 1985;24:75-80.

\section{Ruseva 1988 \{published data only\}}

Ruseva R. [Echographic and hormonal parameters in fetal growth retardation]. Akusherstvo i Ginekologiia 1988;27:15-8.

\section{Serban 1971 \{published data only\}}

Serban MD. [Investigation of placental functional values. II. The placental lactogenic hormone (HPL)]. Studii Si Cercetari de Endocrinologie 1971;22:159-60.

\section{Additional references}

\section{Alere 2015}

Alere. Alere Triage ${ }^{\circledR}$ PIGF Test. http://www.alere.com/ww/en/ product-details/triage-plgf-test.html (accessed 27th August 2015)

\section{Alfirevic 2015}

Alfirevic Z, Stampalija T, Medley N. Fetal and umbilical Doppler ultrasound in normal pregnancy. Cochrane Database of Systematic Reviews 2015, Issue 4. [DOI: 10.1002/14651858.CD001450.pub4]

\section{Alfirevic 2017}

Alfirevic Z, Stampalija T, Dowswell T. Fetal and umbilical Doppler ultrasound in high-risk pregnancies. Cochrane Database of Systematic Reviews 2017, Issue 6. [DOI: 10.1002/14651858.CD007529.pub4]

\section{Bossuyt 2015}

Bossuyt PM, Reitsma JB, Bruns DE, Gatsonis CA, Glasziou PP, Irwig L, et al. STARD 2015: an updated list of essential items for reporting diagnostic accuracy studies. BMJ 2015;351:h5527.

\section{Bricker 2015}

Bricker L, Medley N, Pratt JJ. Routine ultrasound in late pregnancy (after 24 weeks' gestation). Cochrane Database of Systematic Reviews 2015, Issue 6. [DOI: 10.1002/14651858.CD001451.pub4]

\section{Clausson 2001}

Clausson B, Gardosi J, Francis A, Cnattingius S. Perinatal outcome in SGA births defined by customised versus population-based birthweight standards. BJOG: an international journal of obstetrics and gynaecology 2001;108(8):830-4 .

\section{Duenholter 1976}

Duenhoelter JH, Whalley PJ, MacDonald PC. An analysis of the utility of plasma immunoreactive estrogen measurements in determining delivery time of gravidas with a fetus considered at high risk. American Journal of Obstetrics and Gynecology 1976;125(7):889-98.

\section{Ensor 2018}

Ensor J, Deeks JJ, Martin EC, Riley RD. Meta-analysis of test accuracy studies using imputation for partial reporting of multiple thresholds. Research Synthesis Methods 2018;9(1):100-15.

\section{Flenady 2011}

Flenady V, Koopmans L, Middleton P, Frøen JF, Smith GC, Gibbons K, et al. Major risk factors for stillbirth in high-income countries: a systematic review and meta-analysis. Lancet 2011;377(9774):1331-40.

\section{Flenady 2016}

Flenady V, Wojcieszek AM, Middleton P, Ellwood D, Erwich JJ, Coory M, et al. Stillbirths: recall to action in high-income countries. Lancet 2016; Vol. 387, issue 10019:13-9.

\section{Gardosi 2013}

Gardosi J, Madurasinghe V, Williams M, Malik A, Francis A. Maternal and fetal risk factors for stillbirth: population based study. BMJ 2013;346:f108.

\section{GRIT 2003}

GRIT Study Group. A randomised trial of timed delivery for the compromised preterm fetus: short term outcomes and Bayesian interpretation. BJOG: an international journal of obstetrics and gynaecology 2003;110(1):27-32.

\section{Heazell 2013}

Heazell AE, Bernatavicius G, Roberts SA, Garrod A, Whitworth MK, Johnstone ED, et al. A randomised controlled trial comparing standard or intensive management of reduced fetal movements after 36 weeks gestation--a feasibility study. BMC Pregnancy Childbirth 2013;13:95. [DOI: 10.1186/1471-2393-13-95]

\section{Heazell 2015a}

Heazell AE, Worton SA, Higgins LE, Ingram E, Johnstone ED, Jones RL, et al. IFPA Gábor Than Award Lecture: Recognition of placental failure is key to saving babies' lives. Placenta 2015;36(Suppl 1):S20-8

\section{Heazell 2015b}

Heazell AE, Whitworth MK, Duley L, Thornton JG. Use of biochemical tests of placental function for improving pregnancy outcome. Cochrane Database of Systematic Reviews 2015, Issue 11. [DOI: 10.1002/14651858.CD011202.pub2] 


\section{Lawn 2016}

Lawn JE, Blencowe H, Waiswa P, Amouzou A, Mathers C, Hogan D, et al. Stillbirths: rates, risk factors, and acceleration towards 2030. Lancet 2016;387(10018):587-603.

\section{Macaskill 2010}

Macaskill P, Gatsonis C, Deeks JJ, Harbord RM, Takwoingi Y. Chapter 10: analysing and presenting results. In: Deeks JJ, Bossuyt PM, Gatsonis C editor(s). Cochrane handbook for systematic reviews of diagnostic test accuracy. Version 1.0. The Cochrane Collaboration, 2010.

\section{MacKay 2010}

MacKay DF, Smith CG, Dobbie R, Pell JP. Gestational age at delivery and special educational need: retrospective cohort study of 407,503 schoolchildren. PLOS Medicine 2010;7(6):e1000289.

\section{McCowan 2007}

McCowan LM, George-Haddad M, Stacey T, Thompson JM. Fetal growth restriction and other risk factors for stillbirth in a New Zealand setting. Australian \& New Zealand Journal of Obstetrics \& Gynaecology 2007;47(6):450-6.

\section{Morris 2011}

Morris RK, Malin G, Robson SC, Kleijnen J, Zamora J, Khan KS. Fetal umbilical artery Doppler to predict compromise of fetal/ neonatal wellbeing in a high-risk population: systematic review and bivariate meta-analysis. Ultrasound in Obstetrics \& Gynecology 2011;37(2):135-42.

\section{NHS England 2016}

NHS England. Saving Babies' Lives. A care bundle for reducing stillbirth. NHS England, 2016.

\section{NICE 2008}

National Institute for Health and Clinical Excellence. Clinical Guideline 62 - Antenatal Care. National Institute for Health and Clinical Excellence, 2008.

\section{Perkin Elmer 2015}

Perkin Elmer. The potential of PP13 in pre-eclampsia early detection. http://www.perkinelmer.co.uk/Content/ Technicallnfo/TCH_PP13NonUS.pdf (accessed 27th August 2015)

\section{Peters 2018}

Peters LL, Thornton C, de Jonge A, Khashan A, Tracy M, Downe $S$, et al. The effect of medical and operative birth interventions on child health outcomes in the first 28 days and up to 5 years of age: A linked data population-based cohort study. Birth 2018;45(4):347-57.

\section{Proud 1987}

Proud J, Grant AM. Third trimester placental grading by ultrasonography as a test of fetal wellbeing. British Medical Journal 1987;294(6588):1641-4.

\section{Ptacek 2014}

Ptacek I, Sebire NJ, Man JA, Brownbill P, Heazell AE. Systematic review of placental pathology reported in association with stillbirth. Placenta 2014;35(8):552-62.

\section{RCOG 2011}

Royal College of Obstetricians and Gynaecologists. Reduced Fetal Movements: Guideline 57. Royal College of Obstetricians and Gynaecologists, 2011.

\section{RCOG 2013}

Royal College of Obstetricians and Gynaecologists. Smallfor-Gestational-Age Fetus, Investigation and Management (Green-top Guideline No. 31). Royal College of Obstetricians and Gynaecologists, 2013.

\section{RCOG 2014}

Royal College of Obstetricians and Gynaecologists. The Investigation and Management of the Small-for-GestationalAge Fetus - Guideline 31. Royal College of Obstetricians and Gynaecologists, 2014.

\section{Riley 2015}

Riley RD, Ahmed I, Ensor J, Takwoingi Y, Kirkham A, Morris RK, et al. Meta-analysis of test accuracy studies: an exploratory method for investigating the impact of missing thresholds. Systematic Reviews 2015;4:12.

\section{Roche 2015}

Roche. Elecsys ${ }^{\circledR}$ Preeclampsia (sFlt-1 \& PIGF). http:// www.cobas.com/home/product/clinical-andimmunochemistry-testing/elecsys-preeclampsia-assays-sFlt-1PIGF.html (accessed 27th August 2015).

\section{Rutter 2001}

Rutter CM, Gatsonis CA. A hierarchical regression approach to meta-analysis of diagnostic test accuracy evaluations. Statistics in Medicine 2001;20(19):2865-84.

\section{Smith 2002}

Smith GC, Stenhouse EJ, Crossley JA, Aitken DA, Cameron AD, Connor JM. Early pregnancy levels of pregnancy-associated plasma protein a and the risk of intrauterine growth restriction, premature birth, preeclampsia, and stillbirth. Journal of Clinical Endocrinology and Metabolism 2002;87(4):1762-7.

\section{Smith 2006}

Smith GC, Shah I, Crossley JA, Aitken DA, Pell JP, Nelson SM, et al. Pregnancy-associated plasma protein $A$ and alphafetoprotein and prediction of adverse perinatal outcome. Obstetrics and Gynecology 2006;107(1):161-6.

\section{Steinhauser 2016}

Steinhauser S, Schumacher M, Rücker G. Modelling multiple thresholds in meta-analysis of diagnostic test accuracy studies. BMC Medical Research Methodology 2016;16(1):97.

\section{Stock 2012}

Stock SJ, Ferguson E, Duffy A, Ford I, Chalmers J, Norman JE. Outcomes of elective induction of labour compared with 
expectant management: population based study. BMJ 2012;344:e2838.

\section{Takwoingi 2013}

Takwoingi Y, Leeflang MM, Deeks JJ. Empirical evidence of the importance of comparative studies of diagnostic test accuracy. Annals of Internal Medicine 2013;158(7):544-54.

\section{Whiting 2011a}

Whiting P, Westwood M, Beynon R, Burke M, Sterne JA, Glanville J. Inclusion of methodological filters in searches for diagnostic test accuracy studies misses relevant studies. Journal of Clinical Epidemiology 2011;64(6):602-7.

\section{Whiting 2011b}

Whiting PF, Rutjes AW, Westwood ME, Mallett S, Deeks JJ, Reitsma JB, et al. QUADAS-2: a revised tool for the quality

\section{CHARACTERISTICS OF STUDIES}

Characteristics of included studies [ordered by study ID] assessment of diagnostic accuracy studies. Annals of Internal Medicine 2011;155(8):529-36.

\section{Worton 2014}

Worton S, Sibley CP, Heazell AE. Understanding the placental aetiology of fetal growth restriction; could this lead to personalized management strategies?. Fetal and Maternal Medicine Review 2014;25(2):95-116.

\section{References to other published versions of this review Heazell 2016}

Heazell AE, Hayes DJ, Whitworth M, Takwoingi Y, Bayliss SE, Davenport C. Diagnostic accuracy of biochemical tests of placental function versus ultrasound assessment of fetal size for stillbirth and small-for-gestational-age infants. Cochrane Database of Systematic Reviews 2016, Issue 6. [DOI: 10.1002/14651858.CD012245]

\section{Altmann 1978}

\section{Study characteristics}

$$
\text { Patient sampling }
$$

Patient characteristics and setting

\section{Case reports of 10 high-risk pregnancies}

Sample size: 10 women

Gestation at sampling: > 26 weeks

Risk: high risk
hPL measured in serum, values classifies as normal/borderline/abnormal, from a reference group of 242 pregnant women. Grade III used as threshold for placental grading.

SGA defined as birthweight under the 10th percentile for gestational age

Target condition and reference standard(s)

Paper translated from German

Flow and timing

Comparative

\begin{tabular}{llll}
\hline Notes & Paper translated from German \\
\hline Methodological quality & & \\
\hline Item & $\begin{array}{l}\text { Authors' judge- } \\
\text { ment }\end{array}$ & Risk of bias & $\begin{array}{l}\text { Applicability con- } \\
\text { cerns }\end{array}$ \\
\hline
\end{tabular}

\section{DOMAIN 1: Patient Selection}

\begin{tabular}{ll}
\hline Was a consecutive or random sample of patients enrolled? & Yes \\
\hline Was a case-control design avoided? & Yes \\
\hline
\end{tabular}


Altmann 1978 (Continued)

Did the study avoid inappropriate exclusions?

Yes

\begin{tabular}{lll}
\hline Low & High \\
\hline
\end{tabular}

\section{DOMAIN 2: Index Test hPL}

Were the index test results interpreted without knowledge of Yes the results of the reference standard?

If a threshold was used, was it pre-specified? Yes

\begin{tabular}{llll}
\hline & Low & Unclear \\
\hline DOMAIN 2: Index Test Placental grading & Yes & Yes \\
\hline $\begin{array}{l}\text { Were the index test results interpreted without knowledge of } \\
\text { the results of the reference standard? }\end{array}$ & Low \\
\hline If a threshold was used, was it pre-specified?
\end{tabular}

\section{DOMAIN 3: Reference Standard}

Is the reference standards likely to correctly classify the target Yes condition?

Were the reference standard results interpreted without knowl- Unclear edge of the results of the index tests?

Unclear

Low

\section{DOMAIN 4: Flow and Timing}

Was there an appropriate interval between index test and refer- Unclear ence standard?

Did all patients receive the same reference standard?

Yes

Were all patients included in the analysis?

Yes

Unclear

Amini 2014

\section{Study characteristics}

\begin{tabular}{ll}
\hline Patient sampling & $\begin{array}{l}\text { Prospective multicentric cohort study of singleton pregnancies be- } \\
\text { tween } 28 \text { and } 42 \text { weeks. }\end{array}$
\end{tabular}
tween 28 and 42 weeks.

Patient characteristics and setting

\section{Sample size: 404}

Gestation at sampling: 24 hours before delivery

Risk: mixed (some exclusions due to hypertension) 
Amini 2014 (Continued)

Setting: Vali-Asr and Akbar-Abadi teaching hospitals of Tehran University of Medical Sciences, Iran

NICU admission: 79 neonates required NICU admission, 31 from women with hyperuricaemia

Index tests

Blood samples taken within 24 hours preceding delivery and uric acid levels were determined using the enzymatic colorimetric method. Hyperuricemia defined as serum uric acid level 1 SD greater than the appropriate for gestational age as defined by Lind and colleagues.

Target condition and reference standard(s)

Flow and timing

Comparative
SGA defined as birthweight $<10$ th percentile for gestational age according to Fenton growth charts

\begin{tabular}{llll}
\hline Notes & & \\
\hline Methodological quality & Authors' judgement & Risk of bias & $\begin{array}{l}\text { Applicability con- } \\
\text { cerns }\end{array}$ \\
\hline Item & & & \\
\hline
\end{tabular}

\section{DOMAIN 1: Patient Selection}

Was a consecutive or random sample of patients en- Yes

rolled?

\begin{tabular}{lll}
\hline Was a case-control design avoided? & Yes \\
\hline Did the study avoid inappropriate exclusions? & Yes & Low \\
\hline
\end{tabular}

\section{DOMAIN 2: Index Test Uric acid}

Were the index test results interpreted without knowledge Unclear

of the results of the reference standard?

If a threshold was used, was it pre-specified? Yes

Unclear

Low

\section{DOMAIN 3: Reference Standard}

Is the reference standards likely to correctly classify the Yes target condition?

Were the reference standard results interpreted without Yes knowledge of the results of the index tests?

Low

Low

\section{DOMAIN 4: Flow and Timing}


Amini 2014 (Continued)

Was there an appropriate interval between index test and No reference standard?

Did all patients receive the same reference standard?

Yes

Were all patients included in the analysis?

Yes

Low

\section{Baird 2016}

\section{Study characteristics}

\begin{tabular}{ll}
\hline Patient sampling & $\begin{array}{l}\text { Retrospective cohort study, consecutive enrolment of women clini- } \\
\text { cally suspected of FGR }\end{array}$
\end{tabular}

\section{Patient characteristics and setting}

\section{Sample size: 107}

Gestation at sampling: $35-38$ weeks (within 2 weeks of birth)

Risk: high risk (suspected FGR, previous FGR, maternal medical conditions, decreased fetal movements)

Setting: university teaching hospital in Victoria, Australia

Mode of delivery: $45.8 \%$ normal vaginal delivery, $14.1 \%$ instrumental delivery, $12.1 \%$ elective caesarean section, $28 \%$ emergency caesarean section

EFW calculated using Hadlock charts

Target condition and reference standard(s)

SGA defined as birthweight $<10$ th centile for gestational age using the most recent Australian birthweight centiles

Flow and timing

107 pregnancies met the inclusion criteria over a 12-month study period; all were included

\section{Comparative}

Notes

\section{Methodological quality}

\begin{tabular}{llll}
\hline Item Authors' judgement & Risk of bias & $\begin{array}{l}\text { Applicability con- } \\
\text { cerns }\end{array}$
\end{tabular}

\section{DOMAIN 1: Patient Selection}

\begin{tabular}{ll}
\hline Was a consecutive or random sample of patients enrolled? & Yes \\
\hline Was a case-control design avoided? & Yes \\
\hline Did the study avoid inappropriate exclusions? & Yes
\end{tabular}

\begin{tabular}{lcc}
\hline & Low & High \\
\hline Biochemical tests of placental function versus ultrasound assessment of fetal size for stillbirth and small-for-gestational-age infants \\
(Review) \\
Copyright @ 2019 The Cochrane Collaboration. Published by John Wiley \& Sons, Ltd.
\end{tabular}


Baird 2016 (Continued)

\section{DOMAIN 2: Index Test EFW}

Were the index test results interpreted without knowledge of No the results of the reference standard?

If a threshold was used, was it pre-specified? Yes

\begin{tabular}{llll}
\hline & Unclear & Low \\
\hline DOMAIN 3: Reference Standard & & \\
\hline $\begin{array}{l}\text { Is the reference standards likely to correctly classify the target } \\
\text { condition? }\end{array}$ & Yes & Yes \\
\hline $\begin{array}{l}\text { Were the reference standard results interpreted without } \\
\text { knowledge of the results of the index tests? }\end{array}$ & Low Low \\
\hline
\end{tabular}

\section{DOMAIN 4: Flow and Timing}

Was there an appropriate interval between index test and ref- Yes erence standard?

\begin{tabular}{ll}
\hline Did all patients receive the same reference standard? & Yes \\
\hline Were all patients included in the analysis? & Yes \\
\hline
\end{tabular}

\section{Barel 2016}

\section{Study characteristics}

$\begin{array}{ll}\text { Patient sampling } & \begin{array}{l}\text { Women referred to the gynaecologic ultrasound unit for SEFW } 1 \\ \text { week prior to delivery }\end{array}\end{array}$

Patient characteristics and setting

Sample size: 14,089

Gestation at sampling: 1 week before delivery (24-41 weeks)

Risk: mixed

Setting: Assaf Harofe Medical Centre

Index tests

Target condition and reference standard(s)

SGA defined as less than the 10th percentile

Flow and timing

\section{Comparative}

Notes

53 cases (4.3\%) of SGA were delivered before 34 weeks of gestation

Biochemical tests of placental function versus ultrasound assessment of fetal size for stillbirth and small-for-gestational-age infants 
Barel 2016 (Continued)

Methodological quality

\begin{tabular}{llll}
\hline Item & $\begin{array}{l}\text { Authors' judge- } \\
\text { ment }\end{array}$ & Risk of bias & $\begin{array}{l}\text { Applicability con- } \\
\text { cerns }\end{array}$ \\
\hline
\end{tabular}

\section{DOMAIN 1: Patient Selection}

\begin{tabular}{lll}
\hline Was a consecutive or random sample of patients enrolled? & Yes \\
\hline Was a case-control design avoided? & Yes \\
\hline Did the study avoid inappropriate exclusions? & Yes & Low \\
\hline
\end{tabular}

DOMAIN 2: Index Test EFW

Were the index test results interpreted without knowledge of Yes the results of the reference standard?

If a threshold was used, was it pre-specified? Yes

\begin{tabular}{lll}
\hline Low & Low \\
\hline
\end{tabular}

\section{DOMAIN 3: Reference Standard}

Is the reference standards likely to correctly classify the target Yes condition?

Were the reference standard results interpreted without knowl- Yes edge of the results of the index tests?

\begin{tabular}{lll}
\hline DOMAIN 4: Flow and Timing & Low \\
\hline $\begin{array}{l}\text { Was there an appropriate interval between index test and refer- } \\
\text { ence standard? }\end{array}$ & Yes \\
\hline Did all patients receive the same reference standard? & Yes \\
\hline Were all patients included in the analysis? & & Low \\
\hline
\end{tabular}

\section{Beischer 1991}

\section{Study characteristics}

Patient sampling Consecutive patients from 1971-1984 and 1985-1989

Patient characteristics and setting

Sample size: 72,062

Gestation at sampling: $30-34$ weeks 
Beischer 1991 (Continued)

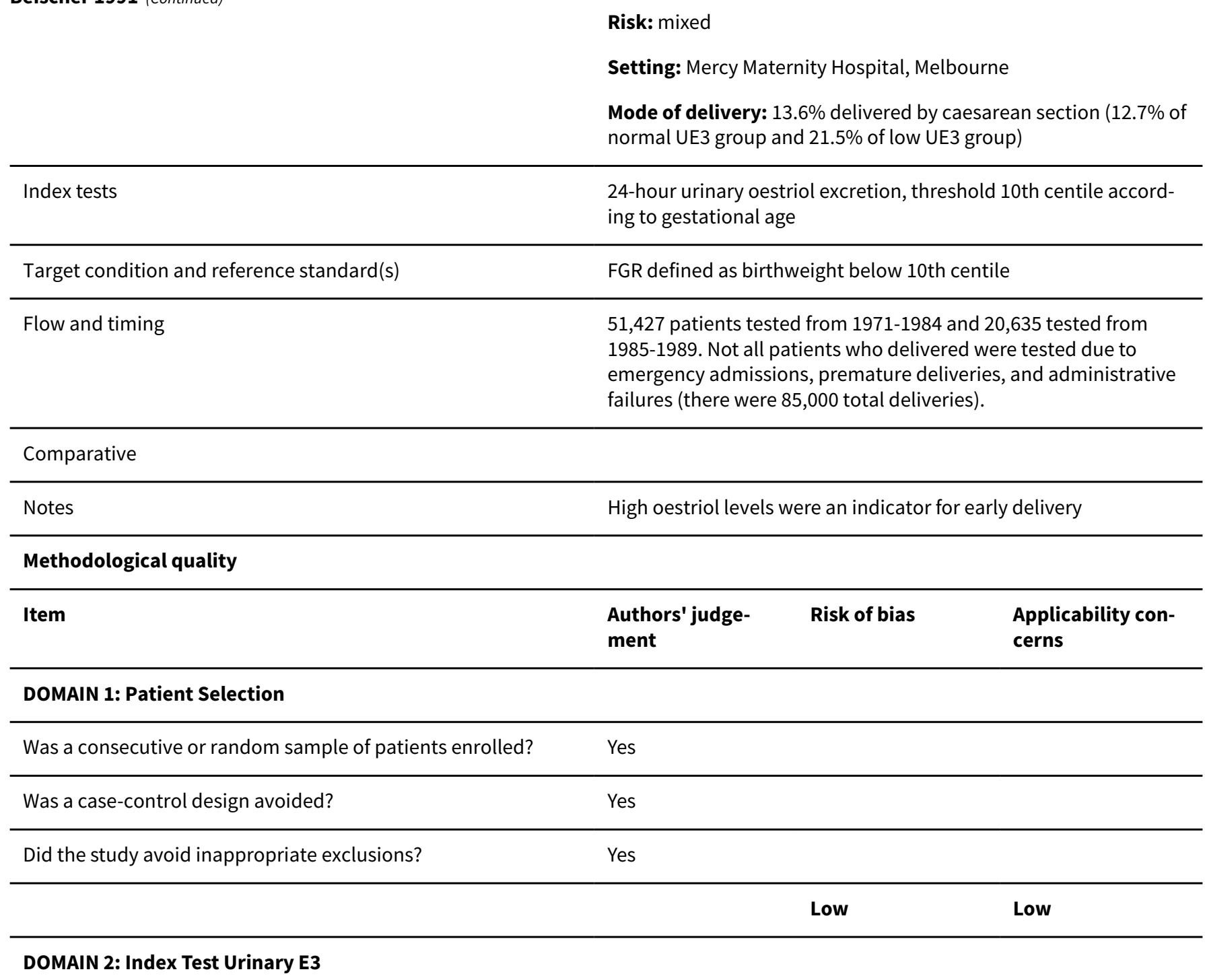

Were the index test results interpreted without knowledge of Yes the results of the reference standard?

\section{es}

\begin{tabular}{lcc}
\hline If a threshold was used, was it pre-specified? & Yes & \\
\hline & Low & High \\
\hline
\end{tabular}

DOMAIN 3: Reference Standard

Is the reference standards likely to correctly classify the target Yes condition?

Were the reference standard results interpreted without knowl- Unclear

edge of the results of the index tests?

Unclear

Low

\section{DOMAIN 4: Flow and Timing}




\section{Beischer 1991 (Continued)}

Was there an appropriate interval between index test and refer- Yes ence standard?

Did all patients receive the same reference standard?

Yes

Were all patients included in the analysis?

No

Low

\section{Bellomo 2011}

\section{Study characteristics}

\begin{tabular}{ll}
\hline Patient sampling & $\begin{array}{l}\text { Prospective cohort of women admitted for suspected hypertension } \\
\text { during pregnancy }\end{array}$
\end{tabular}

\section{Patient characteristics and setting}

\section{Sample size: 163}

Gestation at sampling: $30.4+/-4.1$ weeks

Risk: high (all suspected hypertension, $44.7 \%$ developed preeclampsia)

Mode of delivery: 39\% delivered by caesarean section

Setting: San Giovanni Battista Hospital, Foligno, Italy

Index tests

Uric acid measured in serum, hyperuricemia defined as $>309$ umol/ L

\section{Target condition and reference standard(s)}

Flow and timing

SGA defined as those weighing less than the 10th centile based on nationwide derived centile charts for singleton births

Some patients did not complete the study due to not meeting the BP criteria on entry, elevated proteinuria, incomplete data, insufficient $\mathrm{BP}$ recordings, or withdrawal of consent.

\section{Comparative}

Notes

\section{Methodological quality}

\begin{tabular}{llll}
\hline Item Authors' judgement & Risk of bias & $\begin{array}{l}\text { Applicability con- } \\
\text { cerns }\end{array}$
\end{tabular}

\section{DOMAIN 1: Patient Selection}

\begin{tabular}{ll}
\hline Was a consecutive or random sample of patients enrolled? & Yes \\
\hline Was a case-control design avoided? & Yes \\
\hline Did the study avoid inappropriate exclusions? & Yes
\end{tabular}

\begin{tabular}{lcc}
\hline & Low & High \\
\hline Biochemical tests of placental function versus ultrasound assessment of fetal size for stillbirth and small-for-gestational-age infants \\
(Review) \\
Copyright $\odot 2019$ The Cochrane Collaboration. Published by John Wiley \& Sons, Ltd.
\end{tabular}


Bellomo 2011 (Continued)

\section{DOMAIN 2: Index Test Uric acid}

Were the index test results interpreted without knowledge of Yes the results of the reference standard?
If a threshold was used, was it pre-specified?
Unclear

\begin{tabular}{|c|c|c|c|}
\hline & & Unclear & Low \\
\hline \multicolumn{4}{|l|}{ DOMAIN 3: Reference Standard } \\
\hline $\begin{array}{l}\text { Is the reference standards likely to correctly classify the target } \\
\text { condition? }\end{array}$ & Yes & & \\
\hline \multirow[t]{2}{*}{$\begin{array}{l}\text { Were the reference standard results interpreted without } \\
\text { knowledge of the results of the index tests? }\end{array}$} & Unclear & & \\
\hline & & Unclear & Low \\
\hline \multicolumn{4}{|l|}{ DOMAIN 4: Flow and Timing } \\
\hline $\begin{array}{l}\text { Was there an appropriate interval between index test and ref- } \\
\text { erence standard? }\end{array}$ & Yes & & \\
\hline Did all patients receive the same reference standard? & Yes & & \\
\hline \multirow[t]{2}{*}{ Were all patients included in the analysis? } & No & & \\
\hline & & Unclear & \\
\hline
\end{tabular}

\section{Ben-Haroush 2007}

\section{Study characteristics}

$\begin{array}{ll}\text { Patient sampling } & \begin{array}{l}\text { Women with healthy singleton pregnancies recruited at time of } \\ \text { delivery }\end{array}\end{array}$

$\begin{array}{ll}\text { Patient characteristics and setting } & \text { Sample size: } 259 \\ & \text { Gestation at sampling: 28-34 weeks } \\ & \begin{array}{l}\text { Risk: low (no obstetric complications, hypertensive and diabetic } \\ \text { pregnancies were excluded) }\end{array}\end{array}$

Index tests

Estimated fetal weight calculated using Hadlock's formula and converted to percentiles using locally developed growth charts

\begin{tabular}{ll}
\hline Target condition and reference standard(s) & SGA defined as $<10$ th centile for gestational age \\
\hline Flow and timing & 259 women were included in the study \\
\hline Comparative & \\
\hline Notes
\end{tabular}

Biochemical tests of placental function versus ultrasound assessment of fetal size for stillbirth and small-for-gestational-age infants 
Ben-Haroush 2007 (Continued)

Methodological quality

\begin{tabular}{llll}
\hline Item & $\begin{array}{l}\text { Authors' judge- } \\
\text { ment }\end{array}$ & Risk of bias & $\begin{array}{l}\text { Applicability con- } \\
\text { cerns }\end{array}$ \\
\hline
\end{tabular}

\section{DOMAIN 1: Patient Selection}

Was a consecutive or random sample of patients enrolled?

Was a case-control design avoided?

Did the study avoid inappropriate exclusions?
Yes

Yes

No

Low High

\section{DOMAIN 2: Index Test EFW}

Were the index test results interpreted without knowledge of Yes the results of the reference standard?

If a threshold was used, was it pre-specified?

Yes

\begin{tabular}{lll}
\hline & Low & Low \\
\hline DOMAIN 3: Reference Standard & & Unclear \\
\hline $\begin{array}{l}\text { Is the reference standards likely to correctly classify the target } \\
\text { condition? }\end{array}$ & Yes \\
\hline $\begin{array}{l}\text { Were the reference standard results interpreted without knowl- } \\
\text { edge of the results of the index tests? }\end{array}$ & Low \\
\hline DOMAIN 4: Flow and Timing & Yes \\
\hline $\begin{array}{l}\text { Was there an appropriate interval between index test and refer- } \\
\text { ence standard? }\end{array}$ & Yes \\
\hline Did all patients receive the same reference standard? & Unclear \\
\hline Were all patients included in the analysis? & \\
\hline
\end{tabular}

\section{Benton 2016}

\section{Study characteristics}

Patient sampling Prospective cohort of suspected FGR pregnancies from 3 centres

\footnotetext{
Patient characteristics and setting
}

\section{Sample size: 411}

Age: $18-45$ 
Risk: high (suspected FGR, hypertension and pre-eclampsia excluded)

Setting: 3 sites in Canada, New Zealand, UK

Mode of delivery: 92 inductions, 38 caesarean, 7 instrumental

NICU admission: 36 admission, 26 of these from the low PIGF group

Index tests

Target condition and reference standard(s)

Flow and timing

PIGF measured using Triage immunoassay, very low PIGF defined as $<12$ $\mathrm{pg} / \mathrm{mL}$

SGA defined as below the 3rd centile. Birthweight centile determined by the Canadian standard for multi-ethnicity.

Women recruited from inpatient and outpatient centres at BC Women's Hospital, Vancouver and Ottawa Hospital; cohort of FGR pregnancies from Auckland, New Zealand with banked maternal blood samples; cohort of FGR pregnancies from the UK (PELICAN-FGR Study)

\section{Comparative}

$\begin{array}{ll}\text { Notes } & \text { Placental pathology data were available for } 213 \text { women; } 55 \text { of } 94 \text { with a low } \\ & \text { PIGF were grade II or III, as was one of the } 119 \text { with a normal PIGF. }\end{array}$

\section{Methodological quality}

\begin{tabular}{llcl}
\hline Item & Authors' judgement & Risk of bias & $\begin{array}{l}\text { Applicability con- } \\
\text { cerns }\end{array}$ \\
\hline
\end{tabular}

\section{DOMAIN 1: Patient Selection}

Was a consecutive or random sample of patients en- Yes rolled?

\begin{tabular}{llll}
\hline Was a case-control design avoided? & Yes & \\
\hline Did the study avoid inappropriate exclusions? & Yes & Low & High \\
\hline
\end{tabular}

\section{DOMAIN 2: Index Test PIGF}

Were the index test results interpreted without knowl- Yes edge of the results of the reference standard?

If a threshold was used, was it pre-specified? Yes

\begin{tabular}{lll}
\hline Low & Low \\
\hline
\end{tabular}

\section{DOMAIN 3: Reference Standard}

Is the reference standards likely to correctly classify Yes the target condition?

Were the reference standard results interpreted with- Yes out knowledge of the results of the index tests? 
Benton 2016 (Continued)

Low

High

\section{DOMAIN 4: Flow and Timing}

Was there an appropriate interval between index test Yes

and reference standard?

Did all patients receive the same reference standard? Yes

Were all patients included in the analysis? Yes

Low

\section{Berkowitz 1988}

\section{Study characteristics}

\begin{tabular}{ll}
\hline Patient sampling & $\begin{array}{l}\text { Women with singleton pregnancies selected on the basis of } \\
\text { known risk factors or clinical suspicion of IUGR }\end{array}$ \\
\hline
\end{tabular}

Patient characteristics and setting

\section{Sample size: 168}

Gestation at sampling: 30 to 42 weeks (all last measurements used)

Risk: high (clinical suspicion of IUGR, previous infant with IUGR, complications associated with IUGR, smoking, alcohol/drug abuse, postdates)

Setting: Mount Sinai Medical Centre, New York

\begin{tabular}{ll}
\hline Index tests & EFW calculated using Shepard formula \\
\hline Target condition and reference standard(s) & $\begin{array}{l}\text { SGA defined as below 10th centile for gestational age at birth on } \\
\text { the basis of the nomogram by Brenner and colleagues }\end{array}$
\end{tabular}

\section{Flow and timing}

Comparative

\section{Notes}

\section{Methodological quality}

\begin{tabular}{|c|c|c|c|}
\hline Item & $\begin{array}{l}\text { Authors' judge- } \\
\text { ment }\end{array}$ & Risk of bias & $\begin{array}{l}\text { Applicability con- } \\
\text { cerns }\end{array}$ \\
\hline
\end{tabular}

\section{DOMAIN 1: Patient Selection}

\begin{tabular}{ll}
\hline Was a consecutive or random sample of patients enrolled? & Yes \\
\hline Was a case-control design avoided? & Yes \\
\hline Did the study avoid inappropriate exclusions? & Yes \\
\hline
\end{tabular}


Berkowitz 1988 (Continued)

Low

High

\section{DOMAIN 2: Index Test EFW}

Were the index test results interpreted without knowledge of

the results of the reference standard?

If a threshold was used, was it pre-specified?

Yes

Low Low

\section{DOMAIN 3: Reference Standard}

Is the reference standards likely to correctly classify the target Yes condition?

Were the reference standard results interpreted without knowl- Unclear edge of the results of the index tests?

Unclear

Low

\section{DOMAIN 4: Flow and Timing}

Was there an appropriate interval between index test and refer- Yes ence standard?

Did all patients receive the same reference standard?

Yes

Were all patients included in the analysis?

Yes

Low

Bikmetova 2013

\section{Study characteristics}

\begin{tabular}{ll}
\hline Patient sampling & Retrospective cohort study \\
\hline Patient characteristics and setting & Sample size: 518 \\
& Gestation at sampling: 3rd trimester \\
& Risk: unknown \\
\hline Index tests & Ultrasound formula not known \\
\hline Target condition and reference standard(s) & IUGR definition unknown \\
\hline Flow and timing & \\
\hline Comparative & \\
\hline Notes & \\
\hline
\end{tabular}

\section{Methodological quality}

Biochemical tests of placental function versus ultrasound assessment of fetal size for stillbirth and small-for-gestational-age infants 
Bikmetova 2013 (Continued)

$\begin{array}{llll}\text { Item } & \begin{array}{l}\text { Authors' judge- } \\ \text { ment }\end{array} & \text { Risk of bias } & \begin{array}{l}\text { Applicability con- } \\ \text { cerns }\end{array}\end{array}$

DOMAIN 1: Patient Selection

\begin{tabular}{ll}
\hline Was a consecutive or random sample of patients enrolled? & Yes \\
\hline Was a case-control design avoided? & Yes \\
\hline Did the study avoid inappropriate exclusions? & Yes
\end{tabular}

\begin{tabular}{llll}
\hline DOMAIN 2: Index Test EFW & Low & Unclear \\
\hline $\begin{array}{l}\text { Were the index test results interpreted without knowledge of } \\
\text { the results of the reference standard? }\end{array}$ & Unclear & Unclear & Low \\
\hline If a threshold was used, was it pre-specified? & & Und
\end{tabular}

\section{DOMAIN 3: Reference Standard}

Is the reference standards likely to correctly classify the target Unclear condition?

Were the reference standard results interpreted without knowl- Unclear edge of the results of the index tests?

Unclear

Unclear

\section{DOMAIN 4: Flow and Timing}

Was there an appropriate interval between index test and refer- Unclear ence standard?

Did all patients receive the same reference standard?

Yes

Were all patients included in the analysis?

Yes

Unclear

\section{Callec 2015}

\section{Study characteristics}

\begin{tabular}{ll}
\hline Patient sampling & $\begin{array}{l}\text { Prospective cohort study across } 2 \text { centres between } 2003 \text { and } 2006, \text { diabetes } \\
\text { and illiteracy excluded, as well as intention to deliver outside the hospital or } \\
\text { to move outside the region within } 3 \text { years. }\end{array}$
\end{tabular}

Patient characteristics and setting

\section{Sample size: 1897}

Gestation at sampling: $30-35$ weeks

Risk: mixed 
Callec 2015 (Continued)

Setting: EDEN study, 2 university maternity centres, France

Mode of delivery: 1404 normal vaginal deliveries, 195 instrumental, 298 caesarean sections

NICU admission: 128 admissions, 20 of these from the EFW $<10$ group

\begin{tabular}{ll}
\hline Index tests & EFW measured using Hadlock formula \\
\hline Target condition and reference standard(s) & SGA defined as birthweight below the 10th centile \\
\hline Flow and timing & $\begin{array}{l}2002 \text { women originally included in the cohort; 80 were lost to follow-up, de- } \\
\text { clined to continue participation, or experienced fetal death. } 1 \text { woman with a } \\
\text { stillbirth was also excluded. }\end{array}$ \\
\hline Comparative & $\begin{array}{l}\text { Some elective caesarean sections and inductions were performed due to re- } \\
\text { duced fetal growth; there were higher rates in the FP compared with the FN } \\
\text { group. }\end{array}$
\end{tabular}

\section{Methodological quality}

\begin{tabular}{llll}
\hline Item Authors' judgement & Risk of bias & $\begin{array}{l}\text { Applicability con- } \\
\text { cerns }\end{array}$
\end{tabular}

\section{DOMAIN 1: Patient Selection}

Was a consecutive or random sample of patients en- Yes rolled?

\begin{tabular}{llll}
\hline Was a case-control design avoided? & Yes & \\
\hline Did the study avoid inappropriate exclusions? & No & Unclear & Low \\
\hline
\end{tabular}

\section{DOMAIN 2: Index Test EFW}

Were the index test results interpreted without knowl- Unclear edge of the results of the reference standard?

If a threshold was used, was it pre-specified? Yes

\begin{tabular}{lll}
\hline DOMAIN 3: Reference Standard & Unclear & Low \\
\hline $\begin{array}{l}\text { Is the reference standards likely to correctly classify } \\
\text { the target condition? }\end{array}$ & & Les \\
\hline $\begin{array}{l}\text { Were the reference standard results interpreted with- Unclear } \\
\text { out knowledge of the results of the index tests? }\end{array}$ & Unclear \\
\hline
\end{tabular}

\section{DOMAIN 4: Flow and Timing}


Callec 2015 (Continued)

Was there an appropriate interval between index test Yes and reference standard?

Did all patients receive the same reference standard? Yes

Were all patients included in the analysis? Yes

Low

\section{Campbell 1972}

\section{Study characteristics}

\begin{tabular}{|c|c|c|}
\hline Patient sampling & \multicolumn{2}{|l|}{ All women at risk of FGR } \\
\hline \multirow[t]{5}{*}{ Patient characteristics and setting } & \multicolumn{2}{|l|}{ Sample size: 284} \\
\hline & \multicolumn{2}{|l|}{ Gestation at sampling: unknown } \\
\hline & \multicolumn{2}{|c|}{$\begin{array}{l}\text { Risk: high ( } 268 \text { women clinically suspected of having a small } \\
\text { uterus, } 16 \text { diabetic or with a bad obstetric history) }\end{array}$} \\
\hline & \multicolumn{2}{|c|}{ Setting: Queen Charlotte's Maternity Hospital } \\
\hline & \multicolumn{2}{|c|}{ Mode of delivery: 43 instrumental deliveries, 26 EmCS, 29 EICS } \\
\hline Index tests & \multicolumn{2}{|c|}{$\begin{array}{l}\text { Oestrogens measured as oestriol in } 26 \text { cases and total oestrogens } \\
\text { in the rest. One or no abnormal measurements classed as normal, } \\
2+\text { classed as abnormal; measurements did not have to be consec- } \\
\text { utive. }\end{array}$} \\
\hline Target condition and reference standard(s) & \multicolumn{2}{|c|}{ SGA defined as a birthweight below the 5th centile } \\
\hline \multicolumn{3}{|l|}{ Flow and timing } \\
\hline \multicolumn{3}{|l|}{ Comparative } \\
\hline \multicolumn{3}{|l|}{ Notes } \\
\hline \multicolumn{3}{|l|}{ Methodological quality } \\
\hline Item & $\begin{array}{l}\text { Authors' judge- } \\
\text { ment }\end{array}$ & $\begin{array}{l}\text { Applicability con- } \\
\text { cerns }\end{array}$ \\
\hline
\end{tabular}

\section{DOMAIN 1: Patient Selection}

\begin{tabular}{llll}
\hline Was a consecutive or random sample of patients enrolled? & Unclear \\
\hline Was a case-control design avoided? & Yes & \\
\hline Did the study avoid inappropriate exclusions? & Yes & Low & High
\end{tabular}

\section{DOMAIN 2: Index Test Urinary E3}

Biochemical tests of placental function versus ultrasound assessment of fetal size for stillbirth and small-for-gestational-age infants 
Campbell 1972 (Continued)

Were the index test results interpreted without knowledge of Unclear the results of the reference standard?

If a threshold was used, was it pre-specified?

Yes

Low High

\section{DOMAIN 3: Reference Standard}

Is the reference standards likely to correctly classify the target Yes condition?

Were the reference standard results interpreted without knowl- Unclear edge of the results of the index tests?

\begin{tabular}{lll}
\hline DOMAIN 4: Flow and Timing & Low \\
\hline $\begin{array}{l}\text { Was there an appropriate interval between index test and refer- } \\
\text { ence standard? }\end{array}$ & Yes \\
\hline Did all patients receive the same reference standard? & Yes \\
\hline Were all patients included in the analysis? & Yes \\
\hline
\end{tabular}

Low

\section{Cedard 1979}

\section{Study characteristics}

\section{Patient sampling}

\section{Patient characteristics and setting}

Index tests

Target condition and reference standard(s)

Flow and timing

\section{Comparative}

Biochemical tests of placental function versus ultrasound assessment of fetal size for stillbirth and small-for-gestational-age infants All patients were clinically suspected of IUGR due to lower than expected SFH on 2 consecutive visits

\section{Sample size: 64}

Gestation at sampling: $37-39$ weeks

Risk: high (all clinically suspected of IUGR due to lower than expected SFH on 2 consecutive visits)

Setting: Maternite de Port-Royal, France

Oestriol measured in plasma using the oestriol RIA kit IM 82, levels for normal pregnancies established from 301 values obtained from 88 judged to be free of complications and low defined as < 10th percentile

SGA defined as below the 10th centile, birthweights calculated using Lubchenko curve

Plasma total oestriol was studied in 222 pregnancies, 64 of these had measurements at 37-39 weeks 
Cedard 1979 (Continued)

Notes

\section{Methodological quality}

\begin{tabular}{llll}
\hline Item & Authors' judge- & Risk of bias & $\begin{array}{l}\text { Applicability con- } \\
\text { ment }\end{array}$
\end{tabular}

\section{DOMAIN 1: Patient Selection}

\begin{tabular}{lc} 
Was a consecutive or random sample of patients enrolled? & Yes \\
\hline Was a case-control design avoided? & Yes \\
\hline Did the study avoid inappropriate exclusions? & Yes \\
\hline
\end{tabular}

\begin{tabular}{lll}
\hline High & Low \\
\hline
\end{tabular}

\section{DOMAIN 2: Index Test E3}

Were the index test results interpreted without knowledge of Yes the results of the reference standard?

If a threshold was used, was it pre-specified?

Yes

Low Low

\section{DOMAIN 3: Reference Standard}

Is the reference standards likely to correctly classify the target Yes condition?

Were the reference standard results interpreted without knowl- Unclear edge of the results of the index tests?

\begin{tabular}{lll}
\hline & Unclear & Low \\
\hline DOMAIN 4: Flow and Timing & \\
\hline $\begin{array}{l}\text { Was there an appropriate interval between index test and refer- } \\
\text { ence standard? }\end{array}$ & Yes \\
\hline Did all patients receive the same reference standard? & Yes \\
\hline Were all patients included in the analysis? &
\end{tabular}

Low

\section{Chaiworapongsa 2013}

\section{Study characteristics}

Patient sampling Prospective cohort between November 2003 and August 2006

Patient characteristics and setting Sample size: 1269

Biochemical tests of placental function versus ultrasound assessment of fetal size for stillbirth and small-for-gestational-age infants 
Gestation at sampling: $30-34$ weeks

Risk: mixed (PE excluded in early pregnancy, otherwise mixed)

Setting: Sotero del Rio Hospital, Santiago, Chile

Index tests

PIGF/sVEGFR-1 and PIGF/sEng

SGA defined as birthweight below 10th centile for gestational age according to the Chilean birthweight distribution of a Hispanic population.

Stillbirth defined as death of a fetus before delivery that was not a consequence of an induced termination of pregnancy (including intrapartum and antepartum stillbirth)

Flow and timing

Patients were excluded if they delivered $<34$ weeks $(n=29)$ and did not have a plasma sample collected at 30-34 weeks $(n=326)$

\section{Comparative}

Notes

\section{Methodological quality}

\begin{tabular}{llll}
\hline Item & $\begin{array}{l}\text { Authors' judge- } \\
\text { ment }\end{array}$ & Risk of bias & $\begin{array}{l}\text { Applicability con- } \\
\text { cerns }\end{array}$
\end{tabular}

\section{DOMAIN 1: Patient Selection}

\begin{tabular}{lcc}
\hline Was a consecutive or random sample of patients enrolled? & Yes \\
\hline Was a case-control design avoided? & Yes & \\
\hline Did the study avoid inappropriate exclusions? & Yes & Low \\
\hline
\end{tabular}

\section{DOMAIN 2: Index Test PIGF}

Were the index test results interpreted without knowledge of Yes the results of the reference standard?

\begin{tabular}{lll}
\hline If a threshold was used, was it pre-specified? & No & \\
\hline & High & Unclear \\
\hline
\end{tabular}

\section{DOMAIN 3: Reference Standard}

Is the reference standards likely to correctly classify the target Yes condition?

Were the reference standard results interpreted without knowl- Unclear edge of the results of the index tests?

\begin{tabular}{l} 
Unclear \\
Low \\
\hline
\end{tabular}

\section{DOMAIN 4: Flow and Timing}

Biochemical tests of placental function versus ultrasound assessment of fetal size for stillbirth and small-for-gestational-age infants 
Chaiworapongsa 2013 (Continued)

Was there an appropriate interval between index test and refer- Yes ence standard?

Did all patients receive the same reference standard?

Yes

Were all patients included in the analysis?

No

Low

\section{Chard 1985}

\section{Study characteristics}

\begin{tabular}{ll}
\hline Patient sampling & $\begin{array}{l}\text { Antenatal patients with } 3 \text { or more blood samples at weekly inter- } \\
\text { vals from the 36th week onwards }\end{array}$
\end{tabular}

\section{Patient characteristics and setting}

\section{Sample size: 392}

Gestation at sampling: 36 weeks onwards

Risk: mixed (144 with varying degrees of pre-eclampsia)

Setting: Solihull Hospital, Birmingham UK

Index tests

Target condition and reference standard(s)

$\mathrm{hPL}$ and oestriol measured in serum using well-established commercial kits

IUGR defined as a delivered weight below the 10th percentile for the group (2775 g)

Flow and timing

\section{Comparative}

Notes

\section{Methodological quality}

\begin{tabular}{llll}
\hline Item & $\begin{array}{l}\text { Authors' judge- } \\
\text { ment }\end{array}$ & Risk of bias & $\begin{array}{l}\text { Applicability con- } \\
\text { cerns }\end{array}$
\end{tabular}

\section{DOMAIN 1: Patient Selection}

\begin{tabular}{llll}
\hline Was a consecutive or random sample of patients enrolled? & Yes \\
\hline Was a case-control design avoided? & Yes & \\
\hline Did the study avoid inappropriate exclusions? & Yes & Low \\
\hline
\end{tabular}

\section{DOMAIN 2: Index Test hPL}

Were the index test results interpreted without knowledge of Unclear the results of the reference standard? 
Chard 1985 (Continued)

\begin{tabular}{lcc}
\hline & Unclear & Low \\
\hline DOMAIN 2: Index Test E3 &
\end{tabular}

\section{DOMAIN 2: Index Test E3}

Were the index test results interpreted without knowledge of Unclear the results of the reference standard?

If a threshold was used, was it pre-specified? Yes

Unclear

Low

\section{DOMAIN 3: Reference Standard}

Is the reference standards likely to correctly classify the target Yes condition?

Were the reference standard results interpreted without knowl- Unclear edge of the results of the index tests?

\section{Unclear}

\section{DOMAIN 4: Flow and Timing}

Was there an appropriate interval between index test and refer- Yes ence standard?

\begin{tabular}{ll}
\hline Did all patients receive the same reference standard? & Yes \\
\hline Were all patients included in the analysis? & Yes \\
\hline
\end{tabular}

\section{Chauhan 1999}

\section{Study characteristics}

$\begin{array}{ll}\text { Patient sampling } & \begin{array}{l}162 \text { patients with oligohydramnios and } 162 \text { patients with ade- } \\ \text { quate amniotic fluid }\end{array}\end{array}$

Patient characteristics and setting

Sample size: 324

Gestation at sampling: 3rd trimester, mean 34 weeks

Risk: mixed

Setting: Spartanburg Regional Medical Center, Jackson, Mississippi

\begin{tabular}{ll}
\hline Index tests & EFW, Hadlock formula \\
\hline Target condition and reference standard(s) & SGA defined as below 10th centile for gestational age
\end{tabular}

Flow and timing

Biochemical tests of placental function versus ultrasound assessment of fetal size for stillbirth and small-for-gestational-age infants 
Chauhan 1999 (Continued)

Comparative

$$
\text { Notes }
$$

\section{Methodological quality}

\begin{tabular}{|c|c|c|c|}
\hline Item & $\begin{array}{l}\text { Authors' judge- } \\
\text { ment }\end{array}$ & Risk of bias & $\begin{array}{l}\text { Applicability con- } \\
\text { cerns }\end{array}$ \\
\hline
\end{tabular}

\section{DOMAIN 1: Patient Selection}

Was a consecutive or random sample of patients enrolled?

Was a case-control design avoided?

Did the study avoid inappropriate exclusions?
Yes

Yes

Yes

Low High

\section{DOMAIN 2: Index Test EFW}

Were the index test results interpreted without knowledge of Yes the results of the reference standard?

If a threshold was used, was it pre-specified?

Yes

\begin{tabular}{lll}
\hline & Low & Low \\
\hline DOMAIN 3: Reference Standard & & Unclear \\
\hline $\begin{array}{l}\text { Is the reference standards likely to correctly classify the target } \\
\text { condition? }\end{array}$ & Yes \\
\hline $\begin{array}{l}\text { Were the reference standard results interpreted without knowl- } \\
\text { edge of the results of the index tests? }\end{array}$ & Low \\
\hline DOMAIN 4: Flow and Timing & Yes \\
\hline $\begin{array}{l}\text { Was there an appropriate interval between index test and refer- } \\
\text { ence standard? }\end{array}$ & Yes \\
\hline Did all patients receive the same reference standard? & Low \\
\hline Were all patients included in the analysis?
\end{tabular}

\section{Chauhan 1999a}

\section{Study characteristics}

Patient sampling

287 women with pre-eclampsia and 287 healthy controls

Biochemical tests of placental function versus ultrasound assessment of fetal size for stillbirth and small-for-gestational-age infants 


\section{Chauhan 1999a (Continued)}

Patient characteristics and setting

\section{Sample size: 574}

Gestation at sampling: average 35 weeks

Risk: mixed

Setting: Spartanburg Regional Medical Center, Jackson, Mississippi

Index tests

Target condition and reference standard(s)

SGA defined as below the 10th centile for gestational age

Flow and timing

Comparative

Notes

\section{Methodological quality}

\begin{tabular}{llll}
\hline Item & $\begin{array}{l}\text { Authors' judge- } \\
\text { ment }\end{array}$ & Risk of bias & $\begin{array}{l}\text { Applicability con- } \\
\text { cerns }\end{array}$
\end{tabular}

\section{DOMAIN 1: Patient Selection}

\begin{tabular}{llll}
\hline Was a consecutive or random sample of patients enrolled? & Yes \\
\hline Was a case-control design avoided? & Yes & \\
\hline Did the study avoid inappropriate exclusions? & Yes & Low High \\
\hline
\end{tabular}

\section{DOMAIN 2: Index Test EFW}

Were the index test results interpreted without knowledge of Yes the results of the reference standard?

If a threshold was used, was it pre-specified?

Yes

\begin{tabular}{lll}
\hline Low & Low \\
\hline
\end{tabular}

\section{DOMAIN 3: Reference Standard}

Is the reference standards likely to correctly classify the target Yes condition?

Were the reference standard results interpreted without knowl- Yes edge of the results of the index tests?

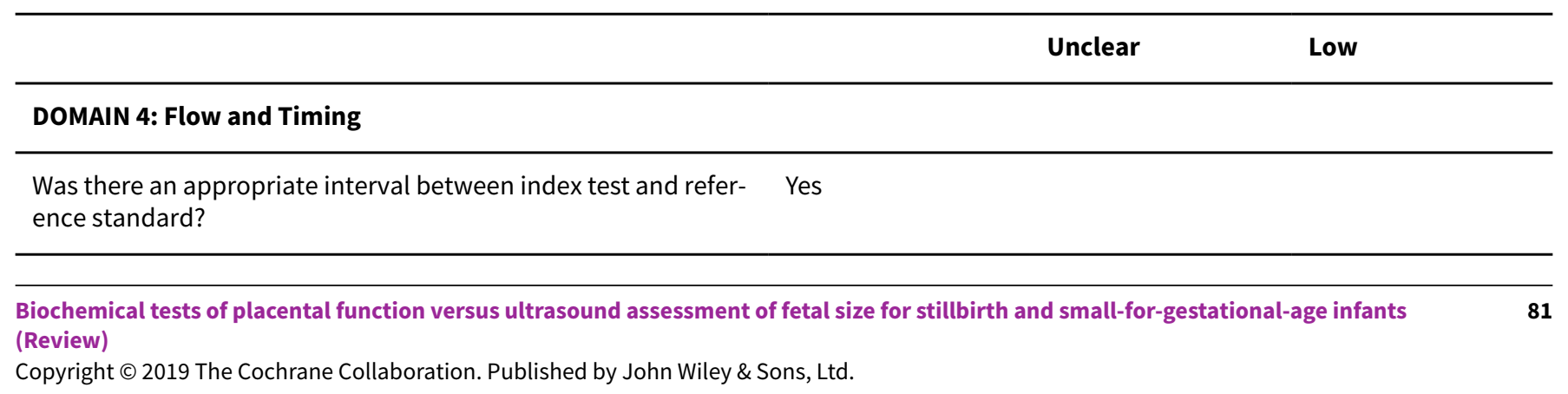




\section{Chauhan 1999a (Continued)}

Did all patients receive the same reference standard?

\section{Chauhan 2003}

\section{Study characteristics}

\section{Patient sampling}

\section{Patient characteristics and setting}

Flow and timing
Retrospective identification of all pregnant patients with hypertension delivered during a 5-year period at 3 centres.

\section{Sample size: 264}

Gestation at sampling: within 21 days of delivery

Risk: high (all women had chronic hypertension)

Setting: centres in Australia (1) and the USA (2)

EFW estimated using Hadlock formula

IUGR defined as birthweight $<10 \%$ for gestational age using the fetal growth curve by Alexander and colleagues in the USA and an Australian growth curve in the other centre

All women with chronic hypertension defined according to ACOG criteria who delivered within 5-year period, had a reliable gestational age, and a SEFW within 3 weeks of delivery. Known fetal anomalies, multiple gestations, gestational hypertension, pre-eclampsia, diabetes mellitus were excluded.

\section{Comparative}

\section{Notes}

\section{Methodological quality}

\begin{tabular}{llll}
\hline Item Authors' judgement & Risk of bias & $\begin{array}{l}\text { Applicability con- } \\
\text { cerns }\end{array}$ \\
\hline
\end{tabular}

\section{DOMAIN 1: Patient Selection}

Was a consecutive or random sample of patients en- Yes rolled?

\begin{tabular}{llll}
\hline Was a case-control design avoided? & Yes & \\
\hline Did the study avoid inappropriate exclusions? & Yes & Low & High \\
\hline
\end{tabular}

\section{DOMAIN 2: Index Test EFW}


Chauhan 2003 (Continued)

Were the index test results interpreted without knowledge Unclear of the results of the reference standard?

If a threshold was used, was it pre-specified?

Yes

Unclear

Low

\section{DOMAIN 3: Reference Standard}

Is the reference standards likely to correctly classify the Yes target condition?

Were the reference standard results interpreted without Unclear knowledge of the results of the index tests?

Unclear

Low

\section{DOMAIN 4: Flow and Timing}

Was there an appropriate interval between index test and Yes reference standard?

Did all patients receive the same reference standard? Yes

Were all patients included in the analysis? Yes

Low

Chen 2012

\section{Study characteristics}

\begin{tabular}{ll}
\hline Patient sampling $\quad$ Prospective cohort study of 105 women with hypertension \\
\hline
\end{tabular}

Patient characteristics and setting

Sample size: 105

Gestation at sampling: $28-36$ weeks

Risk: high

Index tests

Target condition and reference standard(s)

IUGR defined as poor fetal growth. Perinatal death.

Flow and timing

Comparative

Notes

\section{Methodological quality}

\begin{tabular}{|c|c|c|c|}
\hline Item & $\begin{array}{l}\text { Authors' judge- } \\
\text { ment }\end{array}$ & Risk of bias & $\begin{array}{l}\text { Applicability con- } \\
\text { cerns }\end{array}$ \\
\hline
\end{tabular}

Biochemical tests of placental function versus ultrasound assessment of fetal size for stillbirth and small-for-gestational-age infants 
Chen 2012 (Continued)

\section{DOMAIN 1: Patient Selection}

\begin{tabular}{lll}
\hline Was a consecutive or random sample of patients enrolled? & Yes \\
\hline Was a case-control design avoided? & Yes & \\
\hline Did the study avoid inappropriate exclusions? & Yes & Low \\
\hline
\end{tabular}

\section{DOMAIN 2: Index Test Placental grading}

Were the index test results interpreted without knowledge of Yes the results of the reference standard?

\begin{tabular}{lll}
\hline Low & Low \\
\hline
\end{tabular}

\section{DOMAIN 3: Reference Standard}

\section{Is the reference standards likely to correctly classify the target Unclear} condition?

Were the reference standard results interpreted without knowl- Unclear edge of the results of the index tests?

Unclear High

\section{DOMAIN 4: Flow and Timing}

Was there an appropriate interval between index test and refer- Yes ence standard?

Did all patients receive the same reference standard? Yes

Were all patients included in the analysis? Yes

Low

Chen 2012a

\section{Study characteristics}

\section{Patient sampling}

Patient characteristics and setting
High-risk women

\section{Sample size: 113}

Gestation at sampling: $28-36$ weeks

Risk: high

Setting: tertiary hospital with an average of 200 or more deliveries per month 
Chen 2012a (Continued)

Index tests Grannum grade III used as threshold

Target condition and reference standard(s)

Low birthweight defined as below $2500 \mathrm{~g}$, gestational age not taken into account

Flow and timing

Comparative

Notes

\section{Methodological quality}

\begin{tabular}{llll}
\hline Item & $\begin{array}{l}\text { Authors' judge- } \\
\text { ment }\end{array}$ & Risk of bias & $\begin{array}{l}\text { Applicability con- } \\
\text { cerns }\end{array}$ \\
\hline
\end{tabular}

\section{DOMAIN 1: Patient Selection}

\begin{tabular}{ll}
\hline Was a consecutive or random sample of patients enrolled? & Yes \\
\hline Was a case-control design avoided? & Yes \\
\hline Did the study avoid inappropriate exclusions? & Yes \\
\hline
\end{tabular}

\begin{tabular}{lcc}
\hline & Low & High \\
\hline DOMAIN 2: Index Test Placental grading & &
\end{tabular}

Were the index test results interpreted without knowledge of Yes the results of the reference standard?

\begin{tabular}{lll}
\hline If a threshold was used, was it pre-specified? & Yes & Low \\
\hline
\end{tabular}

\section{DOMAIN 3: Reference Standard}

Is the reference standards likely to correctly classify the target Unclear condition?

Were the reference standard results interpreted without knowl- Unclear edge of the results of the index tests?

\begin{tabular}{lll}
\hline & Unclear & High \\
\hline DOMAIN 4: Flow and Timing &
\end{tabular}

Was there an appropriate interval between index test and refer- Yes ence standard?

Did all patients receive the same reference standard?

Were all patients included in the analysis?
Yes

Yes

Low

Biochemical tests of placental function versus ultrasound assessment of fetal size for stillbirth and small-for-gestational-age infants 


\section{Study characteristics}

Patient sampling Prospective cohort study of patients in a routine obstetric clinic

Patient characteristics and setting

\section{Sample size: 15,122}

Gestation at sampling: 28 weeks

Risk: low (hypertension, diabetes mellitus, placenta praevia, anaemia excluded)

Setting: tertiary teaching hospital

Index tests

Placental grading classified using Grannum grading, measured with ultrasound

Stillbirth between 28 and 41 weeks' gestation

19,338 women received examinations at the clinics; 17,991 of these were eligible for further analysis; 15,112 of these met the inclusion criteria

\section{Comparative}

\section{Notes}

\section{Methodological quality}

\begin{tabular}{llll}
\hline Item & $\begin{array}{l}\text { Authors' judge- } \\
\text { ment }\end{array}$ & Risk of bias & $\begin{array}{l}\text { Applicability con- } \\
\text { cerns }\end{array}$ \\
\hline
\end{tabular}

\section{DOMAIN 1: Patient Selection}

\begin{tabular}{llll}
\hline Was a consecutive or random sample of patients enrolled? & Yes \\
\hline Was a case-control design avoided? & Yes & \\
\hline Did the study avoid inappropriate exclusions? & Yes & Low & High \\
\hline
\end{tabular}

\section{DOMAIN 2: Index Test Placental grading}

Were the index test results interpreted without knowledge of Yes the results of the reference standard?

\begin{tabular}{lll}
\hline Low & Low \\
\hline
\end{tabular}

\section{DOMAIN 3: Reference Standard}

Is the reference standards likely to correctly classify the target Yes condition? 
Chen 2015 (Continued)

Were the reference standard results interpreted without knowl- Unclear edge of the results of the index tests?

Low

Low

\section{DOMAIN 4: Flow and Timing}

Was there an appropriate interval between index test and refer- Yes ence standard?

Did all patients receive the same reference standard?

Yes

Were all patients included in the analysis?

Yes

Low

\section{Chervenak 1984}

\section{Study characteristics}

\section{Patient sampling}

Patient characteristics and setting

Target condition and reference standard(s)

Flow and timing

Comparative

Notes

\section{Methodological quality}

\begin{tabular}{llll}
\hline Item & $\begin{array}{l}\text { Authors' judge- } \\
\text { ment }\end{array}$ & Risk of bias & $\begin{array}{l}\text { Applicability con- } \\
\text { cerns }\end{array}$
\end{tabular}

\section{DOMAIN 1: Patient Selection}

\begin{tabular}{llll}
\hline Was a consecutive or random sample of patients enrolled? & Yes \\
\hline Was a case-control design avoided? & Yes & \\
\hline Did the study avoid inappropriate exclusions? & Yes & Low & High \\
\hline
\end{tabular}

\section{DOMAIN 2: Index Test EFW}

Biochemical tests of placental function versus ultrasound assessment of fetal size for stillbirth and small-for-gestational-age infants 


\section{Chervenak 1984 (Continued)}

Were the index test results interpreted without knowledge of Yes the results of the reference standard?

\begin{tabular}{lll}
\hline & Low & Low \\
\hline DOMAIN 3: Reference Standard &
\end{tabular}

\section{DOMAIN 3: Reference Standard}

Is the reference standards likely to correctly classify the target Yes condition?

Were the reference standard results interpreted without knowl- Unclear edge of the results of the index tests?

\begin{tabular}{lll}
\hline DOMAIN 4: Flow and Timing & Unclear & Unclear \\
\hline $\begin{array}{l}\text { Was there an appropriate interval between index test and refer- } \\
\text { ence standard? }\end{array}$ & Yes & Yes \\
\hline Did all patients receive the same reference standard? & Yes \\
\hline Were all patients included in the analysis? & & Low \\
\hline
\end{tabular}

\section{Chew 1976}

\section{Study characteristics}

\begin{tabular}{ll}
\hline Patient sampling & Patients with high-risk pregnancies \\
\hline Patient characteristics and setting & Sample size: 43 \\
& Gestation at sampling: $30-40$ weeks \\
& Risk: high (hypertension, poor obstetric history, suspected IUGR) \\
\hline Index tests & Setting: Kandang Kerbau Hospital, Singapore \\
\hline Target condition and reference standard(s) & Urinary oestriol measured as oestradiol-17-beta \\
\hline Flow and timing & Some samples taken after fetal death \\
\hline Comparative & \\
\hline Notes & \\
\hline
\end{tabular}

\section{Methodological quality}


Chew 1976 (Continued)

$\begin{array}{llll}\text { Item } & \begin{array}{l}\text { Authors'judge- } \\ \text { ment }\end{array} & \text { Risk of bias } & \begin{array}{l}\text { Applicability con- } \\ \text { cerns }\end{array}\end{array}$

DOMAIN 1: Patient Selection

\begin{tabular}{ll}
\hline Was a consecutive or random sample of patients enrolled? & Yes \\
\hline Was a case-control design avoided? & Yes \\
\hline Did the study avoid inappropriate exclusions? & Unclear
\end{tabular}

\begin{tabular}{llll}
\hline & Low & High \\
\hline DOMAIN 2: Index Test Urinary E3 & Yes & Yes \\
\hline $\begin{array}{l}\text { Were the index test results interpreted without knowledge of } \\
\text { the results of the reference standard? }\end{array}$ & Low High \\
\hline If a threshold was used, was it pre-specified?
\end{tabular}

\section{DOMAIN 3: Reference Standard}

Is the reference standards likely to correctly classify the target Yes condition?

Were the reference standard results interpreted without knowl- Yes edge of the results of the index tests?

Low

Low

\section{DOMAIN 4: Flow and Timing}

Was there an appropriate interval between index test and refer- Unclear ence standard?

Did all patients receive the same reference standard?

Yes

Were all patients included in the analysis?

Yes

Low

\section{Chitlange 1990}

\section{Study characteristics}

Patient sampling

Patient characteristics and setting
270 pregnant women with single uncomplicated pregnancies

Sample size: 270

Gestation at sampling: $31-34$ weeks

Risk: low (only normal antenatal women were selected)

Setting: Nowrisjee Wadia Maternity Hospital

Biochemical tests of placental function versus ultrasound assessment of fetal size for stillbirth and small-for-gestational-age infants (Review)

Copyright $\odot 2019$ The Cochrane Collaboration. Published by John Wiley \& Sons, Ltd. 
Chitlange 1990 (Continued)

Mode of delivery: 3 emergency caesarean sections due to intrapartum fetal distress

\begin{tabular}{ll}
\hline Index tests & Placental grading \\
\hline Target condition and reference standard(s) & SGA defined as birthweight $<2500 \mathrm{~g}$ (combined data of IUGR, BW \\
& $<2 \mathrm{~kg}$, and LBW, $2 \mathrm{~kg}$ - to $2.49 \mathrm{~kg}$ ). No adjustments for gestational \\
& age
\end{tabular}

Flow and timing

Comparative

Notes

Methodological quality

\begin{tabular}{|c|c|c|c|}
\hline Item & $\begin{array}{l}\text { Authors' judge- } \\
\text { ment }\end{array}$ & Risk of bias & $\begin{array}{l}\text { Applicability con- } \\
\text { cerns }\end{array}$ \\
\hline
\end{tabular}

DOMAIN 1: Patient Selection

\begin{tabular}{ll}
\hline Was a consecutive or random sample of patients enrolled? & Unclear \\
\hline Was a case-control design avoided? & Unclear \\
\hline Did the study avoid inappropriate exclusions? & Yes \\
\hline
\end{tabular}

\begin{tabular}{lll}
\hline & Unclear & Low \\
\hline DOMAIN 2: Index Test Placental grading & &
\end{tabular}

Were the index test results interpreted without knowledge of Yes the results of the reference standard?

If a threshold was used, was it pre-specified? Yes

\begin{tabular}{lll}
\hline Low & Low \\
\hline
\end{tabular}

\section{DOMAIN 3: Reference Standard}

Is the reference standards likely to correctly classify the target Unclear condition?

Were the reference standard results interpreted without knowl- Yes edge of the results of the index tests?

\begin{tabular}{lll}
\hline Low & High \\
\hline
\end{tabular}

\section{DOMAIN 4: Flow and Timing}

Was there an appropriate interval between index test and refer- Yes ence standard?

Did all patients receive the same reference standard? Yes

Were all patients included in the analysis?

Yes

Biochemical tests of placental function versus ultrasound assessment of fetal size for stillbirth and small-for-gestational-age infants

Copyright $\odot 2019$ The Cochrane Collaboration. Published by John Wiley \& Sons, Ltd. 


\section{Christensen 2015}

\section{Study characteristics}

\begin{tabular}{ll}
\hline Patient sampling & $\begin{array}{l}\text { Retrospective chart review cohort study from } 2000 \text { to } 2009 \text { in a } \\
\text { single academic centre }\end{array}$
\end{tabular}

\section{Patient characteristics and setting}

\section{Sample size: 157}

Gestation at sampling: 3 rd trimester

Risk: high (all pregnancies with SUA)

Setting: University of Utah School of Medicine

EFW calculated using the Hadlock equation

SGA defined as birthweight $<2500$ g, gestational age was not taken into account

425 pregnancies identified, 234 of these were excluded (anomalies present in 165, 35 multiple gestations, birth information unavailable in 27,7 ended in stillbirth).

\section{Comparative}

$$
\text { Notes }
$$

\section{Methodological quality}

\begin{tabular}{llll}
\hline Item & $\begin{array}{l}\text { Authors' judge- } \\
\text { ment }\end{array}$ & Risk of bias & $\begin{array}{l}\text { Applicability con- } \\
\text { cerns }\end{array}$ \\
\hline
\end{tabular}

\section{DOMAIN 1: Patient Selection}

\begin{tabular}{llll}
\hline Was a consecutive or random sample of patients enrolled? & Yes \\
\hline Was a case-control design avoided? & Yes & \\
\hline Did the study avoid inappropriate exclusions? & Yes & Low & High \\
\hline
\end{tabular}

\section{DOMAIN 2: Index Test EFW}

Were the index test results interpreted without knowledge of Unclear
the results of the reference standard?

\begin{tabular}{ll}
\hline If a threshold was used, was it pre-specified? Yes & Y
\end{tabular}

\section{DOMAIN 3: Reference Standard}

Biochemical tests of placental function versus ultrasound assessment of fetal size for stillbirth and small-for-gestational-age infants 


\section{Christensen 2015 (Continued)}

Is the reference standards likely to correctly classify the target Yes condition?

Were the reference standard results interpreted without knowl- Unclear edge of the results of the index tests?

\section{Low}

High

\section{DOMAIN 4: Flow and Timing}

Was there an appropriate interval between index test and refer- Yes ence standard?

\begin{tabular}{ll}
\hline Did all patients receive the same reference standard? & Yes \\
\hline Were all patients included in the analysis? & Yes \\
\hline & Low \\
\hline
\end{tabular}

\section{Elliott 1970}

\section{Study characteristics}

\section{Patient sampling}

Patient characteristics and setting
22 pregnancies where all delivered babies with a birthweight lower than $2500 \mathrm{~g}$ after 37 weeks, part of a series of 104 pregnancies

\section{Sample size: 22}

Gestation at sampling: $3 r d$ trimester

Risk: high (all fetuses weighed under $2500 \mathrm{~g}$ )

Setting: King George V Memorial Hospital, Sydney

Index tests

Oestriol was measured using either Brown and Coyle's method or the semi-automatic method of Brown. Low was defined as a reduction of more than the SD.

Measurements were taken at daily intervals and the values used for diagnosis were the means of the values from the final week before pregnancy

Target condition and reference standard(s)

Stillbirth; intrauterine death after 37 weeks

\section{Flow and timing}

\section{Comparative}

$$
\text { Notes }
$$

We used data for the incidence of stillbirth in this SGA cohort. 5 elective caesarean sections were performed for greatly reduced oestriol excretion.

\section{Methodological quality}

$\begin{array}{llll}\text { Item } & \text { Authors' judgement } & \text { Risk of bias } & \begin{array}{l}\text { Applicability con- } \\ \text { cerns }\end{array}\end{array}$

Biochemical tests of placental function versus ultrasound assessment of fetal size for stillbirth and small-for-gestational-age infants 
Elliott 1970 (Continued)

\section{DOMAIN 1: Patient Selection}

\begin{tabular}{llll}
\hline Was a consecutive or random sample of patients enrolled? & Yes \\
\hline Was a case-control design avoided? & Yes & Low & High \\
\hline Did the study avoid inappropriate exclusions? & Yes & \\
\hline DOMAIN 2: Index Test Urinary E3 & & Yes \\
\hline Were the index test results interpreted without knowledge of & & Yes & Low \\
the results of the reference standard? & & High
\end{tabular}

\section{DOMAIN 3: Reference Standard}

Is the reference standards likely to correctly classify the tar- Yes get condition?

Were the reference standard results interpreted without No knowledge of the results of the index tests?

Low Low

\section{DOMAIN 4: Flow and Timing}

Was there an appropriate interval between index test and Yes reference standard?

Did all patients receive the same reference standard? Yes

Were all patients included in the analysis? Yes

Low

\section{Estel 1989}

\section{Study characteristics}

Patient sampling

Patient characteristics and setting
All women with reduced amniotic fluid measured with ultrasound between 38 and 40 weeks

\section{Sample size: 41}

Gestation at sampling: $38-40$ weeks

Risk: high (reduced amniotic fluid)

Index tests
Placental grading measured using ultrasound, grade III used as threshold

Biochemical tests of placental function versus ultrasound assessment of fetal size for stillbirth and small-for-gestational-age infants 
Estel 1989 (Continued)

Target condition and reference standard(s)

SGA defined as below the 10th weight percentile

Flow and timing

Comparative

Notes From translation notes

\section{Methodological quality}

\begin{tabular}{|c|c|c|c|}
\hline Item & $\begin{array}{l}\text { Authors' judge- } \\
\text { ment }\end{array}$ & Risk of bias & $\begin{array}{l}\text { Applicability con- } \\
\text { cerns }\end{array}$ \\
\hline \multicolumn{4}{|l|}{ DOMAIN 1: Patient Selection } \\
\hline Was a consecutive or random sample of patients enrolled? & Yes & & \\
\hline Was a case-control design avoided? & Yes & & \\
\hline \multirow[t]{2}{*}{ Did the study avoid inappropriate exclusions? } & Unclear & & \\
\hline & & Low & High \\
\hline
\end{tabular}

DOMAIN 2: Index Test Placental grading

Were the index test results interpreted without knowledge of Yes the results of the reference standard?

If a threshold was used, was it pre-specified? Unclear

\begin{tabular}{lll}
\hline DOMAIN 3: Reference Standard & Unclear & Low \\
\hline DOW & & \\
\hline
\end{tabular}

Is the reference standards likely to correctly classify the target Yes condition?

Were the reference standard results interpreted without knowl- Unclear edge of the results of the index tests?

\begin{tabular}{lll}
\hline LOMAIN 4: Flow and Timing & Unclear \\
\hline $\begin{array}{l}\text { Was there an appropriate interval between index test and refer- } \\
\text { ence standard? }\end{array}$ & Unclear \\
\hline Did all patients receive the same reference standard? & Yes & Unclear \\
\hline Were all patients included in the analysis? & & Unclear \\
\hline
\end{tabular}


Fliegner 1979

\section{Study characteristics}

Patient sampling

Patient characteristics and setting
Patients in whom simultaneous serial oestriol and pregnanediol measurements were performed after 30 weeks

\section{Sample size: 329}

Gestation at sampling: after 30 weeks

Risk: mixed (unselected population)

Setting: Royal Women's Hospital, Melbourne, Australia

Mode of delivery: 76 inductions, 42 caesarean sections (22 normal E3, 20 subnormal)

Index tests

Urinary oestriol assays were measured by the method of Brown and colleagues and considered to be subnormal if below a line joining $8 \mathrm{mg} / 24$ hours at 30 weeks' gestation to $12 \mathrm{mg} / 24$ hours at 40 weeks.

Target condition and reference standard(s)

FGR, diagnosed when the infant's weight was less than the 10th percentile for gestational age as seen in patients in the community

Flow and timing

Some pregnancies were terminated if hypertension or pre-eclampsia developed, or if a clinical diagnosis of placental insufficiency was supported by a failure to obtain clear amniotic fluid. Oestriol values were not used to influence treatment.

\section{Comparative}

$$
\text { Notes }
$$

\section{Methodological quality}

\begin{tabular}{llll}
\hline Item & Authors' judgement & Risk of bias & $\begin{array}{l}\text { Applicability con- } \\
\text { cerns }\end{array}$ \\
\hline
\end{tabular}

\section{DOMAIN 1: Patient Selection}

Was a consecutive or random sample of patients en- Yes

rolled?

\begin{tabular}{llll}
\hline Was a case-control design avoided? & Yes \\
\hline Did the study avoid inappropriate exclusions? & Yes & Low Low \\
\hline
\end{tabular}

\section{DOMAIN 2: Index Test Urinary E3}

Were the index test results interpreted without knowl- Yes

edge of the results of the reference standard?

\begin{tabular}{llll}
\hline If a threshold was used, was it pre-specified? & Yes & \\
\hline & Low & Low
\end{tabular}

\section{DOMAIN 3: Reference Standard}

Biochemical tests of placental function versus ultrasound assessment of fetal size for stillbirth and small-for-gestational-age infants 
Fliegner 1979 (Continued)

Is the reference standards likely to correctly classify the Yes target condition?

Were the reference standard results interpreted with- Yes out knowledge of the results of the index tests?

Low

Low

\section{DOMAIN 4: Flow and Timing}

Was there an appropriate interval between index test Yes and reference standard?

\begin{tabular}{ll}
\hline Did all patients receive the same reference standard? & Yes \\
\hline Were all patients included in the analysis? & Yes \\
\hline
\end{tabular}

\section{Freire 2010}

\section{Study characteristics}

Patient sampling

Patient characteristics and setting

Index tests

Target condition and reference standard(s)

Ultrasound EFW, Hadlock formula

Cross-sectional study of 122 pregnant women who had EFW calculated by ultrasonography up to 7 days before delivery

Sample size: 122

Gestation at sampling: $29-41$ weeks

Risk: mixed (unselected population, some prior caesareans)

Setting: Joao Pessoa, Paraiba, Brazil

Flow and timing

\section{Comparative}

Notes

\section{Methodological quality}

\begin{tabular}{llll}
\hline Item & $\begin{array}{l}\text { Authors' judge- } \\
\text { ment }\end{array}$ & Risk of bias & $\begin{array}{l}\text { Applicability con- } \\
\text { cerns }\end{array}$
\end{tabular}

\section{DOMAIN 1: Patient Selection}

Was a consecutive or random sample of patients enrolled?

Was a case-control design avoided?
Yes

Yes 
Freire 2010 (Continued)

\begin{tabular}{lcc}
\hline & Low & Low \\
\hline DOMAIN 2: Index Test EFW &
\end{tabular}

\section{DOMAIN 2: Index Test EFW}

Were the index test results interpreted without knowledge of Yes the results of the reference standard?

\begin{tabular}{|c|c|c|c|}
\hline If a threshold was used, was it pre-specified? & Unclear & & \\
\hline & & Unclear & Unclear \\
\hline \multicolumn{4}{|l|}{ DOMAIN 3: Reference Standard } \\
\hline $\begin{array}{l}\text { Is the reference standards likely to correctly classify the target } \\
\text { condition? }\end{array}$ & Yes & & \\
\hline \multirow[t]{2}{*}{$\begin{array}{l}\text { Were the reference standard results interpreted without knowl- } \\
\text { edge of the results of the index tests? }\end{array}$} & Unclear & & \\
\hline & & Unclear & Low \\
\hline \multicolumn{4}{|l|}{ DOMAIN 4: Flow and Timing } \\
\hline $\begin{array}{l}\text { Was there an appropriate interval between index test and refer- } \\
\text { ence standard? }\end{array}$ & Unclear & & \\
\hline Did all patients receive the same reference standard? & Yes & & \\
\hline \multirow[t]{2}{*}{ Were all patients included in the analysis? } & Yes & & \\
\hline & & Low & \\
\hline
\end{tabular}

\section{Gabbay-Benziv 2016}

\section{Study characteristics}

Patient sampling Retrospective cohort study of all women presenting with sonographic EFW performed within 3 days prior to delivery, July 2007-December 2014

\section{Patient characteristics and setting}

\section{Sample size: 6126}

Gestation at sampling: within 3 days of delivery

Risk: mixed (malformations and abnormalities, multiple births, stillbirths, missing measurements excluded)

Setting: single tertiary university-affiliated medical centre
EFW calculated using Hadlock formula 


\section{Gabbay-Benziv 2016 (Continued)}

Target condition and reference standard(s)

SGA defined as an actual birth weight below the 10th percentile for gestational age, using local growth reference values controlled for gestational age and sex

Flow and timing

6322 women had fetal weight estimation performed within 3 days of delivery, 133 were excluded due to anomalies and abnormalities, 63 were exclude due to lack of measurements.

Comparative

Notes

\section{Methodological quality}

\begin{tabular}{llll}
\hline Item Authors' judgement & Risk of bias & $\begin{array}{l}\text { Applicability con- } \\
\text { cerns }\end{array}$
\end{tabular}

\section{DOMAIN 1: Patient Selection}

\begin{tabular}{ll} 
Was a consecutive or random sample of patients enrolled? & Yes \\
\hline Was a case-control design avoided? & Yes \\
\hline Did the study avoid inappropriate exclusions? & Yes
\end{tabular}

\begin{tabular}{lll}
\hline Low & Low \\
\hline
\end{tabular}

\section{DOMAIN 2: Index Test EFW}

Were the index test results interpreted without knowledge of Yes the results of the reference standard?

If a threshold was used, was it pre-specified? Yes

\begin{tabular}{lll}
\hline & Low & Low \\
\hline DOMAIN 3: Reference Standard &
\end{tabular}

Is the reference standards likely to correctly classify the tar- Yes get condition?

Were the reference standard results interpreted without Unclear knowledge of the results of the index tests?

\begin{tabular}{ll}
\hline LOMAIN 4: Flow and Timing & Low \\
\hline $\begin{array}{l}\text { Was there an appropriate interval between index test and } \\
\text { reference standard? }\end{array}$ & Yes \\
\hline Did all patients receive the same reference standard? & Yes \\
\hline Were all patients included in the analysis? & Yes \\
\hline
\end{tabular}


Geerts 2016

\section{Study characteristics}

Patient sampling

Prospective study of women who had been referred for umbilical artery RI assessment after 32 weeks of pregnancy and the RI found to be normal between February 11th and October 21st 2013

Patient characteristics and setting

\section{Sample size: 210}

Gestation at sampling: after 32 weeks

Risk: high (all women referred due to: reduced SFH, hypertension, diabetes, previous fetal loss, previous abruption or FGR)

Setting: Tygerberg Hospital (a secondary and tertiary referral centre), Cape Town, South Africa, February 11th to October 21st 2013

\section{Index tests}

Target condition and reference standard(s)

Flow and timing
EFW calculated using Hadlock formula. Grade II used as threshold

SGA defined as birthweight below 10th centile for gestational age

228 eligible patients were enrolled during the study period, 18 were excluded ( 3 did not meet criteria, anomalies detected in 10, 3 left before being scanned, 2 withdrew consent)

Comparative

Notes

\section{Methodological quality}

\begin{tabular}{llll}
\hline Item & $\begin{array}{l}\text { Authors' judge- } \\
\text { ment }\end{array}$ & Risk of bias & $\begin{array}{l}\text { Applicability con- } \\
\text { cerns }\end{array}$ \\
\hline
\end{tabular}

\section{DOMAIN 1: Patient Selection}

\begin{tabular}{lll}
\hline Was a consecutive or random sample of patients enrolled? & Yes \\
\hline Was a case-control design avoided? & Yes & \\
\hline Did the study avoid inappropriate exclusions? & Yes & Low \\
\hline
\end{tabular}

\section{DOMAIN 2: Index Test Placental grading}

Were the index test results interpreted without knowledge of Yes
the results of the reference standard?

If a threshold was used, was it pre-specified? Yes

\begin{tabular}{lll}
\hline Low & Low \\
\hline
\end{tabular}

\section{DOMAIN 2: Index Test EFW}

Were the index test results interpreted without knowledge of Yes the results of the reference standard? 
Geerts 2016 (Continued)

\begin{tabular}{lcl}
\hline & Low & Low \\
\hline DOMAIN 3: Reference Standard &
\end{tabular}

\section{DOMAIN 3: Reference Standard}

Is the reference standards likely to correctly classify the target Yes condition?

Were the reference standard results interpreted without knowl- Unclear edge of the results of the index tests?

Low Low

\section{DOMAIN 4: Flow and Timing}

Was there an appropriate interval between index test and refer- Yes ence standard?

\begin{tabular}{ll}
\hline Did all patients receive the same reference standard? & Yes \\
\hline Were all patients included in the analysis? & Yes \\
\hline
\end{tabular}

Low

\section{Gerhard 1986}

\section{Study characteristics}

Patient sampling

Prospective study including all women who visited the outpatient department for the first time before 20 weeks of pregnancy

Patient characteristics and setting

\section{Sample size: 869}

Gestation at sampling: $28-40$ weeks

Risk: mixed (unselected population)

Setting: University Women's Hospital, Heidelberg, Germany

Mode of delivery: 130 caesarean sections, 678 spontaneous onset of labour, 61 instrumental

NICU admission: 122 admissions (20\% sensitivity and 91\% specificity of oestriol screening for predicting NICU admission)

\begin{tabular}{ll}
\hline Index tests & Serum assay \\
\hline Target condition and reference standard(s) & SGA defined as birthweight < 10th percentile for age and sex \\
\hline Flow and timing & $\begin{array}{l}1140 \text { women were included in the study, 260 were eliminated on ac- } \\
\text { count of miscarriages, insufficient examinations, and missed appoint- } \\
\text { ments, } 11 \text { multiple births were not studied. }\end{array}$ \\
\hline
\end{tabular}

\footnotetext{
Comparative
} ments, 11 multiple births were not studied. 
Gerhard 1986 (Continued)

Notes
Test results were examined up until the time of delivery but did not affect management

\section{Methodological quality}

\begin{tabular}{llll}
\hline Item & Authors' judgement & Risk of bias & $\begin{array}{l}\text { Applicability con- } \\
\text { cerns }\end{array}$
\end{tabular}

\section{DOMAIN 1: Patient Selection}

Was a consecutive or random sample of patients en- $\quad$ Yes
rolled?
rolled?

\begin{tabular}{llll}
\hline Was a case-control design avoided? & Yes & \\
\hline Did the study avoid inappropriate exclusions? & Yes & Low & Low \\
\hline
\end{tabular}

\section{DOMAIN 2: Index Test E3}

Were the index test results interpreted without knowledge Yes of the results of the reference standard?

If a threshold was used, was it pre-specified? Yes

Low Low

\section{DOMAIN 3: Reference Standard}

Is the reference standards likely to correctly classify the Yes

target condition?

Were the reference standard results interpreted without Yes

knowledge of the results of the index tests?

Low

Low

\section{DOMAIN 4: Flow and Timing}

\section{Was there an appropriate interval between index test and Yes} reference standard?

\begin{tabular}{ll}
\hline Did all patients receive the same reference standard? & Yes \\
\hline Were all patients included in the analysis? & No \\
\hline
\end{tabular}

\section{Gohari 1978}

\section{Study characteristics}


Gohari 1978 (Continued)

Patient sampling

Patient characteristics and setting

Target condition and reference standard(s)

SGA diagnosed if birthweight was in or below the 10th percentile of mean weight for gestation, gestational age was determined by Dubowitz examination

All patients studies as they either exhibited subnormal uterine growth clinically or had pregnancy complications often associated with IUGR

Sample size: 111

Gestation at sampling: after 30 weeks

Risk: high (suspected IUGR)

Setting: Department of Obstetrics and Gynaecology, Yale University School of Medicine, New Haven, Connecticut

hPL measured using the Placgest immunodiffusion technique or radioimmunoassay

Flow and timing

Comparative

Notes

\section{Methodological quality}

\begin{tabular}{llll}
\hline Item & $\begin{array}{l}\text { Authors' judge- } \\
\text { ment }\end{array}$ & Risk of bias & $\begin{array}{l}\text { Applicability con- } \\
\text { cerns }\end{array}$
\end{tabular}

\section{DOMAIN 1: Patient Selection}

Was a consecutive or random sample of patients enrolled?

Was a case-control design avoided?

Did the study avoid inappropriate exclusions?
Yes

Yes

Yes

Low High

\section{DOMAIN 2: Index Test hPL}

Were the index test results interpreted without knowledge of Yes the results of the reference standard?

\begin{tabular}{llll}
\hline If a threshold was used, was it pre-specified? & Yes & \\
\hline & Low & Unclear \\
\hline
\end{tabular}

\section{DOMAIN 3: Reference Standard}

Is the reference standards likely to correctly classify the target Yes condition?

Were the reference standard results interpreted without knowl- Unclear edge of the results of the index tests? 
Gohari 1978 (Continued)

Unclear

Low

\section{DOMAIN 4: Flow and Timing}

Was there an appropriate interval between index test and refer- Yes ence standard?

Did all patients receive the same reference standard?

Yes

Were all patients included in the analysis?

Yes

Low

\section{Granat 1977}

\section{Study characteristics}

\begin{tabular}{ll}
\hline Patient sampling & $\begin{array}{l}29 \text { severely hypertensive patients from a cohort of } 373 \text { women } \\
\text { who had hPL measurements in the 3rd trimester }\end{array}$
\end{tabular}

Patient characteristics and setting

\section{Sample size: 29}

Gestation at sampling: after 30 weeks

Risk: high (severe hypertension)

Setting: Rothschild Univeristy Hospital, Israel

Mode of delivery: 10 deliveries by caesarean section

$\begin{array}{ll}\text { Index tests } & \text { Serum } \mathrm{hPL} \text { measured using a radioimmunoassay technique, low } \\ & \mathrm{hPL} \text { defined as }<1 \text { SD below the normal means }\end{array}$

Target condition and reference standard(s)

SFD defined as those infants whose weights were below the 10th percentile for gestational age, according to Battaglia and colleagues.

\begin{tabular}{ll}
\hline Flow and timing & \\
\hline Comparative & $\begin{array}{l}2 \times 2 \text { table could only be extracted for the severely hypertensive } \\
\text { group }\end{array}$
\end{tabular}

\section{Methodological quality}

\begin{tabular}{|c|c|c|c|}
\hline Item & $\begin{array}{l}\text { Authors' judge- } \\
\text { ment }\end{array}$ & Risk of bias & $\begin{array}{l}\text { Applicability con- } \\
\text { cerns }\end{array}$ \\
\hline
\end{tabular}

\section{DOMAIN 1: Patient Selection}

\begin{tabular}{ll}
\hline Was a consecutive or random sample of patients enrolled? & Yes \\
\hline Was a case-control design avoided? & Yes \\
\hline Did the study avoid inappropriate exclusions? & Yes \\
\hline \hline
\end{tabular}

Biochemical tests of placental function versus ultrasound assessment of fetal size for stillbirth and small-for-gestational-age infants 
Granat 1977 (Continued)

Low

High

\section{DOMAIN 2: Index Test hPL}

Were the index test results interpreted without knowledge of Yes

the results of the reference standard?

If a threshold was used, was it pre-specified?

Yes

Low Low

\section{DOMAIN 3: Reference Standard}

Is the reference standards likely to correctly classify the target Yes condition?

Were the reference standard results interpreted without knowl- Unclear edge of the results of the index tests?

\begin{tabular}{lll}
\hline DOMAIN 4: Flow and Timing & Unclear & Low \\
\hline $\begin{array}{l}\text { Was there an appropriate interval between index test and refer- } \\
\text { ence standard? }\end{array}$ & Yes \\
\hline Did all patients receive the same reference standard? & Yes \\
\hline Were all patients included in the analysis? & Yes \\
\hline
\end{tabular}

Low

\section{Griffin 2015}

\section{Study characteristics}

\begin{tabular}{ll}
\hline Patient sampling & $\begin{array}{l}\text { Women with singleton pregnancies and reduced SFH across } 11 \\
\text { sites in the UK and Canada }\end{array}$
\end{tabular}

Patient characteristics and setting

\section{Sample size: 592}

Gestation at sampling: $24-37$ weeks

Risk: high

Setting: PELICAN FGR study

Mode of delivery: $68.2 \%$ spontaneous vaginal delivery, $15 \%$ assisted vaginal delivery, $16.7 \%$ caesarean section

Index tests

PIGF measured by plasma assay, EFW formula unclear

Target condition and reference standard(s)

SGA defined using customised BW centiles

Flow and timing

9 women excluded from the analysis due to lack of PIGF/outcome/ultrasound data

Biochemical tests of placental function versus ultrasound assessment of fetal size for stillbirth and small-for-gestational-age infants

(Review)

Copyright @ 2019 The Cochrane Collaboration. Published by John Wiley \& Sons, Ltd. 
Griffin 2015 (Continued)

Comparative

Notes

The EFW and PLGF test included AFI measurements but these did not have much of an effect on the overall results

\section{Methodological quality}

\begin{tabular}{llll}
\hline Item & $\begin{array}{l}\text { Authors' judge- } \\
\text { ment }\end{array}$ & Risk of bias & $\begin{array}{l}\text { Applicability con- } \\
\text { cerns }\end{array}$
\end{tabular}

\section{DOMAIN 1: Patient Selection}

\begin{tabular}{llll}
\hline Was a consecutive or random sample of patients enrolled? & Yes \\
\hline Was a case-control design avoided? & Yes & \\
\hline Did the study avoid inappropriate exclusions? & Yes & Low & High
\end{tabular}

\section{DOMAIN 2: Index Test EFW}

Were the index test results interpreted without knowledge of Yes the results of the reference standard?

If a threshold was used, was it pre-specified? Yes

\begin{tabular}{llll}
\hline Low & Low \\
\hline DOMAIN 2: Index Test PIGF & Yes & \\
\hline $\begin{array}{l}\text { Were the index test results interpreted without knowledge of } \\
\text { the results of the reference standard? }\end{array}$ & Yes & Low \\
\hline If a threshold was used, was it pre-specified?
\end{tabular}

\section{DOMAIN 3: Reference Standard}

Is the reference standards likely to correctly classify the target Yes condition?

Were the reference standard results interpreted without knowl- Unclear edge of the results of the index tests?

\begin{tabular}{lll}
\hline DOMAIN 4: Flow and Timing & Unclear & Low \\
\hline $\begin{array}{l}\text { Was there an appropriate interval between index test and refer- } \\
\text { ence standard? }\end{array}$ & Yes \\
\hline Did all patients receive the same reference standard? & Yes \\
\hline Were all patients included in the analysis? & No
\end{tabular}


Griffin 2015 (Continued)

\section{Unclear}

\section{Gupta 2008}

\section{Study characteristics}

\begin{tabular}{ll}
\hline Patient sampling & Retrospective cohort \\
\hline Patient characteristics and setting & Sample size: 38 \\
& Gestation at sampling: 28-32 weeks \\
& Risk: high (all patients with severe preterm pre-eclampsia) \\
& $\begin{array}{l}\text { Mode of delivery: } 19 \text { normal vaginal deliveries, } 19 \text { caesarean sec- } \\
\text { tions }\end{array}$ \\
\hline Index tests & EFW, formula unknown \\
\hline Target condition and reference standard(s) & $\begin{array}{l}\text { SGA defined as birthweight below the 10th centile for gestational } \\
\text { age }\end{array}$
\end{tabular}

Flow and timing

Comparative

\section{Notes}

\section{Methodological quality}

\begin{tabular}{|c|c|c|c|}
\hline Item & $\begin{array}{l}\text { Authors' judge- } \\
\text { ment }\end{array}$ & Risk of bias & $\begin{array}{l}\text { Applicability con- } \\
\text { cerns }\end{array}$ \\
\hline
\end{tabular}

\section{DOMAIN 1: Patient Selection}

\begin{tabular}{llll}
\hline Was a consecutive or random sample of patients enrolled? & Yes \\
\hline Was a case-control design avoided? & Yes & \\
\hline Did the study avoid inappropriate exclusions? & Yes & Low & High \\
\hline
\end{tabular}

\section{DOMAIN 2: Index Test EFW}

Were the index test results interpreted without knowledge of Yes the results of the reference standard?

\begin{tabular}{lll}
\hline Low & Low \\
\hline
\end{tabular}

\section{DOMAIN 3: Reference Standard}


Gupta 2008 (Continued)

Is the reference standards likely to correctly classify the target Yes condition?

Were the reference standard results interpreted without knowl- Unclear edge of the results of the index tests?

Unclear

Low

\section{DOMAIN 4: Flow and Timing}

Was there an appropriate interval between index test and refer- Yes ence standard?

Did all patients receive the same reference standard? Yes

Were all patients included in the analysis? Yes

Low

Hammad 2015

\section{Study characteristics}

Patient sampling

71 women with uncomplicated pregnancies and confirmed gesta-

tional dates recruited across 3 sites and randomised to an addition-

al ultrasound group

Patient characteristics and setting

\section{Sample size: 71}

Gestation at sampling: after 30 weeks

Risk: low (autoimmune disorders, diabetes, hypertension, history of IUGR, preterm birth, stillbirth, or pre-eclampsia excluded)

Mode of delivery: 53 spontaneous vaginal deliveries, 2 operative deliveries, 16 caesarean sections

NICU admission: 2 admissions

EFW using Hadlock formula

SGA defined as a birthweight $<10$ th centile using Alexander curves

234 women were approached for randomisation, 149 were recruited and $97 \%$ of these had follow-up data.

\section{Comparative}

\section{Notes}

The extra ultrasound group was used, this had the latest measurements taken ( 36 to 37 weeks)

\section{Methodological quality}

\section{Item}

Authors' judgement Risk of bias

Applicability con-

cerns 
Hammad 2015 (Continued)

\section{DOMAIN 1: Patient Selection}

\begin{tabular}{|c|c|c|c|}
\hline Was a consecutive or random sample of patients enrolled? & Yes & & \\
\hline Was a case-control design avoided? & Yes & & \\
\hline \multirow[t]{2}{*}{ Did the study avoid inappropriate exclusions? } & Yes & & \\
\hline & & Low & High \\
\hline \multicolumn{4}{|l|}{ DOMAIN 2: Index Test EFW } \\
\hline $\begin{array}{l}\text { Were the index test results interpreted without knowledge of } \\
\text { the results of the reference standard? }\end{array}$ & Yes & & \\
\hline \multirow[t]{2}{*}{ If a threshold was used, was it pre-specified? } & Yes & & \\
\hline & & Low & Low \\
\hline
\end{tabular}

DOMAIN 3: Reference Standard

Is the reference standards likely to correctly classify the target Yes condition?

Were the reference standard results interpreted without knowledge of the results of the index tests?

\begin{tabular}{lll}
\hline LOMAIN 4: Flow and Timing & Low \\
\hline $\begin{array}{l}\text { Was there an appropriate interval between index test and ref- } \\
\text { erence standard? }\end{array}$ & Yes \\
\hline Did all patients receive the same reference standard? & Yes \\
\hline Were all patients included in the analysis? & Yes \\
\hline
\end{tabular}

Low

\section{Hatfield 2010}

\section{Study characteristics}

Patient sampling

Patient characteristics and setting
Retrospective cohort study from 1999 to 2007

\section{Sample size: 659}

Gestation at sampling: after 26 weeks

Risk: high (all patients had elevated hCG levels)

Setting: Saddleback Memorial Medical Centre

EFW $<10$ th centile, formula unknown 
Hatfield 2010 (Continued)

Target condition and reference standard(s)

Flow and timing

Comparative

\section{Notes}

\section{Methodological quality}

\begin{tabular}{|c|c|c|c|}
\hline Item & $\begin{array}{l}\text { Authors' judge- } \\
\text { ment }\end{array}$ & Risk of bias & $\begin{array}{l}\text { Applicability con- } \\
\text { cerns }\end{array}$ \\
\hline
\end{tabular}

\section{DOMAIN 1: Patient Selection}

\begin{tabular}{lll}
\hline Was a consecutive or random sample of patients enrolled? & Yes \\
\hline Was a case-control design avoided? & Yes & \\
\hline Did the study avoid inappropriate exclusions? & Yes & Low \\
\hline
\end{tabular}

DOMAIN 2: Index Test EFW

Were the index test results interpreted without knowledge of Unclear the results of the reference standard?

If a threshold was used, was it pre-specified? Unclear

\begin{tabular}{llc}
\hline DOMAIN 3: Reference Standard & High & High \\
\hline Is the reference standards likely to correctly classify the target $\quad$ Yes & \\
condition? & Yes & Low \\
\hline $\begin{array}{l}\text { Were the reference standard results interpreted without knowl- } \\
\text { edge of the results of the index tests? }\end{array}$
\end{tabular}

\section{DOMAIN 4: Flow and Timing}

Was there an appropriate interval between index test and refer- Yes ence standard?

Did all patients receive the same reference standard? Yes

Were all patients included in the analysis? Unclear 


\section{Hawkins 2012}

\section{Study characteristics}

Patient sampling

Patient characteristics and setting

Retrospective analysis of 2 databases of hypertensive pregnancies

\section{Sample size: 1306}

Gestation at sampling: after 34 weeks (value closest to delivery was used)

Risk: high (all hypertensive pregnancies, excluding chronic hypertension and renal disease)

Setting: St George Hospital, Australia

NICU admissions: 226 of 1880 NICU or SCN transfer

\section{Index tests}

Uric acid measured in serum, values used to determine hyperuricaemia were corrected for gestational age. Elevated uric acid defined as being 1 SD above the gestation-specific mean.

Target condition and reference standard(s)

SGA defined as a birthweight below the 10th centile

Flow and timing

$\mathrm{n}=1880$ after databases were combined and duplicates were excluded.

\section{Comparative}

$$
\text { Notes }
$$

The presence of hyperuricaemia was not a component in the diagnosis of pre-eclampsia nor in the decision to deliver any pregnancy. Authors were contacted for data.

\section{Methodological quality}

\begin{tabular}{llll}
\hline Item & Authors' judgement & Risk of bias & $\begin{array}{l}\text { Applicability con- } \\
\text { cerns }\end{array}$
\end{tabular}

\section{DOMAIN 1: Patient Selection}

Was a consecutive or random sample of patients enrolled? Yes

Was a case-control design avoided? Yes

Did the study avoid inappropriate exclusions? Yes

\begin{tabular}{lll}
\hline Low & High \\
\hline
\end{tabular}

\section{DOMAIN 2: Index Test Uric acid}

Were the index test results interpreted without knowledge Yes of the results of the reference standard?

\begin{tabular}{llll}
\hline If a threshold was used, was it pre-specified? & Yes & Low & Unclear \\
\hline
\end{tabular}

DOMAIN 3: Reference Standard 
Hawkins 2012 (Continued)

Is the reference standards likely to correctly classify the tar- Yes get condition?

Were the reference standard results interpreted without Yes knowledge of the results of the index tests?

Low

Low

\section{DOMAIN 4: Flow and Timing}

Was there an appropriate interval between index test and Yes reference standard?

\begin{tabular}{ll}
\hline Did all patients receive the same reference standard? & Yes \\
\hline Were all patients included in the analysis? & Yes \\
\hline
\end{tabular}

\section{Hendrix 2000}

\section{Study characteristics}

\section{Patient sampling}

Patient characteristics and setting

Randomised clinical trial of singleton pregnancies with reliable gestational age of 37 weeks or more.

\section{Sample size: 367}

Gestation at sampling: $>37$ weeks

Risk: mixed (unselected population)

Setting: Spartanburg Regional Medical Centre, South Carolina \& Medical College of Georgia, Augusta, Georgia

Comparative

$$
\text { Notes }
$$

\section{Methodological quality}

\begin{tabular}{|c|c|c|c|}
\hline Item & $\begin{array}{l}\text { Authors' judge- } \\
\text { ment }\end{array}$ & Risk of bias & $\begin{array}{l}\text { Applicability con- } \\
\text { cerns }\end{array}$ \\
\hline
\end{tabular}

\section{DOMAIN 1: Patient Selection}

Was a consecutive or random sample of patients enrolled?

Yes 
Hendrix 2000 (Continued)

Was a case-control design avoided?

Yes

Did the study avoid inappropriate exclusions?

Yes

Low

Low

\section{DOMAIN 2: Index Test EFW}

Were the index test results interpreted without knowledge of

Yes the results of the reference standard?

If a threshold was used, was it pre-specified?

Yes

\begin{tabular}{lll}
\hline Low & Low \\
\hline
\end{tabular}

DOMAIN 3: Reference Standard

Is the reference standards likely to correctly classify the target Yes condition?

Were the reference standard results interpreted without knowl- Yes edge of the results of the index tests?

Low

High

\section{DOMAIN 4: Flow and Timing}

Was there an appropriate interval between index test and refer- Yes ence standard?

Did all patients receive the same reference standard?

Yes

Were all patients included in the analysis?

No

Low

\section{Howell 1985}

\section{Study characteristics}

\section{Patient sampling}

Patient characteristics and setting

501 unselected women with a singleton pregnancy

\section{Sample size: 501}

\section{Gestation at sampling: $36-41$ weeks}

Risk: mixed (unselected population; 45 patients with pre-eclampsia, 2 with hypertension, 4 with antepartum haemorrhage, 2 diabetics)

Setting: St Bartholomew's Hospital Medical College \& London Hospital Medical College

Index tests threshold 
Howell 1985 (Continued)

Target condition and reference standard(s)

Low birthweight defined as below the 10th centile for the whole population

Flow and timing

Comparative

Notes

\section{Methodological quality}

\begin{tabular}{llll}
\hline Item & $\begin{array}{l}\text { Authors' judge- } \\
\text { ment }\end{array}$ & Risk of bias & $\begin{array}{l}\text { Applicability con- } \\
\text { cerns }\end{array}$
\end{tabular}

\section{DOMAIN 1: Patient Selection}

\begin{tabular}{lll}
\hline Was a consecutive or random sample of patients enrolled? & Yes \\
\hline Was a case-control design avoided? & Yes \\
\hline Did the study avoid inappropriate exclusions? & Yes & Low \\
\hline
\end{tabular}

\section{DOMAIN 2: Index Test hPL}

Were the index test results interpreted without knowledge of Yes the results of the reference standard?

If a threshold was used, was it pre-specified? Yes

\begin{tabular}{lll}
\hline & Low & Low \\
\hline DOMAIN 3: Reference Standard &
\end{tabular}

Is the reference standards likely to correctly classify the target Yes condition?

Were the reference standard results interpreted without knowl- Unclear edge of the results of the index tests?

\begin{tabular}{ll}
\hline Low & Low \\
\hline DOMAIN 4: Flow and Timing & Yes \\
\hline $\begin{array}{l}\text { Was there an appropriate interval between index test and refer- } \\
\text { ence standard? }\end{array}$ & Yes \\
\hline Did all patients receive the same reference standard? & Yes \\
\hline Were all patients included in the analysis? &
\end{tabular}

\section{Low}




\section{Jauniaux 1996}

\section{Study characteristics}

Patient sampling

Women with abnormal uterine artery Doppler features and/or an increased pulsatility index

\section{Patient characteristics and setting}

\section{Sample size: 41}

Gestation at sampling: $25-28$ weeks

Risk: high (abnormal Doppler, increased pulsatility)

Index tests

Serum levels of uric acid measured by an enzymatic method using uricase, $>4.0 \mathrm{mg} / \mathrm{dL}$ considered to be elevated

Target condition and reference standard(s)

Flow and timing

Comparative
IUGR defined as birthweight $<10$ th centile for local standards

Measurements taken from 41 women who consented

\section{Notes}

Placental histopathological examination revealed extended vascular lesions in 12 complicated cases. These lesions were often combined in cases complicated by PIH and IUGR and by placental abruption.

\section{Methodological quality}

\begin{tabular}{llll}
\hline Item & $\begin{array}{l}\text { Authors' judge- } \\
\text { ment }\end{array}$ & Risk of bias & $\begin{array}{l}\text { Applicability con- } \\
\text { cerns }\end{array}$ \\
\hline
\end{tabular}

\section{DOMAIN 1: Patient Selection}

\begin{tabular}{|c|c|c|c|}
\hline Was a consecutive or random sample of patients enrolled? & Yes & & \\
\hline Was a case-control design avoided? & Yes & & \\
\hline \multirow[t]{2}{*}{ Did the study avoid inappropriate exclusions? } & Yes & & \\
\hline & & Low & Unclear \\
\hline \multicolumn{4}{|l|}{ DOMAIN 2: Index Test Uric acid } \\
\hline $\begin{array}{l}\text { Were the index test results interpreted without knowledge of } \\
\text { the results of the reference standard? }\end{array}$ & Yes & & \\
\hline \multirow[t]{2}{*}{ If a threshold was used, was it pre-specified? } & Yes & & \\
\hline & & Low & Low \\
\hline
\end{tabular}

\section{DOMAIN 3: Reference Standard}

Is the reference standards likely to correctly classify the target Yes condition?

Were the reference standard results interpreted without knowl- Unclear edge of the results of the index tests? 
Jauniaux 1996 (Continued)

Unclear

Low

\section{DOMAIN 4: Flow and Timing}

Was there an appropriate interval between index test and refer- Yes ence standard?

Did all patients receive the same reference standard?

Yes

Were all patients included in the analysis?

Yes

Low

\section{Kazzi 1983a}

\section{Study characteristics}

\begin{tabular}{ll}
\hline Patient sampling & $\begin{array}{l}\text { Prospective observational study of placental grade and fetal ma- } \\
\text { turity }\end{array}$
\end{tabular}

Patient characteristics and setting

\section{Sample size: 109}

Gestation at sampling: within 7 days of delivery

Risk: high (pregnancies with birthweight $<2700$ g)

Setting: Cleveland Metropolitan General Hospital

Index tests

Placental grading determined according to Grannum classification, grade III used as threshold

Target condition and reference standard(s)

SGA defined as a birthweight less than the 10th percentile for gestational age

Flow and timing

109 pregnancies from a cohort of 224 women with birthweight < $2700 \mathrm{~g}$ who were examined sonographically within 7 days of delivery

\section{Comparative}

\section{Notes}

$2700 \mathrm{~g}$ was chosen as it was the maximum weight at which infants could be considered SGA

\section{Methodological quality}

\begin{tabular}{llll}
\hline Item & $\begin{array}{l}\text { Authors' judge- } \\
\text { ment }\end{array}$ & Risk of bias & $\begin{array}{l}\text { Applicability con- } \\
\text { cerns }\end{array}$
\end{tabular}

\section{DOMAIN 1: Patient Selection}

\begin{tabular}{ll}
\hline Was a consecutive or random sample of patients enrolled? & Yes \\
\hline Was a case-control design avoided? & Yes \\
\hline Did the study avoid inappropriate exclusions? & Yes \\
\hline
\end{tabular}


Kazzi 1983a (Continued)

Low

High

\section{DOMAIN 2: Index Test Placental grading}

Were the index test results interpreted without knowledge of

Yes

the results of the reference standard?

If a threshold was used, was it pre-specified?

Yes

\begin{tabular}{lll}
\hline Low & Low \\
\hline
\end{tabular}

DOMAIN 3: Reference Standard

Is the reference standards likely to correctly classify the target Yes condition?

Were the reference standard results interpreted without knowl- Unclear edge of the results of the index tests?

\begin{tabular}{lll}
\hline DOMAIN 4: Flow and Timing & Unclear & Low \\
\hline $\begin{array}{l}\text { Was there an appropriate interval between index test and refer- } \\
\text { ence standard? }\end{array}$ & Yes \\
\hline Did all patients receive the same reference standard? & No \\
\hline Were all patients included in the analysis? &
\end{tabular}

High

Kienast 2016

\section{Study characteristics}

Patient sampling

Patient characteristics and setting
Prospective cohort of women who attended for routine obstetrical care between April and December 2010

\section{Sample size: 346}

Gestation at sampling: $28-32$ weeks

Risk: mixed (unselected population although there is a high incidence of PE in the highlands of Ecuador)

Setting: Hospital Isidro Ayora, Quito, Ecuador

Index tests

Plasma sFlt-1 and PIGF measured using a commercial Roche Elecsys System. Threshold was not pre-specified; the optimal cutoff in terms of maximising both sensitivity and specificity was reported.

\footnotetext{
Target condition and reference standard(s)
}

FGR was defined as a birthweight less than the 10th percentile of a reference group 
Kienast 2016 (Continued)

Flow and timing

Comparative

Notes

\section{Methodological quality}

\begin{tabular}{llll}
\hline Item & $\begin{array}{l}\text { Authors' judge- } \\
\text { ment }\end{array}$ & Risk of bias & $\begin{array}{l}\text { Applicability con- } \\
\text { cerns }\end{array}$
\end{tabular}

\section{DOMAIN 1: Patient Selection}

\begin{tabular}{lll}
\hline Was a consecutive or random sample of patients enrolled? & Yes \\
\hline Was a case-control design avoided? & Yes & \\
\hline Did the study avoid inappropriate exclusions? & Yes & Low \\
\hline
\end{tabular}

\section{DOMAIN 2: Index Test PIGF}

Were the index test results interpreted without knowledge of

the results of the reference standard?

If a threshold was used, was it pre-specified?

No

High Unclear

\section{DOMAIN 3: Reference Standard}

Is the reference standards likely to correctly classify the target Yes condition?

Were the reference standard results interpreted without knowl- Unclear edge of the results of the index tests?

\begin{tabular}{lll}
\hline & Unclear & Low \\
\hline DOMAIN 4: Flow and Timing & & \\
\hline $\begin{array}{l}\text { Was there an appropriate interval between index test and refer- } \\
\text { ence standard? }\end{array}$ & Yes \\
\hline Did all patients receive the same reference standard? & Yes \\
\hline Were all patients included in the analysis? &
\end{tabular}

\section{Study characteristics}


Klebe 1990 (Continued)

Patient sampling

Patient characteristics and setting
Patients with renal transplants from 4 different centres

\section{Sample size: 13}

Gestation at sampling: after 32 weeks

Risk: high

Setting: 4 centres in Denmark

hPL measured in serum, 5th centile used as threshold

SGA defined as outside of normal reference area (below 5th percentile); unclear if this threshold was prespecified

\section{Flow and timing}

Comparative

$$
\text { Notes }
$$

\section{Methodological quality}

\begin{tabular}{llll}
\hline Item & $\begin{array}{l}\text { Authors' judge- } \\
\text { ment }\end{array}$ & Risk of bias & $\begin{array}{l}\text { Applicability con- } \\
\text { cerns }\end{array}$ \\
\hline DOMAIN 1: Patient Selection & & Yes \\
\hline Was a consecutive or random sample of patients enrolled? & Yes \\
\hline Was a case-control design avoided? & Yes & Low \\
\hline Did the study avoid inappropriate exclusions? & & Unclear
\end{tabular}

\section{DOMAIN 2: Index Test hPL}

Were the index test results interpreted without knowledge of Yes the results of the reference standard?

If a threshold was used, was it pre-specified? Unclear

\begin{tabular}{lll}
\hline & Unclear & Low \\
\hline DOMAIN 3: Reference Standard & \\
\hline $\begin{array}{l}\text { Is the reference standards likely to correctly classify the target } \quad \text { Yes } \\
\text { condition? }\end{array}$
\end{tabular}

Were the reference standard results interpreted without knowl- Unclear edge of the results of the index tests?

\begin{tabular}{lll}
\hline & Unclear & High \\
\hline DOMAIN 4: Flow and Timing & & \\
\hline
\end{tabular}


Klebe 1990 (Continued)

Was there an appropriate interval between index test and refer- Yes ence standard?

Did all patients receive the same reference standard?

Yes

Were all patients included in the analysis?

Yes

Low

Kunz 1976

\section{Study characteristics}

\begin{tabular}{ll}
\hline Patient sampling & $\begin{array}{l}\text { Patients presently hospitalised because of, or with history of, sus- } \\
\text { pected placental insufficiency }\end{array}$
\end{tabular}
pected placental insufficiency

\section{Patient characteristics and setting}

Target condition and reference standard(s)

Index tests

\section{Sample size: 83}

Gestation at sampling: third trimester

Risk: high (suspected placental insufficiency or a case history)

$\mathrm{hPL}$ and oestriol determinations both performed in serum. 10 measurements of oestriol were taken but only the last 2 values were used for diagnosis. Biochemical parameters were considered to be pathological if they were below $95 \%$ of the normal values, with 2 values being outside this normal range or with 3 or more values being continuously below the $95 \%$ normal range.

SGA defined if birthweight was below the 10th percentile on the Lubchenko curve

Twin pregnancies and those with doubtful duration were excluded

Flow and timing

Comparative

Notes

\section{Methodological quality}

\begin{tabular}{|c|c|c|c|}
\hline Item & $\begin{array}{l}\text { Authors' judge- } \\
\text { ment }\end{array}$ & Risk of bias & $\begin{array}{l}\text { Applicability con- } \\
\text { cerns }\end{array}$ \\
\hline
\end{tabular}

DOMAIN 1: Patient Selection

\begin{tabular}{lll}
\hline Was a consecutive or random sample of patients enrolled? & Yes \\
\hline Was a case-control design avoided? & Yes & \\
\hline Did the study avoid inappropriate exclusions? & Yes & Low \\
\hline
\end{tabular}

\section{DOMAIN 2: Index Test hPL}


Kunz 1976 (Continued)

Were the index test results interpreted without knowledge of Yes the results of the reference standard?

If a threshold was used, was it pre-specified?

Yes

Low High

\section{DOMAIN 2: Index Test Urinary E3}

Were the index test results interpreted without knowledge of Yes the results of the reference standard?

If a threshold was used, was it pre-specified? Yes

\begin{tabular}{lll}
\hline High & Low \\
\hline
\end{tabular}

\section{DOMAIN 3: Reference Standard}

Is the reference standards likely to correctly classify the target Yes condition?

Were the reference standard results interpreted without knowl- Unclear edge of the results of the index tests?

\begin{tabular}{lll}
\hline & Unclear & Low \\
\hline DOMAIN 4: Flow and Timing & & \\
\hline $\begin{array}{l}\text { Was there an appropriate interval between index test and refer- } \\
\text { ence standard? }\end{array}$ & Yes \\
\hline Did all patients receive the same reference standard? & Yes & Low \\
\hline Were all patients included in the analysis? & & \\
\hline
\end{tabular}

\section{Laurin 1987}

\section{Study characteristics}

Patient sampling

Patient characteristics and setting
All singleton births without major malformations in Malmö in 1983

\section{Sample size: 2205}

Gestation at sampling: 32 weeks

Risk: mixed (94\% of the population, malformations and multiple births excluded)

Setting: Malmö General Hospital, Sweden

Index tests

EFW using formula of Eik-Nes, IUGR defined as a $-15 \%$ deviation for gestational age 
Laurin 1987 (Continued)

Target condition and reference standard(s)

Flow and timing

Comparative

Notes

\section{Methodological quality}

\begin{tabular}{llll}
\hline Item & $\begin{array}{l}\text { Authors' judge- } \\
\text { ment }\end{array}$ & Risk of bias & $\begin{array}{l}\text { Applicability con- } \\
\text { cerns }\end{array}$
\end{tabular}

DOMAIN 1: Patient Selection

\begin{tabular}{llll}
\hline Was a consecutive or random sample of patients enrolled? & Yes \\
\hline Was a case-control design avoided? & Yes & \\
\hline Did the study avoid inappropriate exclusions? & Yes & Low \\
\hline
\end{tabular}

\section{DOMAIN 2: Index Test EFW}

Were the index test results interpreted without knowledge of Yes the results of the reference standard?

If a threshold was used, was it pre-specified?

Yes

Low Low

\section{DOMAIN 3: Reference Standard}

Is the reference standards likely to correctly classify the target Yes condition?

Were the reference standard results interpreted without knowl- Unclear edge of the results of the index tests?

Unclear

Low

\section{DOMAIN 4: Flow and Timing}

Was there an appropriate interval between index test and refer- Yes ence standard?

Did all patients receive the same reference standard?

Yes

Were all patients included in the analysis?

Yes

Low

Biochemical tests of placental function versus ultrasound assessment of fetal size for stillbirth and small-for-gestational-age infants 


\section{Leader 1980}

\section{Study characteristics}

\section{Patient sampling}

Patients admitted antenatally with hypertension, suspicion of IUGR or postmaturity.

\section{Patient characteristics and setting}

\section{Sample size: 135}

Gestation at sampling: $30-42$ weeks

Risk: high (hypertension, suspected IUGR, postmaturity)

Setting: Groote Schuur Hospital, Cape Town

hPL estimations done by radioimmunoassay using the Amersham hPL kit, levels were known but not used to influence treatment
Index tests

Target condition and reference standard(s)

\section{Stillbirth after 30 weeks}

\section{Flow and timing}

Comparative

$$
\text { Notes }
$$

\section{Methodological quality}

\begin{tabular}{|c|c|c|c|}
\hline Item & $\begin{array}{l}\text { Authors' judge- } \\
\text { ment }\end{array}$ & Risk of bias & $\begin{array}{l}\text { Applicability con- } \\
\text { cerns }\end{array}$ \\
\hline
\end{tabular}

\section{DOMAIN 1: Patient Selection}

\begin{tabular}{llll}
\hline Was a consecutive or random sample of patients enrolled? & Yes \\
\hline Was a case-control design avoided? & Yes & \\
\hline Did the study avoid inappropriate exclusions? & Yes & Low & High \\
\hline
\end{tabular}

\section{DOMAIN 2: Index Test hPL}

Were the index test results interpreted without knowledge of Yes the results of the reference standard?

If a threshold was used, was it pre-specified? Yes

\begin{tabular}{l}
\hline Low \\
\hline DOMAIN 3: Reference Standard \\
\hline $\begin{array}{l}\text { Is the reference standards likely to correctly classify the target } \quad \text { Yes } \\
\text { condition? }\end{array}$ \\
$\begin{array}{l}\text { Were the reference standard results interpreted without knowl- No } \\
\text { edge of the results of the index tests? }\end{array}$ \\
\hline
\end{tabular}




\section{DOMAIN 4: Flow and Timing}

Was there an appropriate interval between index test and refer- Yes ence standard?

Did all patients receive the same reference standard?

Yes

Were all patients included in the analysis?

Yes

Low

\section{Lenstrup 1982}

\section{Study characteristics}

\begin{tabular}{ll}
\hline Patient sampling & $\begin{array}{l}\text { Consecutive series of patients examined with CTG in the 35th-36th } \\
\text { week of pregnancy }\end{array}$
\end{tabular}

Patient characteristics and setting

\section{Sample size: 88}

Gestation at sampling: $35-36$ weeks

Risk: mixed (unselected population)

Setting: Herlev Hospital, Denmark

NICU admission: 4 admissions, 3 of these from the reduced variability group

\section{Index tests}

Oestriol and hPL analyses were performed on blood, threshold unclear ('low levels')

Target condition and reference standard(s) SFD defined as birthweight below 10th centile for Danish children

\footnotetext{
Flow and timing
}

\section{Comparative}

\begin{tabular}{ll} 
Notes & $\begin{array}{l}1 \text { patient was hospitalised after CTG because of a low plasma } \\
\text { oestriol level and low EFW. }\end{array}$ \\
$\begin{array}{l}\text { Some incorrect data in Table } 5 ; 2 \text { normal E3/hPL reduced variabili- } \\
\text { ty and normal for date assumed to be } 6 \text { instead. }\end{array}$ \\
\hline
\end{tabular}

\section{Methodological quality}

\begin{tabular}{|c|c|c|c|}
\hline Item & $\begin{array}{l}\text { Authors' judge- } \\
\text { ment }\end{array}$ & Risk of bias & $\begin{array}{l}\text { Applicability con- } \\
\text { cerns }\end{array}$ \\
\hline
\end{tabular}

\section{DOMAIN 1: Patient Selection}

Was a consecutive or random sample of patients enrolled? Yes

Was a case-control design avoided? Yes

Biochemical tests of placental function versus ultrasound assessment of fetal size for stillbirth and small-for-gestational-age infants 
Lenstrup 1982 (Continued)

Did the study avoid inappropriate exclusions?

Yes

\begin{tabular}{lcc}
\hline & Low & Low \\
\hline DOMAIN 2: Index Test hPL &
\end{tabular}

\section{DOMAIN 2: Index Test hPL}

Were the index test results interpreted without knowledge of Yes the results of the reference standard?

\begin{tabular}{llll}
\hline If a threshold was used, was it pre-specified? & Unclear & Unclear & Unclear \\
\hline DOMAIN 2: Index Test E3 & & \\
\hline $\begin{array}{l}\text { Were the index test results interpreted without knowledge of } \\
\text { Yes results of the reference standard? }\end{array}$ & Unclear & & Unclear \\
\hline If a threshold was used, was it pre-specified? & & Unclear
\end{tabular}

\section{DOMAIN 3: Reference Standard}

Is the reference standards likely to correctly classify the target Yes condition?

Were the reference standard results interpreted without knowl- No edge of the results of the index tests?

Low

Low

\section{DOMAIN 4: Flow and Timing}

Was there an appropriate interval between index test and refer- Yes ence standard?

Did all patients receive the same reference standard?

Yes

Were all patients included in the analysis?

Yes

Low

\section{Lilford 1983}

\section{Study characteristics}

\begin{tabular}{ll}
\hline Patient sampling & Unselected women with a singleton pregnancy \\
\hline Patient characteristics and setting & Sample size: 527 \\
& Gestation at sampling: $36-40$ weeks \\
& $\begin{array}{l}\text { Risk: mixed (unselected population; } 27 \text { women with pre-eclamp- } \\
\text { sia, } 7 \text { with antepartum haemorrhage) }\end{array}$ \\
\hline
\end{tabular}

Biochemical tests of placental function versus ultrasound assessment of fetal size for stillbirth and small-for-gestational-age infants 
Lilford 1983 (Continued)

Index tests

Serum assay for hPL, 10th centile used as threshold. The effect of changing centiles on the sensitivity and specificity was looked at.

Target condition and reference standard(s)

FGR defined as a birthweight $<2740 \mathrm{~g}$; the 10 th centile for birthweight in the sample studied

\section{Flow and timing}

Stillbirths were excluded from the calculations as they all occurred before the onset of labour and birthweight would be unrelated to the remainder of the group.

\section{Comparative}

\section{Notes}

\section{Methodological quality}

\begin{tabular}{|c|c|c|c|}
\hline Item & $\begin{array}{l}\text { Authors' judge- } \\
\text { ment }\end{array}$ & Risk of bias & $\begin{array}{l}\text { Applicability con- } \\
\text { cerns }\end{array}$ \\
\hline
\end{tabular}

\section{DOMAIN 1: Patient Selection}

\begin{tabular}{lll}
\hline Was a consecutive or random sample of patients enrolled? & Yes \\
\hline Was a case-control design avoided? & Yes \\
\hline Did the study avoid inappropriate exclusions? & Yes & Low \\
\hline
\end{tabular}

\section{DOMAIN 2: Index Test hPL}

Were the index test results interpreted without knowledge of No the results of the reference standard?

If a threshold was used, was it pre-specified? No

\begin{tabular}{lll}
\hline Low High & Hin 3: Reference Standard &
\end{tabular}

\section{DOMAIN 3: Reference Standard}

Is the reference standards likely to correctly classify the target Yes condition?

Were the reference standard results interpreted without knowl- Unclear edge of the results of the index tests?

\begin{tabular}{lll}
\hline DOMAIN 4: Flow and Timing & Unclear & High \\
\hline $\begin{array}{l}\text { Was there an appropriate interval between index test and refer- } \\
\text { ence standard? }\end{array}$ & Yes \\
\hline Did all patients receive the same reference standard? & Yes \\
\hline Were all patients included in the analysis? & Yes \\
\hline
\end{tabular}


Lilford 1983 (Continued)

MacLeod 2013

\section{Study characteristics}

\begin{tabular}{|c|c|}
\hline Patient sampling & Prospective study of term, cephalic, singleton pregnancies \\
\hline \multirow[t]{4}{*}{ Patient characteristics and setting } & Sample size: 90 \\
\hline & Gestation at sampling: term \\
\hline & Risk: mixed (unselected population) \\
\hline & Setting: Mbarara Regional Referral Hospital, Uganda \\
\hline Index tests & Ultrasound EFW, Hadlock formula \\
\hline Target condition and reference standard(s) & $\begin{array}{l}\text { Low birthweight defined as }<2500 \mathrm{~g} \text {, not adjusted for gestational } \\
\text { age }\end{array}$ \\
\hline \multicolumn{2}{|l|}{ Flow and timing } \\
\hline \multicolumn{2}{|l|}{ Comparative } \\
\hline \multicolumn{2}{|l|}{ Notes } \\
\hline \multicolumn{2}{|l|}{ Methodological quality } \\
\hline Item & $\begin{array}{l}\text { Applicability con- } \\
\text { cerns }\end{array}$ \\
\hline
\end{tabular}

\section{DOMAIN 1: Patient Selection}

\begin{tabular}{lccc}
\hline Was a consecutive or random sample of patients enrolled? & Yes \\
\hline Was a case-control design avoided? & Yes & Yes & Low \\
\hline Did the study avoid inappropriate exclusions? & & \\
\hline & Yes & \\
\hline DOMAIN 2: Index Test EFW & Yes & Low \\
\hline Were the index test results interpreted without knowledge of & Low \\
\hline If a threshold was used, was it pre-specified?
\end{tabular}

\section{DOMAIN 3: Reference Standard}

Is the reference standards likely to correctly classify the target Yes condition?

Biochemical tests of placental function versus ultrasound assessment of fetal size for stillbirth and small-for-gestational-age infants 
MacLeod 2013 (Continued)

Were the reference standard results interpreted without knowl- Unclear edge of the results of the index tests?

Unclear

High

\section{DOMAIN 4: Flow and Timing}

Was there an appropriate interval between index test and refer- Yes ence standard?

Did all patients receive the same reference standard?

Yes

Were all patients included in the analysis?

Yes

Low

\section{Mahran 1988}

\section{Study characteristics}

\section{Patient sampling}

Patients selected at random from obstetric population who attended the Ultrasound Unit in 1983, only those who had sure dates confirmed by early ultrasonic examination.

\section{Patient characteristics and setting}

Index tests

Target condition and reference standard(s)

\section{Sample size: 828}

Gestation at sampling: after 24 weeks

Risk: mixed (unselected population)

Ultrasound EFW, below 2 SD of normal parameters

SGA defined as birthweight below the 10th centile, evaluated by tables constructed by Thomson and colleagues

Flow and timing

Comparative

Notes

\section{Methodological quality}

\begin{tabular}{llll}
\hline Item & $\begin{array}{l}\text { Authors' judge- } \\
\text { ment }\end{array}$ & Risk of bias & $\begin{array}{l}\text { Applicability con- } \\
\text { cerns }\end{array}$ \\
\hline
\end{tabular}

\section{DOMAIN 1: Patient Selection}

\begin{tabular}{llll}
\hline Was a consecutive or random sample of patients enrolled? & Yes \\
\hline Was a case-control design avoided? & Yes & \\
\hline Did the study avoid inappropriate exclusions? & Yes & Low \\
\hline
\end{tabular}


Mahran 1988 (Continued)

\section{DOMAIN 2: Index Test EFW}

Were the index test results interpreted without knowledge of Yes the results of the reference standard?

If a threshold was used, was it pre-specified?

Yes

\begin{tabular}{ll}
\hline & Low \\
\hline DOMAIN 3: Reference Standard & Low \\
\hline $\begin{array}{l}\text { Is the reference standards likely to correctly classify the target } \quad \text { Yes } \\
\text { condition? }\end{array}$ & Low \\
\hline $\begin{array}{l}\text { Were the reference standard results interpreted without knowl- } \\
\text { edge of the results of the index tests? }\end{array}$ & Low \\
\hline DOMAIN 4: Flow and Timing & Yes \\
\hline $\begin{array}{l}\text { Was there an appropriate interval between index test and refer- } \\
\text { ence standard? }\end{array}$ \\
\hline Did all patients receive the same reference standard? & Yes \\
\hline Were all patients included in the analysis? & Low \\
\hline
\end{tabular}

\section{Marin 1979}

\section{Study characteristics}

\begin{tabular}{ll}
\hline Patient sampling & Antenatal patients with amniotic fluid samples \\
\hline Patient characteristics and setting & Sample size: 47 \\
& $\begin{array}{l}\text { Gestation at sampling: after } 33 \text { weeks } \\
\text { Risk: } \text { mixed }\end{array}$ \\
\hline Index tests & $\begin{array}{l}\text { Serum hPL assayed using radioimmunoassay kits, 5th centile used } \\
\text { as threshold }\end{array}$ \\
\hline Target condition and reference standard(s) & 10th centile for gestational age used to define IUGR \\
\hline Flow and timing & \\
\hline Comparative & \\
\hline Notes & \\
\hline
\end{tabular}

\section{Methodological quality}


Marin 1979 (Continued)

$\begin{array}{llll}\text { Item } & \begin{array}{l}\text { Authors'judge- } \\ \text { ment }\end{array} & \text { Risk of bias } & \begin{array}{l}\text { Applicability con- } \\ \text { cerns }\end{array}\end{array}$

DOMAIN 1: Patient Selection

\begin{tabular}{ll}
\hline Was a consecutive or random sample of patients enrolled? & Yes \\
\hline Was a case-control design avoided? & Yes \\
\hline Did the study avoid inappropriate exclusions? & Yes
\end{tabular}

\begin{tabular}{lll}
\hline & Low & Low \\
\hline DOMAIN 2: Index Test hPL &
\end{tabular}

Were the index test results interpreted without knowledge of Unclear
the results of the reference standard?

the results of the reference standard?

\begin{tabular}{lll}
\hline If a threshold was used, was it pre-specified? & Unclear & \\
\hline & Unclear & Low \\
\hline
\end{tabular}

\section{DOMAIN 3: Reference Standard}

Is the reference standards likely to correctly classify the target Yes condition?

Were the reference standard results interpreted without knowl- Unclear edge of the results of the index tests?

Low

Low

\section{DOMAIN 4: Flow and Timing}

Was there an appropriate interval between index test and refer- Yes ence standard?

Did all patients receive the same reference standard?

Yes

Were all patients included in the analysis?

Unclear

\section{Unclear}

\section{McKenna 2005}

\section{Study characteristics}

$$
\text { Patient sampling }
$$

Patient characteristics and setting

Prospective cohort of singleton pregnancies with known gestational age

\section{Sample size: 1802}

Gestation at sampling: 36 weeks

Risk: low (known maternal medical problems, obstetric complications in present or prior pregnancy, fetal abnormalities excluded) 
Flow and timing

\section{Comparative}

Notes

Some pregnancies were induced for suspected fetal compromise, grade III placentas helped to identify these pregnancies

\section{Methodological quality}

\begin{tabular}{llll}
\hline Item Authors' judgement & Risk of bias & $\begin{array}{l}\text { Applicability con- } \\
\text { cerns }\end{array}$
\end{tabular}

\section{DOMAIN 1: Patient Selection}

\begin{tabular}{lll}
\hline Was a consecutive or random sample of patients enrolled? & Yes \\
\hline Was a case-control design avoided? & Yes \\
\hline Did the study avoid inappropriate exclusions? & Yes & \\
\hline
\end{tabular}

\section{DOMAIN 2: Index Test Placental grading}

Were the index test results interpreted without knowledge of Yes the results of the reference standard?

\begin{tabular}{lcc}
\hline If a threshold was used, was it pre-specified? & Yes & Low \\
\hline
\end{tabular}

\section{DOMAIN 3: Reference Standard}

Is the reference standards likely to correctly classify the target Yes condition?

Were the reference standard results interpreted without No knowledge of the results of the index tests?

\begin{tabular}{lll}
\hline & Unclear & Low \\
\hline DOMAIN 4: Flow and Timing & &
\end{tabular}

Was there an appropriate interval between index test and ref- Yes erence standard?

Did all patients receive the same reference standard? Yes 
McKenna 2005 (Continued)

\section{Study characteristics}

$\begin{array}{ll}\text { Patient sampling } & \text { Patients who delivered beyond } 37 \text { weeks with known dates, early } \\ & \text { examination, confirmatory ultrasound, and who delivered within } \\ & 7 \text { days of study were selected from all referrals }\end{array}$

Patient characteristics and setting

\section{Sample size: 246}

Gestation at sampling: $36-38$ weeks

Risk: mixed (unselected apart from no preterm delivery)

Setting: Louisiana State University Medical Centre

Index tests

Placental grade established from the most mature view of the placenta and assigned in accordance with established criteria, grade III used as threshold

Target condition and reference standard(s)

SGA classified as birthweight below 10th centile

Flow and timing

\section{Comparative}

Notes

\section{Methodological quality}

\begin{tabular}{llll}
\hline Item & $\begin{array}{l}\text { Authors' judge- } \\
\text { ment }\end{array}$ & Risk of bias & $\begin{array}{l}\text { Applicability con- } \\
\text { cerns }\end{array}$
\end{tabular}

\section{DOMAIN 1: Patient Selection}

\begin{tabular}{lcc}
\hline Was a consecutive or random sample of patients enrolled? & Yes \\
\hline Was a case-control design avoided? & Yes \\
\hline Did the study avoid inappropriate exclusions? & Yes & Low \\
\hline
\end{tabular}

\section{DOMAIN 2: Index Test Placental grading}

Were the index test results interpreted without knowledge of 
Miller 1988 (Continued)

\section{DOMAIN 3: Reference Standard}

Is the reference standards likely to correctly classify the target Yes condition?

Were the reference standard results interpreted without knowl- Unclear edge of the results of the index tests?

Low Low

\section{DOMAIN 4: Flow and Timing}

Was there an appropriate interval between index test and refer- Yes ence standard?

\begin{tabular}{ll}
\hline Did all patients receive the same reference standard? & Yes \\
\hline Were all patients included in the analysis? & Yes \\
\hline
\end{tabular}

Low

Molvarec 2013

\section{Study characteristics}

Patient sampling

Study group selected from groups of hypertensive women based

on availability of Doppler ultrasound results

\section{Patient characteristics and setting}

Index tests

Target condition and reference standard(s)

\section{Sample size: 89}

Gestation at sampling: mean 32 weeks

Risk: high (all women had hypertensive disorders of pregnancy)

Mode of delivery: 78 caesarean sections

PIGF measured using the Alere Triage test, $12 \mathrm{pg} / \mathrm{mL}$ used as threshold

SGA defined as birthweight below the 10th percentile for gestational age and sex according to a Hungarian birthweight percentile table. All neonates with SGA had an asymmetric size, indicating that they had intrauterine growth restriction and were not constitutionally small.

\section{Flow and timing}

\section{Comparative}

Notes PIGF values were not an indicator for early delivery

\section{Methodological quality}

\begin{tabular}{|c|c|c|c|}
\hline Item & $\begin{array}{l}\text { Authors' judge- } \\
\text { ment }\end{array}$ & Risk of bias & $\begin{array}{l}\text { Applicability con- } \\
\text { cerns }\end{array}$ \\
\hline
\end{tabular}


Molvarec 2013 (Continued)

\section{DOMAIN 1: Patient Selection}

\begin{tabular}{lccc}
\hline Was a consecutive or random sample of patients enrolled? & No & & \\
\hline Was a case-control design avoided? & Yes & Unclear & High \\
\hline Did the study avoid inappropriate exclusions? & & \\
\hline & Yes & \\
\hline DOMAIN 2: Index Test PIGF & Yes & Low \\
\hline Were the index test results interpreted without knowledge of & & Low \\
\hline If a threshold was used, was it pre-specified?
\end{tabular}

DOMAIN 3: Reference Standard

Is the reference standards likely to correctly classify the target Yes condition?

Were the reference standard results interpreted without knowl- Unclear edge of the results of the index tests?

Low Low

\section{DOMAIN 4: Flow and Timing}

Was there an appropriate interval between index test and refer- Yes ence standard?

Did all patients receive the same reference standard? Yes

Were all patients included in the analysis? Yes

Low

Montan 1986

\section{Study characteristics}

Patient sampling

Prospective study of 645 consecutive pregnancies over a 4-month period

\section{Patient characteristics and setting}

\section{Sample size: 307}

Gestation at sampling: 37 weeks

Risk: mixed (unselected pregnancies, 40 admitted due to pregnancy induced hypertension)

Setting: University Hospital of Lund 


\section{Montan 1986 (Continued)}

Index tests

Placental grading was made according to the classification of Grannum and colleagues, grade III used as threshold

Target condition and reference standard(s)

SGA not defined

Flow and timing

654 women were recruited for the study, of which 621 had a scan in weeks 32 to 33.146 gave birth before weeks 38 to 29 , and 96 objected to further examinations.

\section{Comparative}

Notes

\section{Methodological quality}

\begin{tabular}{llll}
\hline Item & $\begin{array}{l}\text { Authors' judge- } \\
\text { ment }\end{array}$ & Risk of bias & $\begin{array}{l}\text { Applicability con- } \\
\text { cerns }\end{array}$
\end{tabular}

\section{DOMAIN 1: Patient Selection}

\begin{tabular}{llll}
\hline Was a consecutive or random sample of patients enrolled? & Yes \\
\hline Was a case-control design avoided? & Yes & \\
\hline Did the study avoid inappropriate exclusions? & Yes & Low \\
\hline
\end{tabular}

\section{DOMAIN 2: Index Test All tests}

Were the index test results interpreted without knowledge of Yes the results of the reference standard?

\begin{tabular}{lll}
\hline Low & Low \\
\hline
\end{tabular}

\section{DOMAIN 2: Index Test Placental grading}

\section{Were the index test results interpreted without knowledge of Yes} the results of the reference standard?

\begin{tabular}{lll}
\hline LOMAIN 3: Reference Standard & Low & Low \\
\hline $\begin{array}{l}\text { Is the reference standards likely to correctly classify the target } \quad \text { Yes } \\
\text { condition? }\end{array}$ & Low & Unclear \\
\hline $\begin{array}{l}\text { Were the reference standard results interpreted without knowl- } \\
\text { edge of the results of the index tests? }\end{array}$
\end{tabular}


Montan 1986 (Continued)

\section{DOMAIN 4: Flow and Timing}

Was there an appropriate interval between index test and refer- Yes ence standard?

Did all patients receive the same reference standard? Yes

Were all patients included in the analysis?

Yes

Nice 2016

\section{Study characteristics}

$\begin{array}{ll}\text { Patient sampling } & \text { Blood collected from healthy pregnancies, women with reduced } \\ & \text { fetal movements, or a suspected SGA fetus after } 28 \text { weeks of ges- } \\ & \text { tation }\end{array}$

Patient characteristics and setting

Sample size: 77

Gestation at sampling: after 28 weeks

Risk: mixed

Setting: St. Mary's Hospital, Manchester UK

NICU admission: 12

Index tests

hPL measured by ELISA (threshold 0.8 MoM), PIGF by Alere Triage, ELISA, and Roche automated immunoassay (threshold $12 \mathrm{pg} / \mathrm{mL}$ )

Target condition and reference standard(s) SGA defined as birthweight $<10$ th centile

Flow and timing

Comparative

Notes Authors contacted for data

\section{Methodological quality}

\begin{tabular}{llll} 
Item & $\begin{array}{l}\text { Authors' judge- } \\
\text { ment }\end{array}$ & Risk of bias & $\begin{array}{l}\text { Applicability con- } \\
\text { cerns }\end{array}$ \\
\hline
\end{tabular}

\section{DOMAIN 1: Patient Selection}

Was a consecutive or random sample of patients enrolled? No

\begin{tabular}{lll}
\hline Was a case-control design avoided? & Yes & \\
\hline Did the study avoid inappropriate exclusions? & Yes & Unclear \\
\hline
\end{tabular}

Biochemical tests of placental function versus ultrasound assessment of fetal size for stillbirth and small-for-gestational-age infants 
Nice 2016 (Continued)

\section{DOMAIN 2: Index Test hPL}

Were the index test results interpreted without knowledge of Yes the results of the reference standard?

If a threshold was used, was it pre-specified? Yes

\begin{tabular}{llll}
\hline LOMAIN 2: Index Test PIGF & Low & Low \\
\hline $\begin{array}{l}\text { Were the index test results interpreted without knowledge of } \\
\text { the results of the reference standard? }\end{array}$ & Yes & Low & Low
\end{tabular}

\section{DOMAIN 3: Reference Standard}

Is the reference standards likely to correctly classify the target Yes condition?

Were the reference standard results interpreted without knowl- Yes edge of the results of the index tests?

\begin{tabular}{lll}
\hline DOMAIN 4: Flow and Timing & Low \\
\hline $\begin{array}{l}\text { Was there an appropriate interval between index test and refer- } \\
\text { ence standard? }\end{array}$ & Yes \\
\hline Did all patients receive the same reference standard? & Yes \\
\hline Were all patients included in the analysis? &
\end{tabular}

Low

Nielsen 1985

\section{Study characteristics}

Patient sampling

Patient characteristics and setting
All births that took place in a geographically well-defined area in the course of 1 year that met the inclusion criteria (expected date of delivery, all measurements, measurements not known to the physicians)

Sample size: 1018

Gestation at sampling: 26 th and 35 th

Risk: mixed (unselected pregnancies) 


\section{Nielsen 1985 (Continued)}

Index tests

Target condition and reference standard(s)
Oestriol measured with a radioimmunoassay kit, 2.5 th centile used as a threshold

SGA defined as bodyweight below the 10th centile, referring to the Danish National Board of Health

1702 births took place; 1660 of these were registered on a form (8 outside hospital and 34 not registered, these were omitted). 13

twin pregnancies, 153 with uncertain date of expected delivery, 213 without measurements, 263 where monitoring was prescribed were all excluded.

\section{Comparative}

Notes

\section{Methodological quality}

\begin{tabular}{llll}
\hline Item Authors' judgement & Risk of bias $\begin{array}{l}\text { Applicability con- } \\
\text { cerns }\end{array}$
\end{tabular}

\section{DOMAIN 1: Patient Selection}

\begin{tabular}{llll}
\hline Was a consecutive or random sample of patients enrolled? & Yes \\
\hline Was a case-control design avoided? & Yes & & Low \\
\hline Did the study avoid inappropriate exclusions? & Yes & Low \\
\hline
\end{tabular}

\section{DOMAIN 2: Index Test E3}

Were the index test results interpreted without knowledge of Yes the results of the reference standard?

\begin{tabular}{llll}
\hline If a threshold was used, was it pre-specified? & Yes & Low \\
\hline
\end{tabular}

\section{DOMAIN 3: Reference Standard}

Is the reference standards likely to correctly classify the target Yes condition?

Were the reference standard results interpreted without Yes knowledge of the results of the index tests?

\begin{tabular}{lll}
\hline & Low & Low \\
\hline DOMAIN 4: Flow and Timing &
\end{tabular}

\footnotetext{
Was there an appropriate interval between index test and ref- Yes erence standard?
} 
Nielsen 1985 (Continued)

\section{Nisbet 1982}

\section{Study characteristics}

$\begin{array}{ll}\text { Patient sampling } & \begin{array}{l}\text { Patients with singleton pregnancies attending routine antenatal } \\ \text { clinic }\end{array}\end{array}$

\begin{tabular}{ll}
\hline Patient characteristics and setting & Sample size: 166 \\
& Gestation at sampling: 3rd trimester (34.3+/- 3.1) \\
& Risk: high (all considered clinically to have small for dates fetuses) \\
& Setting: Aberdeen Maternity Hospital \\
\hline Index tests & $\begin{array}{l}\text { Measurements taken from serum or plasma, oestriol was only } \\
\text { measured when there was sufficient sample volume. }-2 \text { SD used } \\
\text { as threshold }\end{array}$ \\
\hline Target condition and reference standard(s) & $\begin{array}{l}\text { IUGR defined as birthweight below the 10th centile according to } \\
\text { gestation, sex, and parity. }\end{array}$ \\
\hline Flow and timing & $\begin{array}{l}\text { 166 patients were included in the study, only } 103 \text { could be assayed } \\
\text { for oestriol (25 SGA and 38 AGA not included) }\end{array}$
\end{tabular}

\section{Comparative}

\section{Notes}

\section{Methodological quality}

\begin{tabular}{|c|c|c|c|}
\hline Item & $\begin{array}{l}\text { Authors' judge- } \\
\text { ment }\end{array}$ & Risk of bias & $\begin{array}{l}\text { Applicability con- } \\
\text { cerns }\end{array}$ \\
\hline
\end{tabular}

\section{DOMAIN 1: Patient Selection}

\begin{tabular}{llll}
\hline Was a consecutive or random sample of patients enrolled? & Yes \\
\hline Was a case-control design avoided? & Yes & \\
\hline Did the study avoid inappropriate exclusions? & Yes & High & Low
\end{tabular}

\section{DOMAIN 2: Index Test hPL}

Were the index test results interpreted without knowledge of Yes the results of the reference standard?

If a threshold was used, was it pre-specified? Yes 
Nisbet 1982 (Continued)

\section{DOMAIN 2: Index Test E3}

Were the index test results interpreted without knowledge of

the results of the reference standard?

If a threshold was used, was it pre-specified?

Yes

\begin{tabular}{lll}
\hline Low & Low \\
\hline
\end{tabular}

\section{DOMAIN 3: Reference Standard}

Is the reference standards likely to correctly classify the target Yes condition?

Were the reference standard results interpreted without knowl- Unclear edge of the results of the index tests?

\begin{tabular}{lll}
\hline Low & Low \\
\hline DOMA 4l Flow and Timing & & \\
\hline $\begin{array}{l}\text { Was there an appropriate interval between index test and refer- } \\
\text { ence standard? }\end{array}$ & Yes \\
\hline Did all patients receive the same reference standard? & No & Unclear \\
\hline Were all patients included in the analysis? & & \\
\hline
\end{tabular}

\section{Oats 1979}

\section{Study characteristics}

\begin{tabular}{|c|c|}
\hline Patient sampling & Patients in a 7-year period \\
\hline \multirow[t]{4}{*}{ Patient characteristics and setting } & Sample size: 19,119 \\
\hline & Gestation at sampling: from 30 weeks \\
\hline & Risk: mixed (unselected population) \\
\hline & Setting: Mercy Maternity Hospital, Melbourne \\
\hline Index tests & $\begin{array}{l}\text { Urinary oestriol excretion was measured by the method of Brown and col- } \\
\text { leagues, which accounts for gestation. Low E3 patients are from } 2 \text { groups, per- } \\
\text { sistently low ( } 2 \text { or more consecutive low values) and transiently low (only } 1 \\
\text { low value out of the total number of measurements). Values were regarded as } \\
\text { low when below a line joining } 8 \mathrm{mg} / 24 \text { hours at } 30 \text { weeks and } 12 \mathrm{mg} / 24 \text { hours } \\
\text { at } 40 \text { + weeks. }\end{array}$ \\
\hline
\end{tabular}

\footnotetext{
Target condition and reference standard(s)
}

SFD defined as birthweight $<10$ th centile for gestational age in the community. Stillbirths defined according to the criteria used in the Commonwealth of Australia. 
Oats 1979 (Continued)

Flow and timing

\section{Comparative}

Notes

The test was performed as a routine at 30 and 36 weeks and at other times when indicated by complications of pregnancy or by poor past obstetrical history. Study looks at 400 patients with low oestriol in a subsequent pregnancy but also gives results for the whole study population so these were used.

\section{Methodological quality}

\begin{tabular}{llll}
\hline Item Authors' judgement & Risk of bias
\end{tabular}

\section{DOMAIN 1: Patient Selection}

Was a consecutive or random sample of patients Yes enrolled?

\begin{tabular}{ll}
\hline Was a case-control design avoided? & Yes \\
\hline Did the study avoid inappropriate exclusions? & Yes
\end{tabular}

\begin{tabular}{lll}
\hline & Low & Low \\
\hline DOMAIN 2: Index Test Urinary E3
\end{tabular}

\section{DOMAIN 2: Index Test Urinary E3}

Were the index test results interpreted without

knowledge of the results of the reference standard?

If a threshold was used, was it pre-specified? Yes

Low

High

\section{DOMAIN 3: Reference Standard}

Is the reference standards likely to correctly classi- Yes fy the target condition?

\section{Were the reference standard results interpreted Unclear}

without knowledge of the results of the index tests?

\begin{tabular}{llll}
\hline DOMAIN 4: Flow and Timing & Unclear & Low \\
\hline $\begin{array}{l}\text { Was there an appropriate interval between index } \\
\text { test and reference standard? }\end{array}$ & Yes & \\
\hline $\begin{array}{l}\text { Did all patients receive the same reference stan- } \\
\text { dard? }\end{array}$ & Yes & Yes \\
\hline Were all patients included in the analysis? & & \\
\hline
\end{tabular}


Obiekwe 1983

\section{Study characteristics}

\begin{tabular}{|c|c|}
\hline Patient sampling & Unselected women with singleton pregnancies \\
\hline \multirow[t]{3}{*}{ Patient characteristics and setting } & Sample size: 522 \\
\hline & Gestation at sampling: $36-40$ weeks \\
\hline & $\begin{array}{l}\text { Risk: mixed (unselected population; } 27 \text { women with pre-eclamp- } \\
\text { sia, } 7 \text { antepartum haemorrhage) }\end{array}$ \\
\hline Index tests & $\begin{array}{l}\text { hPL measured in serum by immunoassay, } 10 \text { th centile used as } \\
\text { threshold. }\end{array}$ \\
\hline Target condition and reference standard(s) & $\begin{array}{l}\text { IUGR defined as birthweight below } 10 \text { th centile of study popula- } \\
\text { tion }(2740 \mathrm{~g})\end{array}$ \\
\hline Flow and timing & Stillbirths $(n=5)$ excluded from original cohort \\
\hline \multicolumn{2}{|l|}{ Comparative } \\
\hline \multicolumn{2}{|l|}{ Notes } \\
\hline \multicolumn{2}{|l|}{ Methodological quality } \\
\hline Item & $\begin{array}{l}\text { Applicability con- } \\
\text { cerns }\end{array}$ \\
\hline
\end{tabular}

\section{DOMAIN 1: Patient Selection}

\begin{tabular}{llll}
\hline Was a consecutive or random sample of patients enrolled? & Yes \\
\hline Was a case-control design avoided? & Yes & Yos & Low \\
\hline Did the study avoid inappropriate exclusions? & & Low \\
\hline
\end{tabular}

\section{DOMAIN 2: Index Test hPL}

Were the index test results interpreted without knowledge of Yes the results of the reference standard?
If a threshold was used, was it pre-specified?
Unclear

\begin{tabular}{lll}
\hline & Unclear & Low \\
\hline DOMAIN 3: Reference Standard &
\end{tabular}

Is the reference standards likely to correctly classify the target Yes condition?

Were the reference standard results interpreted without knowl- Unclear edge of the results of the index tests?

\begin{tabular}{l}
\hline Unclear \\
\hline Biochemical tests of placental function versus ultrasound assessment of fetal size for stillbirth and small-for-gestational-age infants \\
(Review) \\
Copyright @ 2019 The Cochrane Collaboration. Published by John Wiley \& Sons, Ltd.
\end{tabular}


Obiekwe 1983 (Continued)

\section{DOMAIN 4: Flow and Timing}

Was there an appropriate interval between index test and refer- Yes ence standard?

Did all patients receive the same reference standard? Yes

Were all patients included in the analysis? Yes

\section{Odendaal 1981}

\section{Study characteristics}

\begin{tabular}{ll}
\hline Patient sampling & Patients with positive stress tests \\
\hline Patient characteristics and setting & Sample size: 148 \\
& Gestation at sampling: $25-43$ weeks \\
& Risk: high (positive stress tests, various indications) \\
& Setting: Tygerberg Hospital, South Africa \\
\hline Index tests & hPL and oestriol immunoassay kit used to measure both, 10 th \\
& centile used to define low levels. Centiles derived from curves \\
& used by Tygerberg hospital derived from 432 patients.
\end{tabular}

Target condition and reference standard(s)

SGA defined as birthweight below the 10th percentile for the specific duration of pregnancy, gestational age estimated using a Dubowitz score and weight charts used to assess growth

Flow and timing

Serum oestriol and hPL studies were not performed on all patients as these tests were not initially available; intrauterine deaths were also not included in the estimations of IUGR.

Comparative

$$
\text { Notes }
$$

\section{Methodological quality}

\begin{tabular}{|c|c|c|c|}
\hline Item & $\begin{array}{l}\text { Authors' judge- } \\
\text { ment }\end{array}$ & Risk of bias & $\begin{array}{l}\text { Applicability con- } \\
\text { cerns }\end{array}$ \\
\hline
\end{tabular}

\section{DOMAIN 1: Patient Selection}

Was a consecutive or random sample of patients enrolled?

Was a case-control design avoided?

Did the study avoid inappropriate exclusions?
Yes

Yes

Yes

\begin{tabular}{lll}
\hline High & Low \\
\hline
\end{tabular}

Biochemical tests of placental function versus ultrasound assessment of fetal size for stillbirth and small-for-gestational-age infants 
Odendaal 1981 (Continued)

\section{DOMAIN 2: Index Test hPL}

Were the index test results interpreted without knowledge of Yes the results of the reference standard?

If a threshold was used, was it pre-specified?

Yes

\begin{tabular}{llll}
\hline & Low & Low \\
\hline DOMAIN 2: Index Test E3 & Yes & Low & Low \\
\hline $\begin{array}{l}\text { Were the index test results interpreted without knowledge of } \\
\text { the results of the reference standard? }\end{array}$ & & \\
\hline If a threshold was used, was it pre-specified? & Yes & \\
\hline DOMAIN 2: Index Test Urinary E3 & Yes & Low \\
\hline $\begin{array}{l}\text { Were the index test results interpreted without knowledge of } \\
\text { the results of the reference standard? }\end{array}$
\end{tabular}

\section{DOMAIN 3: Reference Standard}

Is the reference standards likely to correctly classify the target Yes condition?

Were the reference standard results interpreted without knowl- Yes edge of the results of the index tests?

Low Low

\section{DOMAIN 4: Flow and Timing}

Was there an appropriate interval between index test and refer- Yes ence standard?

Did all patients receive the same reference standard? Yes

Were all patients included in the analysis?

No

\section{Unclear}

\section{Odendaal 1997}

\section{Study characteristics}

Patient sampling

Prospective study of women with severe pre-eclampsia.

Patient characteristics and setting

Sample size: 196

Biochemical tests of placental function versus ultrasound assessment of fetal size for stillbirth and small-for-gestational-age infants (Review)

Copyright @ 2019 The Cochrane Collaboration. Published by John Wiley \& Sons, Ltd. 
Gestation at sampling: the week before delivery (blood taken twice a week from admission until delivery, last sample used)

Risk: high (all women with severe pre-eclampsia, all were delivered once 34 weeks was reached)

Setting: Tygerberg Hospital, South Africa - a tertiary hospital to which many patients with severe pre-eclampsia are referred

\begin{tabular}{llll}
\hline Notes & $\begin{array}{l}\text { Patients were delivered once a gestational age of 34 weeks has been } \\
\text { reached or when maternal reasons or abnormal fetal heart rate patterns } \\
\text { were an indication for earlier delivery. }\end{array}$ \\
\hline Methodological quality & Authors' judgement & Risk of bias & $\begin{array}{l}\text { Applicability con- } \\
\text { cerns }\end{array}$ \\
\hline Item & Yes & \\
\hline $\begin{array}{l}\text { WomalN 1: Patient Selection } \\
\text { rolled? }\end{array}$ & Yes & Low \\
\hline Was a case-control design avoided? & Yes & High \\
\hline Did the study avoid inappropriate exclusions? & & \\
\hline
\end{tabular}

\section{DOMAIN 2: Index Test Uric acid}

Were the index test results interpreted without knowl- Yes

edge of the results of the reference standard?

\begin{tabular}{llll}
\hline If a threshold was used, was it pre-specified? & Yes & Low & Low \\
\hline
\end{tabular}

\section{DOMAIN 3: Reference Standard}

Is the reference standards likely to correctly classify Yes the target condition?

Were the reference standard results interpreted with- Unclear out knowledge of the results of the index tests? 
Odendaal 1997 (Continued)

DOMAIN 4: Flow and Timing

Was there an appropriate interval between index test Yes

and reference standard?

Did all patients receive the same reference standard? Yes

Were all patients included in the analysis? No

Low

Ott 1984

\section{Study characteristics}

Patient sampling All patients undergoing ultrasonic examination within 72 hours before delivery

Patient characteristics and setting

\section{Sample size: 595}

Gestation at sampling: after 30 weeks

Risk: mixed (the study population was composed of both highand low-risk patients)

Setting: St Mary's Health Centre, St. Louis, Missouri

Index tests

Ultrasound EFW calculated using the formula of Shepard and colleagues

Target condition and reference standard(s)

SGA classified based on birthweight from gestational age percentile obtained from the normogram of Altman and Coles

Flow and timing

Comparative

Notes

\section{Methodological quality}

\begin{tabular}{llll}
\hline Item & $\begin{array}{l}\text { Authors' judge- } \\
\text { ment }\end{array}$ & Risk of bias & $\begin{array}{l}\text { Applicability con- } \\
\text { cerns }\end{array}$
\end{tabular}

\section{DOMAIN 1: Patient Selection}

\begin{tabular}{llll}
\hline Was a consecutive or random sample of patients enrolled? & Yes \\
\hline Was a case-control design avoided? & Yes & \\
\hline Did the study avoid inappropriate exclusions? & Yes & Low & Low \\
\hline
\end{tabular}

DOMAIN 2: Index Test EFW

Biochemical tests of placental function versus ultrasound assessment of fetal size for stillbirth and small-for-gestational-age infants 
Ott 1984 (Continued)

Were the index test results interpreted without knowledge of the results of the reference standard?

If a threshold was used, was it pre-specified?

Yes

\begin{tabular}{lll}
\hline Low & Low \\
\hline
\end{tabular}

\section{DOMAIN 3: Reference Standard}

Is the reference standards likely to correctly classify the target Yes condition?

Were the reference standard results interpreted without knowl- Unclear edge of the results of the index tests?

\begin{tabular}{lll}
\hline DOMAIN 4: Flow and Timing & Low \\
\hline Was there an appropriate interval between index test and refer- & Yes \\
ence standard? & Yes \\
\hline Did all patients receive the same reference standard? & Yes \\
\hline Were all patients included in the analysis? & \\
\hline
\end{tabular}

Low

Palo 1987

\section{Study characteristics}

\begin{tabular}{ll}
\hline Patient sampling & Admissions due to short SFH measurement \\
\hline Patient characteristics and setting & Sample size: 90 \\
& Gestation at sampling: 1 week before delivery (28-40 weeks) \\
& Risk: high (reduced SFH) \\
& Setting: University Central Hospital, Turku \\
\hline Index tests & $\begin{array}{l}\text { Oestriol measured by radioimmunoassay according to Kaihola, }-2 \\
\text { SD used as threshold }\end{array}$ \\
\hline Target condition and reference standard(s) & IUGR defined as below 10th percentile by weight \\
\hline Flow and timing & $\begin{array}{l}\text { The study combined prospective and retrospective data; prospec- } \\
\text { tive population derived from mothers with reduced SFH plus 'con- } \\
\text { trols' (women without IUGR after screening the whole cohort), ret- } \\
\text { rospective part was mothers with low E3 only so was not included }\end{array}$
\end{tabular}

\footnotetext{
Comparative
}

\section{Notes}

Biochemical tests of placental function versus ultrasound assessment of fetal size for stillbirth and small-for-gestational-age infants 
Palo 1987 (Continued)

Methodological quality

\begin{tabular}{llll}
\hline Item & $\begin{array}{l}\text { Authors' judge- } \\
\text { ment }\end{array}$ & Risk of bias & $\begin{array}{l}\text { Applicability con- } \\
\text { cerns }\end{array}$ \\
\hline
\end{tabular}

\section{DOMAIN 1: Patient Selection}

\begin{tabular}{lll}
\hline Was a consecutive or random sample of patients enrolled? & Yes \\
\hline Was a case-control design avoided? & Yes & \\
\hline Did the study avoid inappropriate exclusions? & Yes & Low \\
\hline
\end{tabular}

\section{DOMAIN 2: Index Test E3}

Were the index test results interpreted without knowledge of Yes the results of the reference standard?

If a threshold was used, was it pre-specified? Yes

\begin{tabular}{lll}
\hline Low & Low \\
\hline
\end{tabular}

\section{DOMAIN 3: Reference Standard}

Is the reference standards likely to correctly classify the target Yes condition?

Were the reference standard results interpreted without knowl- Unclear edge of the results of the index tests?

\begin{tabular}{lll}
\hline LOMAIN 4: Flow and Timing & Low \\
\hline $\begin{array}{l}\text { Was there an appropriate interval between index test and refer- } \\
\text { ence standard? }\end{array}$ & Yes \\
\hline Did all patients receive the same reference standard? & Yes \\
\hline Were all patients included in the analysis? & Yes \\
\hline
\end{tabular}

\section{Palo 1989}

\section{Study characteristics}

Patient sampling Prospective study, women admitted based on clinical suspicion of poor fetal growth.

Patient characteristics and setting

\section{Sample size: 186}

Gestation at sampling: $31-42$ weeks (mean 38.6) 
Palo 1989 (Continued)

\begin{tabular}{ll} 
& Risk: high \\
& Setting: Maternity Clinic of University Central Hospital, Turku \\
\hline Index tests & $\begin{array}{l}\text { EFW calculations were performed using the calculations of Eik-Nes } \\
\text { and colleagues. }\end{array}$ \\
\hline Target condition and reference standard(s) & SGA defined as birthweight below the 10th centile \\
\hline Flow and timing & $\begin{array}{l}\text { 206 women admitted, } 20 \text { excluded because exact BPD or AD data } \\
\text { were not available }\end{array}$
\end{tabular}

\section{Comparative}

Notes

\section{Methodological quality}

\begin{tabular}{llll}
\hline Item & $\begin{array}{l}\text { Authors' judge- } \\
\text { ment }\end{array}$ & Risk of bias & $\begin{array}{l}\text { Applicability con- } \\
\text { cerns }\end{array}$ \\
\hline
\end{tabular}

DOMAIN 1: Patient Selection

\begin{tabular}{ll}
\hline Was a consecutive or random sample of patients enrolled? & Yes \\
\hline Was a case-control design avoided? & Yes \\
\hline Did the study avoid inappropriate exclusions? & Yes Low
\end{tabular}

\section{DOMAIN 2: Index Test EFW}

Were the index test results interpreted without knowledge of Yes the results of the reference standard?

\begin{tabular}{llll}
\hline If a threshold was used, was it pre-specified? & Yes & Low \\
\hline
\end{tabular}

\section{DOMAIN 3: Reference Standard}

Is the reference standards likely to correctly classify the target Yes condition?

Were the reference standard results interpreted without knowl- Unclear edge of the results of the index tests?

Unclear Low

\section{DOMAIN 4: Flow and Timing}

Was there an appropriate interval between index test and refer- Yes ence standard?

Did all patients receive the same reference standard?

Yes 
Palo 1989 (Continued)

\section{Patterson 1983}

\section{Study characteristics}

$\begin{array}{ll}\text { Patient sampling } & \begin{array}{l}\text { Retrospective selection of patients that demonstrated a Grade II } \\ \text { or III placenta (Spanish-surnamed patients only) }\end{array}\end{array}$

Patient characteristics and setting

Sample size: 398

Gestation at sampling: $26-39$ weeks

Risk: high

Setting: Medical Center Hospital, San Antonio, Texas

Index tests

Placental grade assessed according to the criteria of Grannum and associates

\section{Target condition and reference standard(s)}

SGA defined as birthweight below the 10th centile for gestational age.

431 patients were identified, 398 of these underwent delivery at Medical Center Hospital and were included in the study.

\section{Comparative}

Notes

\section{Methodological quality}

\begin{tabular}{llll}
\hline Item & $\begin{array}{l}\text { Authors' judge- } \\
\text { ment }\end{array}$ & Risk of bias & $\begin{array}{l}\text { Applicability con- } \\
\text { cerns }\end{array}$
\end{tabular}

\section{DOMAIN 1: Patient Selection}

\begin{tabular}{lll}
\hline Was a consecutive or random sample of patients enrolled? & No \\
\hline Was a case-control design avoided? & Yes & \\
\hline Did the study avoid inappropriate exclusions? & Yes & High \\
\hline
\end{tabular}

\section{DOMAIN 2: Index Test Placental grading}

Were the index test results interpreted without knowledge of Yes the results of the reference standard? 
Patterson 1983 (Continued)

\section{DOMAIN 3: Reference Standard}

Is the reference standards likely to correctly classify the target Yes condition?

Were the reference standard results interpreted without knowl- Unclear edge of the results of the index tests?

\section{Unclear}

Low

\section{DOMAIN 4: Flow and Timing}

Was there an appropriate interval between index test and refer- Yes ence standard?

\begin{tabular}{ll}
\hline Did all patients receive the same reference standard? & Yes \\
\hline Were all patients included in the analysis? & Yes \\
\hline
\end{tabular}

Low

\section{Redman 1976}

\section{Study characteristics}

Patient sampling

All patients with hypertension. Patients do not comprise a single cohort since new patients entered the study up to 32 weeks of gestation and premature delivery removed other patients from the later periods of the study.

\section{Patient characteristics and setting}

\section{Sample size: 281}

Gestation at sampling: 36 weeks

Risk: high

Index tests

Plasma urate was assayed by the routine automated hydroxylamine method

Target condition and reference standard(s) Stillbirths defined as fetuses born dead after the 24th week of gestation

Flow and timing

Hypertension was confirmed in 332 pregnant patients, 238 of which were participating in a trial of antihypertensive treatment. Some women delivered early; hyperuricaemia was never used as an indicator. 281 women had uric acid measurements at 36 weeks.

\section{Comparative}

Notes

\section{Methodological quality}

\begin{tabular}{llll}
\hline Item & $\begin{array}{l}\text { Authors' judge- } \\
\text { ment }\end{array}$ & Risk of bias & $\begin{array}{l}\text { Applicability con- } \\
\text { cerns }\end{array}$
\end{tabular}

Biochemical tests of placental function versus ultrasound assessment of fetal size for stillbirth and small-for-gestational-age infants 150 
Redman 1976 (Continued)

DOMAIN 1: Patient Selection

\begin{tabular}{llll}
\hline Was a consecutive or random sample of patients enrolled? & No & \\
\hline Was a case-control design avoided? & Yes & \\
\hline Did the study avoid inappropriate exclusions? & Yes & Low & High \\
\hline
\end{tabular}

\section{DOMAIN 2: Index Test Uric acid}

Were the index test results interpreted without knowledge of Yes the results of the reference standard?

\begin{tabular}{llll}
\hline If a threshold was used, was it pre-specified? & Yes & Low \\
\hline
\end{tabular}

\section{DOMAIN 3: Reference Standard}

Is the reference standards likely to correctly classify the target Yes condition?

Were the reference standard results interpreted without knowl- Unclear edge of the results of the index tests?

Unclear Low

\section{DOMAIN 4: Flow and Timing}

Was there an appropriate interval between index test and refer- Yes ence standard?

Did all patients receive the same reference standard? Yes

Were all patients included in the analysis? Yes

Low

Roma 2015

\section{Study characteristics}

Patient sampling

Women were non-selectively enrolled into a randomised trial. Some exclusions based on medical history and history of FGR/PE/stillbirth.

Patient characteristics and setting

\section{Sample size: 1115}

Gestation at sampling: 36 weeks

Risk: mixed

Mode of delivery: 400 inductions, 86 instrumental deliveries and 47 caesarean sections (both for non reassuring fetal status) 
Roma 2015 (Continued)

NICU admission: 1 admission

Index tests

Target condition and reference standard(s)

Flow and timing
EFW calculated using Hadlock formula

SGA defined as a birthweight below the 10th centile

1314 women were assigned to US at 36 weeks, 1115 were analysed (1 stillbirth, 13 preterm births, 185 lost to follow up)

\section{Comparative}

\section{Notes}

Suspected cases of SGA prompted weekly monitoring and elective induction at $37+1$ weeks if UA-PI values were abnormal ( $>95$ th centile); otherwise, monitoring was carried out every 2 weeks and delivery was induced at $40+1$ weeks. Data for US at 36 weeks were used as the last test before delivery.

\begin{tabular}{llll}
\hline Methodological quality & Authors' judgement & Risk of bias & $\begin{array}{l}\text { Applicability con- } \\
\text { cerns }\end{array}$ \\
\hline Item & & \\
\hline DOMAIN 1: Patient Selection & Yes & Yes & Low \\
\hline $\begin{array}{l}\text { Was a consecutive or random sample of patients en- } \\
\text { rolled? }\end{array}$ & Yes & Low \\
\hline Was a case-control design avoided? & & Lid the study avoid inappropriate exclusions?
\end{tabular}

\section{DOMAIN 2: Index Test EFW}

Were the index test results interpreted without knowledge Yes of the results of the reference standard?

If a threshold was used, was it pre-specified? Yes

\begin{tabular}{lll}
\hline DOMAIN 3: Reference Standard & Low & Low \\
\hline $\begin{array}{l}\text { Is the reference standards likely to correctly classify the } \\
\text { target condition? }\end{array}$ & Yes & Unclear \\
\hline $\begin{array}{l}\text { Were the reference standard results interpreted without } \quad \text { Low } \\
\text { knowledge of the results of the index tests? }\end{array}$
\end{tabular}

\section{DOMAIN 4: Flow and Timing}

Was there an appropriate interval between index test and Yes reference standard? 
Roma 2015 (Continued)

Did all patients receive the same reference standard? Yes

Were all patients included in the analysis? Yes

Low

\section{Sagen 1984}

\section{Study characteristics}

Patient sampling Women with severe pre-eclampsia

Patient characteristics and setting

Sample size: 74

Gestation at sampling: 1-3 days before birth

Risk: high

Mode of delivery: 54 caesarean sections, 15 instrumental deliveries, remaining 5 were IUDs

Index tests

Oestriol measured in plasma using a radioimmunoassay, hPL measured in plasma using an immunoassay. Threshold defined as the 10 th centile from a reference group of 40 healthy pregnant women. Measurements taken twice a day but only the last measurement before delivery was used.

Target condition and reference standard(s)

Low birthweight defined as under the 10th centile, weight of the newborn related to a centile scale based on 416,756 liveborn infants without congenital malformations and after normal singleton pregnancy in Norway from 1967-1977

Flow and timing

\section{Comparative}

Notes

Indication for delivery was based on case history, clinical findings, and results of hormonal, biochemical, ultrasonographic, and cardiotocographic tests

\section{Methodological quality}

\begin{tabular}{llll}
\hline Item Authors' judgement & Risk of bias $\begin{array}{l}\text { Applicability con- } \\
\text { cerns }\end{array}$ \\
\hline
\end{tabular}

\section{DOMAIN 1: Patient Selection}

\begin{tabular}{llll}
\hline Was a consecutive or random sample of patients enrolled? & Yes \\
\hline Was a case-control design avoided? & Yes & \\
\hline Did the study avoid inappropriate exclusions? & Yes & Low & High \\
\hline
\end{tabular}

\section{DOMAIN 2: Index Test hPL}

Biochemical tests of placental function versus ultrasound assessment of fetal size for stillbirth and small-for-gestational-age infants 
Sagen 1984 (Continued)

Were the index test results interpreted without knowledge of Yes the results of the reference standard?

If a threshold was used, was it pre-specified? Yes

\begin{tabular}{lll}
\hline Low & Low \\
\hline
\end{tabular}

\section{DOMAIN 2: Index Test E3}

Were the index test results interpreted without knowledge of Yes the results of the reference standard?

If a threshold was used, was it pre-specified? Yes

\begin{tabular}{lll}
\hline Low & Low \\
\hline
\end{tabular}

\section{DOMAIN 3: Reference Standard}

Is the reference standards likely to correctly classify the target Yes condition?

Were the reference standard results interpreted without No knowledge of the results of the index tests?

\begin{tabular}{lll}
\hline & Unclear & Low \\
\hline DOMAIN 4: Flow and Timing & & \\
\hline $\begin{array}{l}\text { Was there an appropriate interval between index test and ref- } \\
\text { erence standard? }\end{array}$ & Yes \\
\hline Did all patients receive the same reference standard? & Yes & Low \\
\hline Were all patients included in the analysis? & & \\
\hline
\end{tabular}

\section{Sekar 2016}

\section{Study characteristics}

\begin{tabular}{ll}
\hline Patient sampling & $\begin{array}{l}\text { Prospective study of all women booked for induction of labour or } \\
\text { elective caesarean section during February to December } 2013\end{array}$
\end{tabular}

Patient characteristics and setting Sample size: 150

Gestation at sampling: 1 week prior to delivery

Risk: mixed

\begin{tabular}{ll}
\hline Index tests & EFW calculated using Hadlock formula \\
\hline Target condition and reference standard(s) & $\begin{array}{l}\text { SGA defined as birthweight below the 10th centile for gestational } \\
\text { age. Doctors and women were both aware of EFWs }\end{array}$ \\
\hline
\end{tabular}


Sekar 2016 (Continued)

Flow and timing

Comparative

Notes

\section{Methodological quality}

\begin{tabular}{llll}
\hline Item & $\begin{array}{l}\text { Authors' judge- } \\
\text { ment }\end{array}$ & Risk of bias & $\begin{array}{l}\text { Applicability con- } \\
\text { cerns }\end{array}$
\end{tabular}

\section{DOMAIN 1: Patient Selection}

\begin{tabular}{ll}
\hline Was a consecutive or random sample of patients enrolled? & Yes \\
\hline Was a case-control design avoided? & Yes \\
\hline Did the study avoid inappropriate exclusions? & Yes \\
\hline
\end{tabular}

\begin{tabular}{lll}
\hline Low & Low \\
\hline DOMAIN 2: Index Test EFW & & Low
\end{tabular}

Were the index test results interpreted without knowledge of Yes the results of the reference standard?

If a threshold was used, was it pre-specified?

Yes

Low Low

\section{DOMAIN 3: Reference Standard}

Is the reference standards likely to correctly classify the target Yes condition?

Were the reference standard results interpreted without knowl- No edge of the results of the index tests?

\begin{tabular}{lll}
\hline DOMAIN 4: Flow and Timing & Unclear & Low \\
\hline $\begin{array}{l}\text { Was there an appropriate interval between index test and refer- } \\
\text { ence standard? }\end{array}$ & Yes & Yes \\
\hline Did all patients receive the same reference standard? & Yes \\
\hline Were all patients included in the analysis? &
\end{tabular}

Low

\section{Shawkat 2015}

\section{Study characteristics}

Biochemical tests of placental function versus ultrasound assessment of fetal size for stillbirth and small-for-gestational-age infants 
Shawkat 2015 (Continued)
Patient sampling
High-risk cohort of women $<35$ weeks gestation

Patient characteristics and setting

Index tests

Target condition and reference standard(s)

\section{Sample size: 261}

Gestation at sampling: test nearest delivery

Risk: high (suspected FGR, superimposed PE)

PIGF measured using Alere Triage; threshold used was very low (< $12 \mathrm{pg} / \mathrm{mL}$ )

SGA defined as $<10$ th centile, fetal death

\section{Flow and timing}

Comparative

\begin{tabular}{llll}
\hline Notes & Surveillance was adjusted according to test results \\
\hline Methodological quality & & Roplicability con- \\
\hline Item & $\begin{array}{l}\text { Authors' judge- } \\
\text { ment }\end{array}$ & Risk of bias & \\
\hline DOMAIN 1: Patient Selection & Yes & Yes \\
\hline Was a consecutive or random sample of patients enrolled? & Yes & High \\
\hline Was a case-control design avoided? & & Low
\end{tabular}

DOMAIN 2: Index Test PIGF

Were the index test results interpreted without knowledge of Yes the results of the reference standard?

If a threshold was used, was it pre-specified?

Yes

\begin{tabular}{|c|c|c|}
\hline & Low & Low \\
\hline \multicolumn{3}{|l|}{ DOMAIN 3: Reference Standard } \\
\hline $\begin{array}{l}\text { Is the reference standards likely to correctly classify the target } \\
\text { condition? }\end{array}$ & Yes & \\
\hline \multirow[t]{2}{*}{$\begin{array}{l}\text { Were the reference standard results interpreted without knowl- } \\
\text { edge of the results of the index tests? }\end{array}$} & No & \\
\hline & Low & Low \\
\hline
\end{tabular}

\section{DOMAIN 4: Flow and Timing}

Was there an appropriate interval between index test and refer- Yes ence standard? 
Shawkat 2015 (Continued)

Did all patients receive the same reference standard?

\section{Siebert 1974}

\section{Study characteristics}

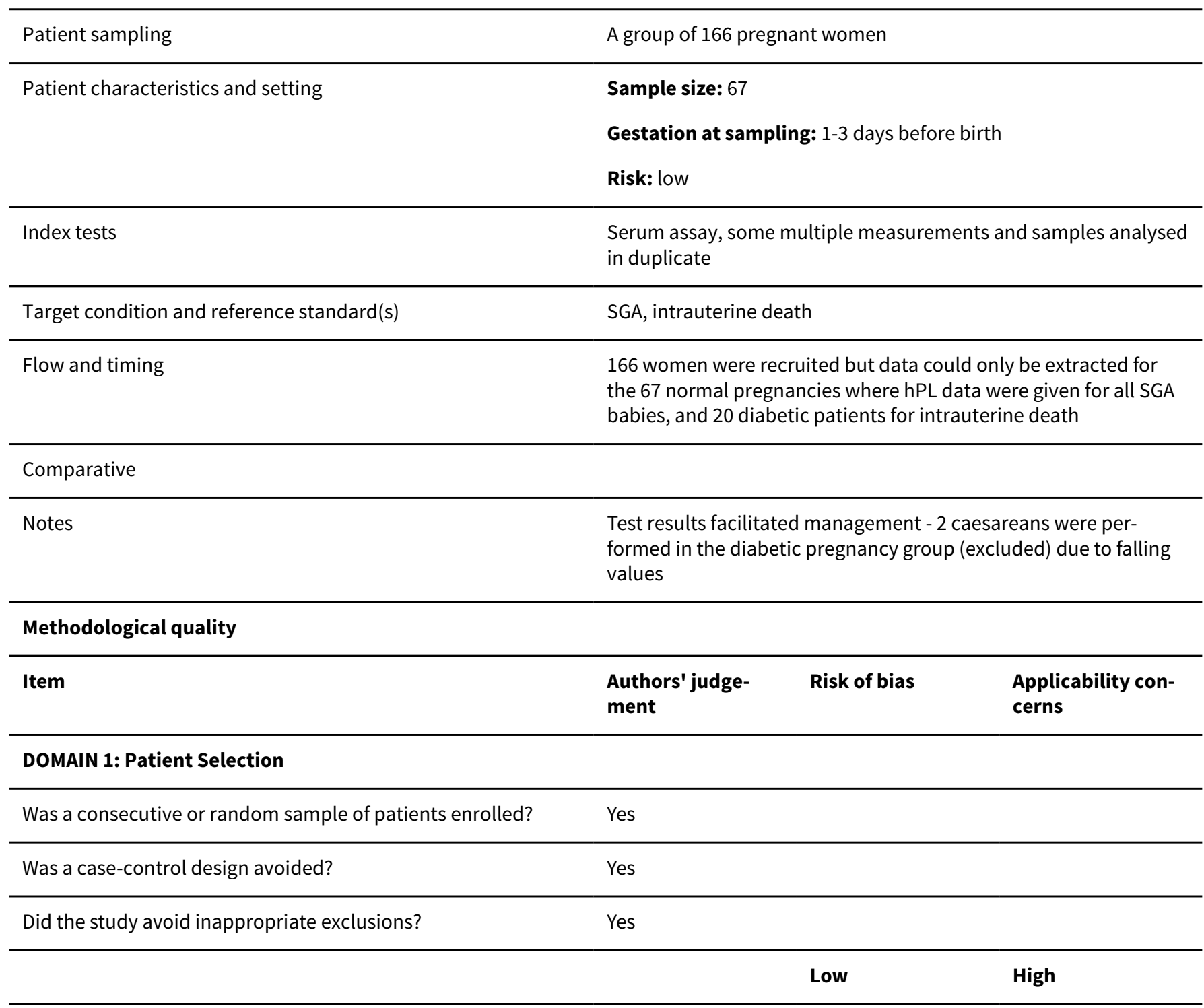

DOMAIN 2: Index Test hPL

Were the index test results interpreted without knowledge of Yes the results of the reference standard?

If a threshold was used, was it pre-specified? 
Siebert 1974 (Continued)

Unclear

Unclear

\section{DOMAIN 3: Reference Standard}

Is the reference standards likely to correctly classify the target Yes condition?

Were the reference standard results interpreted without knowl- No edge of the results of the index tests?

High Low

\section{DOMAIN 4: Flow and Timing}

Was there an appropriate interval between index test and refer- Yes ence standard?

\begin{tabular}{ll}
\hline Did all patients receive the same reference standard? & Yes \\
\hline Were all patients included in the analysis? & Yes \\
\hline
\end{tabular}

\section{Skovron 1991}

\section{Study characteristics}

\section{Patient sampling}

Patients with a singleton gestation who had ultrasound for determination of fetal size between 26 and 34 weeks, 1985-1987. Gestational diabetes, placenta praevia, premature labour excluded.

\section{Patient characteristics and setting}

\section{Sample size: 768}

Gestation at sampling: $26-34$ weeks

Risk: mixed

Index tests

Target condition and reference standard(s)

Flow and timing

Ultrasound EFW calculated using the formula of Shepard and colleagues.

SGA defined as below the 10th centile of birthweight for gestational age and sex using the nomogram developed by Brenner and colleagues.

996 patients recruited, 768 met the inclusion criteria (37 excluded because of incomplete ultrasound data)

\section{Comparative}

\section{Notes}

\section{Methodological quality}

\begin{tabular}{|c|c|c|c|}
\hline Item & $\begin{array}{l}\text { Authors' judge- } \\
\text { ment }\end{array}$ & Risk of bias & $\begin{array}{l}\text { Applicability con- } \\
\text { cerns }\end{array}$ \\
\hline
\end{tabular}

Biochemical tests of placental function versus ultrasound assessment of fetal size for stillbirth and small-for-gestational-age infants 158 (Review)

Copyright $\odot 2019$ The Cochrane Collaboration. Published by John Wiley \& Sons, Ltd. 
Skovron 1991 (Continued)

\section{DOMAIN 1: Patient Selection}

\begin{tabular}{lll}
\hline Was a consecutive or random sample of patients enrolled? & Yes \\
\hline Was a case-control design avoided? & Yes & \\
\hline Did the study avoid inappropriate exclusions? & Yes & Low \\
\hline
\end{tabular}

\section{DOMAIN 2: Index Test EFW}

Were the index test results interpreted without knowledge of Yes the results of the reference standard?

\begin{tabular}{lll}
\hline Low & Low \\
\hline
\end{tabular}

\section{DOMAIN 3: Reference Standard}

Is the reference standards likely to correctly classify the target Yes condition?

Were the reference standard results interpreted without knowl- Unclear edge of the results of the index tests?

Unclear Low

\section{DOMAIN 4: Flow and Timing}

Was there an appropriate interval between index test and refer- Yes ence standard?

Did all patients receive the same reference standard? Yes

Were all patients included in the analysis? No

Low

Sovio 2015

\section{Study characteristics}

Patient sampling

Patient characteristics and setting
Prospective cohort of nulliparous women attending for their dating ultrasound scan between January 2008 and July 2012.

\section{Sample size: 3977}

Gestation at sampling: 28 or 36 weeks (last scan before delivery)

Risk: mixed (the only exclusion criterion was multiple pregnancy)

Mode of delivery: 1924 normal vaginal deliveries, 949 instrumental, 1089 caesarean sections (data missing for mode of delivery for 15 births) 
Sovio 2015 (Continued)

NICU admission: 229 admissions

Index tests

Target condition and reference standard(s)

Flow and timing
Ultrasound EFW calculated using Hadlock equations

SGA defined as a birthweight of less than the 10th percentile for sex and gestational age, calculated from a UK reference

8028 women eligible, 4512 enrolled, 3977 attended all third trimester scans and delivered a liveborn infant after 26 weeks.

\section{Comparative}

Notes We used universal ultrasonography as these were all single measurements (the last scan before birth) and the data for selective ultrasonography includes women who did not have a scan. Results of routine clinical scans were reported but results of research scans were masked.

\begin{tabular}{llll}
\hline Methodological quality & Authors' judgement & Risk of bias & Applicability concerns \\
\hline Item & & \\
\hline DOMAIN 1: Patient Selection & Yes & \\
\hline $\begin{array}{l}\text { Was a consecutive or random sample of patients } \\
\text { enrolled? }\end{array}$ & Yes & Low \\
\hline $\begin{array}{l}\text { Was a case-control design avoided? } \\
\text { Did the study avoid inappropriate exclusions? }\end{array}$ & Yes & Low \\
\hline $\begin{array}{l}\text { DomAIN 2: Index Test EFW } \\
\text { knowledge of the results of the reference standard? }\end{array}$ & Yes & Yes \\
\hline \begin{tabular}{l} 
If a threshold was used, was it pre-specified? \\
\hline
\end{tabular}
\end{tabular}

\section{DOMAIN 3: Reference Standard}

Is the reference standards likely to correctly classi- $\quad$ Yes fy the target condition?

Were the reference standard results interpreted Unclear without knowledge of the results of the index tests?

Low Low

\section{DOMAIN 4: Flow and Timing}

Was there an appropriate interval between index Yes test and reference standard? 
Sovio 2015 (Continued)

Did all patients receive the same reference stan- Yes dard?

Were all patients included in the analysis?

No

\section{Unclear}

\section{Spernol 1989}

\section{Study characteristics}

\begin{tabular}{ll}
\hline Patient sampling & $\begin{array}{l}\text { Women screened prospectively; } 30 \text { with suspected IUGR, } 5 \text { with } \\
\text { infants below the } 10 \text { th centile for weight who were not suspected } \\
\text { SGA, } 75 \text { low-risk pregnancies. }\end{array}$
\end{tabular}

Patient characteristics and setting

\section{Sample size: 110}

Gestation at sampling: unclear, likely to be 3rd trimester

Risk: mixed

\begin{tabular}{|c|c|c|c|}
\hline \multicolumn{4}{|l|}{ Index tests } \\
\hline Target condition and reference standard(s) & \multicolumn{3}{|c|}{ SGA defined as birthweight below the 10th centile } \\
\hline \multicolumn{4}{|l|}{ Flow and timing } \\
\hline \multicolumn{4}{|l|}{ Comparative } \\
\hline \multicolumn{4}{|l|}{ Notes } \\
\hline \multicolumn{4}{|l|}{ Methodological quality } \\
\hline Item & $\begin{array}{l}\text { Authors' judge- } \\
\text { ment }\end{array}$ & Risk of bias & $\begin{array}{l}\text { Applicability con- } \\
\text { cerns }\end{array}$ \\
\hline \multicolumn{4}{|l|}{ DOMAIN 1: Patient Selection } \\
\hline Was a consecutive or random sample of patients enrolled? & Yes & & \\
\hline Was a case-control design avoided? & Unclear & & \\
\hline \multirow[t]{2}{*}{ Did the study avoid inappropriate exclusions? } & Unclear & & \\
\hline & & Unclear & Unclear \\
\hline
\end{tabular}

Were the index test results interpreted without knowledge of

Yes the results of the reference standard?

If a threshold was used, was it pre-specified? Yes 
Spernol 1989 (Continued)

\section{DOMAIN 2: Index Test E3}

Were the index test results interpreted without knowledge of Yes the results of the reference standard?

If a threshold was used, was it pre-specified?

Yes

\begin{tabular}{lll}
\hline & Low & Low \\
\hline DOMAIN 3: Reference Standard & Unclear \\
\hline $\begin{array}{l}\text { Is the reference standards likely to correctly classify the target } \\
\text { condition? }\end{array}$ & Yes \\
\hline $\begin{array}{l}\text { Were the reference standard results interpreted without knowl- } \\
\text { edge of the results of the index tests? }\end{array}$ & Low \\
\hline DOMAIN 4: Flow and Timing & Yes \\
\hline $\begin{array}{l}\text { Was there an appropriate interval between index test and refer- } \\
\text { ence standard? }\end{array}$ & Yes \\
\hline Did all patients receive the same reference standard? & Low \\
\hline Were all patients included in the analysis? & \\
\hline
\end{tabular}

\section{Steiner 1991}

\section{Study characteristics}

Patient sampling 113 pregnant women with suspected IUGR

\begin{tabular}{ll}
\hline Patient characteristics and setting & Sample size: 113 \\
& $\begin{array}{l}\text { Gestation at sampling: 28-40 weeks } \\
\text { Risk: high (all suspected IUGR) }\end{array}$ \\
\hline Index tests & $\begin{array}{l}\text { Serum assay for } \mathrm{hPL} \text {, urinary assay for E3; mean value from } 3 \text { mea- } \\
\text { surements was used for diagnosis. Threshold unclear. }\end{array}$ \\
\hline Target condition and reference standard(s) & IUGR defined as a birthweight below the 10th centile \\
\hline Flow and timing & From translation notes - no details \\
\hline Comparative & \\
\hline Notes &
\end{tabular}

\section{Methodological quality}

Biochemical tests of placental function versus ultrasound assessment of fetal size for stillbirth and small-for-gestational-age infants 
Steiner 1991 (Continued)

$\begin{array}{llll}\text { Item } & \begin{array}{l}\text { Authors'judge- } \\ \text { ment }\end{array} & \text { Risk of bias } & \begin{array}{l}\text { Applicability con- } \\ \text { cerns }\end{array}\end{array}$

DOMAIN 1: Patient Selection

\begin{tabular}{llll}
\hline Was a consecutive or random sample of patients enrolled? & Yes \\
\hline Was a case-control design avoided? & Yes & \\
\hline Did the study avoid inappropriate exclusions? & Yes & Low & High \\
\hline
\end{tabular}

\section{DOMAIN 2: Index Test hPL}

Were the index test results interpreted without knowledge of Yes the results of the reference standard?

If a threshold was used, was it pre-specified? Unclear

\begin{tabular}{lll}
\hline & Unclear & Unclear \\
\hline DOMAIN 2: Index Test Urinary E3 &
\end{tabular}

Were the index test results interpreted without knowledge of Yes the results of the reference standard?

\begin{tabular}{llll}
\hline If a threshold was used, was it pre-specified? & Unclear & \\
\hline & Unclear & Unclear \\
\hline
\end{tabular}

\section{DOMAIN 3: Reference Standard}

Is the reference standards likely to correctly classify the target Yes condition?

Were the reference standard results interpreted without knowl- Unclear edge of the results of the index tests?

\begin{tabular}{lll}
\hline DOMAIN 4: Flow and Timing & Low \\
\hline $\begin{array}{l}\text { Was there an appropriate interval between index test and refer- } \\
\text { ence standard? }\end{array}$ & Unclear \\
\hline Did all patients receive the same reference standard? & Unclear & \\
\hline Were all patients included in the analysis? & Unclear \\
\hline
\end{tabular}


Takeuchi 1985

\section{Study characteristics}

\begin{tabular}{ll} 
Patient sampling $\quad$ Prospective cohort \\
\hline
\end{tabular}

Patient characteristics and setting

\section{Sample size: 210}

Gestation at sampling: within 7 days of delivery (36-41 weeks)

Risk: mixed

Mode of delivery: 20 out of 60 'light-for-dates' fetuses were delivered by CS, 8 for fetal distress

\section{Index tests}

\section{Target condition and reference standard(s)}

Flow and timing
Mean BW of 'light-for-dates' fetuses was 2186 +/- 452 g so was likely adjusted for gestation

36-41 weeks' gestation was chosen as it is closest to delivery but not al women had measurements at this time.

\section{Comparative}

$$
\text { Notes }
$$

\section{Methodological quality}

\begin{tabular}{llll}
\hline Item & $\begin{array}{l}\text { Authors' judge- } \\
\text { ment }\end{array}$ & Risk of bias & $\begin{array}{l}\text { Applicability con- } \\
\text { cerns }\end{array}$ \\
\hline
\end{tabular}

\section{DOMAIN 1: Patient Selection}

\begin{tabular}{llll}
\hline Was a consecutive or random sample of patients enrolled? & Yes \\
\hline Was a case-control design avoided? & Yes & \\
\hline Did the study avoid inappropriate exclusions? & Unclear & Unclear & Low \\
\hline
\end{tabular}

\section{DOMAIN 2: Index Test EFW}

Were the index test results interpreted without knowledge of Yes the results of the reference standard?

If a threshold was used, was it pre-specified? Yes

\begin{tabular}{lll}
\hline & Low & Low \\
\hline DOMAIN 3: Reference Standard
\end{tabular}

\section{DOMAIN 3: Reference Standard}

Is the reference standards likely to correctly classify the target Yes condition?

Were the reference standard results interpreted without knowl- Unclear edge of the results of the index tests? 
Takeuchi 1985 (Continued)

Unclear

Low

\section{DOMAIN 4: Flow and Timing}

Was there an appropriate interval between index test and refer- Yes ence standard?

Did all patients receive the same reference standard?

Yes

Were all patients included in the analysis?

No

Unclear

Trudinger 1979

\section{Study characteristics}

\begin{tabular}{ll}
\hline Patient sampling & $\begin{array}{l}\text { Consecutive series of inpatients studied within } 14 \text { days of delivery } \\
\text { where the fetus was considered to be at high risk }\end{array}$
\end{tabular}

Patient characteristics and setting

\section{Sample size: 59}

Gestation at sampling: after 33 weeks

Risk: high (31 hypertensive, 20 suspected FGR, 2 antepartum haemorrhage, 3 previous stillbirth, 1 diabetes mellitus, 3 other)

Index tests

$\mathrm{hPL}$ measured using radioimmunoassay, 10th centile for a pregnancy of the same maturity used as a threshold

Target condition and reference standard(s)

The clinician was aware of the E3 and ultrasound results but not hPL. SGA below 10th centile for gestational age.

Flow and timing

Comparative

Notes

\section{Methodological quality}

\begin{tabular}{llll}
\hline Item & $\begin{array}{l}\text { Authors' judge- } \\
\text { ment }\end{array}$ & Risk of bias & $\begin{array}{l}\text { Applicability con- } \\
\text { cerns }\end{array}$
\end{tabular}

\section{DOMAIN 1: Patient Selection}

\begin{tabular}{lcc}
\hline Was a consecutive or random sample of patients enrolled? & Yes \\
\hline Was a case-control design avoided? & Yes & \\
\hline Did the study avoid inappropriate exclusions? & Yes & Low High \\
\hline
\end{tabular}

\section{DOMAIN 2: Index Test hPL}

Biochemical tests of placental function versus ultrasound assessment of fetal size for stillbirth and small-for-gestational-age infants 
Trudinger 1979 (Continued)

Were the index test results interpreted without knowledge of Yes the results of the reference standard?

\begin{tabular}{lll}
\hline Low & Low \\
\hline
\end{tabular}

\section{DOMAIN 3: Reference Standard}

Is the reference standards likely to correctly classify the target Yes condition?

Were the reference standard results interpreted without knowl- No edge of the results of the index tests?

\begin{tabular}{lll}
\hline DOMAIN 4: Flow and Timing & Unclear & Low \\
\hline $\begin{array}{l}\text { Was there an appropriate interval between index test and refer- } \\
\text { ence standard? }\end{array}$ & Yes \\
\hline Did all patients receive the same reference standard? & Yes \\
\hline Were all patients included in the analysis? & Yes \\
\hline
\end{tabular}

Low

\section{Turitz 2014}

\section{Study characteristics}

Patient sampling

Patient characteristics and setting

Index tests

Target condition and reference standard(s)
Retrospective cohort of all singleton pregnancies presenting for at least 1 growth ultrasound between 26 and 36 weeks gestational age, January 2008 and December 2011

\section{Sample size: 10,642}

Gestation at sampling: $26-36$ weeks

Risk: mixed (all pregnancies; only exclusions were fetal anomalies, multiple pregnancies, twins with 1 fetal loss)

EFW centiles calculated using Hadlock formula C

SGA defined as birthweight below the 10th centile using the Alexander curve

Flow and timing

\section{Comparative}

\section{Notes}


Turitz 2014 (Continued)

Methodological quality

\begin{tabular}{llll}
\hline Item & $\begin{array}{l}\text { Authors' judge- } \\
\text { ment }\end{array}$ & Risk of bias & $\begin{array}{l}\text { Applicability con- } \\
\text { cerns }\end{array}$ \\
\hline
\end{tabular}

\section{DOMAIN 1: Patient Selection}

\begin{tabular}{lll}
\hline Was a consecutive or random sample of patients enrolled? & Yes \\
\hline Was a case-control design avoided? & Yes \\
\hline Did the study avoid inappropriate exclusions? & Yes & Low \\
\hline
\end{tabular}

DOMAIN 2: Index Test EFW

Were the index test results interpreted without knowledge of Yes the results of the reference standard?

If a threshold was used, was it pre-specified? Yes

\begin{tabular}{lll}
\hline Low & Low \\
\hline
\end{tabular}

\section{DOMAIN 3: Reference Standard}

Is the reference standards likely to correctly classify the target Yes condition?

Were the reference standard results interpreted without knowl- Unclear edge of the results of the index tests?

\begin{tabular}{lll}
\hline & Unclear & Low \\
\hline DOMAIN 4: Flow and Timing & & \\
\hline $\begin{array}{l}\text { Was there an appropriate interval between index test and refer- } \\
\text { ence standard? }\end{array}$ & Yes \\
\hline Did all patients receive the same reference standard? & Yes \\
\hline Were all patients included in the analysis? & & Low \\
\hline
\end{tabular}

\section{Valino 2016}

\section{Study characteristics}

Patient sampling Prospective study of screening for adverse obstetric outcomes in women attending for a routine third trimester hospital visit

Patient characteristics and setting

Sample size: 3953

Gestation at sampling: after 35 weeks 
Valino 2016 (Continued)

Risk: mixed (normal population, no exclusion criteria, some women with pre-eclampsia)

Setting: King's Hospital, London \& Medway Maritime Hospital, Gillingham, Kent

Mode of delivery: 3016 normal vaginal deliveries, 436 elective caesarean sections, 500 emergency caesarean sections (mode of delivery not given for 1 stillbirth)

NICU admission: 232 admissions, 13 of these from the EFW $<5$ group

Index tests

PIGF measured in serum using Roche kit, EFW formula unclear; 5th centile used as a threshold for both tests

Target condition and reference standard(s) SGA defined as birthweight below the 10th centile after correcting for gestational age at delivery

\section{Flow and timing}

Included women are those who consented, had data available on all biomarkers, and resulted in the live birth or stillbirth of a phenotypically normal baby at $>24$ weeks' gestation.

\section{Comparative}

\section{Notes}

The results of the scan were made available to the obstetricians who would have taken specific actions of further monitoring and delivery of the cases of SGA.

\begin{tabular}{llll}
\hline Methodological quality & Authors' judgement & Risk of bias & $\begin{array}{l}\text { Applicability con- } \\
\text { cerns }\end{array}$ \\
\hline Item & & \\
\hline DOMAIN 1: Patient Selection & Yes & \\
\hline $\begin{array}{l}\text { Was a consecutive or random sample of patients en- } \\
\text { rolled? }\end{array}$ & Yes & Low \\
\hline Was a case-control design avoided? & & Low \\
\hline Did the study avoid inappropriate exclusions? & & \\
\hline
\end{tabular}

DOMAIN 2: Index Test EFW

Were the index test results interpreted without knowl- Yes edge of the results of the reference standard?

If a threshold was used, was it pre-specified? Yes

\begin{tabular}{lll}
\hline Low & Low \\
\hline
\end{tabular}

DOMAIN 2: Index Test PIGF

Were the index test results interpreted without knowl- Yes

edge of the results of the reference standard? 
Valino 2016 (Continued)

\section{DOMAIN 3: Reference Standard}

Is the reference standards likely to correctly classify Yes the target condition?

Were the reference standard results interpreted with- No out knowledge of the results of the index tests?

Unclear

Low

\section{DOMAIN 4: Flow and Timing}

Was there an appropriate interval between index test Yes and reference standard?

Did all patients receive the same reference standard? Yes

Were all patients included in the analysis? Yes

Low

Voto 1988

\section{Study characteristics}

\begin{tabular}{ll}
\hline Patient sampling & $\begin{array}{l}\text { Hypertensive pregnant women during the third trimester of preg- } \\
\text { nancy }\end{array}$
\end{tabular}

Patient characteristics and setting

\section{Sample size: 215}

Gestation at sampling: third trimester

Risk: high (all hypertensive)

\begin{tabular}{ll}
\hline Index tests & Threshold $>6 \mathrm{mg} \%$ \\
\hline Target condition and reference standard(s) & $\begin{array}{l}\text { Definition of low birthweight not explicitly stated but it was ad- } \\
\text { justed for gestational age }\end{array}$ \\
\hline
\end{tabular}

Flow and timing

Comparative

Notes

\section{Methodological quality}

\begin{tabular}{llll}
\hline Item & $\begin{array}{l}\text { Authors' judge- } \\
\text { ment }\end{array}$ & Risk of bias & $\begin{array}{l}\text { Applicability con- } \\
\text { cerns }\end{array}$ \\
\hline
\end{tabular}

\section{DOMAIN 1: Patient Selection}

Biochemical tests of placental function versus ultrasound assessment of fetal size for stillbirth and small-for-gestational-age infants 
Voto 1988 (Continued)

Was a consecutive or random sample of patients enrolled? Y

\begin{tabular}{lll}
\hline Was a case-control design avoided? & Yes \\
\hline Did the study avoid inappropriate exclusions? & Yes & Low High \\
\hline
\end{tabular}

\section{DOMAIN 2: Index Test Uric acid}

Were the index test results interpreted without knowledge of Yes the results of the reference standard?

If a threshold was used, was it pre-specified? Unclear

\begin{tabular}{|c|c|c|c|}
\hline & & Unclear & Low \\
\hline \multicolumn{4}{|l|}{ DOMAIN 3: Reference Standard } \\
\hline $\begin{array}{l}\text { Is the reference standards likely to correctly classify the target } \\
\text { condition? }\end{array}$ & Yes & & \\
\hline \multirow[t]{2}{*}{$\begin{array}{l}\text { Were the reference standard results interpreted without knowl- } \\
\text { edge of the results of the index tests? }\end{array}$} & Unclear & & \\
\hline & & Unclear & Low \\
\hline \multicolumn{4}{|l|}{ DOMAIN 4: Flow and Timing } \\
\hline $\begin{array}{l}\text { Was there an appropriate interval between index test and refer- } \\
\text { ence standard? }\end{array}$ & Yes & & \\
\hline Did all patients receive the same reference standard? & Yes & & \\
\hline \multirow[t]{2}{*}{ Were all patients included in the analysis? } & Yes & & \\
\hline & & Low & \\
\hline
\end{tabular}

\section{Walker 2010}

\section{Study characteristics}

Patient sampling Only Caucasian women were included (represent approximately $60 \%$ of pregnant women at University College London Hospitals)

Patient characteristics and setting

Sample size: 1238

Gestation at sampling: $30-34$ weeks

Risk: mixed (exclusion criteria were having a single anatomically normal fetus, normal health status, and uncomplicated obstetrical history)

Mode of delivery: 300 caesarean sections 
Walker 2010 (Continued)

Index tests

Target condition and reference standard(s)

Flow and timing

Flow and timing

Comparative

Notes

Methodological quality

\begin{tabular}{|c|c|c|c|}
\hline Item & $\begin{array}{l}\text { Authors' judge- } \\
\text { ment }\end{array}$ & Risk of bias & $\begin{array}{l}\text { Applicability con- } \\
\text { cerns }\end{array}$ \\
\hline
\end{tabular}

\section{DOMAIN 1: Patient Selection}

\begin{tabular}{lc}
\hline Was a consecutive or random sample of patients enrolled? & Yes \\
\hline Was a case-control design avoided? & Yes \\
\hline Did the study avoid inappropriate exclusions? & No \\
\hline
\end{tabular}

\begin{tabular}{lll}
\hline & High & Low \\
\hline DOMAIN 2: Index Test Placental grading &
\end{tabular}

Were the index test results interpreted without knowledge of Unclear the results of the reference standard?

If a threshold was used, was it pre-specified? Yes

\begin{tabular}{llll}
\hline Unclear & Unclear & Un \\
\hline DOMAIN $3:$ Referencestandard
\end{tabular}

\section{DOMAIN 3: Reference Standard}

Is the reference standards likely to correctly classify the target Yes condition?

Were the reference standard results interpreted without knowl- Unclear edge of the results of the index tests?

\begin{tabular}{lll}
\hline DOMAIN 4: Flow and Timing & Low \\
\hline $\begin{array}{l}\text { Was there an appropriate interval between index test and refer- } \\
\text { ence standard? }\end{array}$ & Unclear \\
\hline Did all patients receive the same reference standard? & Yes \\
\hline Were all patients included in the analysis? & Yes \\
\hline
\end{tabular}

Biochemical tests of placental function versus ultrasound assessment of fetal size for stillbirth and small-for-gestational-age infants 171

(Review)

Copyright (c) 2019 The Cochrane Collaboration. Published by John Wiley \& Sons, Ltd. 
Walker 2010 (Continued)

\section{Weerasinghe 1977}

\section{Study characteristics}

\begin{tabular}{ll}
\hline Patient sampling & $\begin{array}{l}327 \text { patients with antenatal complications, including pre-eclamp- } \\
\text { sia, hypertension, clinical FGR, antepartum haemorrhage, threat- } \\
\text { ened abortion, diabetes mellitus, and premature labour. }\end{array}$
\end{tabular}

Patient characteristics and setting

Sample size: 327

Gestation at sampling: between 30 weeks and term

Risk: high

Index tests

Urinary E3 measured using Lever's method; 920 assays were obtained from 327 patients and a low index test result was defined as 1 or more low values (- 2 SD of mean values)

Target condition and reference standard(s) SGA defined as a birthweight below 2500 g; no adjustment for gestational age

Flow and timing

Comparative

Notes

\section{Methodological quality}

\begin{tabular}{llll}
\hline Item & $\begin{array}{l}\text { Authors' judge- } \\
\text { ment }\end{array}$ & Risk of bias & $\begin{array}{l}\text { Applicability con- } \\
\text { cerns }\end{array}$
\end{tabular}

\section{DOMAIN 1: Patient Selection}

\begin{tabular}{llll}
\hline Was a consecutive or random sample of patients enrolled? & Yes \\
\hline Was a case-control design avoided? & Yes & & High \\
\hline Did the study avoid inappropriate exclusions? & Yes & Low \\
\hline
\end{tabular}

\section{DOMAIN 2: Index Test Urinary E3}

Were the index test results interpreted without knowledge of Yes the results of the reference standard?

If a threshold was used, was it pre-specified?

\section{DOMAIN 3: Reference Standard}


Weerasinghe 1977 (Continued)

Is the reference standards likely to correctly classify the target Unclear condition?

Were the reference standard results interpreted without knowl- Unclear edge of the results of the index tests?

Unclear

High

\section{DOMAIN 4: Flow and Timing}

Was there an appropriate interval between index test and refer- Yes ence standard?

\begin{tabular}{ll}
\hline Did all patients receive the same reference standard? & Yes \\
\hline Were all patients included in the analysis? & Yes \\
\hline & Low \\
\hline
\end{tabular}

\section{Weiner 2016}

\section{Study characteristics}

\section{Patient sampling}

All women were recruited in the active phase of labour (mean cervical dilatation at enrolment $5.5+/-2.1 \mathrm{~cm}$ ).

\begin{tabular}{|c|c|}
\hline Patient characteristics and setting & $\begin{array}{l}\text { Sample size: } 405 \\
\text { Gestation at sampling: after } 37 \text { weeks } \\
\text { Risk: mixed } \\
\text { Setting: Wolfson Medical Centre, Holon, Israel }\end{array}$ \\
\hline Index tests & $\begin{array}{l}\text { EFW calculated using Hadlock formula, sensitivity and specificity } \\
\text { were calculated for detection }(+/-10 \%)\end{array}$ \\
\hline Target condition and reference standard(s) & FGR defined as actual birthweight below the 10th centile \\
\hline \multicolumn{2}{|l|}{ Flow and timing } \\
\hline \multicolumn{2}{|l|}{ Comparative } \\
\hline \multicolumn{2}{|l|}{ Notes } \\
\hline \multicolumn{2}{|l|}{ Methodological quality } \\
\hline Item & $\begin{array}{l}\text { Applicability con- } \\
\text { cerns }\end{array}$ \\
\hline
\end{tabular}

\section{DOMAIN 1: Patient Selection}

Was a consecutive or random sample of patients enrolled?

Was a case-control design avoided?
Yes

Yes 
Weiner 2016 (Continued)

\begin{tabular}{lll}
\hline Unclear & Low & Unclear \\
\hline
\end{tabular}

DOMAIN 2: Index Test EFW

Were the index test results interpreted without knowledge of Yes the results of the reference standard?

If a threshold was used, was it pre-specified? Yes

Low

High

\section{DOMAIN 3: Reference Standard}

Is the reference standards likely to correctly classify the target Yes condition?

Were the reference standard results interpreted without knowl- Unclear edge of the results of the index tests?

Unclear

Low

\section{DOMAIN 4: Flow and Timing}

Was there an appropriate interval between index test and refer- Yes ence standard?

\begin{tabular}{ll}
\hline Did all patients receive the same reference standard? & Yes \\
\hline Were all patients included in the analysis? & Yes \\
\hline
\end{tabular}

\section{Westergaard 1984}

\section{Study characteristics}

Patient sampling Women that were considered to have a normal singleton pregnancy plus women with a normal singleton pregnancy and abnormal past obstetric history

\section{Patient characteristics and setting}

\section{Sample size: 392}

Gestation at sampling: 35 weeks

Risk: mixed

hPL measured by electroimmunoassay, confidence limits of normal ranges were derived from 3648 samples from 721 normal pregnancies.

IUGR defined as birthweight below the 10th centile for gestational age in the Odense populations and assessment based on phenotypic features 


\section{Westergaard 1984 (Continued)}

Flow and timing

Comparative

\begin{tabular}{llll}
\hline Notes & Unclear if results were blinded and/or affected management \\
\hline Methodological quality & & \\
\hline Item & Authors' judgement & Risk of bias & $\begin{array}{l}\text { Applicability con- } \\
\text { cerns }\end{array}$
\end{tabular}

\section{DOMAIN 1: Patient Selection}

Was a consecutive or random sample of patients enrolled? Yes

Was a case-control design avoided? Yes

Did the study avoid inappropriate exclusions? Yes

\begin{tabular}{lll}
\hline Low & Low \\
\hline
\end{tabular}

\section{DOMAIN 2: Index Test hPL}

Were the index test results interpreted without knowledge Yes

of the results of the reference standard?

\begin{tabular}{lll}
\hline If a threshold was used, was it pre-specified? & Unclear & \\
\hline & Unclear & Low \\
\hline
\end{tabular}

\section{DOMAIN 3: Reference Standard}

Is the reference standards likely to correctly classify the tar- Yes get condition?

Were the reference standard results interpreted without Unclear knowledge of the results of the index tests?

816 women were invited to participate, of which 611 were recruited. wirthweights under the 10th centile but no obvious phenotypic features of IUGR were excluded from the analysis. hPL was determined in 392 women at 35 weeks 
Williams 2002

\section{Study characteristics}

Patient sampling

Patient characteristics and setting
All hypertensive women who presented for care between 1992 and 1996

\section{Sample size: 456}

Gestation at sampling: after 20 weeks

Risk: high (patients with gestational hypertension, pre-eclampsia, eclampsia; diabetes and chronic hypertension excluded)

Setting: British Columbia Women's Hospital

$450 \mathrm{umol} / \mathrm{L}$ used as a threshold

SGA infants were defined as being less than the 10th percentile based on the Canadian birthweight percentile figures

Flow and timing

Comparative

$$
\text { Notes }
$$

Data for combined GH and PE from all tables add to 452 (258 GH and $194 \mathrm{PE}$ ) except table 5 ( $258 \mathrm{GH}$ and $198 \mathrm{PE}$ ) but this is the only place that presents totals of SGA so these numbers have to be used.

Management was not based on uric acid levels but unclear as to whether this was because measurements were blinded or not.

\section{Methodological quality}

\begin{tabular}{llll}
\hline Item & Authors' judgement & Risk of bias & $\begin{array}{l}\text { Applicability con- } \\
\text { cerns }\end{array}$ \\
\hline
\end{tabular}

\section{DOMAIN 1: Patient Selection}

\begin{tabular}{llll}
\hline Was a consecutive or random sample of patients enrolled? & Yes \\
\hline Was a case-control design avoided? & Yes & \\
\hline Did the study avoid inappropriate exclusions? & Yes & Low & High \\
\hline
\end{tabular}

\section{DOMAIN 2: Index Test Uric acid}

Were the index test results interpreted without knowledge of Yes the results of the reference standard?

\begin{tabular}{llll}
\hline If a threshold was used, was it pre-specified? & Yes & Low \\
\hline
\end{tabular}

\section{DOMAIN 3: Reference Standard}

Is the reference standards likely to correctly classify the tar- Yes get condition? 
Williams 2002 (Continued)

Were the reference standard results interpreted without Unclear knowledge of the results of the index tests?

Unclear

Low

\section{DOMAIN 4: Flow and Timing}

Was there an appropriate interval between index test and Yes reference standard?

\begin{tabular}{ll}
\hline Did all patients receive the same reference standard? & Yes \\
\hline Were all patients included in the analysis? & Yes \\
\hline
\end{tabular}

Low

\section{Yassaee 2003}

\section{Study characteristics}

\section{Patient sampling}

Cohort study of women with severe pre-eclampsia between 1986 and 2001

\section{Patient characteristics and setting}

\section{Sample size: 103}

Gestation at sampling: unknown

Risk: high

Mode of delivery: 59 caesarean sections

Setting: Taleghani Hospital, Tehran, Iran

\section{Index tests}

No description of when tests were performed

Target condition and reference standard(s) Unclear whether index test results were known. IUGR not defined.

Flow and timing

Comparative

$$
\text { Notes }
$$

\section{Methodological quality}

\begin{tabular}{llll}
\hline Item & $\begin{array}{l}\text { Authors' judge- } \\
\text { ment }\end{array}$ & Risk of bias & $\begin{array}{l}\text { Applicability con- } \\
\text { cerns }\end{array}$ \\
\hline
\end{tabular}

\section{DOMAIN 1: Patient Selection}

\begin{tabular}{ll}
\hline Was a consecutive or random sample of patients enrolled? & Yes \\
\hline Was a case-control design avoided? & Yes \\
\hline Did the study avoid inappropriate exclusions? & Yes \\
\hline
\end{tabular}


Yassaee 2003 (Continued)

Low

High

\section{DOMAIN 2: Index Test Uric acid}

Were the index test results interpreted without knowledge of Unclear

the results of the reference standard?

If a threshold was used, was it pre-specified?

Yes

Unclear

High

\section{DOMAIN 3: Reference Standard}

Is the reference standards likely to correctly classify the target Yes condition?

Were the reference standard results interpreted without knowl- Unclear edge of the results of the index tests?

\begin{tabular}{lll}
\hline DOMAIN 4: Flow and Timing & Unclear & Unclear \\
\hline $\begin{array}{l}\text { Was there an appropriate interval between index test and refer- } \\
\text { ence standard? }\end{array}$ & Unclear & \\
\hline Did all patients receive the same reference standard? & Yes & Yes \\
\hline Were all patients included in the analysis? & & Unclear \\
\hline
\end{tabular}

Ylikorkala 1973

\section{Study characteristics}

Patient sampling Series of pregnancies between 1971 and 1972

Patient characteristics and setting

Sample size: 199

Gestation at sampling: third trimester

Risk: high (mixture of hypertensive, preeclamptic, diabetic, previous IUD)

Setting: Department of Obstetrics and Gynaecology, Oulu University

Index tests

hPL determined using a double antibody radioimmunoassay (HCS Sclavo-Sorin kit), 2.5th centile used as a threshold (calculated according to Herrera 1958)

Target condition and reference standard(s)

Flow and timing
SGA defined as birthweight below the 10th centile for gestational age

687 patients in the series, only data from high-risk patients could be used 
Ylikorkala 1973 (Continued)

Comparative

$\begin{array}{ll}\text { Notes } & \text { Placentas were examined microscopically and } 46 \text { were found to have } \\ \text { degenerative placental changes, } 32 \text { had a dysmature placenta, and } 78 & \text { had normal placental structure. No relationship was found between } \\ \text { microscopic calcifications and serum hPL level. }\end{array}$

Methodological quality

\begin{tabular}{llcl}
\hline Item & Authors' judgement & Risk of bias & $\begin{array}{l}\text { Applicability con- } \\
\text { cerns }\end{array}$ \\
\hline
\end{tabular}

\section{DOMAIN 1: Patient Selection}

\begin{tabular}{llll}
\hline Was a consecutive or random sample of patients enrolled? & Yes \\
\hline Was a case-control design avoided? & Yes & \\
\hline Did the study avoid inappropriate exclusions? & Yes & Low & High
\end{tabular}

\section{DOMAIN 2: Index Test hPL}

Were the index test results interpreted without knowledge Yes

of the results of the reference standard?

If a threshold was used, was it pre-specified? Yes

\begin{tabular}{lll}
\hline Low & Low \\
\hline
\end{tabular}

\section{DOMAIN 3: Reference Standard}

Is the reference standards likely to correctly classify the tar- Yes get condition?

Were the reference standard results interpreted without Unclear

knowledge of the results of the index tests?

Unclear Low

\section{DOMAIN 4: Flow and Timing}

Was there an appropriate interval between index test and Yes reference standard?

\begin{tabular}{lc}
\hline Did all patients receive the same reference standard? & Yes No \\
\hline Were all patients included in the analysis? & Low \\
\hline
\end{tabular}


Zhang 1990

\section{Study characteristics}

\section{Patient sampling}

Patient characteristics and setting

Index tests

Target condition and reference standard(s)

Flow and timing

Comparative

\begin{tabular}{|c|c|c|c|}
\hline Notes & \multicolumn{3}{|c|}{$2 \times 2$ table derived from high-risk patients only } \\
\hline \multicolumn{4}{|l|}{ Methodological quality } \\
\hline Item & $\begin{array}{l}\text { Authors' judge- } \\
\text { ment }\end{array}$ & Risk of bias & $\begin{array}{l}\text { Applicability con- } \\
\text { cerns }\end{array}$ \\
\hline \multicolumn{4}{|l|}{ DOMAIN 1: Patient Selection } \\
\hline Was a consecutive or random sample of patients enrolled? & Yes & & \\
\hline Was a case-control design avoided? & Yes & & \\
\hline \multirow[t]{2}{*}{ Did the study avoid inappropriate exclusions? } & Yes & & \\
\hline & & Low & High \\
\hline
\end{tabular}

\section{DOMAIN 2: Index Test hPL}

Were the index test results interpreted without knowledge of Yes the results of the reference standard?

If a threshold was used, was it pre-specified?

Yes

\begin{tabular}{lll}
\hline Low & Low \\
\hline
\end{tabular}

\section{DOMAIN 3: Reference Standard}

Is the reference standards likely to correctly classify the target Yes condition?

Were the reference standard results interpreted without knowl- Unclear edge of the results of the index tests?
High 
Zhang 1990 (Continued)

\section{DOMAIN 4: Flow and Timing}

Was there an appropriate interval between index test and refer- Unclear ence standard?

Did all patients receive the same reference standard?

Were all patients included in the analysis?
Yes

Yes

ACOG: American College of Obstetricians and Gynecologists; AFI: amniotic fluid index; AGA: appropriate-for-gestational age; BP: blood pressure; BPD: biparietal diameter; BW: birthweight; CTG: cardiotocography; EFW: estimated fetal weight; ELISA: enzyme-linked immunosorbent assay; FGR: fetal growth restriction; FN: false negative; FP: false positive; hCG: human chorionic gonadotrophin;hPL: human placental lactogen; IQR: interquartile range; IUD/IUFD: intrauterine death/intrauterine fetal death; IUGR: Intrauterine growth restriction; NICU: neonatal intensive care unit; PE: pre-eclampsia;PIGF: placental growth factor; PIH: pregnancy induced hypertension; RI: resistance index; SCN: special care nursery; SD: standard deviation; SEFW: sonographic estimated fetal weight;SFD: small-for-dates; SFH: symphysis fundal height SGA: small-for-gestational age; SUA: single umbilical artery; sVEGFR-1: soluble vascular endothelial growth factor receptor-1.

Characteristics of excluded studies [ordered by study ID]

\begin{tabular}{|c|c|}
\hline Study & Reason for exclusion \\
\hline Adekanle 2013 & Relevant reference standard not recorded \\
\hline Agboola 1978 & $2 \times 2$ table could not be extracted \\
\hline Aggarwal 2006 & Relevant reference standard not recorded \\
\hline Agorastos 2014 & Not a prospective or retrospective cross-sectional or cohort study \\
\hline Ahmad 1979 & Relevant reference standard not recorded \\
\hline Aickin 1983 & $2 \times 2$ table could not be extracted \\
\hline Al-Amin 2015 & Relevant index test not included \\
\hline Alahakoon 2014 & Data presented in another paper \\
\hline Alberry 2009 & $2 \times 2$ table could not be extracted \\
\hline Algeri 2013 & Not a prospective or retrospective cross-sectional or cohort study \\
\hline Alvarez-Fernandez 2014 & $2 \times 2$ table could not be extracted \\
\hline Alwasel 2013 & Relevant reference standard not recorded \\
\hline Anastasakis 2008 & Participants do not match population of interest \\
\hline Anderson 1978 & Relevant index test not included \\
\hline Arabin 1993 & $2 \times 2$ table could not be extracted \\
\hline Arabin 1995 & $2 \times 2$ table could not be extracted \\
\hline
\end{tabular}

Biochemical tests of placental function versus ultrasound assessment of fetal size for stillbirth and small-for-gestational-age infants 


\begin{tabular}{|c|c|}
\hline Study & Reason for exclusion \\
\hline Arias 1977 & Relevant index test not included \\
\hline Ariyuki 1995 & Participants do not match population of interest \\
\hline Atzeni 2012 & $2 \times 2$ table could not be extracted \\
\hline Aviram 2015 & $2 \times 2$ table could not be extracted \\
\hline Axelsson 1978 & Relevant reference standard not recorded \\
\hline Baeza Valenzuela1995 & $2 \times 2$ table could not be extracted \\
\hline Bahado-Singh 1998 & Relevant reference standard not recorded \\
\hline Bainbridge 2008 & $2 \times 2$ table could not be extracted \\
\hline Bakketeig 1984 & $2 \times 2$ table could not be extracted \\
\hline Baltajian 2016 & $2 \times 2$ table could not be extracted \\
\hline Barden 1999 & $2 \times 2$ table could not be extracted \\
\hline Bardien 2016 & Relevant reference standard not recorded \\
\hline Baron 1996 & Index test performed continuously over time \\
\hline Barrilleaux 2007 & Relevant reference standard not recorded \\
\hline Bartha 2003 & Not a prospective or retrospective cross-sectional or cohort study \\
\hline Bashir 1982 & Relevant index test not included \\
\hline Bastek 2009 & Not a prospective or retrospective cross-sectional or cohort study \\
\hline Battaglia 1995 & Relevant reference standard not recorded \\
\hline Beischer 1975 & Data presented in another study \\
\hline Bell 1967 & Not a prospective or retrospective cross-sectional or cohort study \\
\hline Benton 2010 & Not a prospective or retrospective cross-sectional or cohort study \\
\hline Benton 2011 & Not a prospective or retrospective cross-sectional or cohort study \\
\hline Benton 2011a & Not a prospective or retrospective cross-sectional or cohort study \\
\hline Benton 2012 & Not a prospective or retrospective cross-sectional or cohort study \\
\hline Benton 2012a & Not a prospective or retrospective cross-sectional or cohort study \\
\hline Benton 2014 & Participants do not match population of interest \\
\hline Benton 2014a & Relevant reference standard not recorded \\
\hline Benz 1980 & Not a prospective or retrospective cross-sectional or cohort study \\
\hline
\end{tabular}

Biochemical tests of placental function versus ultrasound assessment of fetal size for stillbirth and small-for-gestational-age infants 


\begin{tabular}{|c|c|}
\hline Study & Reason for exclusion \\
\hline Berendtsen 1985 & Index test measured continuously over time \\
\hline Bergsjo 1973 & $2 \times 2$ table could not be extracted \\
\hline Berle 1973 & $2 \times 2$ table could not be extracted \\
\hline Berle 1973a & $2 \times 2$ table could not be extracted \\
\hline Berle 1973b & Not a prospective or retrospective cross-sectional or cohort study \\
\hline Berle 1975 & $2 \times 2$ table could not be extracted \\
\hline Bernardes 2013 & Relevant reference standard not recorded \\
\hline Bernatavicius 2013 & Participants do not match population of interest \\
\hline Bersinger 2004 & Not a prospective or retrospective cross-sectional or cohort study \\
\hline Bersinger 2005 & $2 \times 2$ table could not be extracted \\
\hline Bhansali 1975 & Review \\
\hline Bian 1992 & $2 \times 2$ table could not be extracted \\
\hline Biberoglu 2016 & Relevant reference standard not recorded \\
\hline Bieglmayer 1981 & $2 \times 2$ table could not be extracted \\
\hline Bila 1980 & $2 \times 2$ table could not be extracted \\
\hline Bitzer 1985 & $2 \times 2$ table could not be extracted \\
\hline Blaskova 1977 & Relevant index test not included \\
\hline Bligh 2015 & Relevant reference standard not recorded \\
\hline Blitz 2016 & Review \\
\hline Blumenfeld 2007 & $2 \times 2$ table could not be extracted \\
\hline Bobrow 2002 & Not a prospective or retrospective cross-sectional or cohort study \\
\hline Bock 1976 & $2 \times 2$ table could not be extracted \\
\hline Boij 2012 & $2 \times 2$ table could not be extracted \\
\hline Borges 2005 & $2 \times 2$ table could not be extracted \\
\hline Botasheva 2016 & $2 \times 2$ table could not be extracted \\
\hline Boucoiran 2012 & $2 \times 2$ table could not be extracted \\
\hline Branconi 1981 & $2 \times 2$ table could not be extracted \\
\hline Brush 1970 & Participants do not match population of interest \\
\hline
\end{tabular}




\begin{tabular}{|c|c|}
\hline Study & Reason for exclusion \\
\hline Bukowski 2014 & Not a prospective or retrospective cross-sectional or cohort study \\
\hline Butcher 2012 & Participants do not match population of interest \\
\hline Buyon 2011 & Relevant reference standard not recorded \\
\hline Cage 2009 & $2 \times 2$ table could not be extracted \\
\hline Calabrese 2012 & Relevant reference standard not recorded \\
\hline Calderon 2011 & $2 \times 2$ table could not be extracted \\
\hline Campobasso 1967 & Participants do not match population of interest \\
\hline Camus-Bablon 1990 & Relevant reference standard not recorded \\
\hline Carne 1987 & Data presented in another study \\
\hline Castren 1966 & Relevant reference standard not recorded \\
\hline Cavazza 2015 & $2 \times 2$ table could not be extracted \\
\hline Ceccarello 1980 & Relevant index test not included \\
\hline Cefalo 2005 & Commentary \\
\hline Cetin 2014 & $2 \times 2$ table could not be extracted \\
\hline Cetin 2016 & Relevant reference standard not recorded \\
\hline Chaiworapongsa 2008 & $2 \times 2$ table could not be extracted \\
\hline Chaiworapongsa 2012 & Data presented in another study \\
\hline Chaiworapongsa 2013a & $2 \times 2$ table could not be extracted \\
\hline Chaiworapongsa 2013b & $2 \times 2$ table could not be extracted \\
\hline Chambers 1989 & Relevant index test not included \\
\hline Chang 1993 & Relevant index test not included \\
\hline Chang 1994 & Not a prospective or retrospective cross-sectional or cohort study \\
\hline Chapman 1978 & $2 \times 2$ table could not be extracted \\
\hline Chapman 1981 & Participants do not match population of interest \\
\hline Chappell 2002 & $2 \times 2$ table could not be extracted \\
\hline Chard 1982 & Review \\
\hline Chauhan 2012 & $2 \times 2$ table could not be extracted \\
\hline Chawengsettakul 2015 & Relevant reference standard not recorded \\
\hline
\end{tabular}




\begin{tabular}{|c|c|}
\hline Study & Reason for exclusion \\
\hline Chew 2014 & Relevant reference standard not recorded \\
\hline Church 2016 & Not a prospective or retrospective cross-sectional or cohort study \\
\hline Clelia 2013 & Relevant reference standard not recorded \\
\hline Clowse 2011 & Relevant reference standard not recorded \\
\hline Cody 2013 & $2 \times 2$ table could not be extracted \\
\hline Cody 2016 & $2 \times 2$ table could not be extracted \\
\hline Cooley 2011 & $2 \times 2$ table could not be extracted \\
\hline Cordano 1988 & Participants do not match population of interest \\
\hline Craigo 1996 & $2 \times 2$ table could not be extracted \\
\hline Crane 1979 & $2 \times 2$ table could not be extracted \\
\hline Crawford 1985 & $2 \times 2$ table could not be extracted \\
\hline D'Anna 2000 & Relevant reference standard not recorded \\
\hline Daikoku 1979 & $2 \times 2$ table could not be extracted \\
\hline Darling 2014 & Participants do not match population of interest \\
\hline Dave 2016 & Relevant index test not included \\
\hline Dawood 1976 & Participants do not match population of interest \\
\hline De Marchi 1977 & Participants do not match population of interest \\
\hline Del Moral 2015 & Relevant reference standard not recorded \\
\hline Deter 2016 & Relevant reference standard not recorded \\
\hline Di Lorenzo 2013 & $2 \times 2$ table could not be extracted \\
\hline Dombrowski 1992 & Participants do not match population of interest \\
\hline Dombrowski 1992a & Participants do not match population of interest \\
\hline Ducarme 2012 & $2 \times 2$ table could not be extracted \\
\hline Duff 1986 & Relevant index test not included \\
\hline Dutton 2012 & Relevant reference standard not recorded \\
\hline Dutton 2012a & Relevant reference standard not recorded \\
\hline Eik-Nes 1984 & Participants do not match population of interest \\
\hline El-Ahmady 1997 & $2 \times 2$ table could not be extracted \\
\hline
\end{tabular}




\begin{tabular}{|c|c|}
\hline Study & Reason for exclusion \\
\hline Elchalal 2000 & Participants do not match population of interest \\
\hline Ernst 2016 & $2 \times 2$ table could not be extracted \\
\hline Fadigas 2015 & $2 \times 2$ table could not be extracted \\
\hline Falkner 1995 & Relevant index test not included \\
\hline Ferrazzi 1986 & Relevant index test not included \\
\hline Fioretti 1986 & $2 \times 2$ table could not be extracted \\
\hline Fischer-Rasmussen 1971 & $2 \times 2$ table could not be extracted \\
\hline Fisteag-Kiprono 2006 & Relevant reference standard not recorded \\
\hline Forger 2016 & $2 \times 2$ table could not be extracted \\
\hline Fotiou 2015 & $2 \times 2$ table could not be extracted \\
\hline Furuhashi 1984 & $2 \times 2$ table could not be extracted \\
\hline Gabbay-Benziv 2016a & $2 \times 2$ table could not be extracted \\
\hline Gabbay-Benziv 2017 & Abstract for another study \\
\hline Gaillard 2014 & $2 \times 2$ table could not be extracted \\
\hline Gao 2008 & $2 \times 2$ table could not be extracted \\
\hline Garcia-Flores 2015 & Relevant reference standard not recorded \\
\hline Garoff 1976 & $2 \times 2$ table could not be extracted \\
\hline Gaziano 1988 & Participants do not match population of interest \\
\hline Geerts 2007 & Relevant reference standard not recorded \\
\hline Gerhard 1987 & $2 \times 2$ table could not be extracted \\
\hline Gernand 2015 & $2 \times 2$ table could not be extracted \\
\hline Gherzi 1981 & Index test measured continuously over time \\
\hline Giambanco 1986 & Review \\
\hline Giardini 2014 & Relevant reference standard not recorded \\
\hline Gloning 1991 & Relevant index test not included \\
\hline Goetzinger 2013 & Relevant index test not included \\
\hline Goldenberg 1993 & Relevant reference standard not recorded \\
\hline Goldenberg 1997 & Relevant reference standard not recorded \\
\hline
\end{tabular}




\begin{tabular}{|c|c|}
\hline Study & Reason for exclusion \\
\hline Gomez-Roig 2015 & $2 \times 2$ table could not be extracted \\
\hline Gordon 1978 & Relevant reference standard not recorded \\
\hline Grantz 2016 & Relevant reference standard not recorded \\
\hline Gravett 2015 & $2 \times 2$ table could not be extracted \\
\hline Griffin 2014 & Data presented in another study \\
\hline Gris 2015 & $2 \times 2$ table could not be extracted \\
\hline Habib 2002 & $2 \times 2$ table could not be extracted \\
\hline Hargreaves 2011 & $2 \times 2$ table could not be extracted \\
\hline Harper 2014 & Not a prospective or retrospective cross-sectional or cohort study \\
\hline Hassan 1987 & Relevant index test not included \\
\hline Hawkins 2014 & Relevant index test not included \\
\hline Heazell 2014 & Review \\
\hline Henrichs 2016 & Not a prospective or retrospective cross-sectional or cohort study \\
\hline Hensleigh 1977 & Participants do not match population of interest \\
\hline Herraiz 2014 & Not a prospective or retrospective cross-sectional or cohort study \\
\hline Hinkle 2015 & $2 \times 2$ table could not be extracted \\
\hline Hughes 1980 & $2 \times 2$ table could not be extracted \\
\hline Husse 2014 & $2 \times 2$ table could not be extracted \\
\hline Jabeen 1999 & Participants do not match population of interest \\
\hline James-Todd 2015 & Relevant reference standard not recorded \\
\hline Johnson 2011 & Relevant reference standard not recorded \\
\hline Johnstone 2015 & Participants do not match population of interest \\
\hline Karjalainen 1975 & Relevant reference standard not recorded \\
\hline Karlsen 2016 & $2 \times 2$ table could not be extracted \\
\hline Kase 2012 & $2 \times 2$ table could not be extracted \\
\hline Kase 2012a & $2 \times 2$ table could not be extracted \\
\hline Kazzi 1983 & Participants do not match population of interest \\
\hline Khalil 2015 & $2 \times 2$ table could not be extracted \\
\hline
\end{tabular}




\begin{tabular}{|c|c|}
\hline Study & Reason for exclusion \\
\hline Khalil 2016 & $2 \times 2$ table could not be extracted \\
\hline Kihaile 1988 & Participants do not match population of interest \\
\hline Kim 2009 & $2 \times 2$ table could not be extracted \\
\hline Kim 2014 & $2 \times 2$ table could not be extracted \\
\hline Kim 2016 & Participants do not match population of interest \\
\hline Kjos 2015 & $2 \times 2$ table could not be extracted \\
\hline Kneitel 2016 & $2 \times 2$ table could not be extracted \\
\hline Kolovetsiou-Kreiner 2014 & $2 \times 2$ table could not be extracted \\
\hline Kolovetsiou-Kreiner 2015 & $2 \times 2$ table could not be extracted \\
\hline Krochik 2010 & Participants do not match population of interest \\
\hline Kulkarni 1981 & $2 \times 2$ table could not be extracted \\
\hline Kulkarni 2010 & $2 \times 2$ table could not be extracted \\
\hline Kullander 1982 & Relevant index test not included \\
\hline Kundu 1978 & $2 \times 2$ table could not be extracted \\
\hline Kunzig 1975 & $2 \times 2$ table could not be extracted \\
\hline Kunzig 1980 & $2 \times 2$ table could not be extracted \\
\hline Lai 2014 & Relevant reference standard not recorded \\
\hline Larkin 2015 & $2 \times 2$ table could not be extracted \\
\hline Larsen 1992 & $2 \times 2$ table could not be extracted \\
\hline Larsen 1997 & Relevant reference standard not recorded \\
\hline Laurin $1987 a$ & $2 \times 2$ table could not be extracted \\
\hline Lean 2016 & $2 \times 2$ table could not be extracted \\
\hline Leanos-Miranda 2013 & $2 \times 2$ table could not be extracted \\
\hline Lechner 1987 & $2 \times 2$ table could not be extracted \\
\hline Levine 2005 & Not a prospective or retrospective cross-sectional or cohort study \\
\hline Li 2014 & $2 \times 2$ table could not be extracted \\
\hline Little 2016 & $2 \times 2$ table could not be extracted \\
\hline Lobmaier 2014 & $2 \times 2$ table could not be extracted \\
\hline
\end{tabular}




\begin{tabular}{|c|c|}
\hline Study & Reason for exclusion \\
\hline London 1983 & Relevant reference standard not recorded \\
\hline MacDonald 1983 & Not a prospective or retrospective cross-sectional or cohort study \\
\hline Macmillian 1976 & $2 \times 2$ table could not be extracted \\
\hline Maly 1987 & Relevant reference standard not recorded \\
\hline March 2015 & $2 \times 2$ table could not be extracted \\
\hline Margossian 2016 & $2 \times 2$ table could not be extracted \\
\hline Markestad 1997 & Not a prospective or retrospective cross-sectional or cohort study \\
\hline Martins 2005 & Relevant index test not included \\
\hline Masoura 2014 & $2 \times 2$ table could not be extracted \\
\hline Matthews 2017 & $2 \times 2$ table could not be extracted \\
\hline Mazzocco 2014 & Relevant reference standard not recorded \\
\hline McKenna 2003 & Relevant index test not included \\
\hline Melamed 2015 & $2 \times 2$ table could not be extracted \\
\hline Melamed 2016 & $2 \times 2$ table could not be extracted \\
\hline Melamed 2016a & $2 \times 2$ table could not be extracted \\
\hline Merriam 2014 & Participants do not match population of interest \\
\hline Mertens 1975 & Participants do not match population of interest \\
\hline Mirza 2015 & Participants do not match population of interest \\
\hline Miwa 2014 & Relevant reference standard not recorded \\
\hline Mlynarczyk 2015 & $2 \times 2$ table could not be extracted \\
\hline Mlynarczyk 2015a & $2 \times 2$ table could not be extracted \\
\hline Mone 2016 & $2 \times 2$ table could not be extracted \\
\hline Moore 2012 & Relevant reference standard not recorded \\
\hline Morrison 1980 & Participants do not match population of interest \\
\hline Muraguchi 1981 & Participants do not match population of interest \\
\hline Myatt 2013 & $2 \times 2$ table could not be extracted \\
\hline Nadal 2015 & $2 \times 2$ table could not be extracted \\
\hline Nair 2016 & $2 \times 2$ table could not be extracted \\
\hline
\end{tabular}




\begin{tabular}{|c|c|}
\hline Study & Reason for exclusion \\
\hline Nelson 2015 & Participants do not match population of interest \\
\hline Nice 2014 & Not a prospective or retrospective cross-sectional or cohort study \\
\hline Nice 2014a & Not a prospective or retrospective cross-sectional or cohort study \\
\hline Nieder 1976 & $2 \times 2$ table could not be extracted \\
\hline Nielsen 1981 & $2 \times 2$ table could not be extracted \\
\hline Niknafs 2001 & Relevant index test not included \\
\hline O'Connor 2015 & Participants do not match population of interest \\
\hline Obiekwe 1982 & Relevant index test not included \\
\hline Odibo 2014 & $2 \times 2$ table could not be extracted \\
\hline Okonofua 1986 & Participants do not match population of interest \\
\hline Pal 2015 & Participants do not match population of interest \\
\hline Palomaki 2015 & Participants do not match population of interest \\
\hline Palomaki 2015a & Participants do not match population of interest \\
\hline Papastefanou 2014 & $2 \times 2$ table could not be extracted \\
\hline Papastefanou 2015 & $2 \times 2$ table could not be extracted \\
\hline Parra Saavedra 2015 & Relevant reference standard not recorded \\
\hline Parrish 2010 & $2 \times 2$ table could not be extracted \\
\hline Partap 2015 & Relevant reference standard not recorded \\
\hline Pavelka 1982 & Participants do not match population of interest \\
\hline Pecks 2015 & $2 \times 2$ table could not be extracted \\
\hline Peixoto 2016 & $2 \times 2$ table could not be extracted \\
\hline Perez-Cruz 2015 & $2 \times 2$ table could not be extracted \\
\hline Perry 1986 & $2 \times 2$ table could not be extracted \\
\hline Persson 1978 & $2 \times 2$ table could not be extracted \\
\hline Persson 1980 & $2 \times 2$ table could not be extracted \\
\hline Peyronnet 2016 & $2 \times 2$ table could not be extracted \\
\hline Pfeiffer 1990 & $2 \times 2$ table could not be extracted \\
\hline Pinheiro 2014 & $2 \times 2$ table could not be extracted \\
\hline
\end{tabular}




\begin{tabular}{|c|c|}
\hline Study & Reason for exclusion \\
\hline Pledger 1984 & Not a prospective or retrospective cross-sectional or cohort study \\
\hline Pluta 1979 & Participants do not match population of interest \\
\hline Ponce 1995 & $2 \times 2$ table could not be extracted \\
\hline Powers 2010 & Not a prospective or retrospective cross-sectional or cohort study \\
\hline Prakash 2012 & $2 \times 2$ table could not be extracted \\
\hline Qublan 2005 & $2 \times 2$ table could not be extracted \\
\hline Raghuramulu 1978 & $2 \times 2$ table could not be extracted \\
\hline Rajasingam 2009 & $2 \times 2$ table could not be extracted \\
\hline Rasanen 2015 & Relevant reference standard not recorded \\
\hline Reck 1987 & Relevant index test not included \\
\hline Ris-Stalpers 2012 & $2 \times 2$ table could not be extracted \\
\hline Riss 1982 & Relevant reference standard not recorded \\
\hline Rizos 2013 & Not a prospective or retrospective cross-sectional or cohort study \\
\hline Rocca 1995 & $2 \times 2$ table could not be extracted \\
\hline Romero 2008 & Not a prospective or retrospective cross-sectional or cohort study \\
\hline Ronin-Walknowska 1984 & $2 \times 2$ table could not be extracted \\
\hline Rosendahl 1988 & Relevant index test not included \\
\hline Rosendahl 1991 & Relevant index test not included \\
\hline Rothenbacher 2016 & $2 \times 2$ table could not be extracted \\
\hline Ruozi Berretta 1967 & Participants do not match population of interest \\
\hline Sabbagha 1979 & Review \\
\hline Salahuddin 2016 & $2 \times 2$ table could not be extracted \\
\hline Salas 1993 & $2 \times 2$ table could not be extracted \\
\hline Salas 1998 & $2 \times 2$ table could not be extracted \\
\hline Salas 2006 & $2 \times 2$ table could not be extracted \\
\hline Saleh 2015 & Relevant reference standard not recorded \\
\hline Salkie 1977 & $2 \times 2$ table could not be extracted \\
\hline Samanta 1989 & $2 \times 2$ table could not be extracted \\
\hline
\end{tabular}




\begin{tabular}{|c|c|}
\hline Study & Reason for exclusion \\
\hline Sanchez Fernandez 2015 & $2 \times 2$ table could not be extracted \\
\hline Sarandakou 1989 & $2 \times 2$ table could not be extracted \\
\hline Sato 1974 & Participants do not match population of interest \\
\hline Secher 1986 & $2 \times 2$ table could not be extracted \\
\hline Secher 1987 & $2 \times 2$ table could not be extracted \\
\hline Sekar 2015 & $2 \times 2$ table could not be extracted \\
\hline Selbing 1984 & Relevant index test not included \\
\hline Semczuk-Sikora 2007 & $2 \times 2$ table could not be extracted \\
\hline Shaarawy 2001 & $2 \times 2$ table could not be extracted \\
\hline Shah 1996 & $2 \times 2$ table could not be extracted \\
\hline Sharf 1984 & Participants do not match population of interest \\
\hline Sheth 2016 & Relevant reference standard not recorded \\
\hline Shibata 2005 & Not a prospective or retrospective cross-sectional or cohort study \\
\hline Sibiude 2012 & $2 \times 2$ table could not be extracted \\
\hline Sichinava 2014 & $2 \times 2$ table could not be extracted \\
\hline Singer 1970 & $2 \times 2$ table could not be extracted \\
\hline Smith 2014 & Not a prospective or retrospective cross-sectional or cohort study \\
\hline Smith-Bindman 2002 & Participants do not match population of interest \\
\hline Smith-Bindman 2003 & Participants do not match population of interest \\
\hline Soler 1975 & Index test performed continuously over time \\
\hline Sood 1988 & Not a prospective or retrospective cross-sectional or cohort study \\
\hline Sorensen 2000 & $2 \times 2$ table could not be extracted \\
\hline Souka 2012 & $2 \times 2$ table could not be extracted \\
\hline Souka 2013 & $2 \times 2$ table could not be extracted \\
\hline Sovio 2014 & Abstract for an included study \\
\hline Spellacy 1967 & Not a prospective or retrospective cross-sectional or cohort study \\
\hline Spellacy 1975 & Not a prospective or retrospective cross-sectional or cohort study \\
\hline Spellacy 1976 & Not a prospective or retrospective cross-sectional or cohort study \\
\hline
\end{tabular}




\begin{tabular}{|c|c|}
\hline Study & Reason for exclusion \\
\hline Spona 1971 & $2 \times 2$ table could not be extracted \\
\hline Spona 1972 & $2 \times 2$ table could not be extracted \\
\hline Stefanelli 2014 & Participants do not match population of interest \\
\hline Stefanidis 1998 & Not a prospective or retrospective cross-sectional or cohort study \\
\hline Strizhakov 2013 & $2 \times 2$ table could not be extracted \\
\hline Strom 1983 & Not a prospective or retrospective cross-sectional or cohort study \\
\hline Sucak 2010 & $2 \times 2$ table could not be extracted \\
\hline Sudik 1982 & Participants do not match population of interest \\
\hline Sundrani 2013 & $2 \times 2$ table could not be extracted \\
\hline Tajik 2012 & $2 \times 2$ table could not be extracted \\
\hline Takeuchi 1988 & $2 \times 2$ table could not be extracted \\
\hline Tammemae 2016 & $2 \times 2$ table could not be extracted \\
\hline Tayama 1983 & $2 \times 2$ table could not be extracted \\
\hline Taylor 2003 & $2 \times 2$ table could not be extracted \\
\hline Teoh 1971 & Index test performed continuously over time \\
\hline Tonari 1987 & $2 \times 2$ table could not be extracted \\
\hline Torok 1987 & Index test performed continuously over time \\
\hline Triunfo 2014 & $2 \times 2$ table could not be extracted \\
\hline Triunfo 2016 & $2 \times 2$ table could not be extracted \\
\hline Triunfo $2016 a$ & $2 \times 2$ table could not be extracted \\
\hline Tsiakkas 2015 & Relevant reference standard not recorded \\
\hline Tsiakkas 2016 & Relevant reference standard not recorded \\
\hline Turpin 2015 & $2 \times 2$ table could not be extracted \\
\hline Van Rijn 2015 & $2 \times 2$ table could not be extracted \\
\hline Varma 1979 & Relevant index test not included \\
\hline Varma 1982 & $2 \times 2$ table could not be extracted \\
\hline Vatten 2012 & Not a prospective or retrospective cross-sectional or cohort study \\
\hline Vinayagam 2015 & $2 \times 2$ table could not be extracted \\
\hline
\end{tabular}




\begin{tabular}{|c|c|}
\hline Study & Reason for exclusion \\
\hline Wallner 2007 & $2 \times 2$ table could not be extracted \\
\hline Watson 1973 & $2 \times 2$ table could not be extracted \\
\hline Weissbach 1985 & $2 \times 2$ table could not be extracted \\
\hline Whigham 1980 & $2 \times 2$ table could not be extracted \\
\hline White 2016 & Relevant reference standard not recorded \\
\hline Woelkers 2016 & Relevant reference standard not recorded \\
\hline Woo 2016 & Relevant index test not included \\
\hline Woods 2015 & $2 \times 2$ table could not be extracted \\
\hline Wurz 1983 & Participants do not match population of interest \\
\hline Xing 2016 & $2 \times 2$ table could not be extracted \\
\hline Xu 2015 & $2 \times 2$ table could not be extracted \\
\hline Yamaguchi 1979 & $2 \times 2$ table could not be extracted \\
\hline Yanaihara 1984 & Not a prospective or retrospective cross-sectional or cohort study \\
\hline Zail 1975 & $2 \times 2$ table could not be extracted \\
\hline Zera 2011 & $2 \times 2$ table could not be extracted \\
\hline Zhang 2011 & $2 \times 2$ table could not be extracted \\
\hline Zhao 2010 & Not a prospective or retrospective cross-sectional or cohort study \\
\hline Zlatnik 1979 & Participants do not match population of interest \\
\hline Zuckerman 1974 & Participants do not match population of interest \\
\hline
\end{tabular}

Characteristics of studies awaiting classification [ordered by study ID]

\section{Bracali 1968 \\ Study characteristics}

\begin{tabular}{ll}
\hline Patient sampling & Unknown \\
\hline Patient characteristics and setting & Unknown \\
\hline Index tests & Urinary oestriol \\
\hline Target condition and reference standard(s) & Unknown \\
\hline Flow and timing & Unknown \\
\hline
\end{tabular}


Bracali 1968 (Continued)

Comparative

\section{Notes}

\section{Fuks 1990}

\section{Study characteristics}

\begin{tabular}{ll}
\hline Patient sampling & Unknown \\
\hline Patient characteristics and setting & Unknown \\
\hline Index tests & Placental grading \\
\hline Target condition and reference standard(s) & Fetal and neonatal outcomes - unclear \\
\hline Flow and timing & Unknown \\
\hline Comparative & \\
\hline Notes & \\
\hline
\end{tabular}

\section{Jain 2000}

\section{Study characteristics}

\begin{tabular}{ll}
\hline Patient sampling & Unknown \\
\hline Patient characteristics and setting & Unknown \\
\hline Index tests & Placental grading \\
\hline Target condition and reference standard(s) & IUGR \\
\hline Flow and timing & Unknown \\
\hline
\end{tabular}

Comparative

Notes

\section{Khan 2004}

\section{Study characteristics}

\begin{tabular}{ll}
\hline Patient sampling & Unknown \\
\hline Patient characteristics and setting & Unknown \\
\hline Index tests & Ultrasound EFW? \\
\hline
\end{tabular}

Biochemical tests of placental function versus ultrasound assessment of fetal size for stillbirth and small-for-gestational-age infants 
Khan 2004 (Continued)

Target condition and reference standard(s)

IUGR

Flow and timing

Unknown

Comparative

\section{Notes}

\section{Ruseva 1983}

\section{Study characteristics}

\begin{tabular}{ll}
\hline Patient sampling & Unknown \\
\hline Patient characteristics and setting & Unknown \\
\hline Index tests & Unknown \\
\hline Target condition and reference standard(s) & Unknown \\
\hline Flow and timing & Unknown \\
\hline Comparative & \\
\hline Notes & \\
\hline
\end{tabular}

\section{Ruseva 1985}

\section{Study characteristics}

\begin{tabular}{ll}
\hline Patient sampling & Unknown \\
\hline Patient characteristics and setting & Unknown \\
\hline Index tests & Ultrasound EFW \\
\hline Target condition and reference standard(s) & Unknown \\
\hline Flow and timing & Unknown \\
\hline Comparative & \\
\hline Notes
\end{tabular}

\section{Ruseva 1985a}

\section{Study characteristics}

Patient sampling

Unknown

Biochemical tests of placental function versus ultrasound assessment of fetal size for stillbirth and small-for-gestational-age infants 
Ruseva 1985a (Continued)

\begin{tabular}{ll} 
Patient characteristics and setting & Unknown \\
\hline Index tests & Ultrasound EFW \\
\hline Target condition and reference standard(s) & Unknown \\
\hline Flow and timing & Unknown \\
\hline Comparative & \\
\hline Notes
\end{tabular}

\section{Ruseva 1988}

\section{Study characteristics}

\begin{tabular}{ll} 
Patient sampling & Unknown \\
\hline Patient characteristics and setting & Unknown \\
\hline Index tests & Ultrasound EFW \\
\hline Target condition and reference standard(s) & Unknown \\
\hline Flow and timing & Unknown \\
\hline Comparative & \\
\hline
\end{tabular}

Notes

\section{Serban 1971}

\section{Study characteristics}

\begin{tabular}{ll}
\hline Patient sampling & Unknown \\
\hline Patient characteristics and setting & Unknown \\
\hline Index tests & $\mathrm{hPL}$ \\
\hline Target condition and reference standard(s) & Unknown \\
\hline Flow and timing & Unknown \\
\hline Comparative & \\
\hline Notes & \\
\hline
\end{tabular}

EFW: estimated fetal weight; hPL: human placental lactogen; IUGR: Intrauterine growth restriction 


\section{A T A}

Presented below are all the data for all of the tests entered into the review.

\section{Table Tests. Data tables by test}

\begin{tabular}{|c|c|c|}
\hline Test & No. of studies & No. of participants \\
\hline $1 \mathrm{EFW}$ and SGA & 32 & 51702 \\
\hline 2 Placental grading and SGA & 12 & 4940 \\
\hline $3 \mathrm{hPL}$ and SGA & 20 & 3486 \\
\hline 4 E3 and SGA & 9 & 2773 \\
\hline 5 Urinary E3 and SGA & 9 & 92406 \\
\hline 6 PIGF and SGA & 8 & 6997 \\
\hline 7 UA and SGA & 8 & 2884 \\
\hline 8 E3 AND/OR hPL and SGA & 1 & 88 \\
\hline 9 EFW for SGA - 10th centile threshold only & 25 & 47057 \\
\hline $10 \mathrm{hPL}$ for SGA - 10th centile threshold only & 8 & 1414 \\
\hline 11 EFW and SGA3 & 3 & 5678 \\
\hline 13 PIGF and SGA3 & 2 & 1861 \\
\hline $14 \mathrm{hPL}$ and stillbirth & 6 & 544 \\
\hline 15 Urinary E3 and stillbirth & 7 & 92186 \\
\hline 16 PIGF and stillbirth & 4 & 5894 \\
\hline 17 UA and stillbirth & 4 & 2063 \\
\hline 18 Placental grading and stillbirth & 3 & 15236 \\
\hline 19 SGA data from studies with both SGA infants and stillbirths & 17 & 99920 \\
\hline 20 Stillbirth data from studies with both SGA infants and stillbirths & 17 & 100050 \\
\hline 22 PIGF or EFW and SGA & 1 & 343 \\
\hline 23 PIGF or EFW and SGA3 & 1 & 343 \\
\hline
\end{tabular}

Test 1. EFW and SGA. 
Test 2. Placental grading and SGA.

Test 3. hPL and SGA.

Test 4. E3 and SGA.

Test 5. Urinary E3 and SGA.

Test 6. PIGF and SGA.

Test 7. UA and SGA.

Test 8. E3 AND/OR hPL and SGA.

Test 9. EFW for SGA - 10th centile threshold only.

Test 10. hPL for SGA - 10th centile threshold only.

Test 11. EFW and SGA3.

Test 13. PIGF and SGA3.

Test 14. hPL and stillbirth.

Test 15. Urinary E3 and stillbirth. 
Test 16. PIGF and stillbirth.

Test 17. UA and stillbirth.

Test 18. Placental grading and stillbirth.

Test 19. SGA data from studies with both SGA infants and stillbirths.

Test 20. Stillbirth data from studies with both SGA infants and stillbirths.

Test 22. PIGF or EFW and SGA.

Test 23. PIGF or EFW and SGA3. 


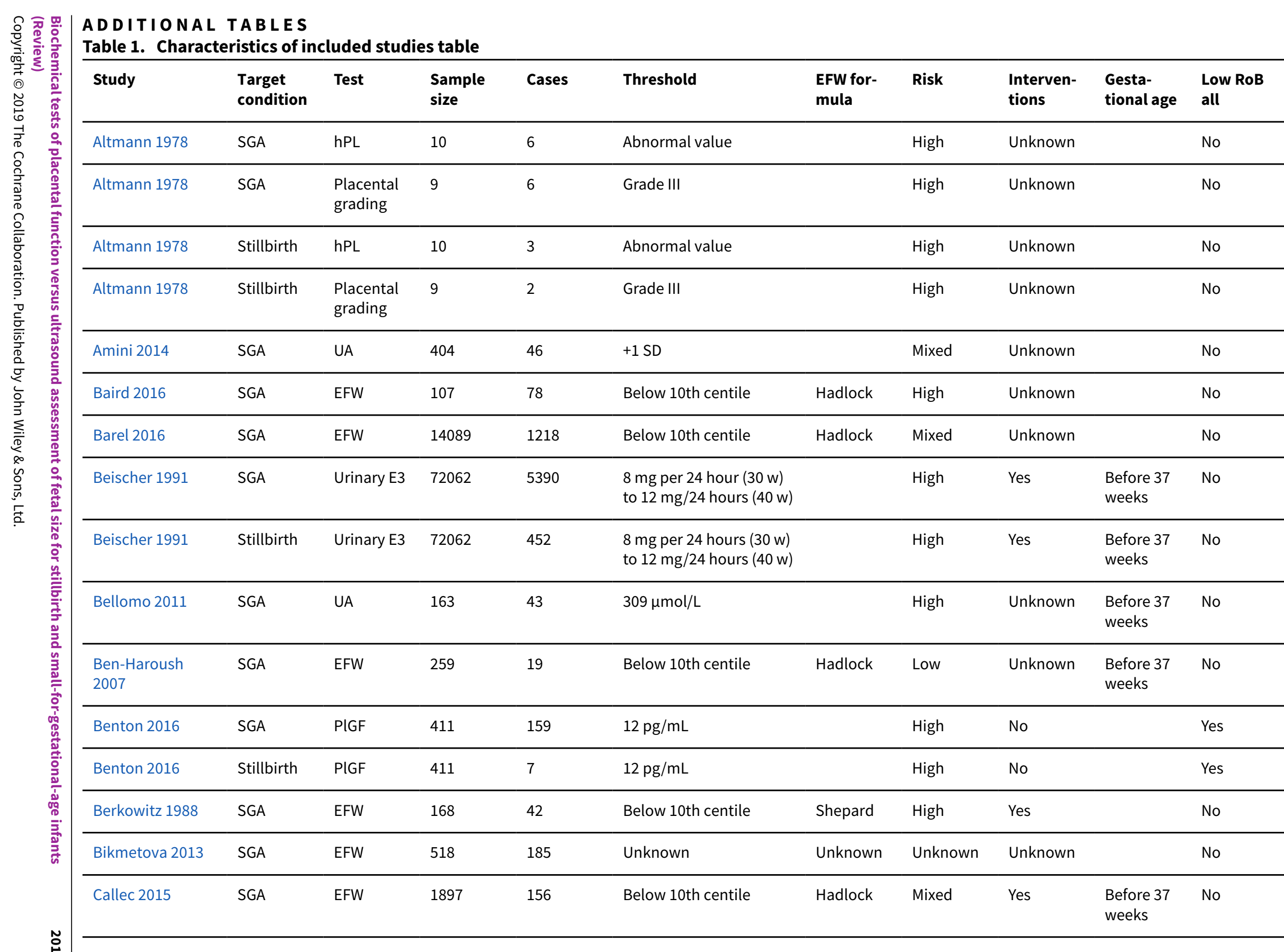




\begin{tabular}{|c|c|c|c|c|c|c|c|c|c|c|}
\hline Campbell 1972 & SGA & Urinary E3 & 284 & 87 & Unknown & & High & Unknown & & Yes \\
\hline Campbell 1972 & Stillbirth & Urinary E3 & 284 & 11 & Unknown & & High & Unknown & & Yes \\
\hline Cedard 1979 & SGA & E3 & 64 & 17 & Below 10th centile & & High & Unknown & $\begin{array}{l}37 \text { weeks } \\
\text { onwards }\end{array}$ & No \\
\hline $\begin{array}{l}\text { Chaiworapongsa } \\
2013\end{array}$ & SGA & PIGF & 1269 & 108 & $<0.3 \mathrm{MoM}$ & & Mixed & Unknown & $\begin{array}{l}\text { Before } 37 \\
\text { weeks }\end{array}$ & No \\
\hline $\begin{array}{l}\text { Chaiworapongsa } \\
2013\end{array}$ & SGA3 & PIGF & 1269 & 23 & $<0.3 \mathrm{MoM}$ & & Mixed & Unknown & $\begin{array}{l}\text { Before } 37 \\
\text { weeks }\end{array}$ & No \\
\hline $\begin{array}{l}\text { Chaiworapongsa } \\
2013\end{array}$ & Stillbirth & PIGF & 1269 & 5 & $<0.12 \mathrm{MoM}$ & & Mixed & Unknown & $\begin{array}{l}\text { Before } 37 \\
\text { weeks }\end{array}$ & No \\
\hline Chard 1985 & SGA & E3 & 392 & 39 & Below 10th centile & & Mixed & Unknown & & No \\
\hline Chard 1985 & SGA & hPL & 392 & 39 & Below 10th centile & & Mixed & Unknown & & No \\
\hline Chauhan 1999 & SGA & EFW & 324 & 44 & Below 10th centile & Hadlock & Mixed & Unknown & & No \\
\hline Chauhan 1999a & SGA & EFW & 574 & 59 & Below 10th centile & Hadlock & Mixed & Unknown & & No \\
\hline Chauhan 2003 & SGA & EFW & 264 & 58 & Below 10th centile & Hadlock & High & Yes & & No \\
\hline Chen 2012 & SGA & $\begin{array}{l}\text { Placental } \\
\text { grading }\end{array}$ & 105 & 36 & Grade III & & High & Unknown & & No \\
\hline Chen 2012 & Stillbirth & $\begin{array}{l}\text { Placental } \\
\text { grading }\end{array}$ & 105 & 13 & Grade III & & High & Unknown & & No \\
\hline Chen 2012a & SGA & $\begin{array}{l}\text { Placental } \\
\text { grading }\end{array}$ & 113 & 23 & Grade III & & High & No & $\begin{array}{l}\text { Before } 37 \\
\text { weeks }\end{array}$ & Yes \\
\hline Chen 2015 & Stillbirth & $\begin{array}{l}\text { Placental } \\
\text { grading }\end{array}$ & 15122 & 99 & Grade III & & Low & Unknown & $\begin{array}{l}\text { Before } 37 \\
\text { weeks }\end{array}$ & Yes \\
\hline Chervenak 1984 & SGA & EFW & 179 & 17 & L99CL & Shepard & High & Unknown & & No \\
\hline Chew 1976 & SGA & Urinary E3 & 43 & 15 & Below 2.5 th centile & & High & No & & Yes \\
\hline
\end{tabular}




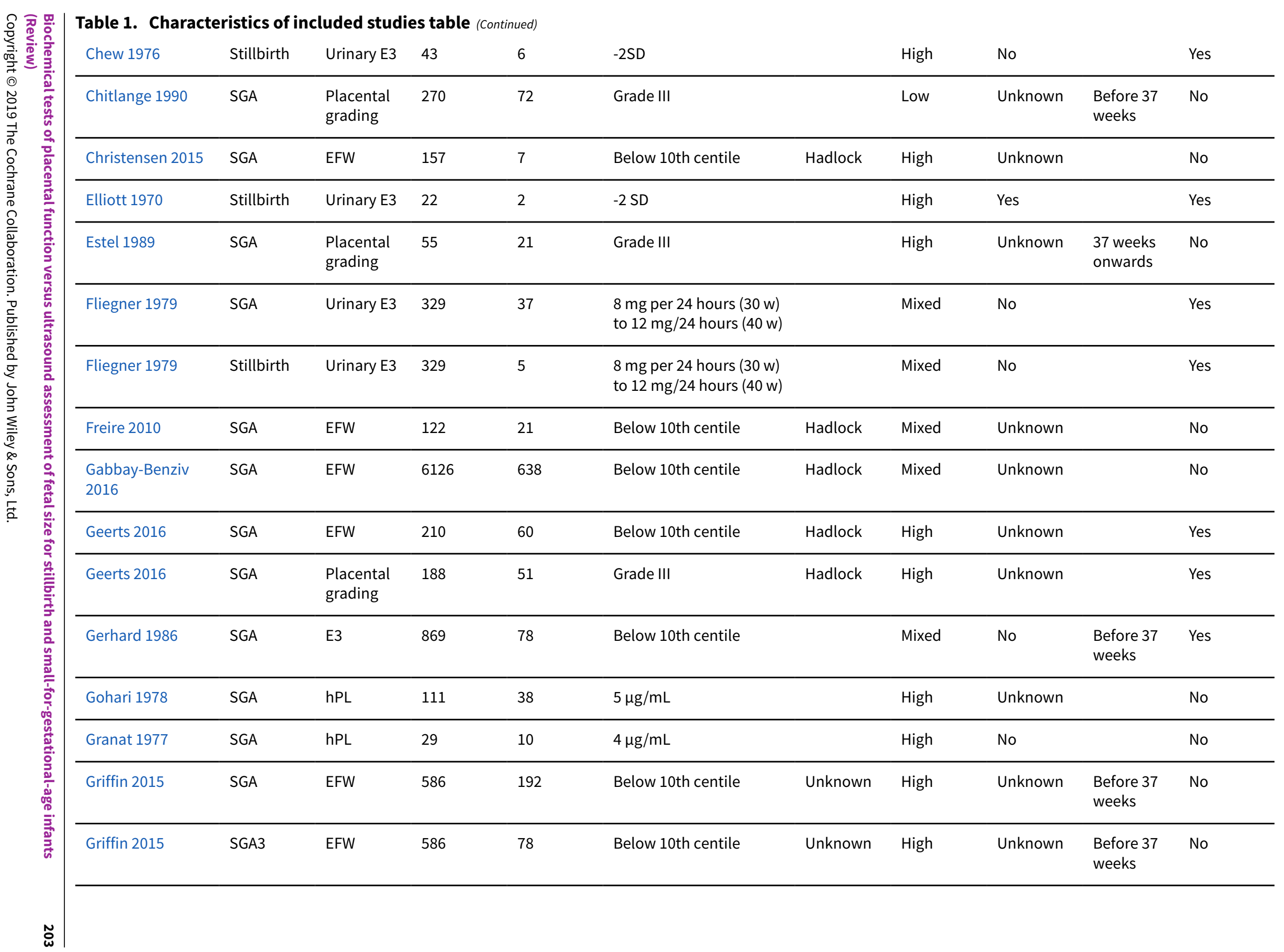




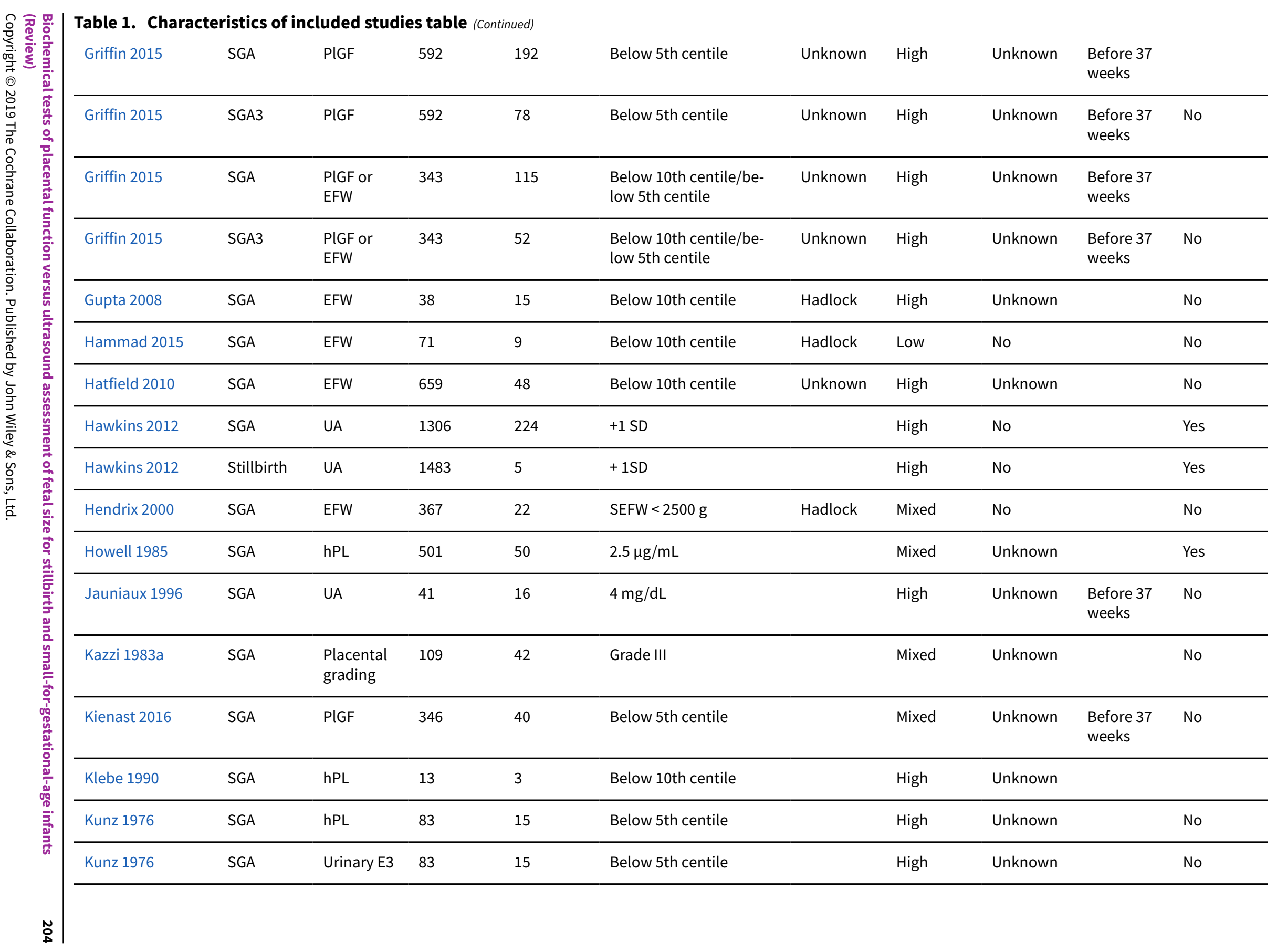




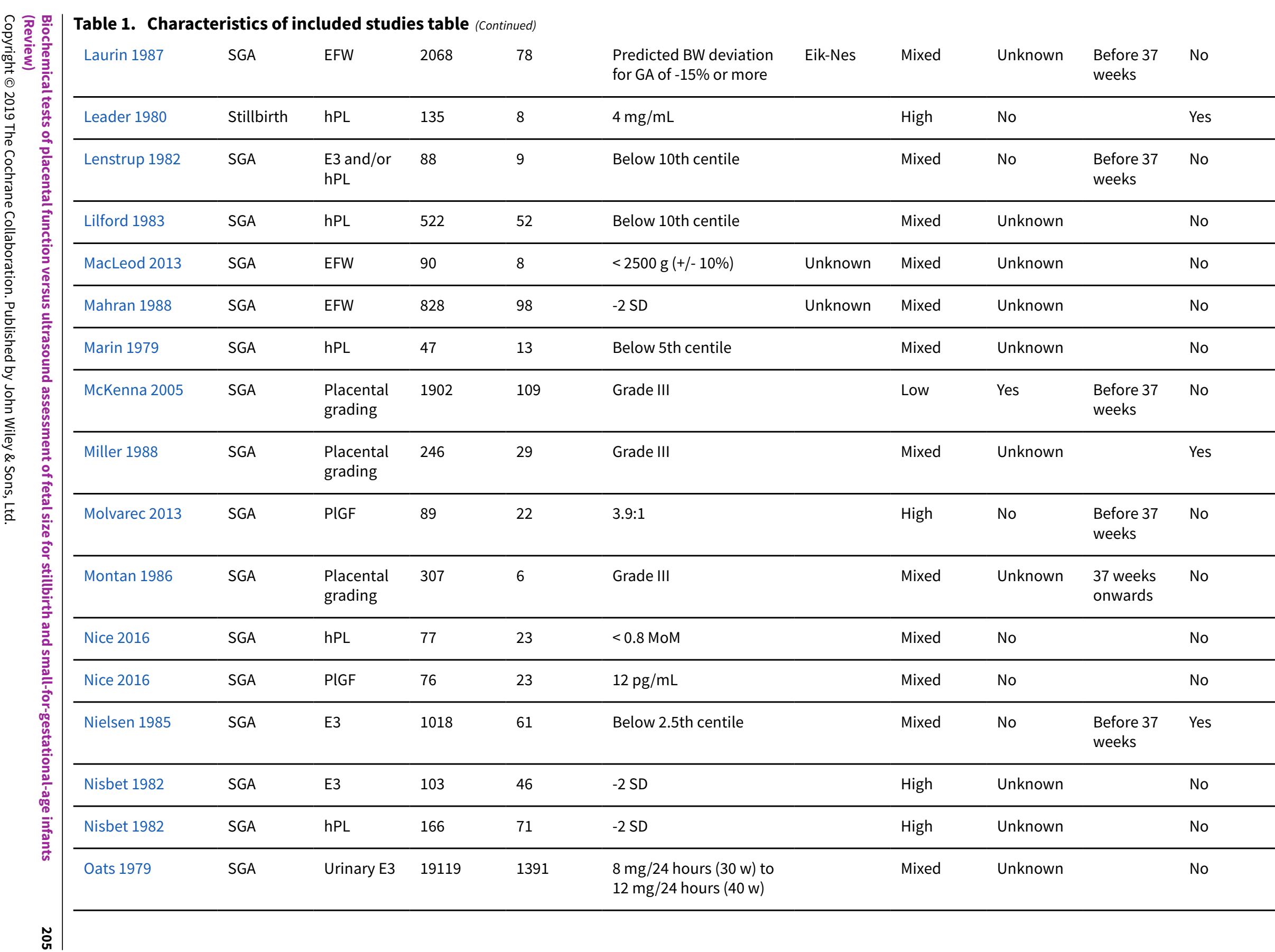




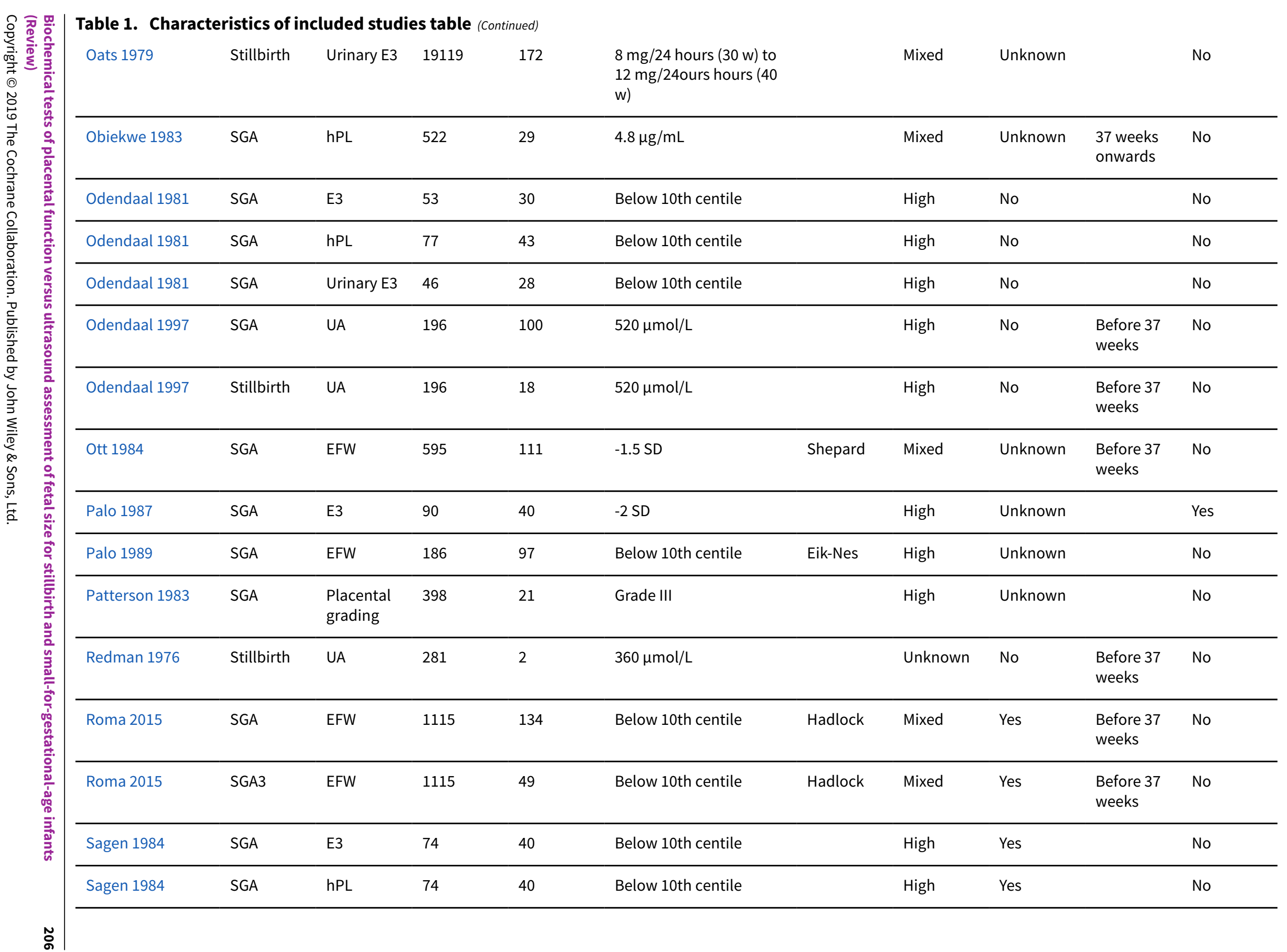




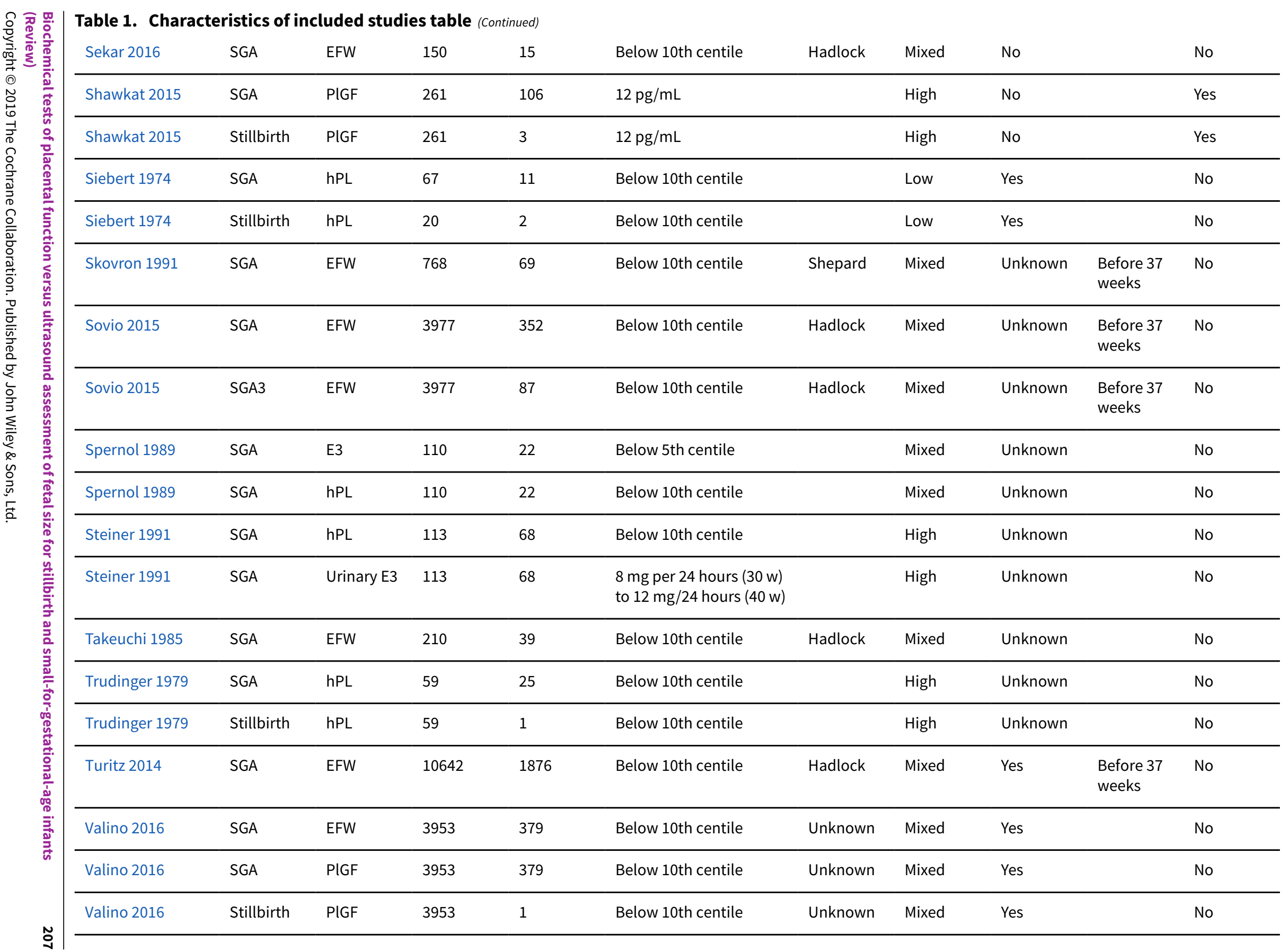




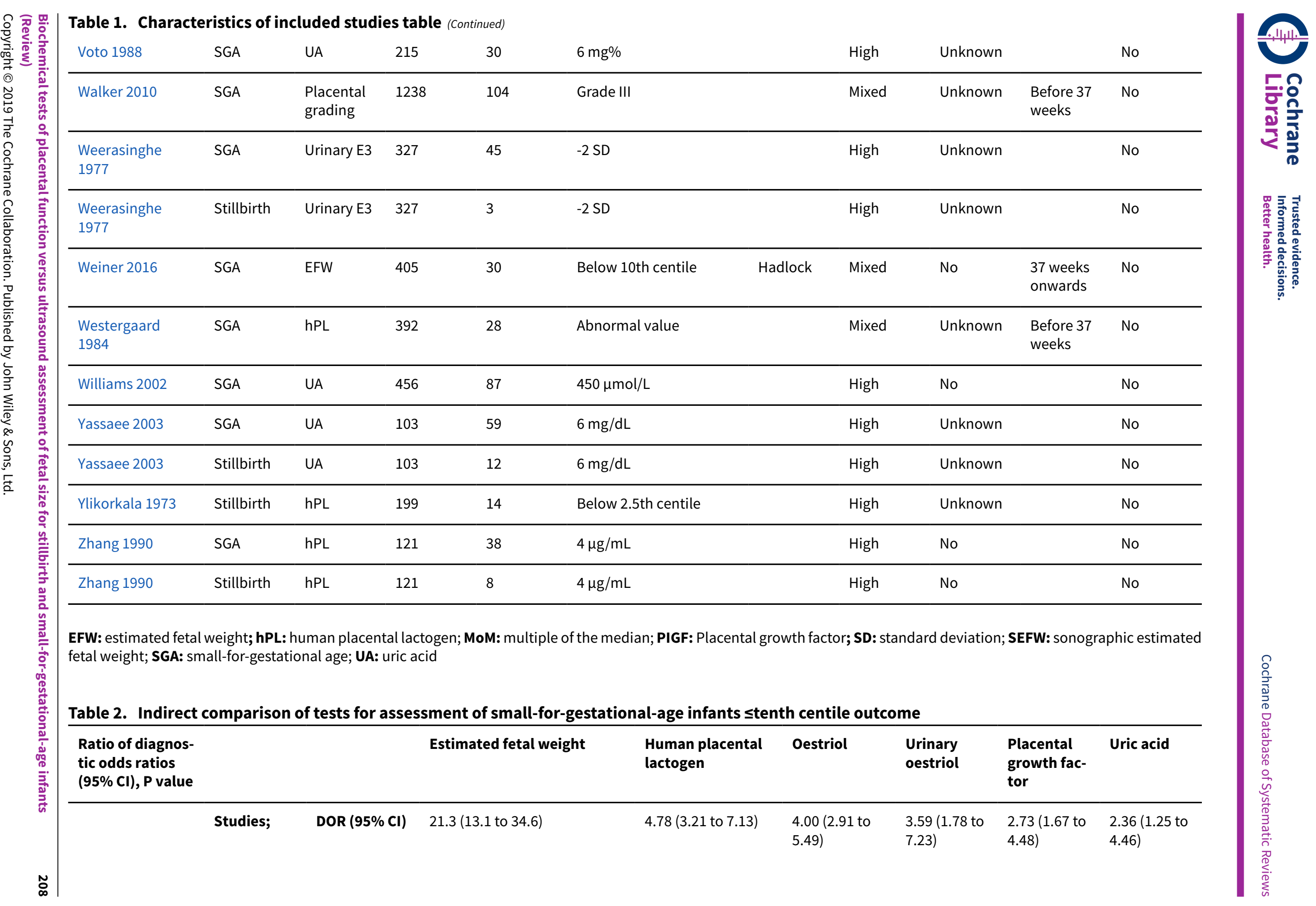




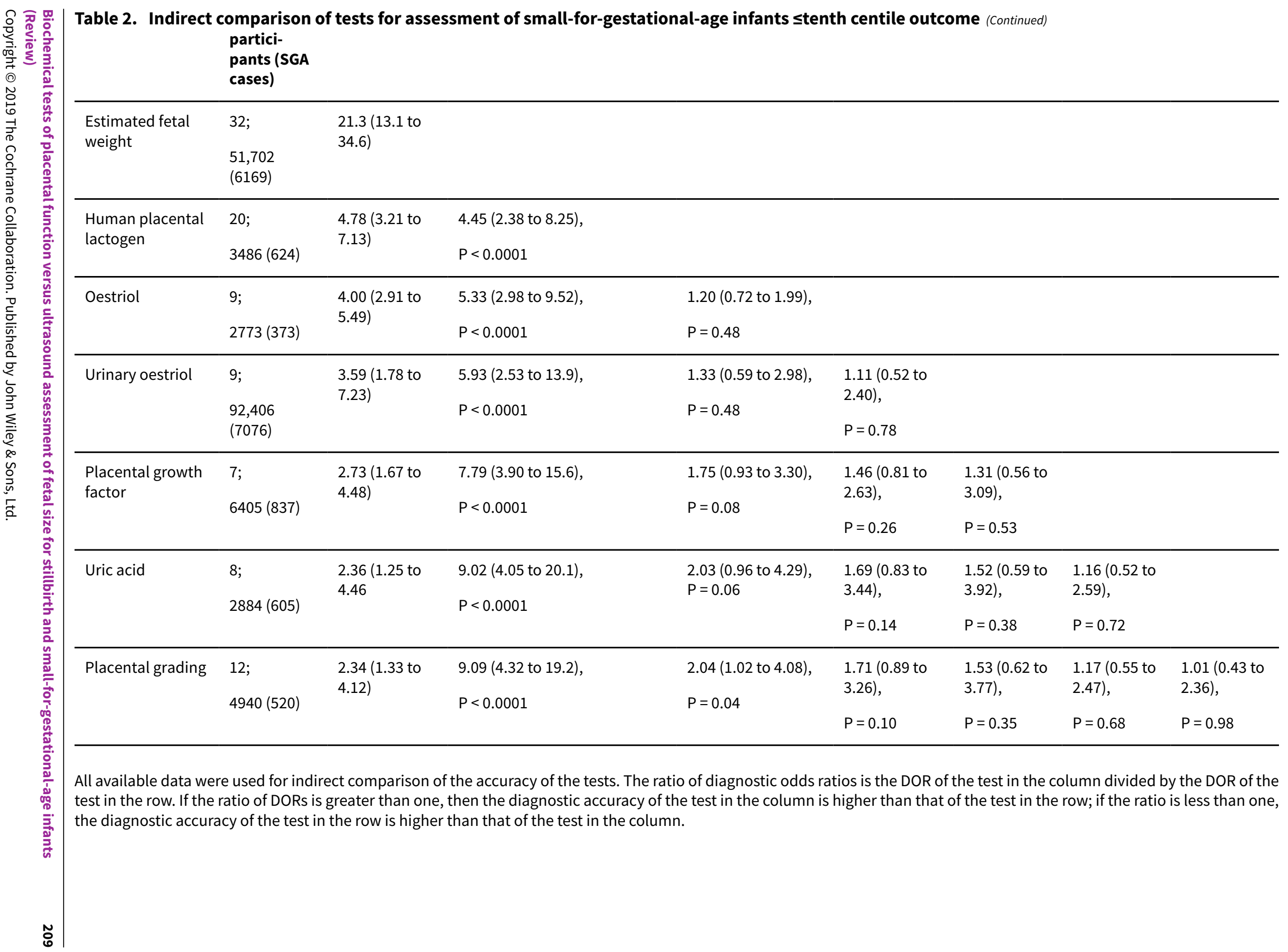


Table 3. Comparison of test accuracy at different levels of prevalence of small-for-gestational-age (birthweight stenth centile) infants

\begin{tabular}{|c|c|c|c|c|c|}
\hline $\begin{array}{l}\text { Prevalence } \\
\text { (\%) }\end{array}$ & Specificity & $\begin{array}{l}\text { False posi- } \\
\text { tives }\end{array}$ & Test & Sensitivity $(95 \% \mathrm{Cl})$ & $\begin{array}{l}\text { Missed SGA } \\
\text { infants }\end{array}$ \\
\hline \multirow[t]{7}{*}{10} & 0.74 & 234 & EFW & 0.88 (0.82 to 0.92$)$ & 12 \\
\hline & & & hPL & 0.63 (0.53 to 0.71$)$ & 38 \\
\hline & & & Oestriol & $0.58(0.51$ to 0.66$)$ & 42 \\
\hline & & & Urinary oestriol & 0.56 (0.39 to 0.72$)$ & 45 \\
\hline & & & PIGF & $0.49(0.37$ to 0.61$)$ & 52 \\
\hline & & & Uric acid & $0.45(0.31$ to 0.61$)$ & 55 \\
\hline & & & Placental grading & $0.45(0.32$ to 0.59$)$ & 55 \\
\hline \multirow[t]{7}{*}{19} & 0.74 & 211 & EFW & $0.88(0.82$ to 0.92$)$ & 23 \\
\hline & & & $\mathrm{hPL}$ & 0.63 (0.53 to 0.71$)$ & 71 \\
\hline & & & Oestriol & $0.58(0.51$ to 0.66$)$ & 80 \\
\hline & & & Urinary oestriol & 0.56 (0.39 to 0.72$)$ & 84 \\
\hline & & & PIGF & 0.49 (0.37 to 0.61$)$ & 97 \\
\hline & & & Uric acid & 0.45 (0.31 to 0.61$)$ & 104 \\
\hline & & & Placental grading & 0.45 (0.32 to 0.59$)$ & 105 \\
\hline \multirow[t]{7}{*}{35} & 0.74 & 169 & EFW & $0.88(0.82$ to 0.92$)$ & 42 \\
\hline & & & hPL & 0.63 (0.53 to 0.71$)$ & 131 \\
\hline & & & Oestriol & $0.58(0.51$ to 0.66$)$ & 146 \\
\hline & & & Urinary oestriol & 0.56 (0.39 to 0.72$)$ & 155 \\
\hline & & & PIGF & 0.49 (0.37 to 0.61$)$ & 179 \\
\hline & & & Uric acid & $0.45(0.31$ to 0.61$)$ & 192 \\
\hline & & & Placental grading & $0.45(0.32$ to 0.59$)$ & 193 \\
\hline \multirow[t]{5}{*}{10} & 0.88 & 108 & EFW & 0.74 (0.64 to 0.83 ) & 26 \\
\hline & & & $\mathrm{hPL}$ & 0.39 (0.30 to 0.49$)$ & 61 \\
\hline & & & Oestriol & 0.35 (0.28 to 0.43$)$ & 65 \\
\hline & & & Urinary oestriol & $0.33(0.20$ to 0.50$)$ & 68 \\
\hline & & & PIGF & $0.24(0.15$ to 0.38$)$ & 76 \\
\hline
\end{tabular}

Biochemical tests of placental function versus ultrasound assessment of fetal size for stillbirth and small-for-gestational-age infants 
Table 3. Comparison of test accuracy at different levels of prevalence of small-for-gestational-age (birthweight stenth centile) infants (Continued)

\begin{tabular}{|c|c|c|c|c|c|}
\hline & & & Uric acid & 0.27 (0.19 to 0.38$)$ & 73 \\
\hline & & & Placental grading & $0.24(0.15$ to 0.36$)$ & 76 \\
\hline \multirow[t]{7}{*}{19} & 0.88 & 97 & EFW & 0.74 (0.64 to 0.83 ) & 49 \\
\hline & & & $\mathrm{hPL}$ & 0.39 (0.30 to 0.49$)$ & 116 \\
\hline & & & Oestriol & 0.35 (0.28 to 0.43$)$ & 123 \\
\hline & & & Urinary oestriol & $0.33(0.20$ to 0.50$)$ & 128 \\
\hline & & & PIGF & $0.24(0.15$ to 0.38$)$ & 144 \\
\hline & & & Uric acid & 0.27 (0.19 to 0.38$)$ & 139 \\
\hline & & & Placental grading & $0.24(0.15$ to 0.36$)$ & 145 \\
\hline \multirow[t]{7}{*}{35} & 0.88 & 78 & EFW & $0.74(0.64$ to 0.83$)$ & 90 \\
\hline & & & $\mathrm{hPL}$ & $0.39(0.30$ to 0.49$)$ & 212 \\
\hline & & & Oestriol & 0.35 (0.28 to 0.43$)$ & 227 \\
\hline & & & Urinary oestriol & $0.33(0.20$ to 0.50$)$ & 235 \\
\hline & & & PIGF & 0.24 (0.15 to 0.38$)$ & 265 \\
\hline & & & Uric acid & $0.27(0.19$ to 0.38$)$ & 255 \\
\hline & & & Placental grading & 0.24 (0.15 to 0.36$)$ & 266 \\
\hline \multirow[t]{7}{*}{10} & 0.96 & 36 & EFW & 0.47 (0.35 to 0.59$)$ & 53 \\
\hline & & & hPL & 0.17 (0.12 to 0.23$)$ & 84 \\
\hline & & & Oestriol & $0.14(0.11$ to 0.19$)$ & 86 \\
\hline & & & Urinary oestriol & 0.13 (0.07 to 0.23$)$ & 87 \\
\hline & & & PIGF & $0.10(0.07$ to 0.16$)$ & 90 \\
\hline & & & Uric acid & 0.09 (0.05 to 0.16$)$ & 92 \\
\hline & & & Placental grading & 0.09 (0.05 to 0.15$)$ & 92 \\
\hline \multirow[t]{5}{*}{19} & 0.96 & 23 & EFW & 0.47 (0.35 to 0.59$)$ & 101 \\
\hline & & & hPL & $0.17(0.12$ to 0.23$)$ & 159 \\
\hline & & & Oestriol & 0.14 (0.11 to 0.19$)$ & 163 \\
\hline & & & Urinary oestriol & $0.13(0.07$ to 0.23$)$ & 166 \\
\hline & & & PIGF & 0.10 (0.07 to 0.16$)$ & 171 \\
\hline
\end{tabular}


Table 3. Comparison of test accuracy at different levels of prevalence of small-for-gestational-age (birthweight stenth centile) infants (Continued)

\begin{tabular}{|c|c|c|c|c|c|}
\hline & & & Uric acid & $0.09(0.05$ to 0.16$)$ & 173 \\
\hline & & & Placental grading & 0.09 (0.05 to 0.15$)$ & 174 \\
\hline \multirow[t]{7}{*}{35} & 0.96 & 26 & EFW & $0.47(0.35$ to 0.59$)$ & 186 \\
\hline & & & $\mathrm{hPL}$ & $0.17(0.12$ to 0.23$)$ & 292 \\
\hline & & & Oestriol & $0.14(0.11$ to 0.19$)$ & 301 \\
\hline & & & Urinary oestriol & 0.13 (0.07 to 0.23$)$ & 305 \\
\hline & & & PIGF & $0.10(0.07$ to 0.16$)$ & 315 \\
\hline & & & Uric acid & 0.09 (0.05 to 0.16$)$ & 319 \\
\hline & & & Placental grading & $0.09(0.05$ to 0.15$)$ & 319 \\
\hline
\end{tabular}

EFW: estimated fetal weight; hPL: human placental lactogen; PIGF: placental growth factor.

The sensitivities were estimated from the SROC curves at quartiles of the observed specificity in the included studies. Using these sensitivities and specificities, along with quartiles of prevalence from the included studies, the numbers of missed SGA infants and false positives were calculated based on a hypothetical cohort of 1000 pregnant women predicted to have a small-for-gestational-age infant.

Table 4. Indirect comparison of biochemical tests for predicting stillbirth

\begin{tabular}{|c|c|c|c|c|c|}
\hline \multirow{3}{*}{$\begin{array}{l}\text { Ratio of diagnostic } \\
\text { odds ratios }(95 \% \mathrm{Cl}) \text {, } \\
\text { P value }\end{array}$} & & & Placental growth factor & $\begin{array}{l}\text { Human placental } \\
\text { factor }\end{array}$ & $\begin{array}{l}\text { Urinary } \\
\text { oestriol }\end{array}$ \\
\hline & & & & & \\
\hline & $\begin{array}{l}\text { Studies; } \\
\text { participants } \\
\text { (stillbirths) }\end{array}$ & DOR $(95 \% \mathrm{Cl})$ & 49.2 (12.7 to 191$)$ & 11.4 (4.29 to 30.2$)$ & $\begin{array}{l}5.83(4.91 \text { to } \\
6.92)\end{array}$ \\
\hline Placental growth factor & 4; $5894(16)$ & $\begin{array}{l}49.2(12.7 \\
191)\end{array}$ & & & \\
\hline $\begin{array}{l}\text { Human placental lacto- } \\
\text { gen }\end{array}$ & $6 ; 544(36)$ & $\begin{array}{l}11.4(4.29, \\
30.2)\end{array}$ & $\begin{array}{l}4.32 \text { (0.81 to } 23.0) \\
P=0.08\end{array}$ & & \\
\hline Urinary oestriol & $7 ; 92,186(651)$ & $\begin{array}{l}5.83(4.91, \\
6.92)\end{array}$ & $\begin{array}{l}8.44(2.15 \text { to } 33.1) \\
P=0.004\end{array}$ & $\begin{array}{l}1.95(0.72 \text { to } 5.27), \\
P=0.17\end{array}$ & \\
\hline Uric acid & $4 ; 2063(37)$ & $\begin{array}{l}4.02(0.95 \\
17.0)\end{array}$ & $\begin{array}{l}12.2(1.69 \text { to } 88.5) \\
P=0.016\end{array}$ & $\begin{array}{l}2.83 \text { (0.50 to } 16.1 \text { ), } \\
P=0.22\end{array}$ & $\begin{array}{l}1.45(0.34 \text { to } \\
6.19), \\
P=0.60\end{array}$ \\
\hline
\end{tabular}

All available data were used for the indirect comparison of the accuracy of the tests. The ratio of diagnostic odds ratios is the DOR of the test in the column divided by the DOR of the test in the row. If the ratio of DORs is greater than one, then the diagnostic accuracy of the test in the column is higher than that of the test in the row; if the ratio is less than one, the diagnostic accuracy of the test in the row is higher than that of the test in the column. 
Table 5. Comparison of test accuracy at different levels of prevalence of stillbirth

\begin{tabular}{|c|c|c|c|c|c|}
\hline $\begin{array}{l}\text { Prevalence } \\
\text { (\%) }\end{array}$ & Specificity & $\begin{array}{l}\text { False posi- } \\
\text { tives }\end{array}$ & Test & Sensitivity $(95 \% \mathrm{Cl})$ & $\begin{array}{l}\text { Missed still- } \\
\text { births }\end{array}$ \\
\hline \multirow[t]{4}{*}{0.9} & 0.63 & 367 & PIGF & 0.97 (0.88 to 0.99$)$ & 1 \\
\hline & & & $\mathrm{hPL}$ & $0.87(0.72$ to 0.95$)$ & 2 \\
\hline & & & Urinary oestriol & $0.77(0.74$ to 0.80$)$ & 3 \\
\hline & & & Uric acid & $0.70(0.36$ to 0.91$)$ & 3 \\
\hline \multirow[t]{4}{*}{1.7} & 0.63 & 364 & PIGF & 0.97 (0.88 to 0.99$)$ & 1 \\
\hline & & & $\mathrm{hPL}$ & $0.87(0.72$ to 0.95$)$ & 3 \\
\hline & & & Urinary oestriol & $0.77(0.74$ to 0.80$)$ & 4 \\
\hline & & & Uric acid & $0.70(0.36$ to 0.91$)$ & 6 \\
\hline \multirow[t]{4}{*}{9.1} & 0.63 & 336 & PIGF & 0.97 (0.88 to 0.99$)$ & 4 \\
\hline & & & hPL & $0.87(0.72$ to 0.95$)$ & 12 \\
\hline & & & Urinary oestriol & $0.77(0.74$ to 0.80$)$ & 21 \\
\hline & & & Uric acid & $0.70(0.36$ to 0.91$)$ & 28 \\
\hline \multirow[t]{4}{*}{0.9} & 0.78 & 218 & PIGF & 0.93 (0.78 to 0.98$)$ & 1 \\
\hline & & & $\mathrm{hPL}$ & $0.76(0.55$ to 0.90$)$ & 3 \\
\hline & & & Urinary oestriol & 0.62 (0.58 to 0.66$)$ & 4 \\
\hline & & & Uric acid & $0.53(0.21$ to 0.83$)$ & 5 \\
\hline \multirow[t]{4}{*}{1.7} & 0.78 & 216 & PIGF & $0.93(0.78$ to 0.98$)$ & 2 \\
\hline & & & $\mathrm{hPL}$ & $0.76(0.55$ to 0.90$)$ & 5 \\
\hline & & & Urinary oestriol & 0.62 (0.58 to 0.66$)$ & 7 \\
\hline & & & Uric acid & $0.53(0.21$ to 0.83$)$ & 8 \\
\hline \multirow[t]{4}{*}{9.1} & 0.78 & 200 & PIGF & 0.93 (0.78 to 0.98$)$ & 7 \\
\hline & & & $\mathrm{hPL}$ & $0.76(0.55$ to 0.90$)$ & 22 \\
\hline & & & Urinary oestriol & 0.62 (0.58 to 0.66$)$ & 35 \\
\hline & & & Uric acid & $0.53(0.21$ to 0.83$)$ & 43 \\
\hline \multirow[t]{2}{*}{0.9} & 0.89 & 109 & PIGF & $0.86(0.61$ to 0.96$)$ & 2 \\
\hline & & & hPL & $0.58(0.35$ to 0.79$)$ & 4 \\
\hline
\end{tabular}


Table 5. Comparison of test accuracy at different levels of prevalence of stillbirth (Continued)

\begin{tabular}{|c|c|c|c|c|c|}
\hline & & & Urinary oestriol & $0.42(0.38$ to 0.46$)$ & 6 \\
\hline & & & Uric acid & $0.33(0.11$ to 0.68$)$ & 7 \\
\hline \multirow[t]{4}{*}{1.7} & 0.89 & 108 & PIGF & 0.86 (0.61 to 0.96$)$ & 3 \\
\hline & & & hPL & 0.58 (0.35 to 0.79$)$ & 8 \\
\hline & & & Urinary oestriol & $0.42(0.38$ to 0.46$)$ & 10 \\
\hline & & & Uric acid & $0.33(0.11$ to 0.68$)$ & 12 \\
\hline \multirow[t]{4}{*}{9.1} & 0.89 & 100 & PIGF & 0.86 (0.61 to 0.96$)$ & 13 \\
\hline & & & hPL & 0.58 (0.35 to 0.79$)$ & 38 \\
\hline & & & Urinary oestriol & $0.42(0.38$ to 0.46$)$ & 53 \\
\hline & & & Uric acid & $0.33(0.11$ to 0.68$)$ & 61 \\
\hline
\end{tabular}

hPL: human placental lactogen; PIGF: placental growth factor.

The sensitivities were estimated from the SROC curves at quartiles of the observed specificity in the included studies. Using these sensitivities and specificities, along with quartiles of prevalence from the included studies, the numbers of missed stillbirths and false positives were calculated based on a hypothetical cohort of 1000 pregnant women predicted to have a stillbirth.

\section{A P P E N D I C ES}

\section{Appendix 1. Examples of placental function tests available for diagnostic use (compiled 29th March 2016)}

Placental growth factor (PIGF)

Triage PIGF (Alere, San Diego) - point of care fluorescence immunoassay (http://www.plgf.com/home/proposed-clinical-use-of-plgf/aleretriage-plgf.html)

Elecsys $^{\mathrm{TM}}$ Preeclampsia (sFlt-1 \& PIGF) - automated immunoassay performed on Roche platform

(http://www.cobas.com/home/product/clinical-and-immunochemistry-testing/elecsys-preeclampsia-assays-sFlt-1-PIGF.html)

Oestriol (E3)

AutoDELFIA Unconjugated Estriol (Perkin Elmer) - automated fluorescence immunoassay performed on Perkin-Elmer platform. (http:// www.perkinelmer.co.uk/product/autodelfia-unconjugated-estriol-ue3-ki-b083-301)

Beckman Coulter - automated immunoassay performed on Beckman Coulter platform (https://www.beckmancoulter.com/wsrportal/ bibliography?docname=DS14764A\%20Access\%20Unconjugated\%20Estriol\%20US\%20Data\%20Sheet.pdf)

Elecsys ${ }^{\mathrm{TM}}$ Estradiol - automated immunoassay performed on Roche platform (http://www.cobas.com/content/dam/cobas_com/pdf/lists/ parameter-list-swa.pdf)

\section{Appendix 2. Search strategy}

\section{Database: Ovid MEDLINE(R) 1946 to October Week 32016 (October 26th 2016)}

Search Strategy:

1 Placental insufficiency/

2 ((placenta\$ or f?etoplacental or uteroplacental) adj2 (insufficien\$ or fail\$ or function\$)).ti,ab.

3 fetal movement/

Biochemical tests of placental function versus ultrasound assessment of fetal size for stillbirth and small-for-gestational-age infants 
4 fetal growth retardation/

5 ((reduc\$ or decline\$) adj2 f?etal movement).ti,ab.

6 (stillborn or stillbirth).ti,ab.

7 Stillbirth/

8 ((f?etal or intrauterine or intra-uterine) adj2 (growth or death\$ or loss\$)).ti,ab.

9 IUGR.ti,ab.

10 (small adj2 gestational age).ti,ab.

11 ((neonatal or perinatal or fetal or birth\$ or deliver\$) adj2 outcome\$).ti,ab.

12 f?etal move\$.ti,ab.

13 or $/ 1-12$

14 oestradiol.ti,ab.

15 estradiol.ti,ab.

16 exp Estradiol/

17 oestriol.ti,ab.

18 exp progesterone/

19 progesterone.ti,ab.

20 exp pregnenolone/

21 pregnenolone.ti,ab.

$22 \exp$ Chorionic Gonadotropin/

23 human chorionic gonadotrophin.ti,ab.

24 hCG.ti,ab.

25 placental lactogen/

26 hPL.ti,ab.

27 human placental lactogen.ti,ab.

28 human placental growth hormone.ti,ab.

29 placental protein 13.ti,ab.

30 placental growth factor.ti,ab.

31 plasma placental protein.ti,ab.

32 pregnancy specific glycoprotein $\$ . t i, a b$.

33 Pregnancy-Specific beta 1-glycoproteins/

34 schwangerschaft protein 1.ti,ab.

35 pregnancy specific beta 1-glycoprotein.ti,ab.

36 exp ultrasonography, Prenatal/

37 (sonograph\$ or ultraso\$).ti,ab.

38 Grannum grading.ti,ab.

Biochemical tests of placental function versus ultrasound assessment of fetal size for stillbirth and small-for-gestational-age infants 
39 biomarkers/

40 biomarker\$.mp. or marker\$.ti,ab.

41 or $/ 14-40$

4213 and 41

43 limit 42 to humans

Database: Ovid MEDLINE(R) In-Process \& Other Non-Indexed Citations (October 25, 2016)

Search Strategy:

1 (placenta\$ or f?etoplacental or uteroplacental) adj2 (insufficien\$ or fail\$ or function\$)).ti,ab.

2 ((reduc\$ or decline\$) adj2 fe?tal movement).ti,ab.

3 (stillborn or stillbirth).ti,ab.

4 ((f?etal or intrauterine or intra-uterine) adj2 (growth or death\$ or loss\$)).ti,ab.

5 IUGR.ti,ab.

6 (small adj2 gestational age).ti,ab.

7 ((neonatal or perinatal or fetal or birth\$ or deliver\$) adj2 outcome\$).ti,ab.

8 f?etal move\$.ti,ab.

9 or/1-8

10 oestradiol.ti,ab.

11 estradiol.ti,ab.

12 oestriol.ti,ab.

13 progesterone.ti,ab.

14 pregnenolone.ti,ab.

15 human chorionic gonadotrophin.ti,ab.

16 hCG.ti,ab.

17 hPL.ti,ab.

18 human placental lactogen.ti,ab.

19 human placental growth hormone.ti,ab.

20 placental protein 13.ti,ab.

21 placental growth factor.ti,ab.

22 plasma placental protein.ti,ab.

23 pregnancy specific glycoprotein $\$ . t i, a b$.

24 schwangerschaft protein 1.ti,ab.

25 pregnancy specific beta 1-glycoprotein.ti,ab.

26 (sonograph\$ or ultraso\$).ti,ab.

27 Grannum grading.ti,ab.

28 placental lactogen.ti,ab.

Biochemical tests of placental function versus ultrasound assessment of fetal size for stillbirth and small-for-gestational-age infants 
29 biomarker\$.ti,ab.

30 marker\$.ti,ab.

31 or $/ 10-30$

329 and 31

\section{Database: Embase (Ovid) 1974 to week 4 October 2016}

\section{Search Strategy:}

1 ((placenta\$ or fetoplacental or foetoplacental or uteroplacental) adj2 (insufficien\$ or fail\$ or function\$)).ti,ab.

2 ((reduc\$ or decline\$) adj2 (fetal or foetal) adj movement)).ti,ab.

3 (stillborn or stillbirth).ti,ab.

4 ((fetal or foetal or intrauterine or intra-uterine) adj2 (growth or death\$ or loss\$)).ti,ab.

5 IUGR.ti,ab.

6 (small adj2 gestational age).ti,ab.

7 ((neonatal or perinatal or fetal or foetal or birth\$ or deliver\$) adj2 outcome\$).ti,ab.

8 (fetal or foetal) adj move\$.ti,ab.

9 exp placenta insufficiency/

10 exp fetus movement/

11 exp intrauterine growth retardation/

12 exp stillbirth/

13 oestradiol.ti,ab.

14 estradiol.ti,ab.

15 exp estradiol/

16 exp estriol/

17 oestriol.ti,ab.

18 exp progesterone/

19 progesterone.ti,ab.

20 exp pregnenolone/

21 pregnenolone.ti,ab.

22 exp chorionic gonadotropin/

23 human chorionic gonadotropin.ti,ab.

24 hCG.ti,ab.

25 placental lactogen.ti,ab.

26 exp placenta lactogen/

27 hPL.ti,ab.

28 human placental growth hormone.ti,ab.

29 exp placenta protein/

Biochemical tests of placental function versus ultrasound assessment of fetal size for stillbirth and small-for-gestational-age infants 
30 placental protein 13.ti,ab.

31 placental growth factor.ti,ab.

32 plasma placental protein.ti,ab.

33 pregnancy specific glycoprotein $\$$.ti,ab.

34 exp pregnancy specific beta1 glycoprotein/

35 schwangerschaft protein 1.ti,ab.

36 pregnancy specific beta 1-glycoprotein.ti,ab.

37 exp fetus echography/

38 sonograph\$ or ultrason\$.ti,ab.

39 Grannum grading.ti,ab.

40 biological marker/

41 biomarker\$ or marker\$.ti,ab.

42 or/13-41

43 or $/ 1-12$

4442 and 43

45 limit 44 to human

Database: Cochrane Library (Wiley) (CENTRAL) Issue 7 of 122016 (DARE, HTA,EED) Issue 2 of 4 2015, (CDSR) Issue 7 of 122016

Search strategy:

\#1 MeSH descriptor: [Placental Insufficiency] explode all trees

\#2 (placenta* or fetoplacental or foetoplacental or uteroplacental) near/2 (insufficienc* or fail* or function*)

\#3 MeSH descriptor: [Fetal Movement] explode all trees

\#4 MeSH descriptor: [Fetal Growth Retardation] explode all trees

\#5 (reduc* or declin*) near/2 ("fetal move*") or (("foetal move*")

\#6 stillborn or stillbirth

\#7 MeSH descriptor: [Stillbirth] explode all trees

\#8 (fetal or foetal or intrauterine or intra-uterine) near/2 (growth or death* or loss ${ }^{\star}$ )

\#9 IUGR

\#10 small near/2 (gestational next age)

\#11 (neonatal or perinatal or fetal or birth ${ }^{\star}$ or deliver $^{\star}$ ) near/2 (outcome*)

$\# 12$ fetal next move*

$\# 13 \# 1$ or \#2 or \#3 or \#4 or \#5 or \#6 or \#7 or \#8 or \#9 or \#10 or \#11 or \#12

\#14 oestradiol

\#15 estradiol

\#16 oestriol

\#17 progesterone

Biochemical tests of placental function versus ultrasound assessment of fetal size for stillbirth and small-for-gestational-age infants 
\#18 MeSH descriptor: [Estradiol] explode all trees

\#19 MeSH descriptor: [Progesterone] explode all trees

\#20 pregnenolone

\#21 MeSH descriptor: [Pregnenolone] explode all trees

\#22 MeSH descriptor: [Chorionic Gonadotropin] explode all trees

\#23 "human chorionic gonadotrop*"

\#24 hCG

$\# 25 \mathrm{hPL}$

\#26 MeSH descriptor: [Placental Lactogen] explode all trees

\#27 "human placental lactogen"

\#28 "human placental growth hormone"

\#29 "placental protein 13"

\#30 "placental growth factor"

\#31 "plasma placental protein"

\#32 "pregnancy specific glycoprotein ${ }^{\star "}$

\#33 MeSH descriptor: [Pregnancy-Specific beta 1-Glycoproteins] explode all trees

\#34 "schwangerschaft protein 1"

\#35 "pregnancy specific beta 1-glycoprotein"

\#36 MeSH descriptor: [Ultrasonography, Prenatal] explode all trees

\#37 sonograph* or ultraso*

\#38 "Grannum grading"

\#39 MeSH descriptor: [Biological Markers] explode all trees

\#40 biomarker* or marker*

$\# 41 \# 14$ or \#15 or \#16 or \#17 or \#18 or \#19 or \#20 or \#21 or \#22 or \#23 or \#24 or \#25 or \#26 or \#27 or \#28 or \#29 or \#30 or \#31 or \#32 or \#33 or \#34 or \#35 or \#36 or \#37 or \#38 or \#39 or \#40

$\# 42 \# 13$ and \#41

\section{Database: CINAHL (Ebsco) 1937 - present (28 October 2016)}

Search strategy:

S1 (placenta* or fetoplacental or foetoplacental or uteroplacental) N2 (insufficienc ${ }^{\star}$ or fail* or function ${ }^{\star}$ )

S2 (MH"Placental Insufficiency")

S3 (MH"Fetal Movement")

S4 (MH"Fetal Growth Retardation")

S5 (reduc* or decline) N2 (fetal move* or foetal move*)

S6 stillborn or stillbirth

S7 (MH"Perinatal Death")

Biochemical tests of placental function versus ultrasound assessment of fetal size for stillbirth and small-for-gestational-age infants 
S8 (fetal or foetal or intrauterine or intra-uterine) N2 (growth or death ${ }^{\star}$ or loss ${ }^{\star}$ )

S9 IUGR

S10 (small) N2 (gestational age)

S11 (neonatal or perinatal or fetal or birth* or deliver ${ }^{\star}$ N2 (outcome ${ }^{\star}$ )

S12 fetal move* or foetal move*

$\mathrm{S} 13 \mathrm{~S} 1$ or $\mathrm{S} 2$ or $\mathrm{S} 3$ or $\mathrm{S} 4$ or $\mathrm{S} 5$ or $\mathrm{S} 6$ or $\mathrm{S} 7$ or $\mathrm{S} 8$ or $\mathrm{S} 9$ or $\mathrm{S} 10$ or $\mathrm{S} 11$ or $\mathrm{S} 12$

S14 oestradiol or estradiol or oestriol or progesterone or pregnenolone

S15 (MH"Estradiol")

S16 (MH"Progesterone+")

S17 (MH "Gonadotropins, Chorionic")

S18 human chorionic gonadotrophin

S19 hCG

S20 placental lactogen

S21 human placental growth hormone

S22 placental protein 13

S23 placental growth factor

S24 plasma placental protein

S25 pregnancy specific glycoprotein*

S26 schwangerschaft protein 1

S27 pregnancy specific beta 1-glycoprotein*

S28 (MH"Ultrasonography, Prenatal”)

S29 sonograph* or ultraso*

S30 Grannum grading

$\mathrm{S} 31 \mathrm{~S} 14$ or S15 or S16 or S17 or S18 or S19 or S20 or S21 or S22 or S23 or S24 or S25 or S26 or S27 or S28 or S29 or S30

S32 S13 and S31

S33 S13 and S31 Limiters exclude MEDLINE records

Searches were also performed in ClinicalTrials.gov and WHO ICTRP; based on the nature of these databases full search strategies were not constructed, searches were performed using key terms such as: "stillbirth*" AND "predictors OR placenta*".

Appendix 3. QUADAS 2 tool for assessing methodological quality of included studies

\begin{tabular}{llllll}
\hline Domain & Signalling question & Signalling question & $\begin{array}{l}\text { Signalling } \\
\text { question }\end{array}$ & Risk of bias & $\begin{array}{l}\text { Concerns about ap- } \\
\text { plicability }\end{array}$ \\
\hline Patient selec- & $\begin{array}{l}\text { Was a consecutive or ran- } \\
\text { dom sample of patients en- } \\
\text { tion }\end{array}$ & $\begin{array}{l}\text { Was a case-control } \\
\text { design avoided? }\end{array}$ & $\begin{array}{l}\text { Did the study } \\
\text { avoid inap- } \\
\text { propriate ex- } \\
\text { clusions? }\end{array}$ & $\begin{array}{l}\text { Could the se- } \\
\text { lection of pa- }\end{array}$ & $\begin{array}{l}\text { Are there concerns } \\
\text { that the included pa- } \\
\text { troduced bias? }\end{array}$ \\
& & & tients and setting do
\end{tabular}

Biochemical tests of placental function versus ultrasound assessment of fetal size for stillbirth and small-for-gestational-age infants 220 (Review)

Copyright $\odot 2019$ The Cochrane Collaboration. Published by John Wiley \& Sons, Ltd. 
not match the review question?

Yes if participants were consecutively enrolled or if all eligible participants were enrolled or participants were randomly sampled.

No if participants were selected from those eligible.

Unclear if participant selection was not clear from the report.
Yes if a case control design was avoided. Noif a case control design was used.

Unclear if the study design could not be determined from the report.

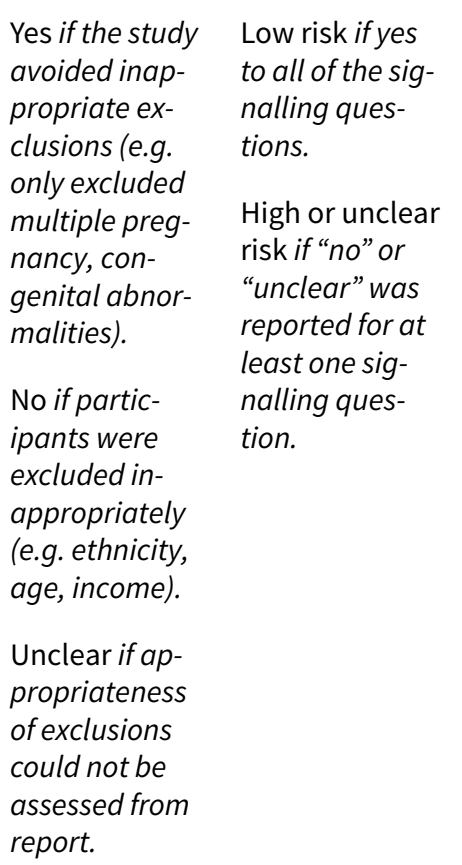

Low concern if the sample of pregnant women represent the women indicated by the review question and if inappropriate exclusions were avoided.

High concern if the sample of pregnant women are different from those indicated in the review question.

Unclear concern if insufficient information was available.

\begin{tabular}{lll}
\hline Index test - & Were the index test results & If a threshold was \\
& interpreted without knowl- & $\begin{array}{l}\text { used was it pre-spec- } \\
\text { test of placen- }\end{array}$ \\
$\begin{array}{l}\text { edge of the results of the } \\
\text { tal function }\end{array}$ & ified?
\end{tabular}
reference standard?

\section{Could the con-} duct or interpretation of the index test have introduced bias?

Low risk if yes to all of the signalling questions. interpreted without knowledge of the reference standard.

No if the result(s) of the test of placental function was interpreted with knowledge of the reference standard.

Unclear if this was not clear in the report.
Yes if the criteria for a positive result of the placental function test were pre-specified.

No if the criteria for a positive result were not pre-specified or deviated from that specified.

Unclear if this was not clear from the report. risk if "no" or "unclear" was reported for at least one signalling question.

Are there concerns that the index test, its conduct or its interpretation differ from the review question?

Low concern if the placental function test was performed as described in the review question (e.g. after 24 High or unclear weeks of pregnancy to assess placental function).

High concern if the placental function test was performed in a different way to that described in the review question.

Unclear concern if insufficient information was available.

Could the reference standard, its conduct or interpretation have introduced bias?
Are there concerns that the target condition as defined by the reference standard does not match the question?

Biochemical tests of placental function versus ultrasound assessment of fetal size for stillbirth and small-for-gestational-age infants 
Yes if an acceptable reference standard was used (e.g. SGA = birthweight < 10th centile, Stillbirth = baby born with no signs of life after 24 weeks' gestation).

No if pregnancy outcome was not classified by an acceptable reference standard (e.g. low birthweight $<2.5$ $\mathrm{kg}$ ).

Unclear if this was not clear from the report.
Yes if pregnancy outcome (live or stillbirth), and a diagnosis of a small for gestational age infant was made without the knowledge of results of the placental function test.

No if pregnancy outcome and a diagnosis of a small for gestational age infant were made with the knowledge of the results of the placental function test.

Unclear if this was not clear from the report.
Low risk if yes to all of the signalling questions.

High or unclear risk if "no" or "unclear" was reported for at least one signalling question.
Low concern if acceptable reference standards were used and if the reference standard was interpreted without the knowledge of the placental function test.

High concern if an acceptable reference standard was not used or the results were interpreted with knowledge of the result of the placental function test.

Unclear concern if insufficient information was available.

\begin{tabular}{|c|c|c|c|c|}
\hline $\begin{array}{l}\text { Flow and Tim- } \\
\text { ing }\end{array}$ & $\begin{array}{l}\text { Was there an appropriate } \\
\text { interval between the in- } \\
\text { dex test and reference stan- } \\
\text { dard? }\end{array}$ & $\begin{array}{l}\text { Did all patients re- } \\
\text { ceive the same refer- } \\
\text { ence standard? }\end{array}$ & $\begin{array}{l}\text { Were all pa- } \\
\text { tients in- } \\
\text { cluded in the } \\
\text { analysis? }\end{array}$ & $\begin{array}{l}\text { Could the pa- } \\
\text { tient flow have } \\
\text { introduced } \\
\text { bias? }\end{array}$ \\
\hline & $\begin{array}{l}\text { Yes If acquisition of the index } \\
\text { test occurred prior to birth } \\
\text { (reference standards both } \\
\text { determined after birth). } \\
\text { No if sample acquired af- } \\
\text { ter delivery of the infant (i.e. } \\
\text { known reference standard). } \\
\text { Unclear if this was not clear } \\
\text { from the report. }\end{array}$ & $\begin{array}{l}\text { Yes if all participants } \\
\text { had the outcome of } \\
\text { pregnancy and birth- } \\
\text { weight recorded. } \\
\text { No if some partici- } \\
\text { pants do not have the } \\
\text { outcome of pregnan- } \\
\text { cy and birthweight } \\
\text { recorded. } \\
\text { Unclear if this was } \\
\text { not clear from the re- } \\
\text { port. }\end{array}$ & $\begin{array}{l}\text { Yes if all par- } \\
\text { ticipants re- } \\
\text { cruited to the } \\
\text { study were in- } \\
\text { cluded in the } \\
\text { final analysis. } \\
\text { No if all par- } \\
\text { ticipants were } \\
\text { not includ- } \\
\text { ed in the final } \\
\text { analysis. } \\
\text { Unclear if this } \\
\text { was not clear } \\
\text { from the re- } \\
\text { port. }\end{array}$ & $\begin{array}{l}\text { Low risk if yes } \\
\text { to all of the sig- } \\
\text { nalling ques- } \\
\text { tions. } \\
\text { High or unclear } \\
\text { risk if "no" or } \\
\text { "unclear" was } \\
\text { reported for at } \\
\text { least one sig- } \\
\text { nalling ques- } \\
\text { tion. }\end{array}$ \\
\hline
\end{tabular}

\section{Appendix 4. Glossary}

Aneuploidy: a condition where there are an abnormal number of chromosomes in a cell

Centile: percentile, below the tenth centile means in the bottom $10 \%$

Ductus venosus: a fetal blood vessel that helps carry oxygenated blood to the heart

Echotexture: the appearance of human tissue when looked at using ultrasound

Efficacy:efficiency, the ability of a test to produce the desired result

False negative: a negative test result in an individual with the condition of interest

Biochemical tests of placental function versus ultrasound assessment of fetal size for stillbirth and small-for-gestational-age infants 
False positive: a positive test result in an individual without the condition of interest

Heterogeneity: variation, diversity

Fetal growth restriction (FGR: a condition where a fetus fails to attain its growth potential, i.e. is smaller than expected for its genetic potential.

hPL - human placental lactogen - a protein made by the trophoblast layer of the placenta.

Morphology: appearance, structure

Placental analyte: a substance produced by the placenta that can be measured and analysed

PIGF: placental growth factor- a protein made by the trophoblast layer of the placenta.

Small-for-gestational-age infant (SGA infant): the condition where the fetal weight or birthweight is beneath a specific threshold, generally considered to be the 10th centile.

SROC plot: summary receiver operator characteristic plot - a scatterplot of estimates of sensitivity and specificity from included studies.

Umbilical artery Doppler: a measurement of fetal blood flow through the umbilical artery using Doppler ultrasound.

Uterine artery Doppler: a measurement of maternal blood flow through the uterine artery using Doppler ultrasound.

\section{Appendix 5. Risk of bias and applicability concerns summary for each study, by index test}

Figure 14, Figure 15, Figure 16, Figure 17, Figure 18, Figure 19, Figure 20 
Figure 14. Risk of bias and applicability concerns summary: review authors' judgements about each domain for each included study of human placental lactogen (hPL)

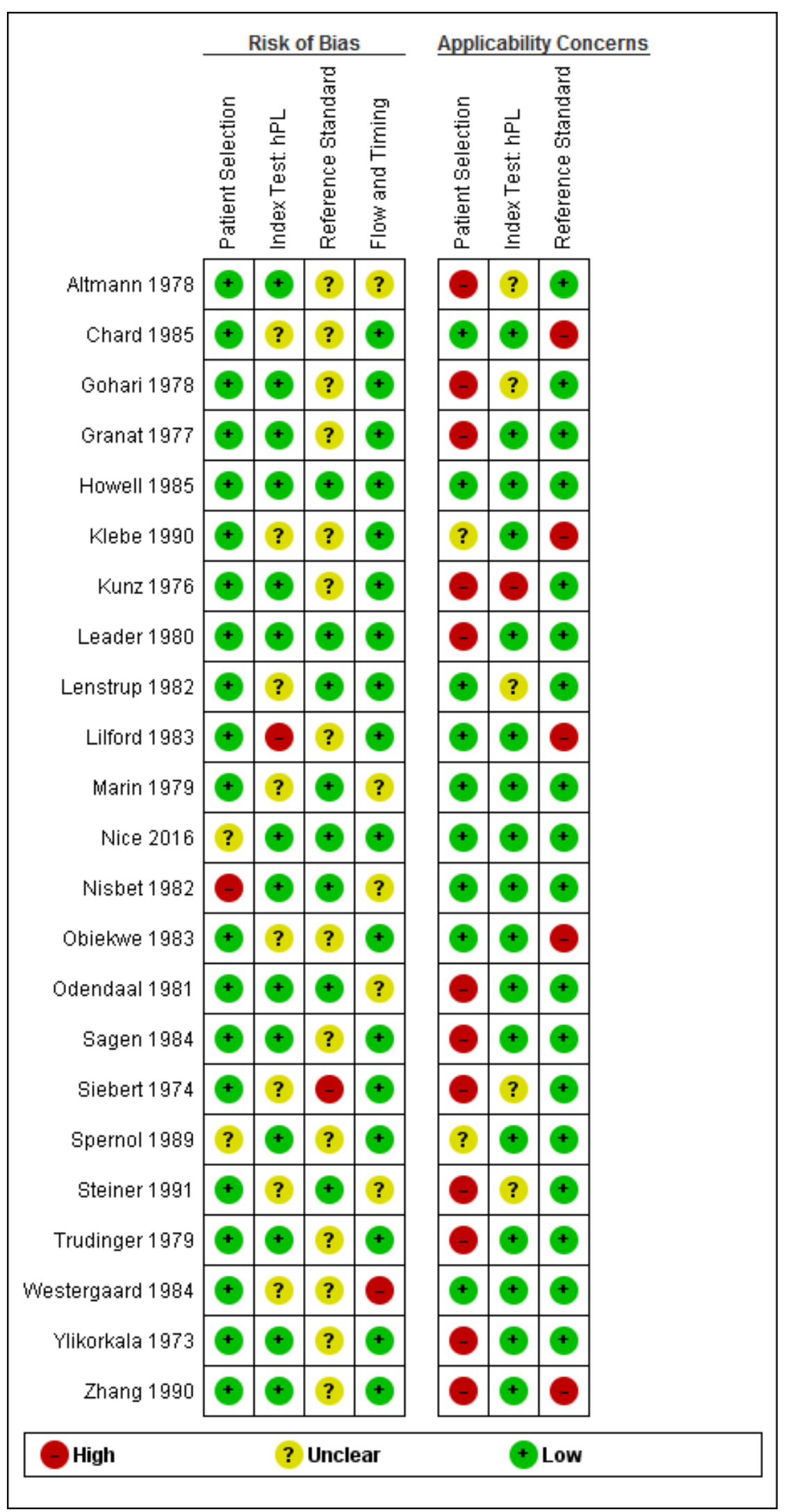

Biochemical tests of placental function versus ultrasound assessment of fetal size for stillbirth and small-for-gestational-age infants 
Figure 15. Risk of bias and applicability concerns summary: review authors' judgements about each domain for each included study of placental grading.

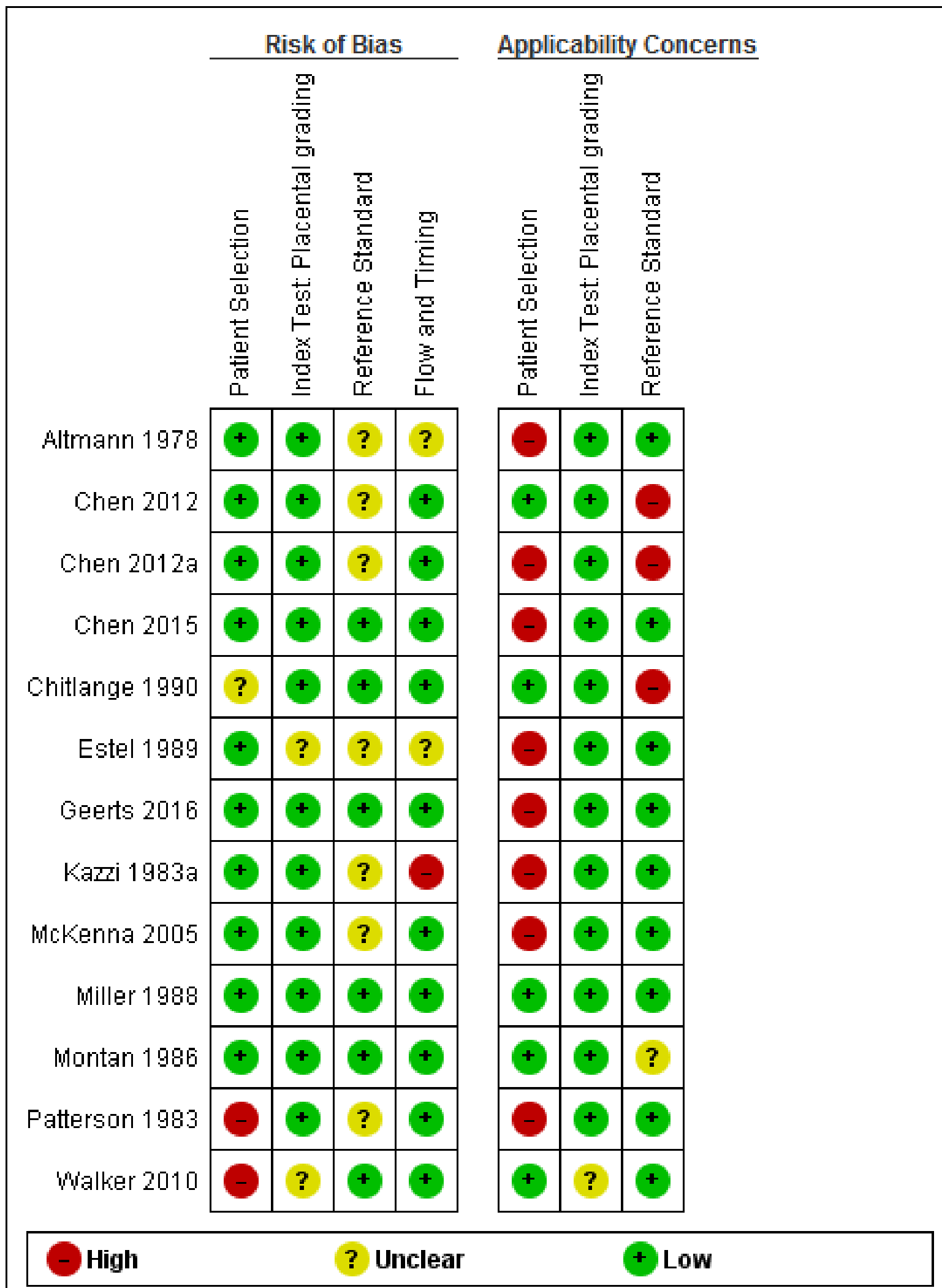

Biochemical tests of placental function versus ultrasound assessment of fetal size for stillbirth and small-for-gestational-age infants 
Figure 16. Risk of bias and applicability concerns summary: review authors' judgements about each domain for each included study of serum oestriol (E3).

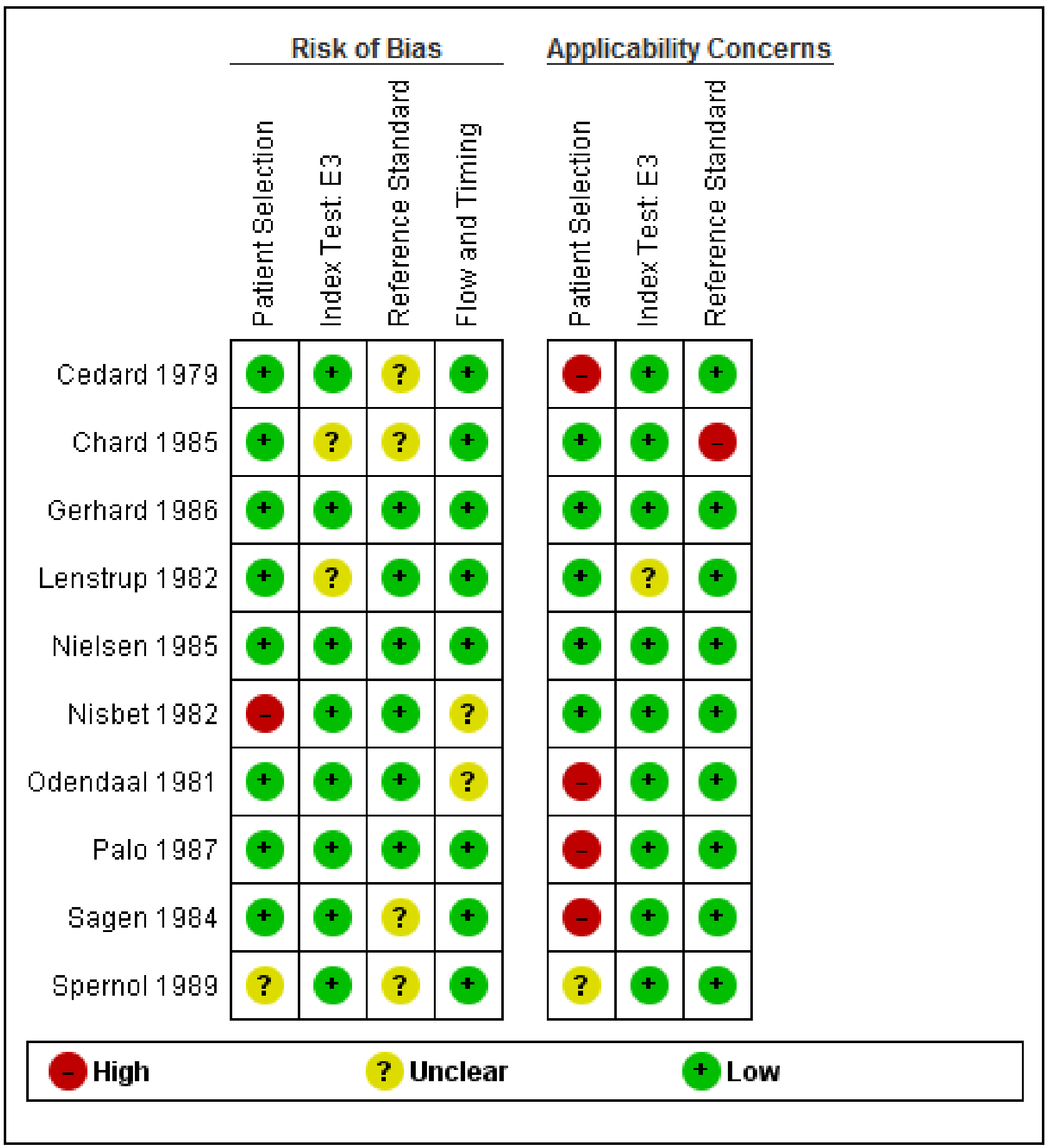


Figure 17. Risk of bias and applicability concerns summary: review authors' judgements about each domain for each included study of estimated fetal weight (EFW).

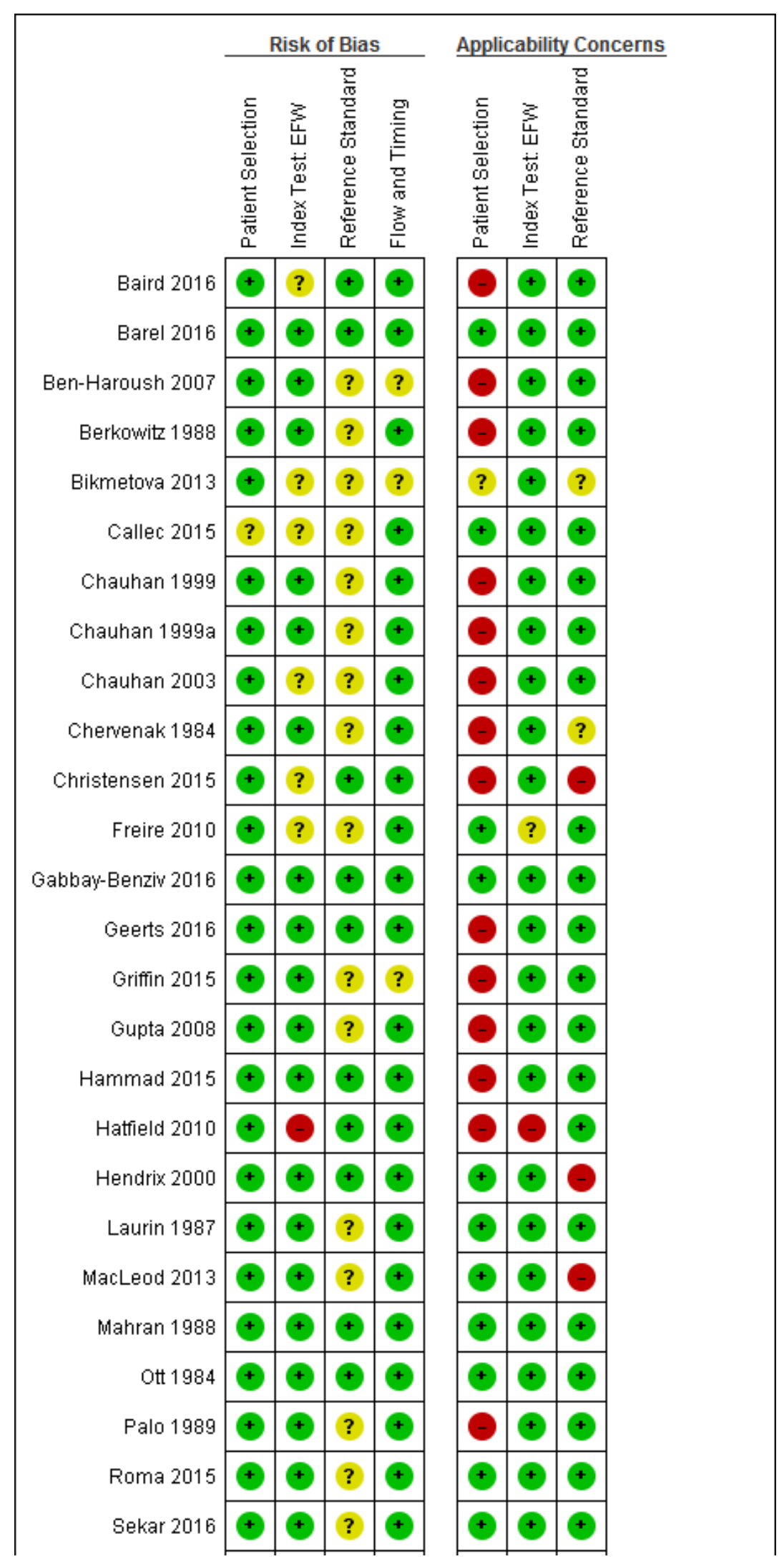

Biochemical tests of placental function versus ultrasound assessment of fetal size for stillbirth and small-for-gestational-age infants 
Figure 17. (Continued)

\begin{tabular}{|c|c|c|c|c|c|c|c|}
\hline Sekar 2016 & + & + & $?$ & + & $\odot$ & + & + \\
\hline Skovron 1991 & $\odot$ & $\bullet$ & $?$ & + & $\oplus$ & 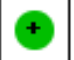 & + \\
\hline Sovio 2015 & + & + & + & $?$ & + & + & $\oplus$ \\
\hline Takeuchi 1985 & $?$ & $\odot$ & $?$ & $?$ & $\oplus$ & + & + \\
\hline Turitz 2014 & + & $\odot$ & $?$ & + & $\odot$ & $\odot$ & + \\
\hline Valino 2016 & + & + & $?$ & + & $\odot$ & + & $\oplus$ \\
\hline Weiner 2016 & + & + & $?$ & + & $?$ & $\ominus$ & + \\
\hline & & $? \mathrm{U}$ & iclea & & & $+\mathrm{Lc}$ & \\
\hline
\end{tabular}


Figure 18. Risk of bias and applicability concerns summary: review authors' judgements about each domain for each included study of placental growth factor (PIGF).

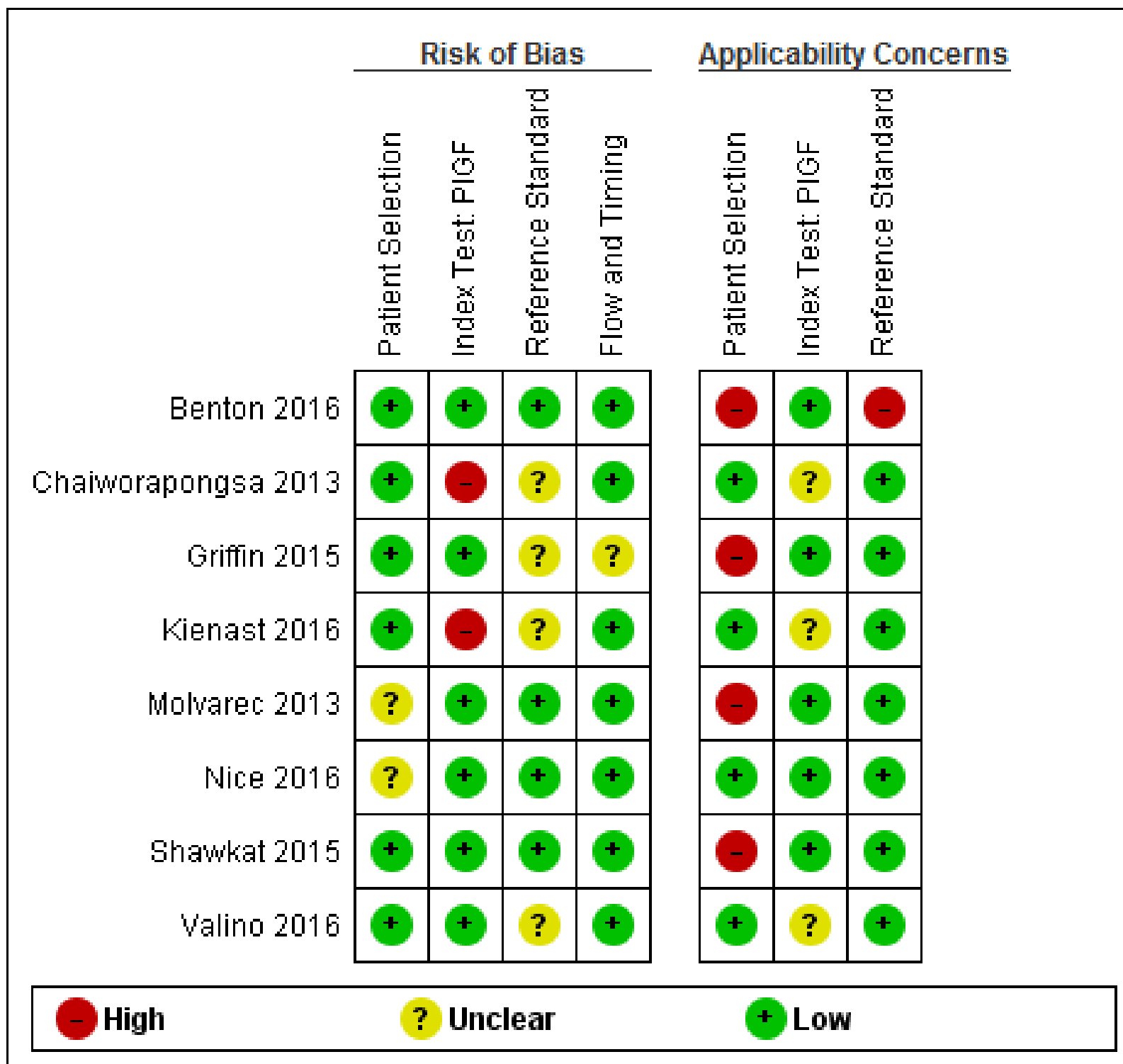


Figure 19. Risk of bias and applicability concerns summary: review authors' judgements about each domain for each included study of uric acid.

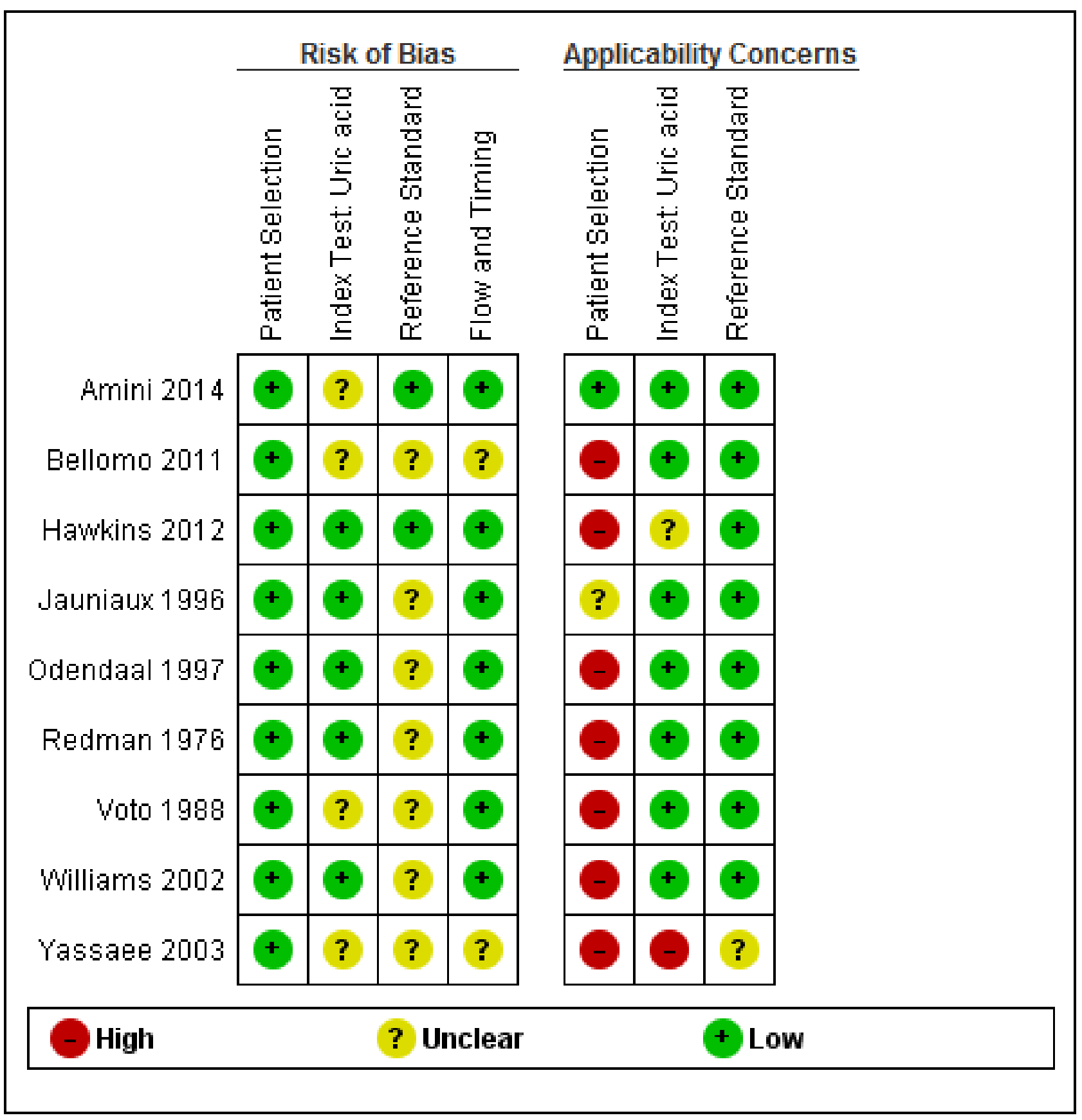


Figure 20. Risk of bias and applicability concerns summary: review authors' judgements about each domain for each included study of urinary oestriol (UE3).

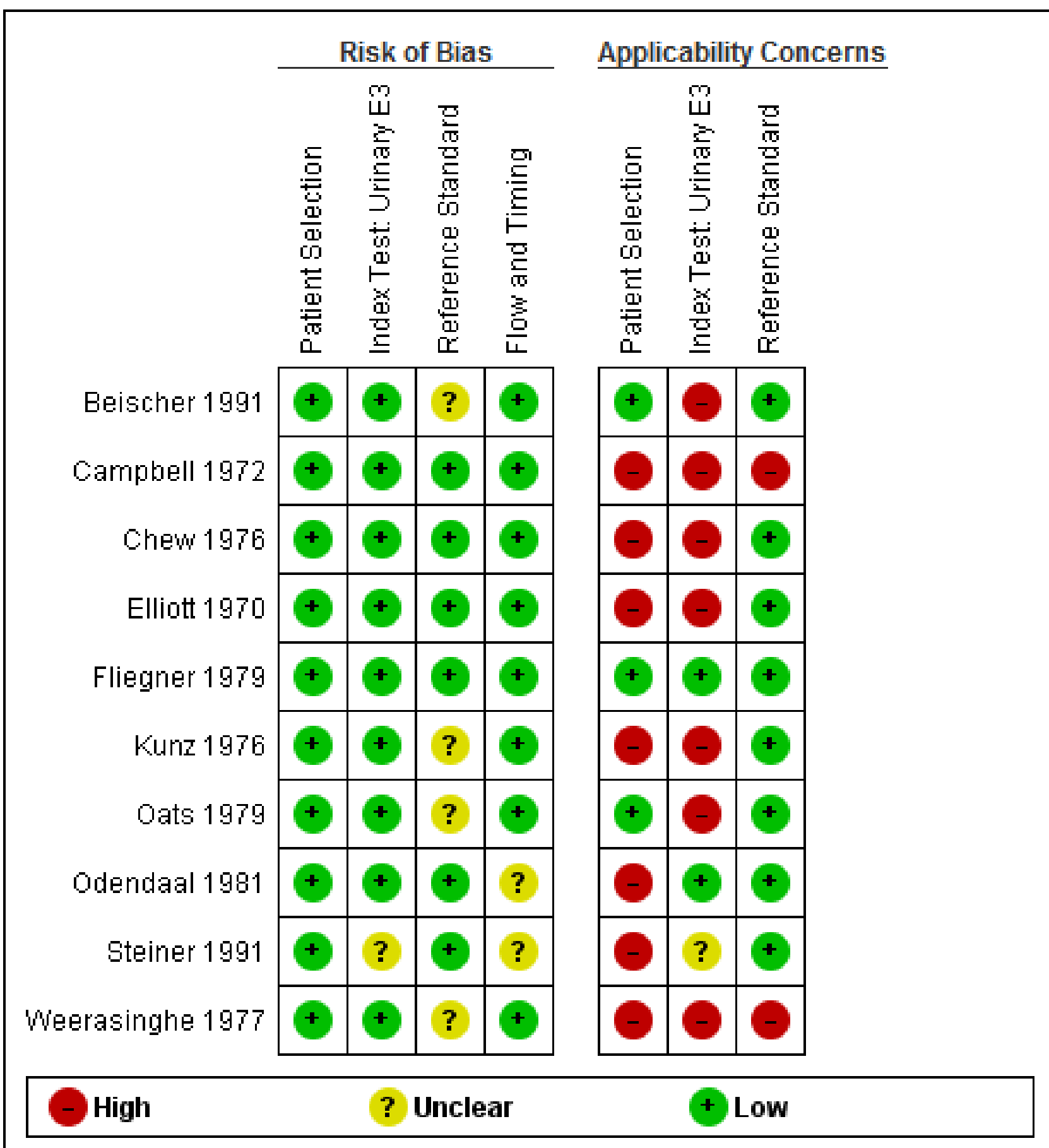




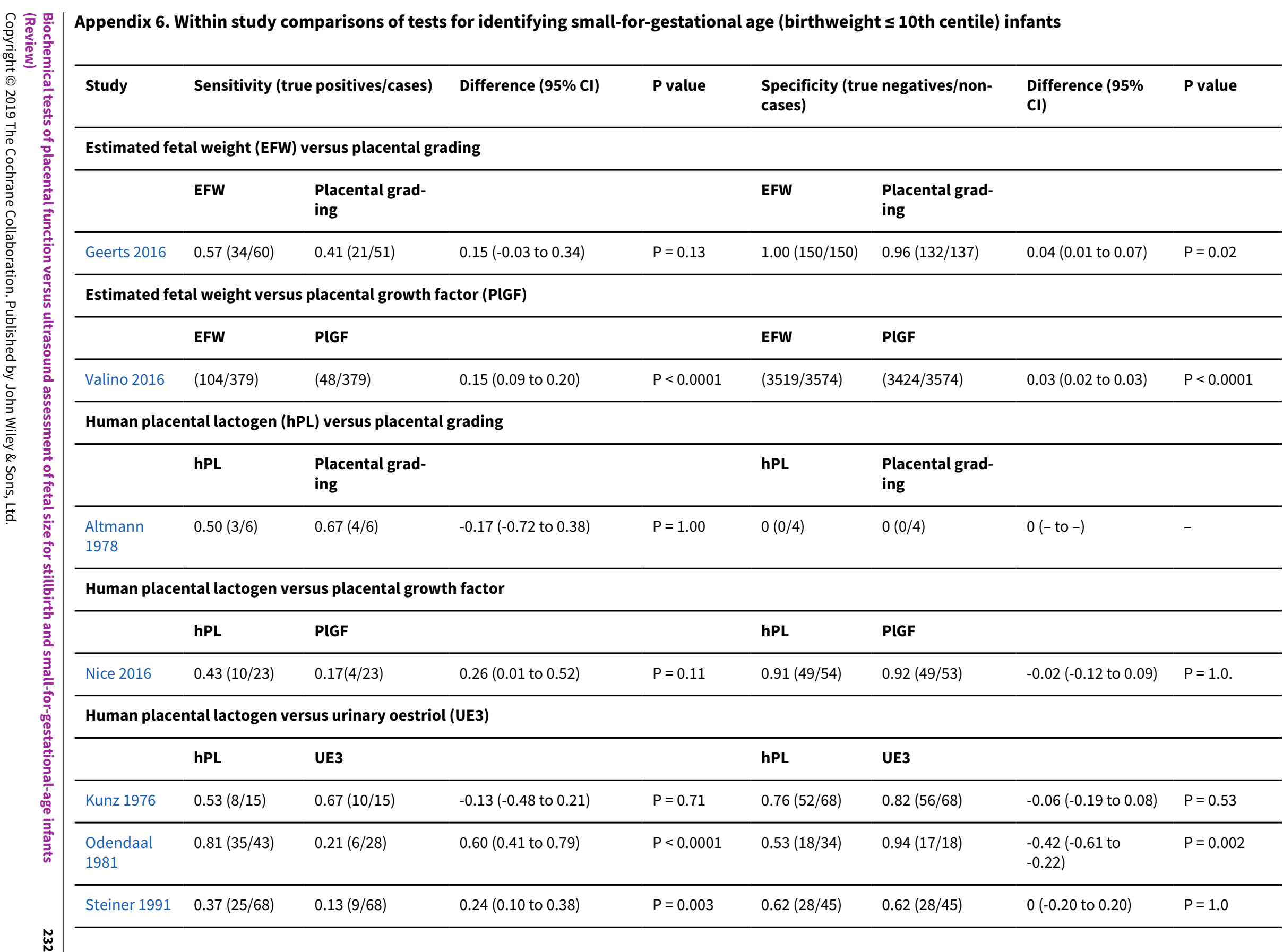




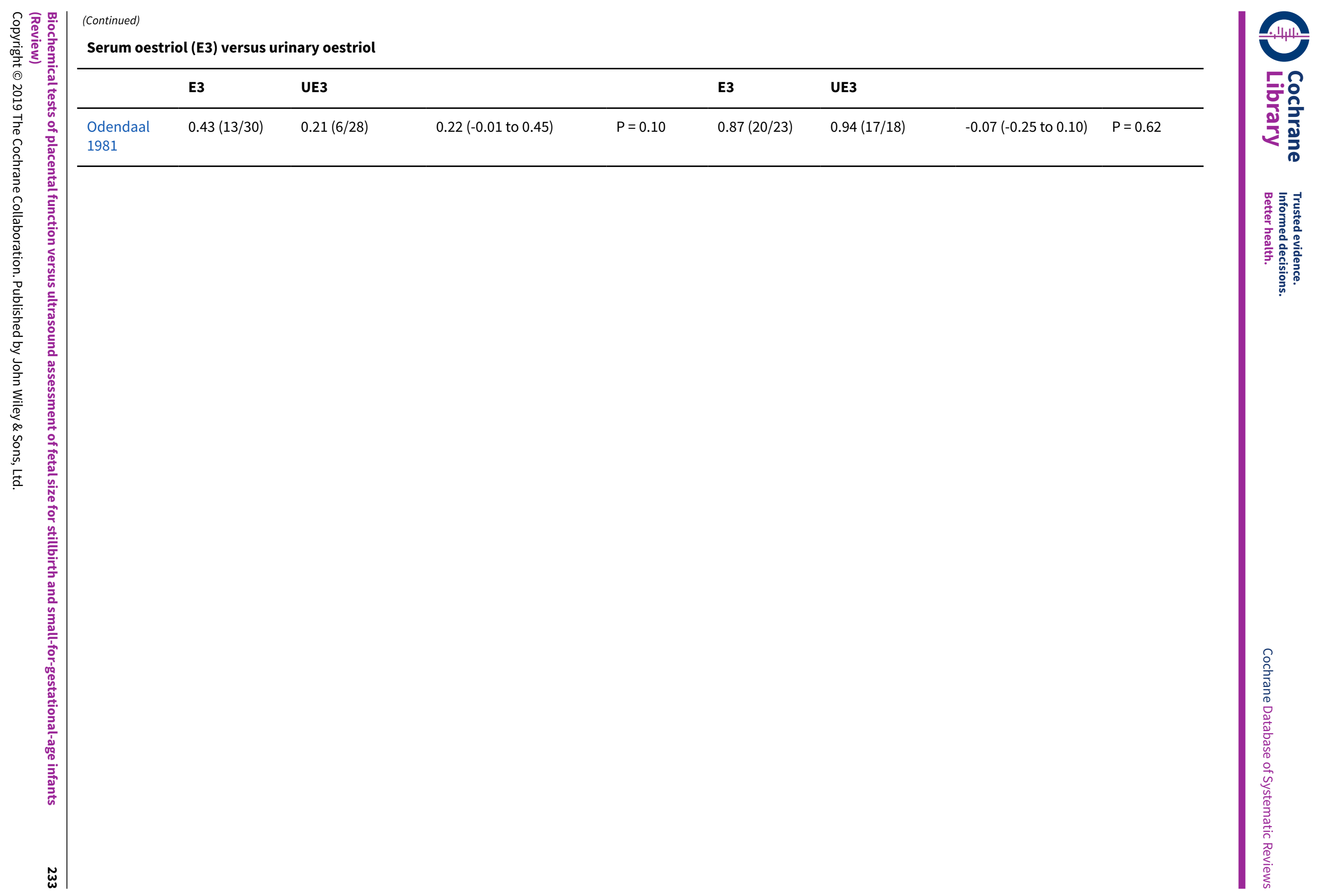


Differences in sensitivities and specificities between tests evaluated within each study are presented in the table. Five studies that evaluated hPL and oestriol were not included in this table as meta-analysis was performed (see Figure 10). The three studies of hPL versus urinary oestriol used different thresholds (see Figure 5).

\section{Appendix 7. Studies with evaluations of both small-for-gestational age (birthweight $\leq 10$ th centile) infants and stillbirths}

Estimates of sensitivity and specificity from studies that evaluated biochemical tests for both SGA infants and stillbirths (Figure 21)

Figure 21. Forest plot of studies with evaluations of both small-for-gestational-age (SGA birthweight $\leq$ tenth centile) infants and stillbirth. E3 = oestriol; hPL = human placental lactogen; PIGF = placental growth factor; UA = uric acid. Two studies (Altmann 1978; Chen 2012) evaluated placental grading for both SGA and stillbirth but not possible to include them on the plot. Studies are sorted by test and study identifier.

\begin{tabular}{lrrrrrrr}
\multicolumn{7}{l}{ SGA data from studies with both SGA infants and stillbirths } \\
Study & TP & FP & FN & TN & Risk & Test & Sensitivity $(95 \%$ Cl) \\
Benton 2016 & 87 & 70 & 72 & 182 & High & PIGF & $0.55[0.47,0.63]$ \\
Chaiworapongsa 2013 & 38 & 184 & 70 & 977 & Mixed & PIGF & $0.35[0.26,0.45]$ \\
Shawkat 2015 & 18 & 43 & 88 & 112 & High & PIGF & $0.17[0.10,0.26]$ \\
Valino 2016 & 48 & 150 & 331 & 3424 & Mixed & PIGF & $0.13[0.09,0.16]$ \\
Hawkins 2012 & 168 & 621 & 56 & 461 & High & UA & $0.75[0.69,0.81]$ \\
Odendaal 1997 & 8 & 13 & 92 & 83 & High & UA & $0.08[0.04,0.15]$ \\
Yassaee 2003 & 41 & 12 & 18 & 32 & High & UA & $0.69[0.56,0.81]$ \\
Beischer 1991 & 1454 & 5621 & 3936 & 61051 & High & Urinary E3 & $0.27[0.26,0.28]$ \\
Campbell 1972 & 46 & 34 & 41 & 163 & High Urinary E3 & $0.53[0.42,0.64]$ \\
Chew 1976 & 0 & 0 & 15 & 28 & High Urinary E3 & $0.00[0.00,0.22]$ \\
Fliegner 1979 & 22 & 57 & 15 & 235 & Mixed & Urinary E3 & $0.59[0.42,0.75]$ \\
Oats 1979 & 497 & 2064 & 894 & 15664 & Mixed & Urinary E3 & $0.36[0.33,0.38]$ \\
Weerasinghe 1977 & 36 & 98 & 9 & 184 & High & Urinary E3 & $0.80[0.65,0.90]$ \\
Altmann 1978 & 3 & 4 & 3 & 0 & High & hPL & $0.50[0.12,0.88]$ \\
Siebert 1974 & 1 & 2 & 10 & 54 & Low & hPL & $0.09[0.00,0.41]$ \\
Trudinger 1979 & 10 & 4 & 15 & 30 & High & hPL & $0.40[0.21,0.61]$ \\
Zhang 1990 & 25 & 42 & 13 & 41 & High & hPL & $0.66[0.49,0.80]$
\end{tabular}

Stillbirth data from studies with both SGA infants and stillbirths

$\begin{array}{lrrrrrrrr}\text { Study } & \text { TP } & \text { FP } & \text { FN } & \text { TN } & \text { Risk } & \text { Test } & \text { Sensitivity }(95 \% \text { Cl) } & \text { Specificity }(95 \% \text { Cl) } \\ \text { Benton 2016 } & 6 & 151 & 1 & 253 & \text { High } & \text { PIGF } & 0.86[0.42,1.00] & 0.63[0.58,0.67] \\ \text { Chaiworapongsa 2013 } & 4 & 71 & 1 & 1193 & \text { Mixed } & \text { PIGF } & 0.80[0.28,0.99] & 0.94[0.93,0.96] \\ \text { Shawkat 2015 } & 2 & 59 & 1 & 199 & \text { High } & \text { PIGF } & 0.67[0.09,0.99] & 0.77[0.72,0.82] \\ \text { Valino 2016 } & 1 & 197 & 0 & 3755 & \text { Mixed } & \text { PIGF } & 1.00[0.03,1.00] & 0.95[0.94,0.96] \\ \text { Hawkins 2012 } & 3 & 883 & 2 & 595 & \text { High } & \text { UA } & 0.60[0.15,0.95] & 0.40[0.38,0.43] \\ \text { Odendaal 1997 } & 3 & 18 & 15 & 160 & \text { High } & \text { UA } & 0.17[0.04,0.41] & 0.90[0.84,0.94] \\ \text { Yassaee 2003 } & 12 & 41 & 0 & 50 & \text { High } & \text { UA } & 1.00[0.74,1.00] & 0.55[0.44,0.65] \\ \text { Beischer 1991 } & 163 & 6912 & 289 & 64698 & \text { High Urinary E3 } & 0.36[0.32,0.41] & 0.90[0.90,0.91] \\ \text { Campbell 1972 } & 6 & 74 & 5 & 199 & \text { High Urinary E3 } & 0.55[0.23,0.83] & 0.73[0.67,0.78] \\ \text { Chew 1976 } & 0 & 0 & 6 & 37 & \text { High Urinary E3 } & 0.00[0.00,0.46] & 1.00[0.91,1.00] \\ \text { Fliegner 1979 } & 5 & 74 & 0 & 250 & \text { Mixed Urinary E3 } & 1.00[0.48,1.00] & 0.77[0.72,0.82] \\ \text { Oats 1979 } & 90 & 2471 & 82 & 16476 & \text { Mixed Urinary E3 } & 0.52[0.45,0.60] & 0.87[0.86,0.87] \\ \text { Weerasinghe 1977 } & 3 & 131 & 0 & 193 & \text { High Urinary E3 } & 1.00[0.29,1.00] & 0.60[0.54,0.65] \\ \text { Altmann 1978 } & 2 & 1 & 1 & 6 & \text { High } & \text { hPL } & 0.67[0.09,0.99] & 0.86[0.42,1.00] \\ \text { Siebert 1974 } & 1 & 2 & 1 & 16 & \text { Low } & \text { hPL } & 0.50[0.01,0.99] & 0.89[0.65,0.99] \\ \text { Trudinger 1979 } & 1 & 13 & 0 & 45 & \text { High } & \text { hPL } & 1.00[0.03,1.00] & 0.78[0.65,0.87] \\ \text { Zhang 1990 } & 8 & 59 & 0 & 54 & \text { High } & \text { hPL } & 1.00[0.63,1.00] & 0.48[0.38,0.57]\end{array}$
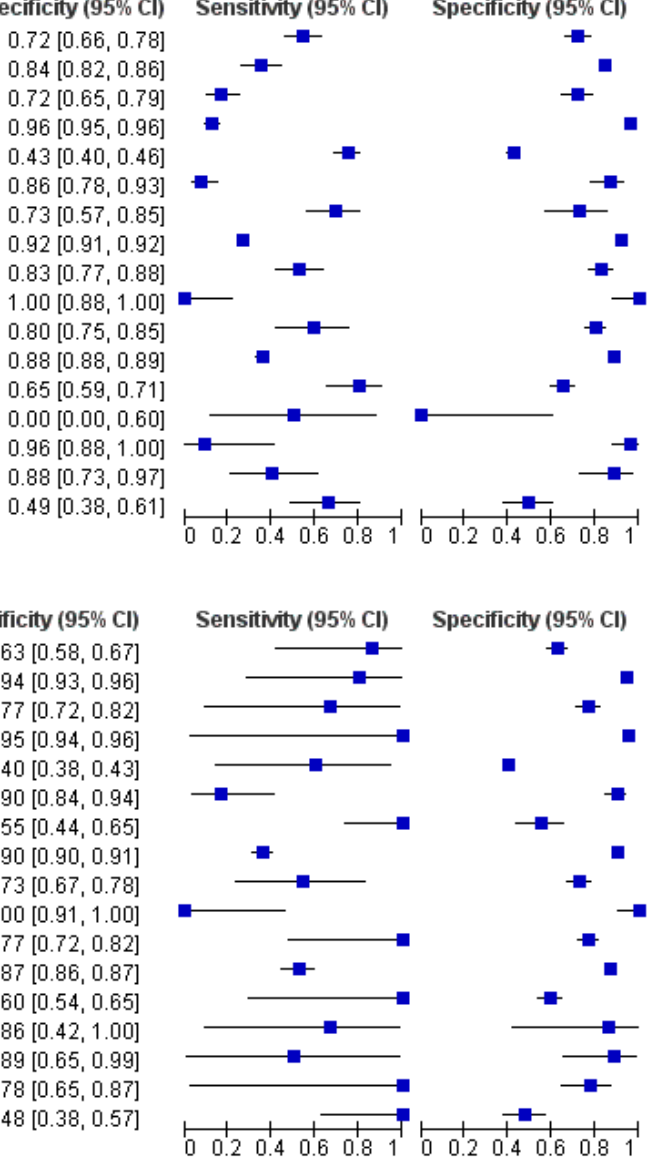

WHAT'S NEW

\begin{tabular}{lll}
\hline Date & Event & Description \\
\hline 7 June 2019 & Amended & Corrected typographical error in abstract background. \\
\hline
\end{tabular}

Biochemical tests of placental function versus ultrasound assessment of fetal size for stillbirth and small-for-gestational-age infants 


\section{CONTRIBUTIONS OF AUTHORS}

AEP Heazell (AEPH) and Clare Davenport (CD) conceived the idea for the systematic review. All authors contributed to the design of the review and writing the protocol. Susan Bayliss (SEB) undertook the literature searches. AEPH, Dexter Hayes (DH) and Melissa Whitworth (MKW) screened the titles and abstracts and extracted data from included studies. Yemisi Takwoingi (YT) performed the statistical analysis. All authors contributed to the final manuscript. AEPH is the guarantor for the review.

\section{DECLARATIONS OF INTEREST}

Susan Bayliss: none known.

Clare Davenport's employer (The University of Birmingham) received funding for her participation in this review as part of an NIHR clinical fellowship awarded to Alexander Heazell (the lead author and contact person).

Dexter Hayes: none known.

Yemisi Takwoingi's employer (The University of Birmingham) received funding for her participation in this review as part of an NIHR clinical fellowship awarded to Alexander Heazell (the lead author and contact person).

Melissa Whitworth was on the NICE guideline development group for Intrapartum Care in High Risk Pregnancy and travel to committee meetings was paid by NICE

Alexander Heazell has received research grants from Alere (UK) and Action Medical Research to investigate placental factors in maternal serum in women with reduced fetal movements. He is also a Supervisor for a Clinical Research Fellowship from Action Medical Research which incorporates projects to detect placental factors in maternal serum. In addition, he holds a Clinician Scientist Award from National Institute of Health Research (NIHR) (CS-2013-13-009) and this review is part of that programme of work. The views expressed here are those of the author(s) and not necessarily those of the NHS, the NIHR or the Department of Health.

\section{SOURCES OF SUPPORT}

\section{Internal sources}

- No sources of support supplied

\section{External sources}

- National Insitute of Health Research, UK.

Alexander Heazell is funded by a Clinician Scientist Award from the National Institute of Health Research (CS-2013-009). This protocol presents independent research funded by the National Institute for Health Research (NIHR). The views expressed are those of the author(s) and not necessarily those of the NHS, the NIHR or the Department of Health.

\section{DIFFERENCES BETWEEN PROTOCOLANDREVIEW}

There are some minor differences between our published protocol (Heazell 2016) and this review.

- Methods/investigation of heterogeneity: in our protocol we stated "Where a sufficient number of studies assess the same index test, potential sources of heterogeneity will be separated into clinical (e.g. population studied, test type) and methodological (as appropriate) sources". In the review, we clarified this and edited the methods to "Where a sufficient number of studies assessed the same index test and there were at least four studies per subgroup of a categorical covariate, we performed meta-regression by adding the potential source of heterogeneity as a covariate to the HSROC model".

\section{- Statistical analysis and data synthesis}

* We clarified the use of the terms SGA (for SGA defined as birthweight $\leq 10$ th centile) and SGA3 for SGA defined as birthweight < 3rd centile.

* We added "Before performing meta-analyses to compare test accuracy, we performed meta-analysis of each test separately for preliminary investigation of the shape of the SROC curve of each test and to explore if assuming common variances across tests for the random effects would be reasonable".

* We added "When there were adequate data, we also allowed the variance parameters for accuracy and threshold to depend on test type, i.e. differences in accuracy and threshold modelled as random effects"

* We also added "To quantify differences in accuracy between tests, we computed ratios of diagnostic odds ratios when SROC curves were symmetric or a common shape was assumed. Using the estimate statement within NLMIXED, we also estimated sensitivities along the SROC curves at fixed values of specificity that correspond to the median and interquartile range of specificities from the studies included in the comparative meta-analysis. We used these values along with the median and interquartile range of the 
prevalence estimated from the studies to compute numbers of missed cases and false positives in a hypothetical cohort of 1000 pregnant women. We used these frequencies to illustrate the accuracy of the tests in absolute terms"

\section{N DEX TERMS}

\section{Medical Subject Headings (MeSH)}

*Infant, Small for Gestational Age; *Pregnancy Outcome; *Ultrasonography, Prenatal; Fetal Development [*physiology]; Fetal Growth Retardation; Perinatal Mortality; Placenta [*diagnostic imaging]; Stillbirth

\section{MeSH check words}

Female; Humans; Infant, Newborn; Pregnancy 